NUREG/CR-5978

SAND92-2688

\title{
Source Term Attenuation by Water in the Mark I Boiling Water Reactor Drywell
}

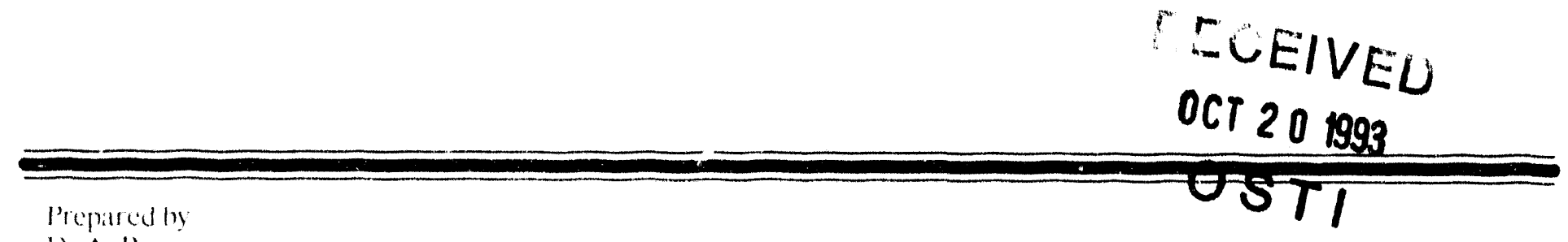

prepared by

1). A. Powers

Sandia National Laboratories

Operated by

Sandia Corporation

Prepared for

U.S. Nuclear Regulatory (ommission 


\section{AVAILABILITY NOTICE}

Avalability of Reference Materials Crted in NRC Publications

Most documents clted in NAC publications will be avallable from one of the following sources:

1. The NAC Public Document Room, 2120 L Street, NW, Lower Level, Washingtcin. DC, 20555-0001

2. The Superintendent of Documents, U.S. Government Printing Office. Mall Stop SSOP. Washington. DC $20402-9328$

3. The National Technical Iniormation Service, Springfield, VA 22161

Although the listing that follows represents the majority of documents cited in NRC publlications, It is not intended to be exhaustive

Referenced documents avallable for Inspection and copying for a fee from the NRC Fubllc Document Room include NRC correspondence and internal NRC memoranda: NFIC Offlce of Inspection and Enforcement bulletins, circulars, Information notices, Inspection and investigation notices; L.Jcensee Event Reports; vendor reports and correspondence: Commission papers: and applicant and licensee documents and correspondence

The following documents in the NUREG series are avallable for purchase from the GPO Sales Prograri): formal NRC staff and contractor reports, NRC-spcnsored conference proceedings, and NRC booklets and brochures. Also avallable are Regulatory Guides, NAC regulations in the Code of Fegeral Regulations, and Nuclear Regulatory Commission issuances.

Documents available frorn the Natlonal Technical Information Service Include NUREG series reports and technical reports prepared by other federal agencies and reports prepared by the Atomic Energy Commis. sion, forerunner agency to the Nuclear Regulatory Commission.

Documents avallable trom public and speclal technical llbraries include all open IIterature items, such as books. Journal and perlodical articles. and transactions. Federal Heg/ster notices, fecleral and state legislation, and congresslonal reports can usually be obtained from these llbrarles.

Documents such as theses. dissertations, forelen reports and translations, and non. NRC conference proceedings are avallable for purchase from the organization sponsuring the publication cited.

Single coples of NFC draft reports are avallable free, to the extent of supply, upon written request to the Office of Information Resources Management. Distribution Section, U.S. Nuclear Regulatory Commission. Washington, DC 205550001

Coples of Industry codes and standards used in a substantive manner in the NRC regulatory process are maintained at the NRC Library, 7920 Norfolk Avenue. Bethesda. Maryland, and are avallable there for reference use by the public. Codes and standards are usually copyrighted and may be purchased from the orlginating organlzation or. If they are Amerlcan Natlonal Standards, from the American National Standards Institute. 1430 Broadway. Now York. NY 10018

\section{DISCLAIMER NOTICE}

This repon was preparod as ari account of work sponsor od by an agency of the United States Government. Neither the United States Government nor any agency thereot, or any of their employees, makes any warranty. expresed or implied, or assumes any legal hability of responsibility for any inird party's use, or the results of such use, of any information, apparatus, product or process disclosed in this report, or represents that its use by such therd party would not intringe privately owned rights. 
NUREG/CR-5978

SAND92-2688

\section{Source Term Attenuation by \\ Water in the Mark I Boiling \\ Water Reactor Drywell}

Manuscript Completed: August 1993

Date Published: September 1993

Prepared by

D. A. Powers

Sandia National Laboratories

Albuquerque, NM 87185

Prepared for

Division of Systems Research

Office of Nuclear Regulatory Research

U.S. Nuclear Regulatory Commission

Washington, DC 20555-0001

NRC FIN L1484 


\begin{abstract}
Analyses are presented to show that water admitted to the drywell of a Mark I boiling water reactor can significantly attenuate radionuclide releases during severe reactor accidents. This attenuation can be achieved whether or not water is able to prevent or delay failure of the drywell. Attenuation of releases of radioactive materials is achieved by the actions of water pools maintained over core debris interacting with concrete in the drywell and by the actions of drywell sprays.
\end{abstract}

A mechanistic model is formulated of the aerosol scrubbing by a water pool overlying core debris that is interacting with concrete. Eighteen uncertain features of the model are identified. A quantitative uncertainty analysis of the model is described. Cumulative probability distribution functions are developed at confidence levels of 50,90, and 95 percent for the decontamination factors that can be achieved by water pools 30 and $50 \mathrm{~cm}$ deep with subcooling of $0,2,5,10,20,30,50$, and $70^{\circ} \mathrm{C}$. These distribution functions show with high confidence that the radionuclide emissions during core debris interactions with concrete can be reduced by a factor of 10 and perhaps by a factor in excess of 100 by shallow, subcooled water pools. It is argued that similar decontamination factors would be realized even if core debris penetrated the Mark I liner and flowed into the reactor torus room.

Features of spray systems in the drywells of Mark I containments are described. A mechanistic model is formulated of the aerosol scrubbing that can be achieved by drywell sprays. Nineteen uncertain features of the model are identified and quantities are defined to describe the uncertainty of these features. Ranges of values for uncertain quantities and distributions for values within these ranges are defined. A quantitative uncertainty analysis of the model is described. Cumulative probability distribution functions are developed at confidence levels of 50,90 and 95 percent for the decontamination coefficient produced by sprays for water fluxes into the drywell of $0.002,0.01$ and $0.25 \mathrm{~cm}^{3} / \mathrm{cm}^{2}$-s. Rapid removal of aerosols by spray droplets can be expected with high confidence only for the highest water fluxes $\left(\sim 0.25 \mathrm{~cm}^{3} \mathrm{H}_{2} \mathrm{O} / \mathrm{cm}^{2}-\mathrm{s}\right)$. These high water fluxes are within the capabilities of spray systems in some Mark I drywells. At lower water fluxes, decontamination of the drywell atmosphere can be achieved if drywell failure is delayed and the leak rate following drywell failure is not large.

Correlations of the results obtained in the uncertainty analyses of decontamination by water pools and by sprays are used in an example analysis of a hypothetical accident at a Mark I boiling water reactor. 


\section{Contents}

Page

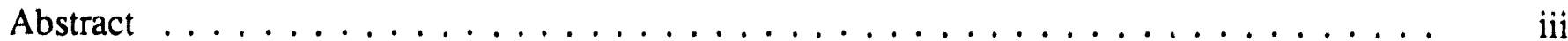

Table of Contents $\ldots \ldots \ldots \ldots \ldots \ldots \ldots \ldots \ldots \ldots$

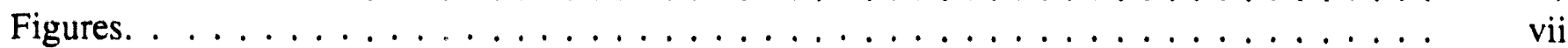

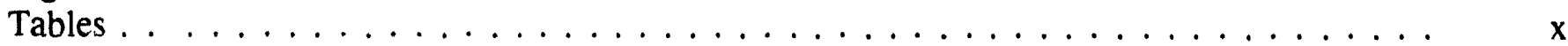

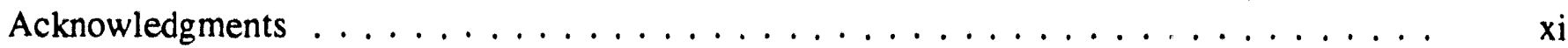

Executive Summary $\ldots \ldots \ldots \ldots \ldots \ldots \ldots \ldots \ldots \ldots \ldots \ldots \ldots \ldots \ldots$

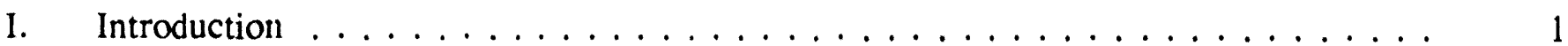

II. Source Term Attenuation by an Overlying Water Pool ................ 9

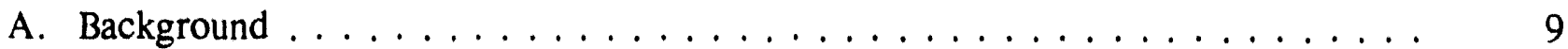

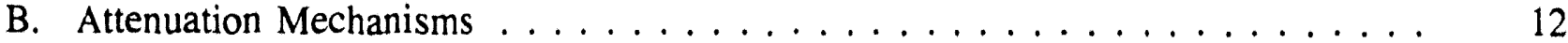

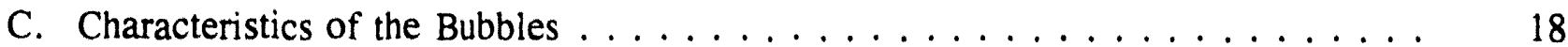

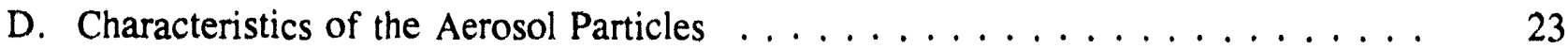

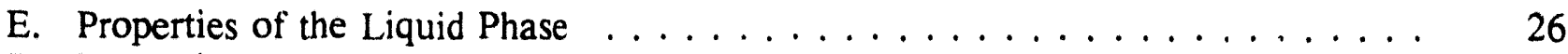

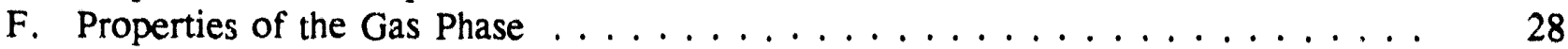

III. Analysis of Source Term Attenuation by Overlying Water Pools in Mark I

Reactors ................................ 34

A. Quantitative Analysis of Uncertainty . . . . . . . . . . . . . . . . . . . . . . . . . . . . . . . .

B. Specific Uncertainties Considered . . . . . . . . . . . . . . . . . . 35

1. Uncertainty in Drywell Pressure . . . . . . . . . . . . . . . . . . . . 37

2. Uncertainty in Concrete Erosion Rate $\ldots \ldots \ldots . \ldots \ldots$

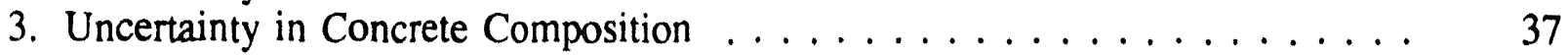

4. Uncertainty in the Gas Composition . . . . . . . . . . . . . . . 37

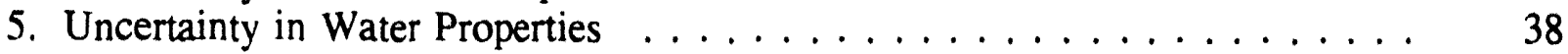

6. Uncertainty in Aerosol Size Distribution . . . . . . . . . . . . 39

7. Uncertainty in Bubble Size ..................... 39

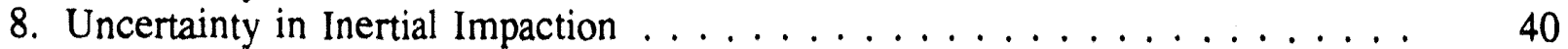

9. Uncertainty in Boiling Heat Flux . . . . . . . . . . . . . . . . . 40

C. Predictions of the Decontamination Factors . . . . . . . . . . . . . . . . 40

IV. Source Term Attenuation by Drywell Sprays _ . . . . . . . . . . . . . . . . . 47

A. Background . . . . . . . . . . . . . . . . . . . . . . . . . . 47

B. Trapping of Aerosol Particles by Water Droplets . . . . . . . . . . . . . . . 49

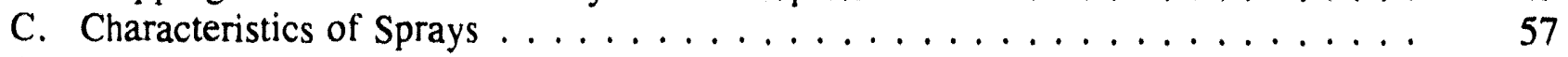

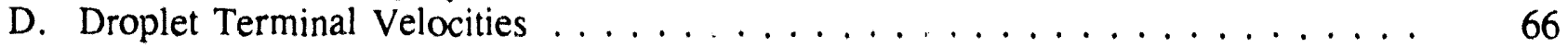

E. Droplet Trajectories . . . . . . . . . . . . . . . . . . . . . . . . . 69

F. Droplet Agglomeration . . . . . . . . . . . . . . . . . . . . . . . 69

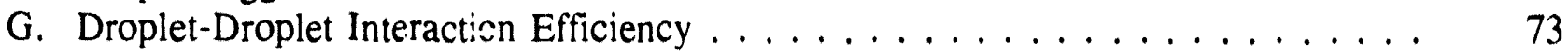

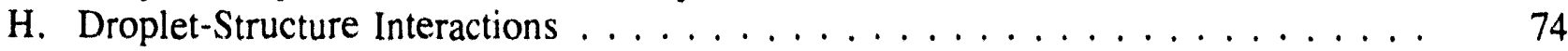




\section{Contents (Concluded)}

Page

V. Analysis of Source Term Attenuation by Drywell Sprays . . . . . . . . . . . . . . . 77

A. Specific Uncertainties Considered . . . . . . . . . . . . . . . 77

1. Uncertainty in Drywell Pressure and Temperature . . . . . . . . . . . 77

2. Uncertainty in the Viscosity of Gas Mixtures . . . . . . . . . . . . . . . . 82

3. Uncertainty in the Surface Tension of Water . . . . . . . . . . . . . . . . 83

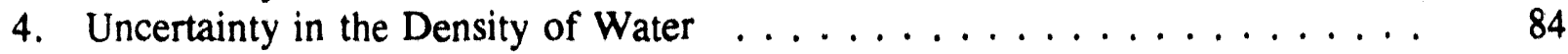

5. Uncertainty in the Initial Droplet Size . . . . . . . . . . . . . . 84

6. Uncertainty in the Droplet Shape . . . . . . . . . . . . . . . . . 85

7. Uncertainty in the Droplet Terminal Velocities . . . . . . . . . . . . 85

8. Uncertainty in Droplet-Droplet Interactions . . . . . . . . . . . . . 86

9. Uncertainty in the Initial Aerosol Size Distribution . . . . . . . . . . . 87

10. Uncertainty in the Aerosol Shape Factors . . . . . . . . . . . . . . . . . 89

11. Uncertainty in Collection Efficiency by Impaction and Interception . . . . . . . 89

12. Uncertainty in $\epsilon$ (imp,pot) . . . . . . . . . . . . . . . . . . 90

13. Uncertainty in Collection Efficiencies in the Transition Flow Regime . . . . . 90

14. Uncertainty in Aerosol Collection Efficiency by Diffusion . . . . . . . . . . . . 91

15. Uncertainty in the Summation of Efficiencies ................ 91

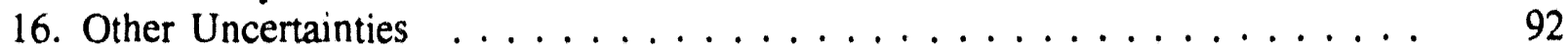

B. Model Description . . . . . . . . . . . . . . . . . . . . . . . . . . . . . . 92

C. Results of the Uncertainty Analysis . . . . . . . . . . . . . . . . . . . . . . . . 96

D. Efferts of Unsprayed Volumes . . . . . . . . . . . . . . . . . . . . . . . 109

E. Simple Currelation of the Results . . . . . . . . . . . . . . . . . 112

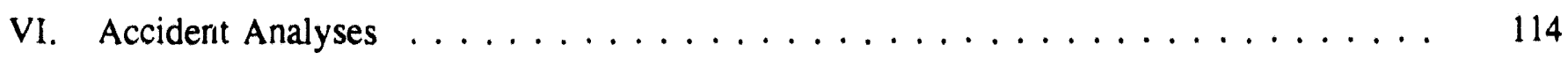

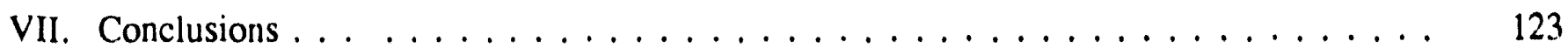

VIII. References. . . . . . . . . . . . . . . . . . . . . . . . . . . . . 124

Appendix A: Statistics of Order Distributions $\ldots \ldots \ldots \ldots \ldots \ldots \ldots$ A-1

Appenuix B: Detailed Results of the Uncertainty Analyses of Decontamination by

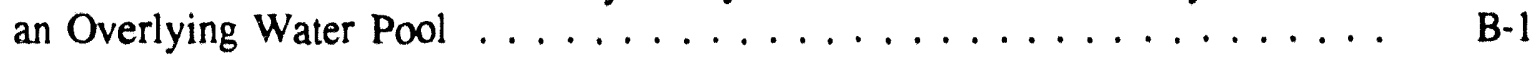

Appendix C: Uncertainty Distributions for the Spray Decoritamination Coefficient . . . . . C $\quad$ -

Appendix D: Cumulative Probability Distributions for $\lambda\left(m_{\mathrm{f}}\right) / \lambda\left(\mathrm{m}_{\mathrm{f}}=0.9\right) \ldots \ldots$ D-1 


\section{Figures}

Figure

$\underline{\text { Page }}$

1 Schematic diagram of the Mark I containment for a boiling water reactor . . . . . . . 2

2 Pressure within a Mark I boiling water reactor containment during a severe reactor

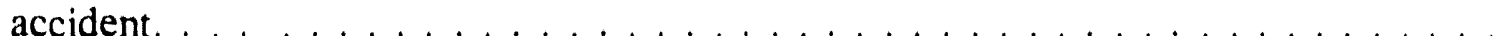

3 Conceptual drawing of core debris draining from the Mark I drywell into the torus

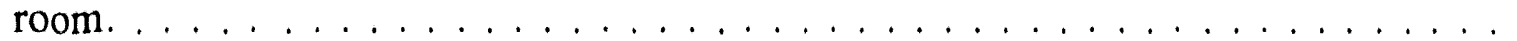

4 Calculated rates of aerosol generation during core debris interactions with concrete in a Mark I boiling water reactor drywell

5 Decontamination factors produced by sedimentation, diffusion, and inertial impaction as functions of aerosol particle size $\ldots \ldots \ldots \ldots \ldots$

6 Aerosol capture efficiencies for sedimentation, diffusion, and inertial impaction as functions of bubble size $\ldots \ldots \ldots \ldots \ldots$

7 Initial bubble size as a function of the superficial gas velocity $\ldots \ldots \ldots$

8 Terminal rise velocity of bubbles in water as a function of bubble size . . . . . . . .

9 Predicted mean aerosol particle sizes during core debris interactions with concrete in severe reactor accidents at a Mark I boiling water reactor $\ldots \ldots \ldots \ldots$

10 Effects of inorganic solutes on the surface tension of water at $293 \mathrm{~K} \ldots \ldots \ldots$

11 Cumulative probability distributions for the decontamination factors by water pools 30 and $50 \mathrm{~cm}$ deep and 10 degrees subcooled $\ldots \ldots \ldots \ldots$

12 Median values of the decontamination factor at 50 percent confidence level for water pools 30 and $50 \mathrm{~cm}$ deep as functions of subcooling

1310 percentile and 90 percentile values of the decontamination factors at

90 percent confidence level for water pools 30 and $50 \mathrm{~cm}$ deep as functions of water subcooling

$14 \epsilon$ (imp, pot) and $\epsilon$ (imp, trans) as functions of aerosol particle size and water drop size

$15 \epsilon$ (int, pot) and $\epsilon$ (int, trans) as a function of aerosol particle size for droplets in air at $298 \mathrm{~K}$ and $1 \mathrm{~atm}$

16 Overall capture efficiency as a function of aerosol particle size for various water drop sizes according to the additive and compound models described in the text. 


\section{Figures (Continued)}

Figure

Page

17 Schematic diagram of the spray nozzle and spray patterns $\ldots \ldots \ldots \ldots$

18 Volumetric flow rates through the Model 1-7G25 and Model 1-7G3 spray nozzles as functions of water pressure

19 Volume-weighted mean droplet sizes produced by the Model 1-7G25 and Model $1-7 \mathrm{G} 3$ spray nozzles as functions of water pressure $\ldots \ldots \ldots \ldots \ldots$

20 Droplet size distribution data for the Model $1-7 \mathrm{G} 3$ spray nozzle . . . . . . . . . . .

21 Comparison of the terminal velocities of water droplets in air at $298 \mathrm{~K}$ and $1 \mathrm{~atm}$ predicted by Models $\mathrm{A}$ and $\mathrm{B} \ldots \ldots \ldots \ldots \ldots$

22 Comparison of the usual collision efficiency (bold line) to theoretical analyses of the collision efficiency of a $500 \mu \mathrm{m}$ droplet (symbols) and an alternate model (dashed line) described in the text $\ldots \ldots \ldots \ldots \ldots \ldots \ldots$

23 Size distributions of aerosols in the drywell of a Mark I boiling water reactor during various accidents as predicted with the Source Term Code Package

24 Cumulative probability distribution for $\lambda$ in the cases $\mathrm{Q}=0.25 \mathrm{~cm}^{3} / \mathrm{cm}^{2}-\mathrm{s}$,

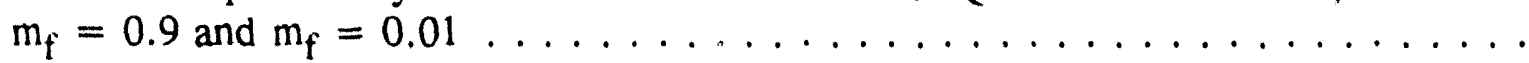

25 Median values of $\lambda\left(\mathrm{m}_{\mathrm{f}}-0.9\right)$ for $\mathrm{Q}=0.25,0.01$, and $0.002 \mathrm{~cm}^{3} / \mathrm{cm}^{2}-\mathrm{s}$ as functions of $\mathrm{m}_{\mathrm{f}} \ldots \ldots \ldots \ldots \ldots \ldots \ldots \ldots$

26 Sampled values of $\lambda\left(\mathrm{m}_{\mathrm{f}}=0.01\right)$ plotted against sampled values of $\lambda\left(\mathrm{m}_{\mathrm{f}}=0.9\right)$ for $\mathrm{Q}=0.25 \mathrm{~cm}^{3} / \mathrm{cm}^{2}-\mathrm{s}$

27 Sampled values of $\lambda\left(\mathrm{m}_{\mathrm{f}}=0.01\right) / \lambda\left(\mathrm{m}_{\mathrm{f}}=0.9\right)$ plotted against sampled values of $\lambda\left(\mathrm{m}_{\mathrm{f}}=0.9\right)$ for $\mathrm{Q}=0.25 \mathrm{~cm}^{3} / \mathrm{cm}^{2}-\mathrm{s}$

28 Median values of $\lambda\left(m_{\mathrm{f}}=0.9\right)$ as functions of $m_{\mathrm{f}}$ for $\mathrm{Q}=0.25,0.01$ and $0.002 \mathrm{~cm}^{3} / \mathrm{cm}^{2}-\mathrm{s}$

$29 \lambda\left(m_{f}=0.9\right)$ as a function of water flux,$Q \ldots \ldots \ldots \ldots \ldots$

30 Median values $\lambda\left(m_{f}\right) / \lambda\left(m_{f}=0.9\right)$ as functions of water flux, $Q$, for $m_{f}=0.5$,

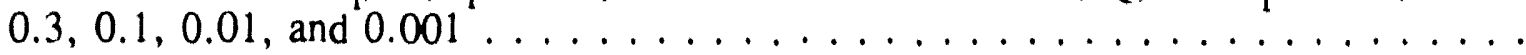

31 Aerosol concentrations in the drywell during an ATWS accident with no water present

32 Aerosol concentrations in the drywell when a $50 \mathrm{~cm}$ deep water pool subcooled by $20^{\circ} \mathrm{C}$ is maintained over the core debris . 


\section{Figures (Concluded)}

Figure

Page

33 Aerosol concentrations in the drywell when a $50 \mathrm{~cm}$ deep water pool subcooled by $2^{\circ} \mathrm{C}$ is maintained over the core debris $\ldots \ldots \ldots \ldots 118$

34 Effects of sprays on aerosol concentrations in the drywell atmosphere . . . . . . . 119

35 Effects of sprays operated at a water flux of $0.01 \mathrm{~cm}^{3} / \mathrm{cm}^{2}-\mathrm{s}$ on aerosol concentrations in the drywell ....................... 121

36 Comparison of aerosol concentrations considering various mitigation

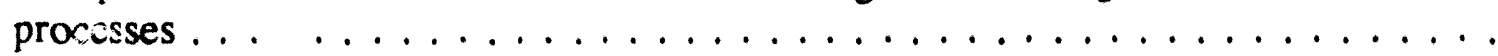




\section{Tables}

Table

Page

1 Properties of pure water $\ldots \ldots \ldots \ldots \ldots \ldots \ldots \ldots \ldots \ldots \ldots$

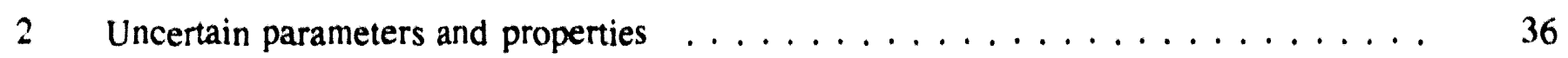

3 Summary of the result for decontamination by a water pool $\ldots \ldots \ldots \ldots \ldots$

4 Properties of water and $\mathrm{ir} \ldots \ldots \ldots \ldots \ldots \ldots \ldots \ldots \ldots$

5 Characteristics of drywell sprays in some Mark I boiling water reactors . . . . . . 59

6 Droplet size data for the Model $1-7 \mathrm{G} 3$ spray nozzle $\ldots \ldots \ldots \ldots \ldots$

7 Uncertain quantities considered in the analysis of spray decontamination . . . . . . . 78

8 Droplet size bins $\ldots \ldots \ldots \ldots \ldots \ldots \ldots \ldots \ldots \ldots \ldots \ldots \ldots \ldots$

9 Example cumulative probability distributions for the spray decontamination coefficient for a water flux of $0.25 \mathrm{~cm}^{3} / \mathrm{cm}^{2}-\mathrm{s}$ and the mass fraction of aerosol remaining in the drywell atmosphere equal to $0.9 \ldots \ldots \ldots \ldots \ldots \ldots$

10 Summary of uncertainty analyses for $Q=0.25 \mathrm{~cm}^{3} / \mathrm{cm}^{2}-\mathrm{s} \ldots \ldots \ldots 100$

11 Summary of uncertainty analyses for $Q=0.01 \mathrm{~cm}^{3} / \mathrm{cm}^{2}-\mathrm{s} \ldots \ldots \ldots 101$

12 Summary of uncertainty analyses for $Q=0.002 \mathrm{~cm}^{3} / \mathrm{cm}^{2}-\mathrm{s} \ldots \ldots \ldots 102$

13 Summary of probability distributions for $\lambda\left(m_{f}\right) / \lambda\left(m_{f}=0.9\right) \ldots \ldots \ldots 107$ 


\section{Acknowledgements}

The author acknowledges the final editorial assistance he has received in the course of preparing this work from R. Cochrell and the graphic arts work of T. Salazar. The author also acknowledges the sacrifice by $S$. Powers of her kitchen and dining room tables for six months to the masses of paper generated during this work. 


\section{Executive Summary}

The document describes the effects on the source term that water pools and sprays in the Mark I boiling water reactor would have. Detailed phenomenological models of the decontamination of aerosol-laden gas bubbles rising through a water pool and of the removal of aerosols by spray droplets are developed. The decontamination of bubbles by water pools occurs by:

- condensation of excess steam in subcooled water pools.

- sedimentation of aerosols within bubbles.

- diffusion of aerosol particles to bubble walls, and

- inertial impaction of aerosoi particles with bubble walls in the cases where gases within the bubble circulate.

Spray droplets remove aerosols from the drywell atmosphere by:

- impaction of particles too big to follow stream lines of flow around the droplets,

- interception of particle whose size is big enough that the particle extends across stream lines to contact the droplets, and

- diffusion of particles to droplet surface.

Eighteen uncertain features of the model of decontamination of aerosol-laden gases by water pools are identified. Nineteen uncertain features of the model of spray removal of aerosols from the drywell atmosphere are identified. These uncertainties include:

- uncertainties in the quantitative description of phenomena and processes responsible for trapping of aerosol particles by water in the form of pools or spray droplets,

- uncertainty in the physical properties of the drywell atmosphere, contaminated water and aerosol particles, and

- uncertainty in the bouncary conditions and initial conditions dictated by the progression of severe accidents in Mark I boiling water reactors.

Parametric quantities are defined to describe these various uncertainties. Credible ranges for the values of the parametric quantities are established based on data, analyses and, where necessary, judgement. Subjective probability density functions for values of the parametric quantities within these ranges are assigned according to a set of rules:

- a uniform probability density function is assigned to a parameter whose meaningful range of values spans less than one order of magnitude,

- a uniform probability density function is assigned to the logarithm of a parameter whose meaningful range of values spans more than one order of magnitude, and 
Executive

- a lognormal distribution is assigned to parameters for which there are data or other reasons to believe the probability densities are more peaked around a median value than would be indicated by a uniform or log-uniform probability density function.

Because of the uncertain features of the respective models, decontamination factors that can be produced by water pools and the rates of aerosol removal by sprays in the drywells of Mark I containments are uncertain. Uncertainty distributions for the decontamination factors and spray removal rate constants are constructed from samples of the distributions obtained using a Monte Carlo sampling. The samples were of a size that there was a 99 percent confidence that 95 percent of the possible range of values of the predicted quantity was sampled. The uncertainty distributions were constructed using a nonparametric statistical analysis to distinguish between phenomenological uncertainty and stochastic uncertainty that arises from the use of finite samples of the distribution.

Uncertainty distributions were obtained for the decontamination of gases produced during core debris/concrete interactions by water pools 30 and $50 \mathrm{~cm}$ deep subcooled by 0 to 70 degrees Kelvin.

The rate constant for spray decontamination of a drywell atmosphere was found to depend on the extent of atmosphere decontamination as well as water flux through the atmosphere. Uncertainty distributions are developed for the rate constants for spray removal of aerosols for water fluxes of $0.25,0.01$ and $0.002 \mathrm{~cm}^{3} \mathrm{H}_{2} \mathrm{O} / \mathrm{cm}^{2}$-s and decontamination facturs of $1.1,2,3.3,10,100$ and 1000 .

Results obtained in these uncertainty analyses are applied to several hypothetical severe accident situations. The calculations done for these cases show that the amount of radioactive material available for release in the event of failure of the Mark I liner can be reduced substantially by water in the drywell. Appropriate design for water pool depth, subcooling, spray water flux and spray operation time can produce decontamination factors of over 100 relative to cases in which water is not available in the drywell. Thus, even if water in the drywell is unable to prevent containment failure the water can reduce substantially the amount of radioactive material released from the nuclear plant and consequently, the consequences of a severe reactor accident. 


\section{Introduction}

Risk to the public from the use of nuclear power was shown as early as 1975 to be small and to come predominantly from severe accidents that exceed the design basis of the power plants [1]. Public consequences of severe accidents come about only if the accident leads to the failure of the protective barriers in a plant and if large quantities of radioactive materials are released from the plant. This usually means that to produce large consequences the severe accident must cause the protective containment of the nuclear reactor to rupture. There must, however, also be a substantial amount of radioactivity suspended in the containment atmosphere at the time of containment rupture or following containment rupture for these large public consequences to develop. The so-called NUREG-1150 study [2] has confirmed these general conclusions for five different types of nuclear power plants. The study provides quantitative analyses of both the probability of containment failure and the probability of a large radioactivity release following containment failure at each of these nuclear power plants.

Findings in the NUREG-1150 study for the specific case of a Mark I boiling water reactor present an interesting example. Relative to other types of nuclear power plants, the probability that Mark I boiling water reactors will have accidents that go beyond the design basis is low. The boiling water reactors have automatic depressurization capabilities. Once depressurized, the reactor coolant system can be supplied coolant from a variety of low-pressure sources to prevent core meltdown. If, despite the many sources of water, an accident progresses to core melting, theie are still many protective features of the Mark I containment that can prevent the release of large amounts of radioactivity. In most severe accidents hypothesized as possible in the Mark I reactors, effluents produced during core degradation within the reactor coolant system including radioactive vapors and aerosols released from overheated fuel must pass through the reactor's steam suppression pool. This pool will scrub particulate and soluble radioactive materials from the effluent [3-5]. The effluent stream of hydrogen and steam is substantially cleansed of radioactive materials except, perhaps, for noble gases.

Safety concerns with the Mark I boiling water reactor increase if severe accidents can progress to the point that core debris penetrates the reactor vessel and falls into the reactor drywell (see Figure 1). Though the drywell of a Mark I containment has a very strong, steel, pressure boundary [6], the drywell is of small volume $\left(<200,000 \mathrm{ft}^{3}\right.$ or $\left.<5100 \mathrm{~m}^{3}\right)$. The drywell can be pressurized quickly once core debris is outside the reactor vessel. An example of the pressurization of tue drywell calculated to take place in a particular, hypothetical severe accident [7] is shown in Figure 2. Gases and heat partitioned into the containment atmosphere as the core materials expelled from the vessel interact with the concrete are responsible for this pressurization. With continued pressurization, the Mark I boiling water reactor containment can rupture and radioactive materials suspended in the containment atmosphere can be released into the reactor building and eventually outside the plant [8].

The Mark I containments also use elastomeric seals. Overheating of these seals, especially in the presence of ionizing radiation from radionuclides released from the fuel, can also cause a loss of containment integrity $[8-10]$ and a release of radioactivity.

Threats to the integrity of the Mark I containment are of keen interest. In 1985, an alternate mechanism for containment failure in the Mark I boiling water reactor was identified. Greene et al. [11] showed that core debris expelled from the reactor coolant system could spread out of the pedestal region, across the drywell floor of a Mark I containment, and come into direct contact with the steel liner that constitutes the con:tinment pressure boundary. For most of the accident cases considered, contact between the core debris and the liner was predicted to lead to liner melting and a loss of containment 
Introduction

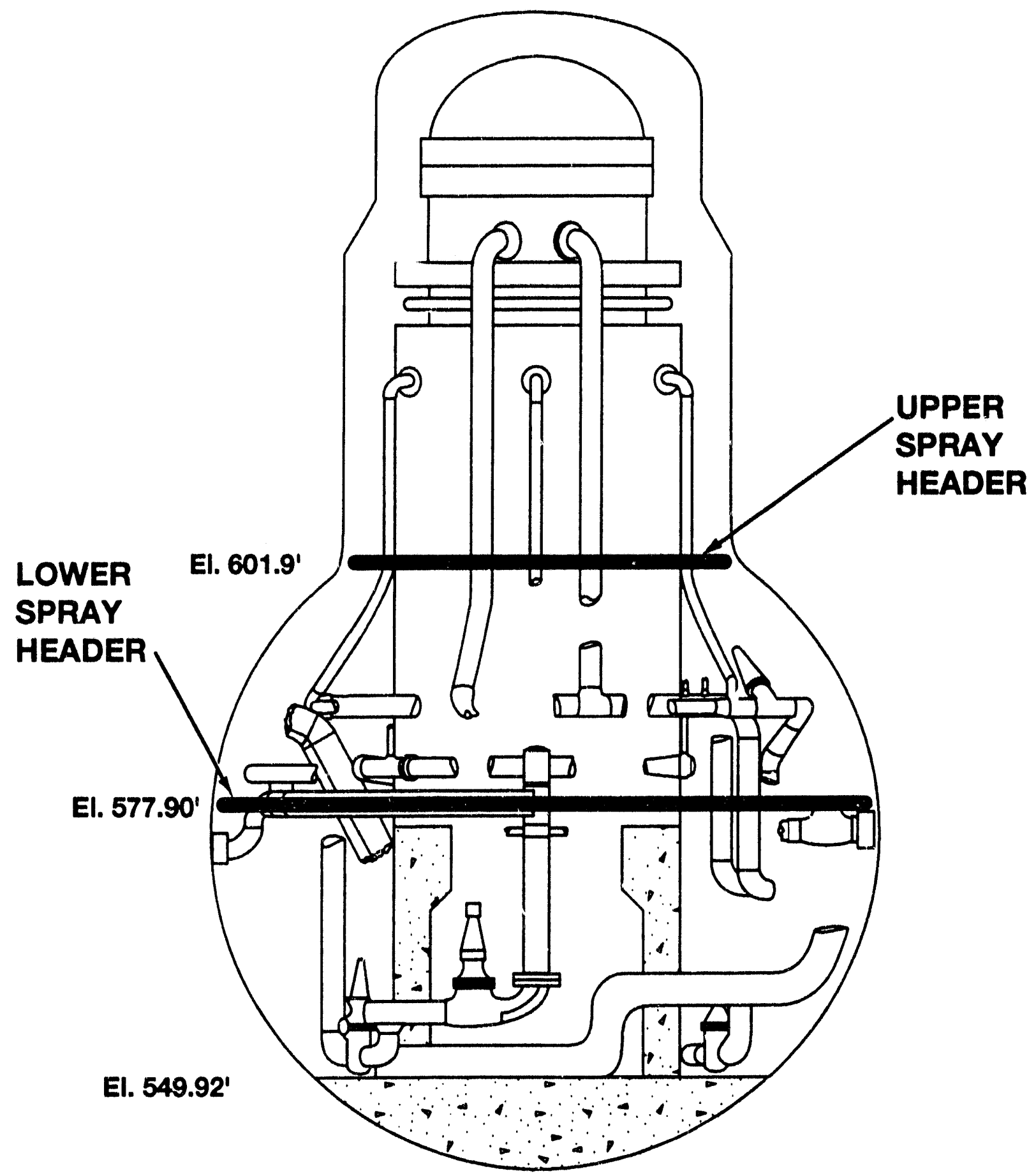

Figure 1 Schematic diagram of the Mark I containment for a boiling water reactor. Much of the piping and other structures within the drywell has been deleted for the purposes of clarity. Note that elevations are given in feet where $1 \mathrm{ft}=30.48 \mathrm{~cm}$. 
Introduction

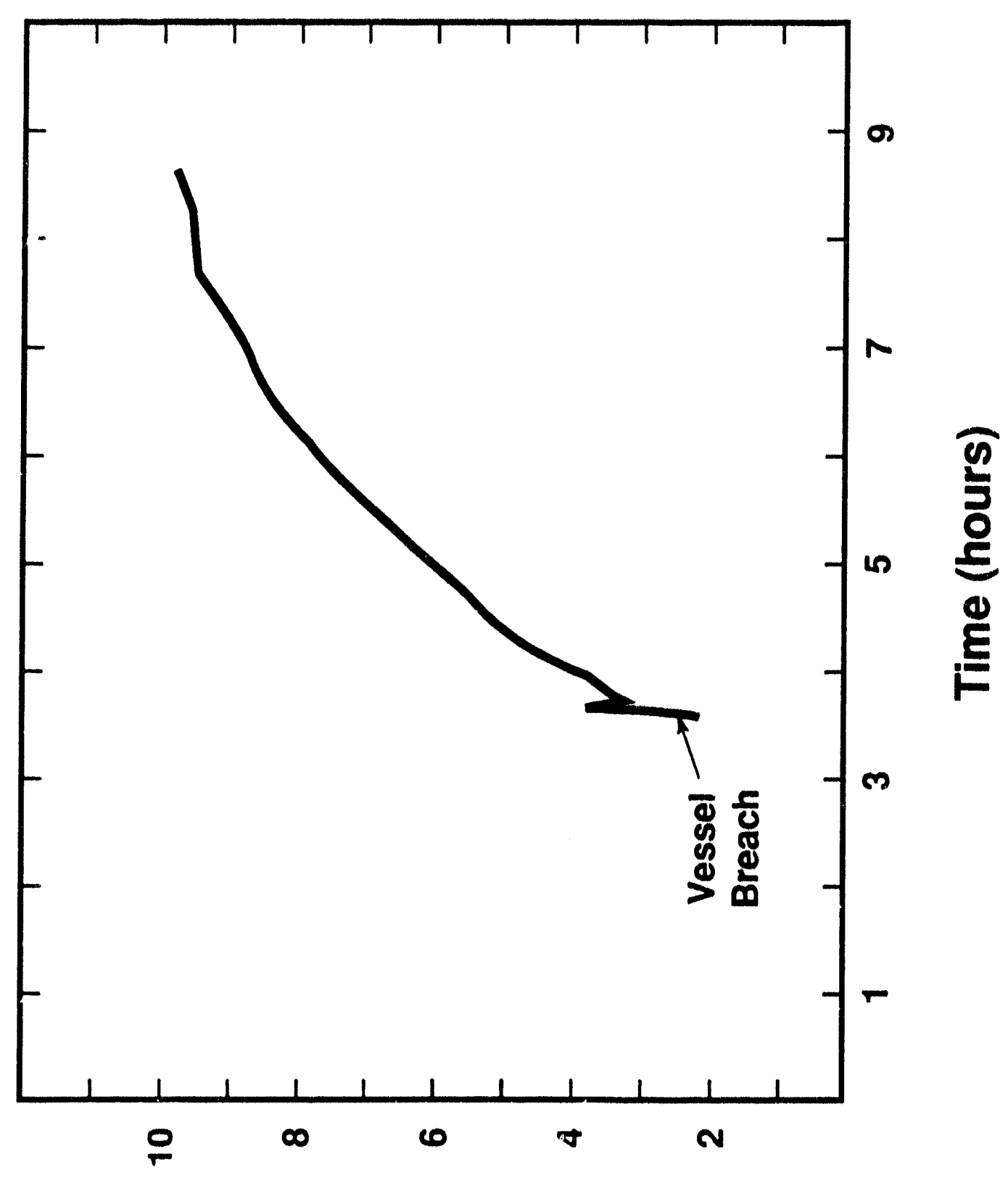

品

흘

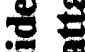

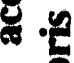

s

\&

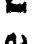

\&

8

8.

00

답

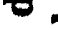

륭

툐

9

8

害菌至

$\infty$

$\approx$

政

톨

$8 \pm$

二.

要

๘

욜

造

$=8$

(sule) əגnssədd łuəuu!̣ełuoว

造施

8 
Introduction

integrity. Some attempts have been made to contradict these findings [12]. Most other analyses have tended to support the contention that contact of high-temperature core debris with the Mark I drywell liner without water present causes containment failure [?,13]. The probability of containment failure in the event of a core meltdown or severe accident in a Mark I boiling water reactor is high relative to this conditional probability in other reactors [2]. In pursuit of defense-in-depth against risks associated with the use of nuclear power there is interest in mitigating the threat of liner failure as a result of interactions with core debris on the drywell floor.

Several mitigation schemes have been suggested including the installation of a refractory barrier at the openings from the pedestal region of the drywell to prevent core debris contact with the liner [14]. The simplest mitigation strategy that has been suggested is to assure that water is present in the drywell at the time core debris is expelled from the reactor coolant system into the reactor cavity. It has been hypothesized that a water pool on the drywell floor might prevent or at least it might delay contact between molten core debris and the liner. Furthermore, with an overlying water present, the liner would act as a "cooling fin." Heat imparted to the liner would conduct up through the liner and be removed by boiling water. Again, even if the water did not ultimately prevent liner failure, it would surely delay failure. Delays in the time of containment failure are significant. They provide time to implement emergency response measures. They also allow time for natural processes to attenuate the amount of radioactivity suspended in the containment atmosphere and available for release when containment integrity is lost.

Qualitative arguments on the mitigation by water of the threat posed to the drywell liner by core debris were not persuasive during the analyses of uncertainty done for the NUREG-1150 study [2]. Some of the experts elicited during this study felt that water would have a powerful mitigating effect on core debris interactions with the liner. Others believed that the potential effects of water were overestimated and the threat to the liner was little altered by presence of water on the drvwell floor. As a result of this disparity in expert opinions, the conditional probability of containment failure estimated in NUREG1150 remained high for the Mark I boiling water reactor relative to other types of containment.

The U.S. Nuclear Regulatory Commission has initiated a more thorough, probabilistic examination of the effects water can have on melt/liner interactions [15]. Preliminary results of this work have been subjected to intense expert scrutiny. The results do support the contention that water on the drywell floor will reduce dramatically the probability of early containment failure during a severe accident in a Mark I boiling water reactor.

The analyses of core debris/liner interactions now being done do not indicate that the possibility of eventual failure of the Mark I containment by some mechanism is reduced. Nor do the studies consider all possible interactions of core debris with the liner. Such things as splashing melt onto the liner by pressure-driven melt expulsion or as a result of energetic melt/water interactions are not considered. It is, however, useful to notice that water in the drywell can mitigate severe accidents at Mark I boiling water reactors in ways other than preservation of liner integrity during interactions with core debris. In particular, water in the drywell could attenuate substantially the amount of radioactive material that could escape the plant in the event that containment did fail by whatever mechanism. That is, a reduction in the source term of radioactivity from the containment can be achieved whether or not water can prevent liner melt-through or mitigate pressurization within the containment. 
Radioactive aerosols are injected into the drywell atmosphere by three important processes:

- release of radioactive species during core debris interactions with concrete,

- release of radioactive species from residual fuel in the reactor coolant system after core debris has penetrated the reactor vessel, and

- revaporization or resuspension of radionuclides deposited in the reactor coolant system during core degradation early in the reactor accident.

Once core debris has penetrated the reactor vessel, released radionuclides accumulate in the drywell atmosphere rather than being forced through the steam suppression pool. The very effective scrubbing of radioactive materials from the effluents by the suppression pool is no longer possible. Only the slower processes of aerosol sedimentation and deposition naturally attenuate the amount of radioactive material suspended in the drywell atmosphere and available for release from the nuclear plast should the drywell rupture.

Introduction of water into the drywell provides additional mechanisms to reduce the amount of radioactivity available for release from the plant in the event of drywell failure. A water pool overlying core debris in the drywell will scrub aerosols froli gases evolved during core debris interactions with concrete. Though the overlying water pool will typically be shallower than a steam suppression pool, the physical phenomene responsible for mitigating the radionuclide release during core debris interactions with concrete are quite similar to the physical phenomena responsible for decontamination by steam suppression pools. Decontamination can be achieved by a water poul overlying core debris interacting with concrete even though the water does not quench and cool the core debris [16]. This decontamination can be substantial especially if the water pool is subcooled.

Water pools overlying core debris in the Mark I drywell have the very attractive feature iat they will follow the debris should the debris penetralc the liner. Were core debris to penetrate the liner, it would seem likely that debris would flow along the annulus between the steel liner and the concrete shield building. Eventually the debris would encounter an opening for a downcomer for the steam suppression pool. Debris would flow through this opening into the so-called "torus room." (See Figure 3.) Once core debris had drained from the drywell along this route, water would surely follow it not accompany the debris. Except, perhaps, for a brief transient period, the core debris would remain covered with water. In the torus room core debris could be spread over a very broad area v/hich might be expected to further mitigate some of the release of radioactivity from the debris. Also, the continued supply of water could lead to very deep water pools overlying debris in the torus room and, consequently, very extensive scrubbing of aerosol-laden gases being evolved from the debris.

Additional mitigation of the radionuclide source term can be achieved depending on how water is admitted to the Mark I drywell. Essentially, there are two ways readily available to supply this water. Water can be injected into the reactor coolant system via the normal routes. Core debris will have penetrated the reactor vessel at this stage in an accident. The water, then, will drain from the reactor coolant system into the drywell. Or, water can be admitted to the drywell by the drywell sprays.

Either mechanism for water admission could attenuate the release of radioactivity beyond the attenuation provided by the water pool overlying core debris on the drywell floor. Water injected into the reactor 
Introduction

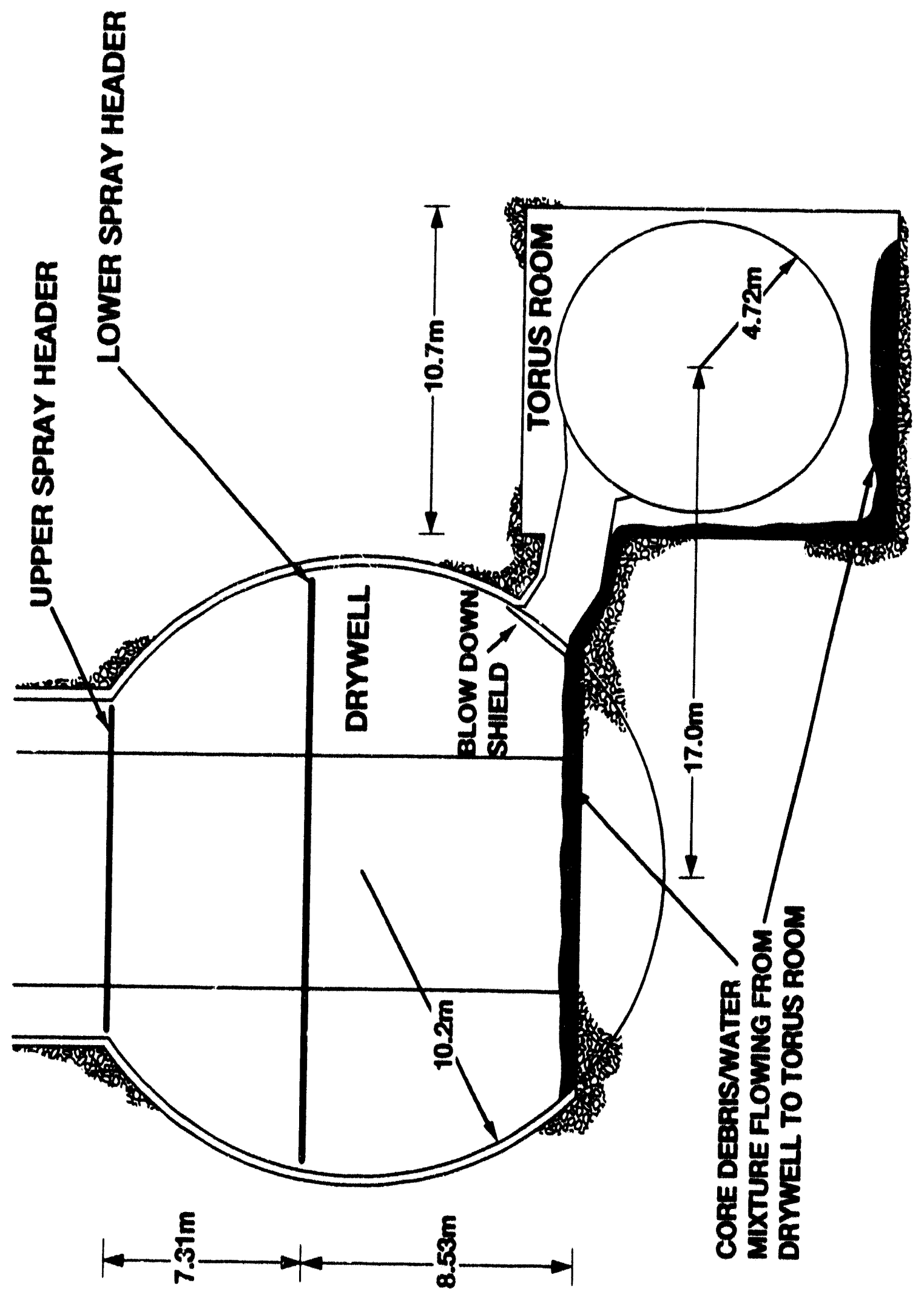

है 
coolant system would cool the surfaces of the reactor coolant system and reduce or delay the revaporization of radionuclides deposited on these surfaces. Depending on the precise routes taken by the water flow, a substantial fraction of the deposited radionuclides might be leached or dissolved from the reactor coolant system so that they could not revaporize. Water added to the reactor coolant system by the core sprays might cool residual fuel sufficiently that there would be no significant additional releases of radionuclides from this residual fuel. The biggest additional source term attenuation would be achieved by admitting water to the drywell - *ith the drywell sprays. The sprays would, of course. cool the drywell atmosphere, thus reducing loads on the containment and at least delaying containment failure by overpressurization. The sprays would cool the reactor vessel and at least reduce the heating that drives revaporization. But, the most important effects of spray would be to sweep aerosol particles from the containment atmosphere regardless of whether these particles were produced by core degradation, revaporization or the interactions of core debris with concrete. The drywell sprays augment the attenuation of the radionuclide release during core debris interactions with concrete in the drywell provided by the overlying water pool. Sprays replace the attenuation of the radionuclide release from other sources provided by the steam suppression pool earlier in a severe accident before core debris penetrated the reactor vessel.

Studies at the systems level to indicate which of the two routes of water addition is most likely to be available and which is to be preferred have not appeared. Injection via the normal routes into the reactor coolant system most likely will not be available for accidents in which automatic depressurization of the reactor coolant system occurred. Were these water sources available, it is likely that the reactor incident could not have progressed to a severe accident. On the other hand, the normal, low pressure water injection routes may become available for accident management in cases in which the core degradation processes take place at elevated pressure. Only after core debris has penetrated and depressurized the reactor vessel would the low pressure water sources be available for accident mitigation. Or, the low pressure water injection may become available only as a result of accident recovery efforts that were successful too late to prevent meltdown of the core and expulsion of the core into the drywell. Use of drywell sprays may be resisted because, at least at some plants, water for these sprays is drawn from the low pressure injection system. Operators may prefer to retain the full capability of the low pressure injection in the hope that recovery efforts would make these capabilities available to them.

Despite issues concerning the way water can be provided to the drywell, the qualitative arguments made above show that water additions to the drywell could provide substantial risk reduction by attenuating the inventory of suspended radioactivity available for release from the plant should containment fail. This attenuation can be achieved whether the drywell water significantly delays containment failure or not. Attenuation can continue even after containment failure. The issue, then, is to ascertain how much attenuation of radionuclide release can be achieved by drywell water. Source term attenuation by water pcols overlying core debris in the Mark I drywell and source term attenuation by drywell sprays are examined quantitatively in the balance of this document.

There are uncertainties in the prediction of decontamination that can be achieved by water pools and sprays in the Mark I containments. These uncertainties arise from a variety of sources. Boundary and initial conditions seeded for the predictions are highly variable among the many types of acciderits hypothesized to occur in Mark I boiling water reactors [2, 15]. Even for a specified accident at a specified nuclear puwer plant the details of accident progression are not so perfectly known that boundary and initial conditions can be accurately specified. Models now available to predict the 


\section{Introduction}

performance of sprays and water pools are not perfect. Some uncertainty must be ascribed to predictions obtained with these models.

With these uncertainties in mind, the analyses presented below were developed following a procedure successfully used to analyze other uncertain severe accident source term issues [17-21]. Physical phenomena that lead to decontamination by overlying water pools and by sprays are briefly described. The various sources of uncertainty are identified. Quantitative uncertainty analyses of the decontamination processes are described. The uncertainty analysis is conducted by a Monte Carlo sampling of the predictions of mechanistic models of the processes. The resu!ts of the Monte Carlo sampling are then analyzed with non-parametric, order statistics methods. This analysis is used to construct quantitatively characterized uncertainty distributions for the predictions of the decontamination that can be achieved by overlying water pools and by sprays in the Mark I containment. In Chipters II and III the physical phenomena responsible for source term attenuation are described. In Chapters IV and V similar discussions are presented for source term attenuation by sprays. Chapter VI is a description of likely source term reductions that can be achieved with drywell water in reactor accidents. 


\section{Source Term Attenuation by an Overlying Water Pool}

\section{A. Background}

By hypothesis, water is to be supplied to the drywell of a Mark I boiling water reactor at a rate sufficient to maintain a water pool over the core debris. The physical phenomena that lead to scrubbing of aerosols from gases sparging through this water pool are described in this chapter.

Early in the course of core debris expulsion from the reactor coolant system it may not be physically possible to maintain a coolant layer over the core debris. A core debris stream is hypothesized [15] to fall some $10 \mathrm{~m}$ from the reactor vessel into the pedestal region. If watet is present on the drywell floor at the time core debris penetrates the vessel, a very dynanic interaction between water and core debris will take place. Large volumes of steam will be generated which might push water out of the pedestal region or even elutriate debris droplets out of the pedestal region. This dynamic period is not considered here. Rather, the quasi-steady state in which a coherent water pool overlies a pool of core debris is the situation of interest.

An inherent conservatism in the analysis is developed because attention is directed toward cases in which a very large fraction of the core inventory has been expelled from the reactor coolant system. Spreading of the core debris over the drywell floor is assumed to be complete. The water supply and the overtlow of water into downcomers for the steam suppression pool are assumed to be in balance. Water is presumed not capable of completely quenching the core debris. This is consistent with all data now available concerning the simultaneous interactions of core debris with concrete and coolant (see for example References 16 and 22). There are, however, suggestions that tests done to date are not sufficiently representative of the real interactions that would take place in the drywell under severe accident conditions [23]. Under sufficiently representative conditions, it is contended, water will quench the core debris. Were this quenching to occur, source terms from the ex-vessel interactions of core debris would, of course, be negligible. Radioactivity releases from residual fuel in the ruptured reactor vessel or releases by revaporization of materials deposited on surfaces of the reactor coolant system would still be possible.

Early in the course of core debris interactions with concrete in the drywell, the water supply necessary to maintain a water pool over the core debris would have to be relatively large. The water supply would have to compensate for boiling losses as a result of both decay heat and exothermic chemical reactions in the core debris. Core debris produced in severe reactor accidents is usually calculated [7] to be rich in metallic zirconium. This metallic zirconium is highly reactive toward the condensed and gaseous products of concrete decomposition:

$$
\begin{gathered}
\mathrm{Zr}+2 \mathrm{H}_{2} \mathrm{O}-\mathrm{ZrO}_{2}+2 \mathrm{H}_{2} \\
\Delta \mathrm{H}(\mathrm{rxn})=-580321 \mathrm{~J} \\
\mathrm{Zr}+2 \mathrm{CO}_{2}-\mathrm{ZrO}_{2}+2 \mathrm{CO} \\
\Delta \mathrm{H}(\mathrm{rxn})=-527887 \mathrm{~J} \\
\mathrm{Zr}+\mathrm{SiO}_{2}(\mathrm{l})=\mathrm{ZrO}_{2}+\mathrm{Si}(\mathrm{l}) \\
\Delta \mathrm{H}(\mathrm{rxn})=-148377 \mathrm{~J}
\end{gathered}
$$


where $\Delta H(r \times n)$ is the enthalpy of reaction using the chemical convention so that when heat is produced by a chemical reaction the value of $\Delta H(r \times n)$ is negative. The exoergic reactions of zirconium can produce heating rates in core debris that are several times heating rates produced by radioactive decay.

Once the highly reactive species in the core debris are consumed, the water supply necessary to maintain a water pool must only compensate for boiling that comes from decay heating in the debris. In fact, there are water supply capabilities in some Mark I containments that are sufficient to maintain the water pool subcooled at least once vigorous, exoergic chemical reactions have ceased. For instance, drywell sprays at the Brown's Ferry units 1 and 2 can supply 517 liters of water per second. At unit 3, the sprays can supply 577 liters per second. On the other hand, some Mark I drywell sprays have been modified to curtail the flow of water to about 50 liters per second out of concern that under some circumstances the sprays might cool the drywell atmosphere so much that pressure within the drywell is less than the external atmospheric pressure. The Mark I pressure boundary is not designed to withstand external pressurization.

The mechanics available for supplying water to the drywell are not the issues of interest here. The basis for the discussions below is that a water pool can be maintained over the core debris. It is evident that the water pool can be saturated or subcooled.

Water ponls that can be maintained in the drywells of Mark I boiling water reactors will not be deep. Without some modifications, water will flow into the downcomers for the steam suppression pool. The lower lips for the downcomers in the Brown's Ferry Mark I boiling water reactors are $61 \mathrm{~cm}$ above the floor. At other Mark I boiling water reactors, the lower lip for the downcomers may be at other elevations above the drywell floors. A relatively complete meltdown of the Mark I reactor core would produce a debris bed with a "collapsed height" of about $22 \mathrm{~cm}$. The depth of the water pool, if gas holdup in the debris is considered, might then be onily $30 \mathrm{~cm}$. Given that the lower lips of the steam suppression pool downcomers are $60 \mathrm{~cm}$ above the flow, it is unlikely that overlying water pools will be deeper than about $50 \mathrm{~cm}$. It is possible to get deepet water pools in the drywell by completely flooding the steam suppression pool torus. This, however, requires steps to be taken that are outside the scope of analysis undertaken here. Consequently, very deep water pools are not considered here. Deep water pools can develop if molten core debris flows into the torus room (see above).

Were there no water present, core debris interacting with concrete would be expected to injec: enormous quantities of aerosol into the reactor containment atmosphere. Predictions of the rates of aerosol generation during core debris interactions with concrete in a Mark I boiling water reactor are shown in Figure 4 [8]. Core debris first deposited on the drywell floor is usually predicted to be at a fairly low temperature. Aerosol generation increases as the core debris heats because of radioactive decay and the exoergic reactions of conciete decomposition products with zirconium in the core debris. Core debris produced in severe accidents at Mark I boiling water reactors is often predicted to be quite rich in zirconium so heating of the core debris by chemical reactions can be prolonged. Very intense release of aerosols from the core debris lasts for 4 to 5 hours after core debris first contacts the concrete. (Note that for the calculations shown in Figures 4 and 5 , core debris was not allowed to spread outside the pedestal region of the drywell. Spreading of the debris might accentuate the rates of chemical reaction of debris constituents and thus shorten the period of intense radionuclide release and aerosol generation. On the other hand slow deposition of debris into the drywell might prolong the period of high aerosol generation by renewing the concentration of reactive zirconium in the core debris.) Once the reactive constituents of core debris are consumed, temperatures in the core debris drop rapidly. A fairly steady, 


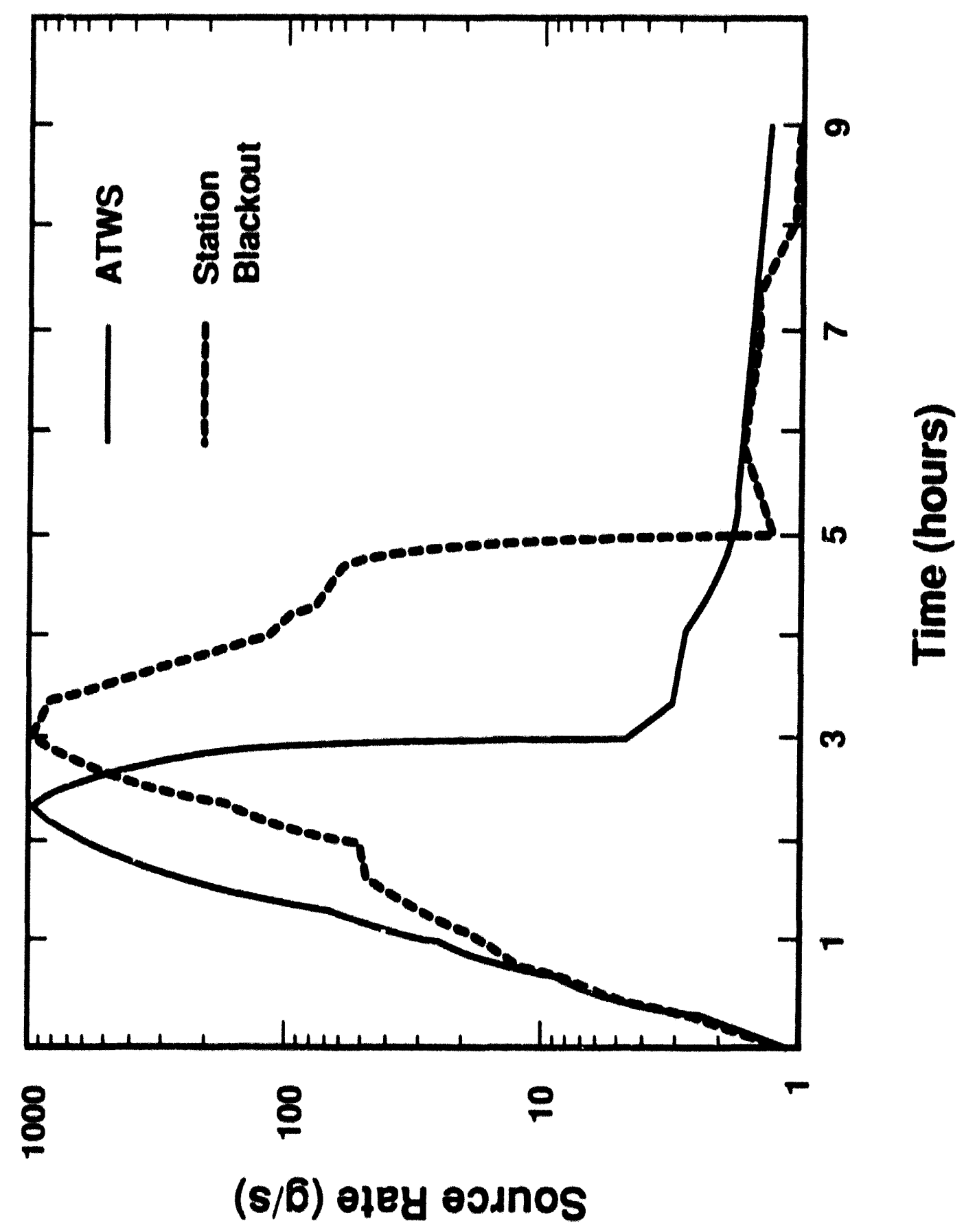

Source Term

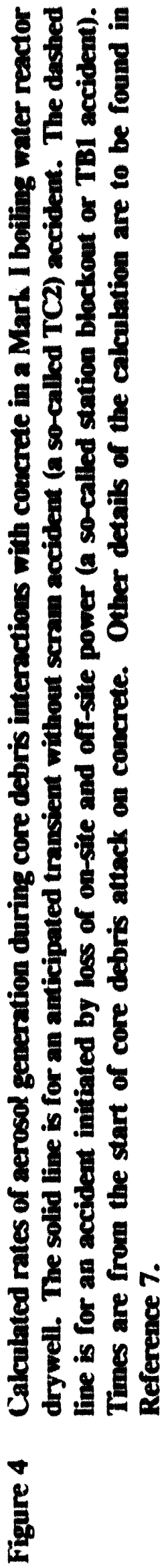




\section{Source Term}

low, aerosol generation rate develops. Though aerosol generation is shown only for about 10 hours in Figure 4, aerosol generation can continue for days at these low rates. Most of the radionuclide release occurs during the high temperature phase of the core debris intaractions. But, tellurium release persists even into the long term, low intensity, release phase of the interactions [24]. Consequently, from a radionuclide source term perspective, mitigation by an overlying water pool of even the late phase releases is still of interest.

\section{B. Attenuation Mechanisms}

The predominant mode by which aerosols are generated during core debris interactions with concrete is the vaporization of volatile constituents of the melt. Water vapor and carbon dioxide released from the concrete sparge through and react with the molten core debris. Bubbles of gas in the melt provide free surfaces for the vaporization of species from the melt. At the temperatures expected to exist in mixtures of core debris and concrete decomposition products, nearly all the melt constituents have significant vapor pressures and will contribute vapor to the bubbles. When bubbles emerge from the core debris, the vapors are released into a cooler environment, and they condense to form aerosol particles. When bubbles burst at the surface of core debris, aerosols can be formed by mechanical processes. Typically, mechanical generation of aerosols is a small fraction of the aerosol generation by vaporization [25]. Late in the course of core debris interactions with concrete when melt temperatures are quite low, the mechanical generation of aerosols can become comparable to aerosol generation by vaporization. Mechanical aerosol generation becomes the predominant mode of radionuclide release at very low core debris temperatures.

In principle, the essential phenomına $\mathrm{rc}$ ' onsible for atrosul generation are not greatly changed when a water pool overlies the core debris if water does not quench the debris. The one complication arises because water will cause a crust of solidified material to form at the interface between the water and the core debris. "The crusts are quite porous so aerosol-laden gases readily pass through the crusts. Crusts might interfere in the mechanical formation of aerosols by bubbles bursting at the surface of molten debris. The fine pore structure of the crusts might provide excellent surfaces for the deposition of aerosols. None of these effects are considered here. The only attenuation of aerosol generation attributed to water pools is the scrubbing of aerosols from gas bubbles rising through the water pools.

Gases produced by melt attack on concrete are assumed here to mix with steam produced by the boiling of water oit the crust surface. The mixing is easiest to imagine if water is in film boiling on the crust surface. Then, gases emerging through the pores in the crust combine in the steam film at the interiace with water. Taylor instability of the low density gas layer below the liquid water leads to bubble formation. Available experimental information suggests, however, that water on core debris crusts is in nucleate rather than film boiling. It must, then, be imagined that free surfaces formed by gases emerging from the pore structure provide excellent water vapor generation sites induced by the heat flux from the crust. When enough gas and steam has entered a bubble, the bubble detaches form the crust and rises through the water pool.

\footnotetext{
* Some specialists have suggested that such crusts are unstable and will fragment into coolable debris. The many tests that have now been done of combined core debris-concrete-coolant interactions have not shown this phenomenon. It is neglected here. Crusts are assumed to be stable for this work, as has been shown in all tests to date.
} 
Aerosols within a gas bubble rising through the water pool can be "scrubbed" from the gas because:

- aerosols sediment onto the walls of the bubble.

- aerosols viffuse to the walls of the bubble, and

- aerosols inertially impact the walls of the bubble.

Sedimentation is just the gravitational settling of particles within the bubble. Sedimentation rates are significant only for the larger aerosol particles uch as those generated by mechanical processes at the surface of the molten core debris. Diffusion ot aerosol particles is the result of the spatially stochastic impulses imparted to the particles by collisions with gas molecules. Diffusion efficiently transports only very small particles (diameters $s 0.1 \mu \mathrm{m}$ ) to the bubble walls on the time scales of interest. Impaction of aerosol particles with the bubble walls occurs because the gases within the bubble can circulate as the bubble rises. Particles that are too big to respond to the accelerations involved in the circulatory motion of the gas can be carried into the bibble walls. Circulation of the gases is thou $\mathrm{g}_{\mathrm{b}}$ to depend on the purity of the water as well as the size of the bubble [26]. Impurities in the water can accumulate on the bubble surface and retard circulation of gas within the bubble.

It is assumed here that once a particle contacts the water it is permanently trapped in the water. Surface tension and van der Waals forces are thought to be sufficiently strong to preclude bounce or reentrainment of the particles.

Consider a bubble containing a mass $M(x)$ of aerosols of particle sizc $d_{p}$. The bubble is distorted into an oblate ellipsoid of eccentricity $E$ and has a volume equivalent to a spherical bubble of size $D_{p}$. The extent to which particles are scrubbed from the bubble by sedimentation, diffusion and impaction per unit of rise distance is given by:

$$
\frac{d M(x)}{d x}=-\left\{\alpha_{s}\left(D_{h}, d_{p}\right)+\alpha_{D}\left(D_{b}, d_{p}\right)+\alpha_{I}\left(D_{b}, d_{p}\right)\right\} M(x)
$$

where

$x=$ distance of the bubble from the point of release into the water pool.

$a_{s}\left(D_{b}, d_{p}\right)=$ aerosol trapping coefficient for the sedimentation of particles in the bubble.

$\alpha_{D}\left(D_{b}, d_{p}\right)=$ aerosol trapping coefficient for the diffusion of particles within the bubble.

$\alpha_{I}\left(D_{b}, d_{p}\right)=$ aerosol trapping coefficient for the inertial impaction of particles within the bubble.

The coefficients in this differential equation for particle scrubbing are given by $[18,27]$ : 
Source Term

- Sedimentation:

$$
\alpha_{s}\left(D_{h}, d_{p}\right)=1.5 E^{2 / 3} J / D_{b} U_{T}
$$

where

$$
\begin{aligned}
E= & \text { ratio of the maximum bubble axis divided by the minimum bubble axis (see discussion } \\
& \text { of bubble shapes) } \\
J & =g \rho_{p} d_{p}^{2} \bar{c} / 18 \mu g \\
g & =\text { acceleration due to gravity }=980 \mathrm{~cm} / \mathrm{s}^{2} \\
\rho_{\mathrm{p}}= & \text { density of the material making up the aerosol particle } \\
\overline{\mathrm{c}}= & \text { Cunningham slip correction } \\
= & 1+\left(\frac{2 \lambda}{\mathrm{d}_{\mathrm{p}}}\right)[1.257+0.4 \text { exp }(-0.55 \mathrm{~d} / \lambda)] \\
\lambda= & \text { mean free path of a gas molecule } \approx\left[\sqrt{2} \pi \mathrm{d}_{\mathrm{g}}^{2} \mathrm{~N}_{\mathrm{A}} \mathrm{P} / 82.06 \mathrm{~T}\right]^{-1} \mathrm{~cm} \\
\mathrm{~d}_{\mathrm{g}}= & \text { diameter of a gas molecule } \\
\mathrm{N}_{\mathrm{A}}= & \text { Avogadro's number }=6.022 \times 10^{23} \\
\mathrm{P} & =\text { absolute pressure in atmospheres }(101325 \mathrm{~Pa}) \\
\mu_{\mathrm{g}}= & \text { viscosity of gas } \\
\mathrm{U}_{\mathrm{T}}= & \text { terminal rise velocity of the bubble }
\end{aligned}
$$

- Diffusion:

$$
\alpha_{D}\left(D_{b}, d_{p}\right)=6 \sqrt{\frac{8 \theta}{\pi U_{T} D_{b}^{3}}}\left\{\frac{\left(E^{2}-1\right) f(E)}{1+\sqrt{4+2\left(E^{2}-1\right)}}\right\}
$$


where

$$
\begin{aligned}
\theta & =\text { particle diffusion coefficient }=\mathrm{kT} \bar{c} / 3 \pi \mu_{\mathrm{g}} \mathrm{d}_{\mathrm{p}} \\
\mathrm{k} & =\text { Boltzmann's constant }=1.3807 \times 10^{-16} \mathrm{ergs} / \mathrm{K} \\
T & =\text { absolute temperature in Kelvin } \\
\mathrm{f}(\mathrm{E}) & =\left[\frac{1.16 \mathrm{E}^{2}}{\mathrm{E}^{2}-1}-\sqrt{(2)}\right]^{1 / 2}\left[\frac{\mathrm{E}^{2} \tan ^{-1}\left(\sqrt{\mathrm{E}^{2}-1}\right)}{\sqrt{\mathrm{E}^{2}-1}-1}\right]^{-1 / 2}
\end{aligned}
$$

Note that $f(E)$ approaches $1.625 /\left(E^{2}-1\right)$ as $E$ approaches 1 .

- Inertial Impaction:

$$
\alpha_{I}\left(D_{b}, d_{p}\right)=6 U_{T} \tau g(E) / D_{b}^{2}
$$

where

$$
\begin{aligned}
\tau & =\rho_{p} d_{p}{ }^{2} \bar{c} / 18 \mu g \\
g(E) & =\frac{E^{4 / 3}\left[\left(E^{2}-1\right)+\left(E^{2}-1\right)^{3 / 2}\left(E^{2}-2\right) \tan ^{-1}\left(\sqrt{E^{2}-1}\right)\right]}{\left[E^{2}-1-E^{2} \tan ^{-1}\left(\sqrt{E^{2}-1}\right)\right]^{2}}
\end{aligned}
$$

Note: $g(E=1)=3$

The dependencies of these aerosol trapping coefficients on particle size and bubble size are shown in Figures 5 and 6, respectively. Diffusion is, as expected, most efficient for trapping very' small particles. Impaction and sedimentation increase with increasing aerosol particle size. In sum, the three trapping mechanisms yield an overall trapping coefficient that passes through a minimum when plotted against aerosol particle size. The precise location of this minimum depends on bubble size and properties of the system in question, but, typically the minimum trapping is for particles about $0.3 \mu \mathrm{m}$ in diameter.

The variation in the overall trapping coefficient has enormous ramifications on the decontamination that can be achieved by a water pool overlying core debris. Evolved aerosols with a distribution of sizes will not be uniformly scrubbed from rising bubbles. Rather, very large and very small particles will be removed much more easily than particles having sizes in the vicinity of the minimum in the overall trapping coefficient. Thus, not only does a water pool attenuate the magnitude of the aerosol production, it also changes the particle size distribution of what aerosols do pass through the water pool. 
Saturated Pool

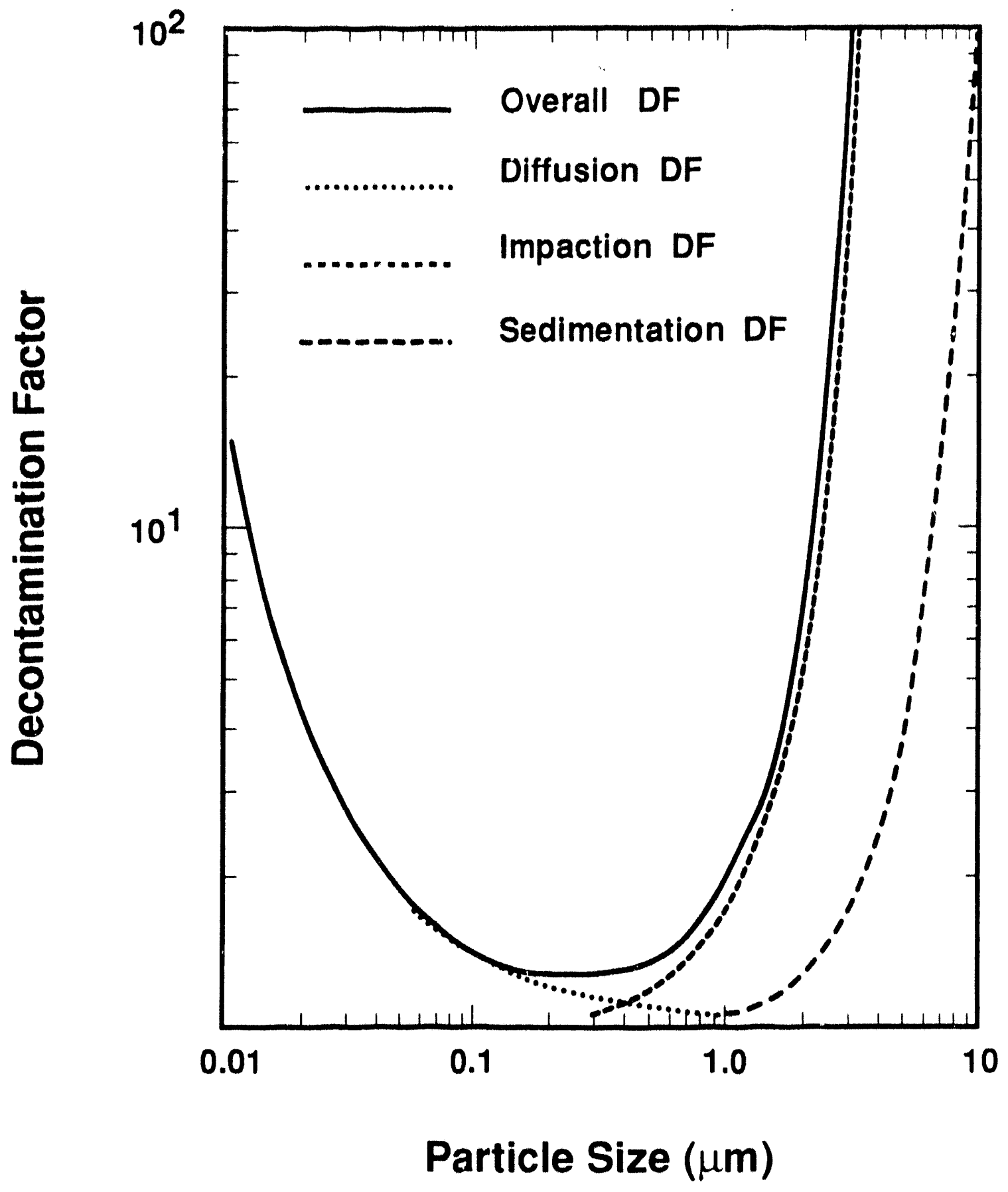

Figure 5 Decontamination factors produced by sedimentation, diffusion, and inertial impaction as functions of aerosol particle size $\left(D_{b}=1.0 \mathrm{~cm}\right)$ 
Source Term

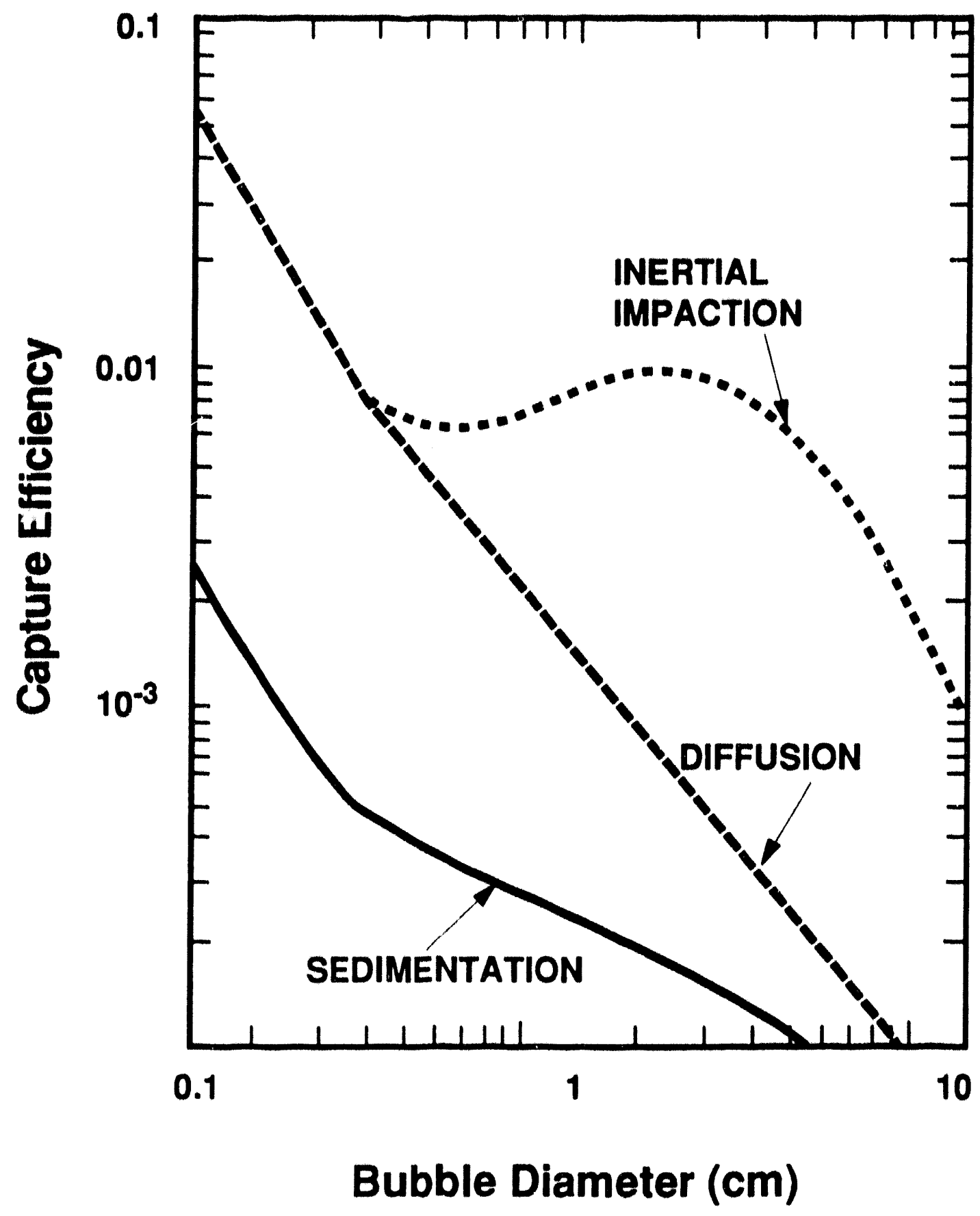

Figure 6 Aerosol capture efficiencies for sedimentation, diffusion, and inertial impaction as functions of bubble size $\left(d_{p}=0.5 \mu \mathrm{m}\right)$ 


\section{Source Term}

All three of the mechanisms for aerosol trapping by a water pool increase in efficiency as the size of the bubble decreases. The increase in the efficiency of trapping by inertial impaction is not continuous since gases within very small bubbles $(<0.2 \mathrm{~cm})$ are thought not to circulate [26].

The sensitivities of the trapping coefficients to bubble size is thought to be responsible for the efficient decontamination that can be achieved by subcooled water pools. Bubbles of steam and gases from tha concrete will shrink when injected into a subcooled water pool as excess steam condenses on the bubble walls. It is presumed that the Stefan flows created during the condensation will sweep aerosols to the bubble walls with an efficiency that is independent of the aerosol particle size. The amount of decontamination of the bubble achieved as the bubble equilibrates with the subcooled water pool is just proportional to the volume change of the bubble. This can be a significant decontamination. A more important factor is, however, that the final bubble is smaller. Aerosol trapping is more efficient as this smaller bubble rises through the pool than in a corresponding case in which the pool is not subcooled.

This view of bubble formation and collapse in a subcooled pool can be questioned. The only support for the model is that it does lead to fairly accurate predictions of the decontamination achieved in the SWISS-2 test [16].

It is evident from the models for the trapping coefficients that the decontamination that can be achieved by an overlying water pool depends on:

- characteristics of the bubbles

- characteristics of the aerosol particles, and

- properties of the liquid phase and the gas.

These topics are discussed in the subsections below.

\section{Characteristics of the Bubbles}

There has been little careful study of the bubbles formed when water boils on core debris. An experimental technique developed by Brockmann et al. [28] holds the promise of being capable of providing the data needed to more accurately define the initial sizes of bubbles that rise up through a water pool overlying core debris. Until better data are available, a simple intuitive model is adopted:

a. At low gas generation rates the porous crust that separates the molten core debris from the overlying water pool would behave much like a porous plate. The size of bubbles escaping from such a porous plate is given by the Fritz equation [29]:

$$
D_{b}=0.0105 \psi\left[\sigma_{1} / g\left(\rho_{1}-\rho_{g}\right)\right]^{1 / 2}
$$

where

$$
\Psi=\text { contact angle (degrees) between water and the frozen core debris }
$$




$$
\begin{aligned}
& \sigma_{1}=\text { surface tension of the liquid } \\
& \rho_{1}=\text { density of the liquid } \\
& \rho_{g}=\text { density of the gas }
\end{aligned}
$$

b. At very high rates of gas generation, the size of the bubbles initially released into the water pool is determined by Taylor instability [30]:

$$
D_{b}=2 C\left[\rho_{1} /\left(p_{1}-\rho_{g}\right) g\right]^{1 / 2}
$$

where $\mathrm{C}$ is a constant given various values between 1.9 and 4.

c. Between these limiting values for very high and very low gas generation rates, the initial bubble diameter is thought to depend on the rate of gas generation as described by the Davidson-Schular equation for low viscosity fluids [31]:

$$
D_{b}=1.11\left(\frac{6}{\pi}\right)^{1 / 3} \frac{v_{s}^{0.4}}{g^{0.2}} \quad \mathrm{~cm}
$$

where $V_{s}$ is the total superficial vapor velocity (gas and steam) from the crust surface.

Initial bubble diameter as a function of the superficial gas velocity is shown in Figure 7. The initial bubble diameters shown in this figure are, in fact, the diameters of spherical bubbles with the same volumes as the actual bubbles. An actual bubble is thought to distort into oblate ellipsoid with semi-major axis a and semi-minor axis b. Then,

$$
D_{b}=2 a / E^{1 / 3}
$$

where $E=a / b$ is the eccentricity of the bubble. The eccentricities of bubbles rising in wat thave been correlated by [32]:

$$
1 / E=\left\{\begin{array}{cc}
1 & \text { for Ta } \leq 1 \\
\left\{0.81+0.206 \tanh \left[2\left(0.8-\log _{10} \mathrm{Ta}\right)\right]\right\}^{3} \\
0.24 & \text { for } 1<\mathrm{Ta} \leq 39.8 \\
& \text { for } \mathrm{Ta}>39.8
\end{array}\right.
$$


Source Term

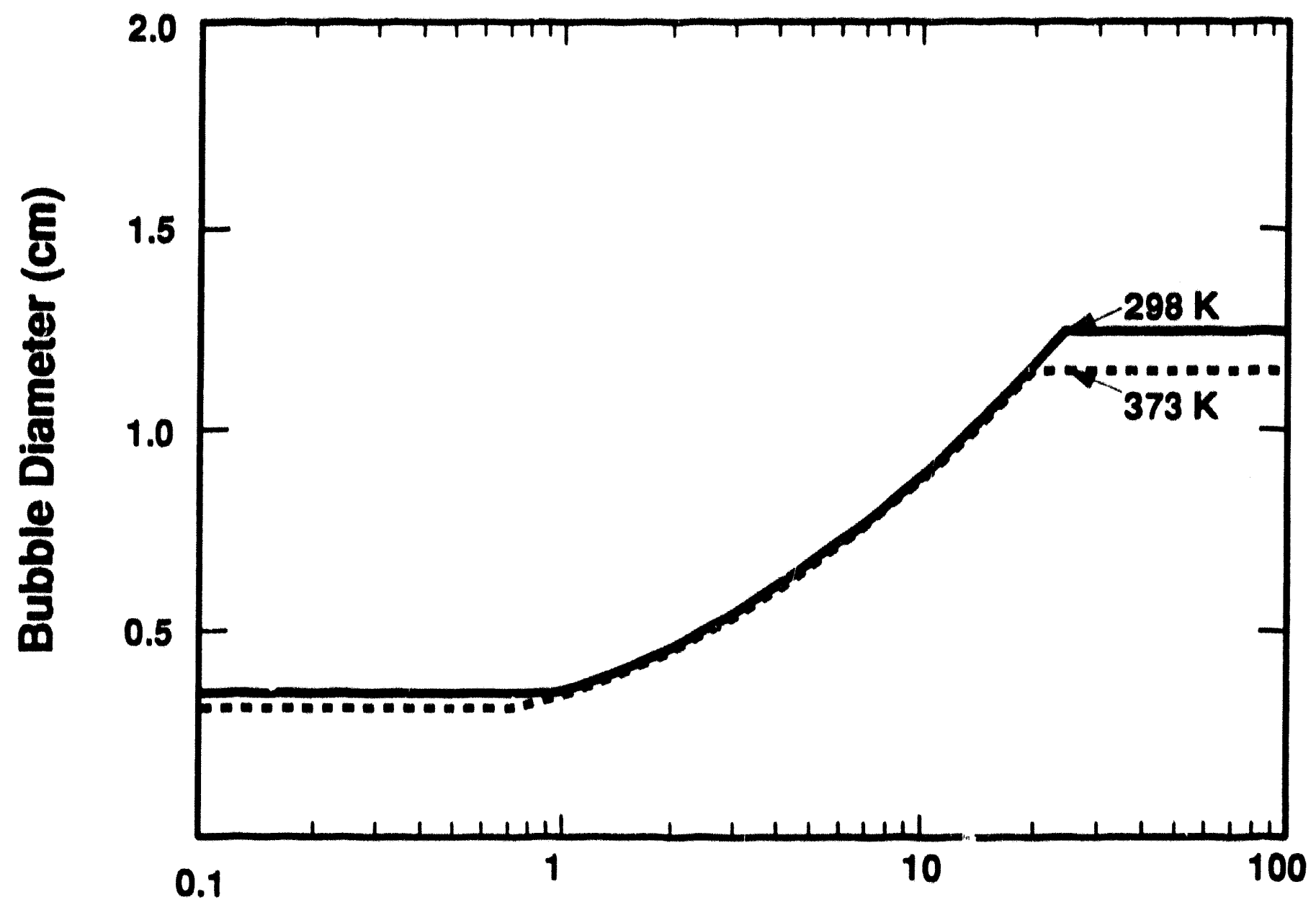

Superficial Gas Velocity (cm/s)

Figure 7 Initial bubble size as a function of the superficial gas velocity 
where

$$
\begin{aligned}
T a & =\operatorname{Re} M^{0.23} \\
M & =\text { Morton number }=g \mu_{1}^{4} / \rho_{1} \sigma_{1}^{3} \\
\operatorname{Re} & =\text { Reynolds number }=U_{T} \rho_{1} D_{h} / \mu_{1} \\
\mu_{1} & =\text { viscosity of the liquid phase }
\end{aligned}
$$

Note that bubbles with $\mathrm{Ta}>\mathbf{3 9} .8$ are actually spherical-cap or ellipsoidal-cap bubbles.

Terminal velocities of tising bubbles have a complex dependence on bubble size and liquid properties in very pure water [26]. Water pools overlying core debris that is interacting with concrete will not be pure for long. Water pools used in the SWISS tests [16] very quickly became heavily contaminated by dissolved and suspended solids. The contamination did not all come from aerosols trapped in the water pool. Much of the contamination was the result of the actions hot water has on concrete and the solidified crust of core debris. Terminal velocities of bubbles rising through contaminated water have been correlated by [33]:

$$
U_{T}=\mu_{1} M^{-0.149}\left(J_{0}-0.857\right) / \rho_{1} D_{h}
$$

where

$$
\begin{aligned}
& J_{0}= \begin{cases}0.94 \quad H^{0.757} & \text { for } 2 \leq H \leq 59.3 \\
3.42 \quad H^{0.441} & \text { for } H>59.3\end{cases} \\
& H=(4 / 3) E_{0} M^{-0.149}\left(\mu_{1} / \mu_{w}\right)^{-0.1} \\
& E_{o}=\text { Eotvos number }=g \rho_{1} D_{b}^{2} ; \sigma_{1} \\
& \mu_{w}=0.009 \text { Poises }
\end{aligned}
$$

The terminal velocities of bubbles of various sizes rising through water are shown in Figure 8.

As a bubble rises through the water pool, it grows as a result of the loss of hydrostatic head. At the level of approximation adopted here, the growth of the bubble during its rise through the water pool is describeo by [25]: 
Source Term

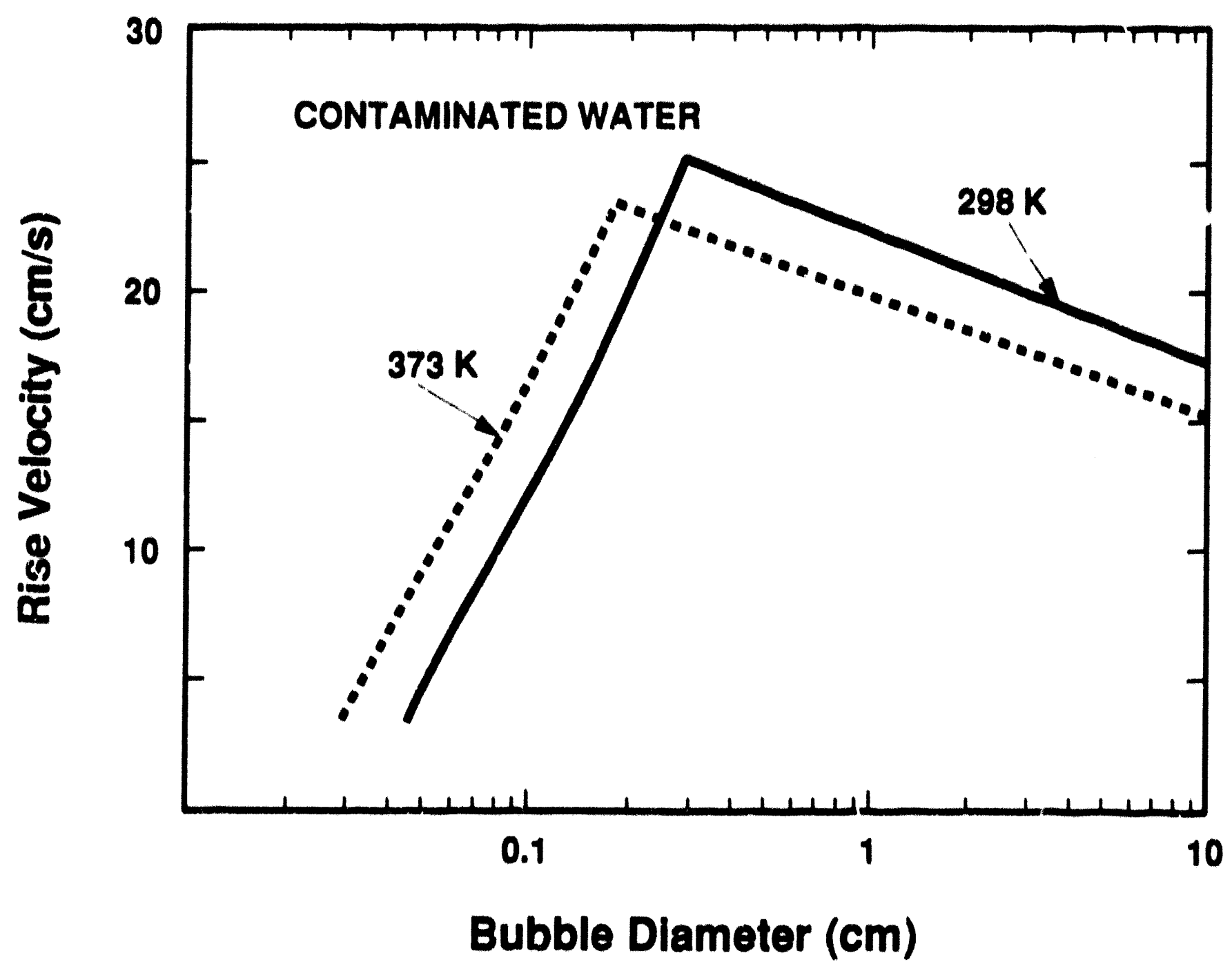

Figure 8 Terminal rise velocity of bubbles in water as a function of bubble size 


$$
\frac{D_{b}^{3}(0)}{D_{b}^{3}(x)}=\frac{P_{a t m s}+g P_{1}(H-x) / 1033.3}{P_{a t m s}+g P_{1} H / 1033.3}
$$

where

$$
\begin{aligned}
D_{h}(0) & =\text { initial bubble diameter } \\
D_{h}(x) & =\text { bubble diameter at a distance } x \text { above the point of bubble formation } \\
H & =\text { depth of the water pool } \\
P_{\text {atms }} & =\text { pressure in the gas phase above the wattr pool }
\end{aligned}
$$

Bubble growth is not unlimited. The envelope defining a bubble is not rigid. Discurbances in this envelope form, grow and are swept away as the bubble rises. If a bubble grows too large, disturbance in the bubble envelope can grow to bubble dimensions before being swept away. When this happens. the bubblc splits ("calves"), Levich [34] has formulated a simple criterion for the maximum stable bubble size:

$$
D_{b}^{c}=1.8 \sigma_{1} / U_{T}^{2}\left[\rho_{g} P_{1}^{2}\right]^{1 / 3}
$$

This is the criterion adopted here to define the maximum bubble size. More detailed stability analyses indicate somewhat smaller values for the maximum stable bubble size [25]. It takes time for the instability of bubbles to cause calving. The time necessary for instabilities to grow to produce "calving" increases as the bubble size approaches the maximum stable bubble size. Since pools of interest heie are shallow and the residence times of bubbles in the pools are short, metastable bubbles can rise through the pool. The larger maximum size defined by the Levich criterior may, then, be a more realistic description of the largest bubble to be expected for the processes of interest here.

\section{Characteristics of the Aerosol Particles}

There have been many measurements of the size distributions of aerosols produced when high temperature melts interact with concrete. Brockmann [35] has reviewed much of this data. In the VANESA model of aerosol generation during core debris interactions with concrete, the aerosols are considered to have lognormal size distributions with mean sizes given by [25]:

$$
d_{p}(\text { inean })=0.266\left[\frac{A}{\rho_{p}}\right] \mu m
$$


Source Term

where

$$
\begin{aligned}
& A=\text { mass concentration of aerosols in the gas }\left(g / \mathrm{m}^{3}\right) \\
& \left.\rho_{p}=\text { material density of the aerosol particles }, g / \mathrm{cm}^{3}\right)
\end{aligned}
$$

The geometric standard deviation of the distribution is taken to be 2.3 which is a weighted average of geometric standard deviations of 1.6 to 3.2 measured in experiments.

Mean sizes of the aerosols predicted [8] to form during core debris-concrete interaction in a Mark 1 containment are shown in Figure 9. During the periods of intense aerosol generation, aerosol sizes become quite large. As the aerosol generation rates fall, mean aerosol particle sizes fall to 0.2 to $0.3 \mu \mathrm{m}$. The trends shown in this figure are cenainly in qualitative accord with experimental observations from tests of high temperature melt interactions with concrete without water present.

There have been no measurements of the size distributions of aerosols tha: emerge from water pools overlying core debris interacting with concrete. Certainly there have been no measurements of the size distributions of aerosols that emerge from the core debris and enter the water pool. In the absence of any actual data. it is certainly convenient to assume that the size distribution of aerosols that enter an overlying water pool is the same as the aerosol distribution that would be produced were no water pool present. Unfortunately, there is no reason to believe this is true.

Aerosols are produced in melt/concrete interactions by a combination of nucleation of paricles from supersaturated vapor and the condensation of vapur on particles. Nucleation, of course, generates fine. so-called "embryonic," particles whereas condensation of vapor leads to particle growth. The relative contributions of nucleation and condensation affect the number and size of the so-called "primary" aerosol particles, that is, aerosol particles that exist prior to any agglomeration of particles. The relative contributions of these two processes depend on the nature of the thermal gradient the vapors pass through as they emerge from inolten core debris. Though no detailed analyses have been done, it would certainly appear that the thermal gradient above molteil core debris when a water pool is present would be different than when a water pool is not present. Whether the differences are enough to alter significantly the initial aerosol size distribution is, of course, not known.

As the primary particles are generated, they begin to coagulate. In tests of melt interactions with concrete, aerosols are collected at points some substantial distance away from the region of aerosol formation. There is, then, a substantial opportunity for aerosol coagulation. When a water prol is present, the time available for aerosol coagulation is much shorter. At first examination, it would appear that the aerosol that enters a water pool would not have as coarse a size distribution. as have aerosols sampled in tests without a water pool present.

The elemental composition of vapors emerging from molten core debris is complex. The aerosul formation process is rapid. Consequently, it would be expected that aerosol formation would involve simultaneous nucleation and condensation of vapors so that there would be little variation in the composition of particles across the size spectrum of the aerosol. The exception would arise when particles produced by mechanical processes are compared to particles produced from vapors. Test data have not definitively proven that the compositions of aerosol particles are not size dependent. This 


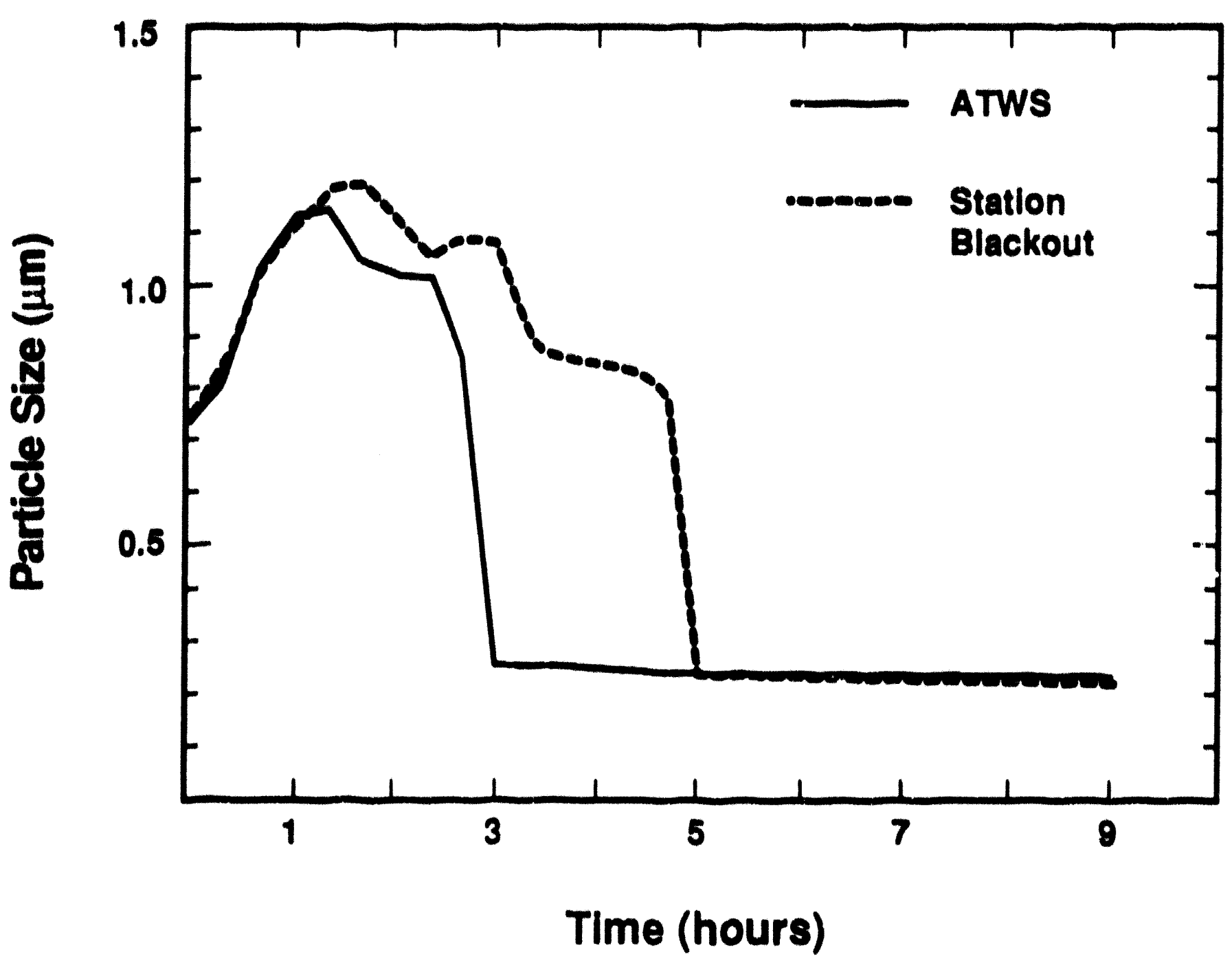

Figure 9 Predicted mean aerosol particle sizes during core debris interactions with concrete in severe reactor accidents at a Mark I bolling water reactor 
Source Term

independence is still assumed here. That is, decontamination factors found here for the overall aerosol can be used also as the decentamination factors for individual elements.

\section{E. Properties of the Liquid Phase}

The physical properties of the liquid phase enter into most of the correlations of bubble behavior and aerosol capture described above. The pertinent phy ical properties of pure water are shown in Table 1. These properties of pure water are quite accurately known relative to many other aspects of recontamination by overlying water pools. The water making up the pools will, however, not be pure for long during core debris interactions with concrete. Water collected during the SWISS-2 test [16] was found to contain 0.2 to 0.05 grams of suspended solids per kilogram of water and an undetermined amount of dissolved solids.

Suspended and dissolved solids will affect the thermophysical properties of the water. The density of the liquid phase is altered to be:

$$
\rho_{1}=\left|\rho(w)-\frac{S}{V}\right|\left(1-\phi_{s}\right)+\rho(s) \phi_{s}
$$

where

$$
\begin{aligned}
\rho_{1} & =\text { liquid density } \\
\rho(w) & =\text { density of pure water } \\
S / V & =\text { mass of dissolved solute per unit volume } \\
\Phi_{S} & =\text { volume fraction of suspended solids } \\
\rho(s) & =\text { density of solids suspended in the liquid }
\end{aligned}
$$

Dissolved solids will alter the viscosity of water:

$$
\frac{\mu\left(s o l^{\prime} n\right)}{\mu(w)}=1+2.5 \phi
$$

where

$$
\begin{aligned}
\mu(\text { sol'n) }= & \text { viscosity of the solution } \\
\mu(w)= & \text { viscosity of pure water } \\
\phi= & \text { ratio of ions and neutral molecules produced hy the solute to the number of water } \\
& \text { molecules in the liquid }
\end{aligned}
$$


Table 1 Properties of pure water

Density $\left(\mathrm{g} / \mathrm{cm}^{3}\right)$
\[ (\mathrm{w})=0.849397+1.29812 \times 10^{-3} \mathrm{~T}-2.69233 \times 10^{-6} \mathrm{~T}^{2} \]
Viscosity (Poises)
$\log _{10} \mu(w)=\log _{10}(0.01002)+\frac{\left[1.3272(293-\mathrm{T})-1.52 \times 10^{-3}(\mathrm{~T}-293)^{2}\right]}{(\mathrm{T}-168)}$
Surface Tension (dyne/cm)
$o(w)=34.6(\mathrm{~T} / 704)^{-0.8373}$
Vapor Pressure (atms)
$\ln \mathrm{P}=-7938.16 / \mathrm{T}+88.912-12.1215 \ln (\mathrm{T})+0.011079 \mathrm{~T}$


There are several models in the literature that describe the effects of suspended solids on the viscosity of a liquid [36]. These models all yield rather similar results for concentrations of solids amounting to less than 30 volume percent. The model adopted here is:

$$
\frac{\mu \text { (slurry) }}{H}=\frac{0.403}{0.403-\phi_{s}}
$$

where

$$
\begin{aligned}
\mu(\text { slurry }) & =\text { viscosity of the mixture of liquid and suspended solids } \\
\mu_{1} & =\text { viscosity of the liquid including the effects of dissolved materials } \\
\phi_{S} & =\text { volume fraction of suspended solids }
\end{aligned}
$$

None of the material thought likely to enter a water pool overlying core debris is an especially strong surface active agent. The effects of some inorganic solutes on the surface tension of water [37] are shown in Figure 10. Solutes may either increase or decrease the surface tension and the effect increases with concentration. The effects of mixtures of solutes is not known nor is the surface tension of water with prototypic solutes known. It seems likely, however, from the data shown in Figure 10 that solutes at concentrations expected to develop in water overlying core debris will alter the surface tension by no more than about \pm 10 percent.

\section{F. Properties of the Gas Phase}

The major constituents of the gas phase that make up bubbles rising through a water pool overlying core debris in the drywell of a Mark I containment will be hydrogen, steam, carbon monoxide and carbon dioxide. Hydrogen, carbon monoxide and carbon dioxide come from the attack by core debris on concrete. A small fraction of steam will also come from the attack on concrete. Most of the steam ccmes from the boiling of water at the interfacial crust between core debris and the water pool.

Concrete, when heated to sufficiently high temperatures [38, 39], evolves steam and carbon dioxide. Steam that evolves from the concrete comes primarily from the cement phase of concrete. It is present in the cement phase as "gel" water and water of hydration. This type of water evolves at temperatures between 378 and $420 \mathrm{~K}$. Water is also present as hydroxide groups notably as $\mathrm{Ca}(\mathrm{OH})_{2}$, in the cement phase. This $\mathrm{Ca}(\mathrm{OH})_{2}$ decomposes at around $680 \mathrm{~K}$ to produce water vapor. All concretes used in nuclear reactors have about the same type of cement and thus about the same amount of water bound as hydroxide groups. Consequently, the major differences in the water content in various concretes come from the relative humidity of air around the concrete during service. Concretes typically contain between 5 and 8 weight percent water.

Carbon dioxide evolved from concrete comes from the decomposition of calcareous material in the concrete which occurs at temperatures of about $960 \mathrm{~K}$. All concretes contain some calcareous material. At the very minimum, calcium carbonate forms by reaction of atmospheric carbon dioxide with calcium hydroxide: 


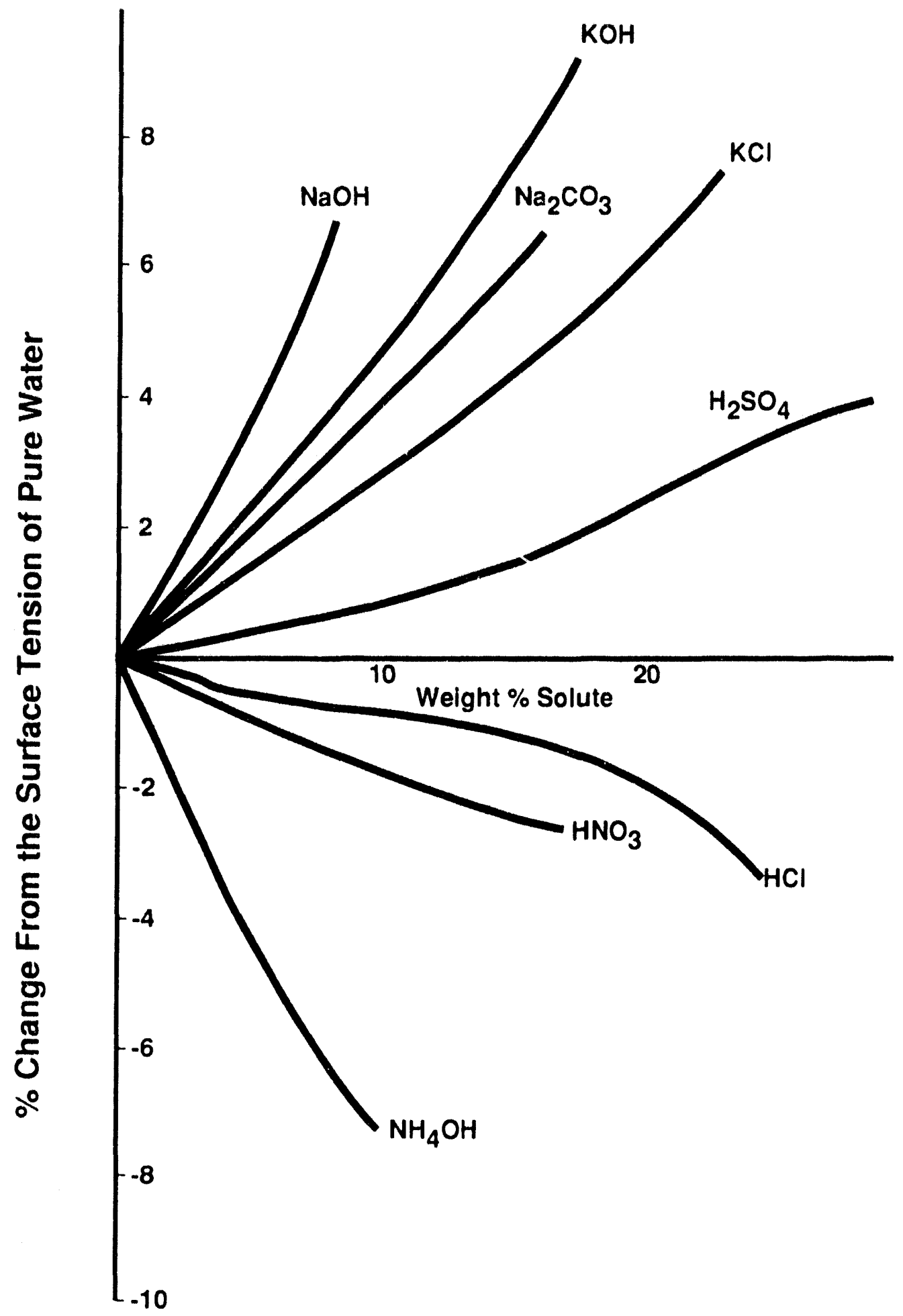

Figure 10 Effects of inorganic solutes on the surface tension of water at $293 \mathrm{~K}$ 
Source Term

$$
\mathrm{CO}_{2}(\mathrm{~g})+\mathrm{Ca}(\mathrm{OH})_{2}-\mathrm{CaCO}_{3}+\mathrm{H}_{2} \mathrm{O}
$$

This reaction begins when the concrete is first placed and continues throughout the service life of the concrete. Because of this reaction, all concretes have at least 1 weight percent $\mathrm{CO}_{2}$ bound up as a carbonate.

Some concretes contain very much more carbon dioxide. These concretes use calcareous material as an aggregate. Usually, the aggregates are calcite $\left(\mathrm{CaCO}_{3}\right)$ or dolomite $\left(\mathrm{CaMg}\left(\mathrm{CO}_{3}\right)_{2}\right)$. When crushed calcareous aggregate is also used as the fine aggregate, the concretes may contain over 36 weight percent carbon dioxide as carbonates. When silicon dioxide is used as the fine aggregate, and calcareous material is used as the coarse aggregate (so-called limestone-common sand concrete) the concrete contains over 20 weight percent carbon dioxide.

Carbon dioxide and steam are evolved from the concrete at temperatures well below the ablation temperature of the concrete. When molten core debris interacts with the concrete, steady-state temperature profiles develop ahead of the ablation front after a brief transient period (see for example References 16, 38, and 40). As a result, the isotherms that define the temperatures of the various concrete decomposition processes advance into the concrete at very nearly the same rate as the ablation front. Gas generation during the interaction of core debris with concrete is proportional to the concrete ablation with a proportionality constant determined by the concrete composition.

Concrete erosion rates vary over the course of core debris interactions with concrete. The initial transient interaction of high temperature melts with concrete can produce erosion rates in excess of $100 \mathrm{~cm} / \mathrm{hr}$ [41]. These initial rates decline quickly. Vigorous attack on concrete during the quasi-steady state when the melt is rich in zirconium will produce erosion rates as high as $35 \mathrm{~cm} / \mathrm{hr}$ [42]. Once zirconium is consumed from the melt, erosion rates can be as low as about $3 \mathrm{~cm} / \mathrm{hr}$ [43].

Gases evolved from the concrete react with the core debris. The reactions of carbon dioxide and steam yield carbon monoxide and hydrogen:

$$
\begin{aligned}
\mathrm{Fe}(\mathrm{l})+\mathrm{CO}_{2} & =\mathrm{FeO}(\mathrm{l})+\mathrm{CO} \\
\mathrm{Fe}(\mathrm{l})+\mathrm{H}_{2} \mathrm{O} & =\mathrm{FeO}(\mathrm{l})+\mathrm{H}_{2} \\
2 \mathrm{Cr}(\mathrm{l})+3 \mathrm{CO}_{2} & =\mathrm{Cr}_{2} \mathrm{O}_{3}(\mathrm{l})+3 \mathrm{CO} \\
2 \mathrm{Cr}(\mathrm{l})+3 \mathrm{H}_{2} \mathrm{O} & =\mathrm{Cr}_{2} \mathrm{O}_{3}(\mathrm{l})+3 \mathrm{H}_{2} \\
\mathrm{Zr}(\mathrm{l})+2 \mathrm{CO}_{2} & =\mathrm{ZrO}_{2}(\mathrm{l})+2 \mathrm{CO} \\
\mathrm{Zr}(\mathrm{l})+2 \mathrm{H}_{2} \mathrm{O} & =\mathrm{ZrO}_{2}(\mathrm{l})+2 \mathrm{H}_{2}
\end{aligned}
$$

\footnotetext{
* Some experiments involving high temperature melt interactions with concrete may not show this proportionality. This is nearly always because the small concrete test fixtures develop cracks that would not form in the massive concrete structures of a nuclear reactor. Cracks provide low-resistance flow paths for gas that permit the gases to flow away from rather than through the high temperature melt.
} 
There is some thet modynamic evidence that highly reactive metals such as $\mathrm{Zr}$ and possibly $\mathrm{Cr}$ can reduce carbon dioxide completely to elemental carbon:

$$
\mathrm{Zr}+\mathrm{CO}_{2} * \mathrm{ZrO}_{2}+[\mathrm{C}]_{\text {melt }}
$$

Evidence of this complete reduction has not yet been obtained in tests of melt interactions with concrete $[44,45]$.

The extent of reaction depends on the composition of the melt. When there is metallic zirconium in the melt, reduction can be very extensive. The hydrogen to steam partial pressure ratio in gases emerging from the melt is about $10^{5}$. When zirconium and chromium have been oxidized from the melt, the hydrogen-to-steam partial pressure ratio in gases emerging from the melt is only about 2 .

The partial pressures of carbon monoxide and carbon dioxide in the gases emerging from the melt are related to the hydrogen-to-steam partial pressure ratio by the "shift gas" reaction:

$$
\begin{gathered}
\mathrm{CO}_{2}+\mathrm{H}_{2}=\mathrm{CO}+\mathrm{H}_{2} \mathrm{O} \\
\mathrm{K}(\mathrm{T})=\frac{\mathrm{P}(\mathrm{CO}) \mathrm{P}\left(\mathrm{H}_{2} \mathrm{O}\right)}{\mathrm{P}\left(\mathrm{CO}_{2}\right) \mathrm{P}\left(\mathrm{H}_{2}\right)}=\exp \left[\frac{-4078.3}{\mathrm{~T}}+3.705\right]
\end{gathered}
$$

where

$$
\begin{aligned}
& K(T)=\text { equilibrium constant } \\
& P(i)=\text { partial pressure of gas species } \mathrm{i}=\mathrm{CO}, \mathrm{CO}_{2}, \mathrm{H}_{2}, \mathrm{H}_{2} \mathrm{O}
\end{aligned}
$$

As gases cool after emerging from the core debris, this equilibrium is maintained until a temperature is reached below which the kinetics of gas reactions are slow in comparison to the time scale of interest. If temperatures fall quickly below that so-called "quench" temperature, the gas composition is "frozen" at the equilibrium composition for the quench temperature. Cooling rates for gases emerging from melts interacting with concrete without a water pool present are sufficient to produce this quenching behavior. Quench temperatures are usually found to be between 1000 and $1300 \mathrm{~K}$ [46-48]. Quenching behavior at similar temperatures would, then, be expected to definitely occur when a water pool overlies the core debris.

With specification of the concrete erosion rate, hydrogen-to-steam partial pressure ratio and the "quench" temperature, the carbon dioxide, carbon monoxide and hydrogen contents of the gas sparging through the water pool can be determined. To specify the steam concentration, if is necessary to consider boiling at the crust-water interface. The boiling of water on the crust is complicated by the "barbotage" effect of gases generated by the attack on concrete [49]. For a long time, it was thought that water would be in film boiling on the crusts of debris and that the heat flux from the crust to the water would be enhanced by the barbotage effect as well as subcooling of the water [50]. Experimental data seem to indicate, however, that water is in nucleate boiling on the crusts. Heat fluxes to the water observed in 
Source Term

the SWISS-2 test were 70 to $80 \mathrm{~W} / \mathrm{cm}^{2}$ [16]. The recent MACE lest indicated similar overall heat fluxes with periodic excursions as high as $160 \mathrm{~W} / \mathrm{cm}^{2}[50]$.

The recent WETCOR-1 test [22] suggests heat fluxes can be as low as $30 \mathrm{~W} / \mathrm{cm}^{2}$. Heat flux, and consequently steam production, during boiling on core debris must be considered quite uncertain. Recent uncertainty analyses by Theofanous et al. [15] consider the uncertainty range to be 50 to $100 \mathrm{~W} / \mathrm{cm}^{2}$. A requirement for advanced reactor designs suggested by the Electric Power Research Institute [12] demands that the heat flux be at least $50 \mathrm{~W} / \mathrm{cm}^{2}$. Once the heat flux is selected, the steam flux can be estimated and the gas composition of the aerosol-laden gas bubbles that enter the water pool overlying core debris can be specified.

Gas phase properties are sensitive to gas composition. The gas density is probably specified adequately by the ideal gas law:

$$
\rho_{g}=\frac{P\left(\mathrm{H}_{2}\right) 2.016}{\mathrm{RT}}+\frac{\mathrm{P}\left(\mathrm{H}_{2} \mathrm{O}\right) 18.015}{\mathrm{RT}}+\frac{\mathrm{P}(\mathrm{CO}) 28.00}{\mathrm{RT}}+\frac{\mathrm{P}\left(\mathrm{CO}_{2}\right) 44.001}{\mathrm{RT}}
$$

where $R$ is the universal gas constant.

The viscosity of the gas mixture can be estimated from the Herning-Zipperer equation [52]:

$$
\mu_{g}=\frac{\sum_{i=1}^{N} P(i) \mu(i) M(i)^{1 / 2}}{\sum_{i=1}^{N} P(i) M(i)^{1 / 2}}
$$

where

$$
\begin{aligned}
N & =\text { number of gas species } \\
P(i) & =\text { partial pressure of the } i^{\text {th }} \text { gas species } \\
M(i) & =\text { molecular weight of the } i^{\text {th }} \text { gas species } \\
\mu(i) & =\text { viscosity of the } i^{\text {th }} \text { gas species when pure and at the same temperature as the mixture. }
\end{aligned}
$$

The pure gas viscosities are [25]:

$$
\mu\left(\mathrm{H}_{2}\right)=\frac{1.5769 \times 10^{-6} \mathrm{~T}^{0.705712}}{(1-3.378 / \mathrm{T})} \quad \text { Poises }
$$




$$
\begin{array}{ll}
\mu\left(\mathrm{H}_{2} \mathrm{O}\right) & =\frac{0.950 \times 10^{-6} \mathrm{~T}^{0.892912}}{(1+207.219 / \mathrm{T})} \quad \text { Poises } \\
\mu(\mathrm{CO}) & =\frac{14.151 \times 10^{-6} \mathrm{~T}^{0.502012}}{(1+117.178 / \mathrm{T})} \quad \text { Poises } \\
\mu\left(\mathrm{CO}_{2}\right) & =\frac{15.957 \times 10^{-6} \mathrm{~T}^{0.457212}}{(1+246.744 / \mathrm{T})} \quad \text { Poises }
\end{array}
$$

Predictions obtained with the Herning-Zipperer equation agree with data for $\mathrm{CO}-\mathrm{H}_{2}$ mixtures at $298 \mathrm{~K}$ to within about 2 percent [25]. Predictions for steam-air mixtures agree with data to within about 4 percent [18]. 


\section{Analysis of Source Term Attenuation by Overlying Water Pools in Mark I Reactors}

\section{A. Quantitative Analysis of Uncertainty}

The previous chapter described the physical phenomena that affect aerosol scrubbing by a water pool overlying core debris interacting with concrete. In this chapter, predictions are made of the source term attenuation that can be achieved by such pools in severe accidents in Mark I boiling water reactors. The discussion of the pertinent physical phenomena in Chapter II identified several areas of phenomenological uncertainty. Other uncertainties arise, of course, in the application of the models described in Chapter Il to specific situations. Many of the additional uncertainties arise because of variations in the boundary conditions and initial conditions among the various severe reactor accidents hypothesized to occur in Mark I boiling water reactors [2]. Understanding of the details of the progression of severe reactor accidents up to the point core debris is expelled into the Mark I containment is imperfect. This, too, can add uncertainty to the predicted performance of overlying water pools. All of these uncertainties need to be taken into account in the prediction of source term attenuation by the overlying water pool.

A number of approaches to the estimation of uncertainty have been used in the analysis of severe reactor accidents. Theofanous has categorized and criticized these approaches [53, 54]. Frequently "expert opinion" or "engineering judgment" is used as the basis for estimating the uncertainty in predictions made for high level issues such as decontamination by overlying water pools. The expert opinions or e. gineering judgments concerning these major issues of accident analysis may be obtained informally by the analysts [55] or in a highly structured polling of internal and external authorities selected to represent the range of views within the technical community.

This approach to uncertainty, no matter how elaborately conducted, does not provoke a great deal of confidence. There have not been enough severe reactor accidents to support anyone's claim to have expertise in the evaluation of such high level questions as the decontamination performance of water pools under severe reactor accident conditions. Engineering judgment is suspected because of the all too human tendency to underestimate the magnitude of uncertainty in areas of great uncertainty. But, the greatest flaw in past approaches to uncertainty is that they are difficult to reproduce. Almost never is a scrutable account of the expert opinion or engineering judgment set down so that a knowledgeable individual who accepts the basic assumptions can follow the logic and the arithmetic to arrive at the same conclusions reached by the "expert" or the engineer.

An alternate approach to the estimation of uncertainty is adopted here. This approach, first articulated by Theofanous [54], attempts to avoid the failings of the past uses of expert opinion and engineering judgment though both expert opinion and engineering judgment are still used. The essential step in the analysis of uncertainty is to decompose a high level question into its component phenomenological parts. This decomposition is done until each part is in area where there are or could be data and true expertise could exist. Uncertainties within these individual phenomenological areas can be identified. Furthermore, defensible ranges for the values of uncertain quantities can be prescribed. The definitions of uncertain quantities and the prescription of ranges for the values of these uncertain quantities are where expert opinion and engineering judgment ar: heavily used. More confidence can be had in this use of expert opinion and engineering judgment because there are, or at the very least could be, data bases and 
theoretical bases for the expertise or judgment. Furthermore, it is convenient, if not mandatory, that the bases for the opinions and judgments in individual phenomenological areas be described in a way that is scrutable by other knowledgeable individuals. Conclusions reached by the experts can be reproduced by others if the articulated assumptions are accepted.

Once the decomposition of an issue has been done, uncertainties identified and ranges for uncertain quantities prescribed, the overall uncertainty in the high 'evel issue can be defined. The mechanics adopted here involve Monte Carlo sampling of the predictions for an issue derived from the component phenomenological parts. The sampling is done by randomly selecting values for the uncertain quantities as prescribed by the probability distributions of values within the prescribed ranges. These sampled values of the uncertain quantities are then used in the calculation of the phenomena of interest.

Definition of probability distributions for uncertain quantities is, unfortunately, a subjective task. Though there have been some studies of the definition of these distributions [55], the author of this work knows of no mechanical or non-controversial method for defining these distributions. All that can be done is to clearly indicate what distributions are used. For the work described here, the probability density functions for values of uncertain quantities within prescribed ranges are defined by rules:

- Where significant values of an uncertain quantity span less than an order of magnitude, the probability density function for values of the uncertain quantity is taken to be a constant over the prescribed range and zero outside the range. This is called a "uniform" distribution.

- When significant values of an uncertain quantity span a range that is more than an order of magnitude, the probability density function for the logarithm of the value of the quantity is taken to be a constant over the prescribed range. This is called a "log-uniform" distribution.

- In those few cases in which a significant data base exists for an uncertain quantity, the probability distribution is taken to be lognormal. The limits of the prescribed range for values of the quantity are assumed to define the 1 st and the 99 th percentile of the cumulative distribution.

The predictions obtained with the Monte Carlo sampling constitute a sample of the true uncertainty distribution in the extent of decontamination by the pool. For the issue at hand here, the predictions constitute a sample of the distribution in values of the decontamination that can be achieved by a water pool overlying core debris in the drywell of a Mark I containment. This sample can be used to construct an estimate of the true distribution of values of the decontamination. Because the sample is finite, the estimate of the true distribution can be made only to a limited level of confidence. The mathematics and statistical analysis used to construct the estimate of the true distribution and to characterize the confidence level of the estimates are presented in Appendix A of this report.

\section{B. Specific Uncertainties Considered}

The specific uncertainties considered here in the analysis of aerosol scrubbing by an overlying water pool are summarized in Table 2. Ranges for many of the uncertain quantities listed in the table have been selected based on the discussions of physical phenomena presented in Chapter II. Probability density functions for values within the ranges are specified by the "rules" listed above. Other features of the various uncertain quantities are discussed below: 
Table 2 Uncertain parameters and properties

\begin{tabular}{|c|c|c|}
\hline Parameter or property & Range & Probabillty density \\
\hline Ambient Pressure & 1.9 atms & uniform \\
\hline Concrete Erosion Rate & $3.35 \mathrm{~cm} / \mathrm{hr}$ & log-uniform \\
\hline $\begin{array}{l}\text { Carbon Dioxide Weight } \\
\text { Fraction in Concrete }\end{array}$ & $0.01-0.36$ & log-uniform \\
\hline Water Weight Fracion in Concrete & $0.05-0.08$ & uniform \\
\hline $\begin{array}{l}\text { Hydrogen-to-Steam Partial Pressure } \\
\text { Ratio }\end{array}$ & $2 \cdot 10^{5}$ & log-uniform \\
\hline $\mathrm{CO} / \mathrm{CO}_{2}$ Quench Temperature & $1000-1300 \mathrm{~K}$ & uniform \\
\hline Solute Mass & $0.05-100 \mathrm{~g} / \mathrm{kg} \mathrm{H}_{2} \mathrm{O}$ & uniform \\
\hline Volume Fraction Suspended Solid & 0.0 .1 & uniform \\
\hline Density of Suspended Solids & $1.6 \mathrm{~g} / \mathrm{cm}^{3}$ & uniform \\
\hline $\begin{array}{l}\text { Sign Indicator for Uncertainty in Water } \\
\text { Surface Tension }\end{array}$ & $0-1$ & uniform \\
\hline Mean Aerosol Particle Size & $0.25-2.5 \mu \mathrm{m}$ & $\log$-uniform \\
\hline Geometric Standard Deviation & $1.6-3.2$ & uniform \\
\hline Aerosol Material Density & $1.5 \cdot 10.0 \mathrm{~g} / \mathrm{cm}^{3}$ & uniform \\
\hline $\begin{array}{l}\text { Coefficient in Davidson-Schular Model } \\
\text { for Initial Bubble Size }\end{array}$ & $1-1.54$ & uniform \\
\hline Contact Angle in Fritz Formula & $20-120^{\circ}$ & uniform \\
\hline $\begin{array}{l}\text { Coefficient in the Taylor Instability } \\
\text { Model for Bubble Size }\end{array}$ & $1.9-4$ & uniform \\
\hline Multiplier for Inertial Impaction & $0-1$ & uniform \\
\hline Boiling Heat Flux & $0.16-1.6 \mathrm{MW} / \mathrm{m}^{2}$ & $\begin{array}{c}\log \text { normal } \\
\mu=0.5=\text { mean } \\
\sigma=1.64 .5=\text { std. dev. }\end{array}$ \\
\hline
\end{tabular}




\section{Uncertulnty in Drywell Pressure}

The atmospheric pressure in the drywell of a Mark 1 containment during core debris interactions with concrete and water is one of the boundary conditions that varies among the many, hypothetical, core melting accidents that have been defined for Mark I boiling watet reactors. The pressure affects both aerosol trapping and steam production by boiling. It is only possible for generic analyses to assume pressure in the drywell is between atmospheric pressure and the estimated failure pressure of the containment. Mark I containments, though small, are quite strong. Estimates [6] of the failure pressures of these containments range to over 10 atmospheres absolute pressure. The estimates have been made for reactor containments as designed. Fabrication errors and corrosion of the steel liners since installation undoubtably reduce the failıre pressure for the containments though the failure pressure will still be well above the design pressure which takes into account fabrication errors and corrosion. A range of 1 to 9 atmospheres for the drywell pressure was selected here to capture, at least, the offect of pressure on the predictions of performance.

\section{Uncertainty in Concrete Erosion Rate}

Based on the discussions in Chapter II the concrete erosion rate has been selected to vary over the range of 3 to $35 \mathrm{~cm} / \mathrm{hr}$. The erosion rate does of course vary with time during a specific accident. Time resolved decontamination factors are not sought in the analyses presented here, so time variations in the concrete erosion rates are not considered. In principle, the concrete erosion rate is correlated with the composition of the concrete since the heat that inust be imparted to a calcareous concrete to ablate a given volume of the concrete is greater than the heat needed to ablate siliceous concretes [38;. Inspection of a variety of published analyses of core debris interactions with concrete [7. 24] does not reveal a clear correlation in the erosion rates with concrete type. There are enough variations in the initial and boundary conditions for core debris/concrete interactions that the sensitivity of erosion rate to concrete type is overwhelmed.

\section{Uncertuinty In Concrete Composittion}

As discussed in Chapter II, the carbon dioxide contents of structural concretes vary between weight fractions of 0.01 in concretes with siliceous aggregates to 0.36 in concretes made using calcareous materials as both the coarse and the fine aggregate. A survey of what little information is available for Mark I containments revealed only that there are reactors that use siliceous, calcareous, and limestonecommon sand concretes. Consequently, a distribution of the weight tractions of $\mathrm{CO}_{2}$ was used in the analyses below. Clearly, there is no distribution in this quantity for a specific plant.

As discussed in Chapter II, the weight fraction of water in the concrete was taken to be uncertain over the range of 0.05 to 0.08 .

\section{Uncertainty in the Gas Composition}

The ratio of the partial pressures of hydrogen and steam in gases that emerge from the core debris Jepends on the composition of the core debris. When the core debris is rich in metallic zirconium the ratio is quite large, on the order of $10^{5}$. When reactive metals in the core debris have been oxidized the ratio is only about 2 . The initial composition of the core debris is determined by the rather uncertain predictions of reactor accident progression prior to the onset of core debris interactions with concrete in the Mark I drywell. Whatever the initial composition, the core debris composition, and consequently the hydrogen-to-steam partial pressure ratio in gases emerging from the core debris, varies during the 
Analysis

interactions with concrete. For a specific set of initial conditions this variation can be predicted with acceptable accuracy. When averaged over a broad range of initial and boundary conditions the hydrogen-to-steam ratio becomes an uncertain quantity.

The temperature at which gas kinetics significantly affect the evolution in the gas composition is an important factor in the prediction of the gas composition. The range for this quench temperature selected here. $1000-1300 \mathrm{~K}$, is the range inferred from various tests of high temperature melt interactions with concrete $[38,46,47]$.

\section{Uncertainty in Water Propertles}

Solids dissolved in the water affect water properties. There is little information available on how much material will bo able to dissolve in the water pool. It is possible that water supplied to the drywell may contain additives such as boric acid and sodium hydrexide. An especially likely source of additional solute mass is the concrete. At high temperatures involvisd in the ablation of concrete alkali metals ( $\mathrm{Na}$ and $\mathbf{K}$ ) are vaporized from the concrete. These alkali molals are, of course, quite soluble in water. The concentrations of dissolved species of this type will increase in the water pool if water is recirculated from the steam suppression pool. The range for the concentrations of dissolved mass was selected somewhat arbitrarily to capture the uncertainty that exists as the water becomes contaminated with dissolved materials.

Much of the material in the water pool will not dissolve. Rather, it will be present as suspended solids. Aside from the fact that suspended solids are present in the water, there is little information on how much suspended material can be present. To some extent the volume fraction of suspended solids will depend on whether water supplied to the drywell is recirculated. The range of the volume fraction of solids selecteo here was limited to an upper bound of 0.1 . Above a volume fraction of suspended solids of 0.1 the liquid phase begins to behave significantly differently than water.

Solid species found suspended in water during tests of the simultaneous interactions of high temperature melts with concrete and with water $[16]$ include $2 \mathrm{ZO}_{2}\left(\rho=5.9 \mathrm{~g} / \mathrm{cm}^{3}\right) \quad \mathrm{SiO}_{2}\left(\rho=2.2 \mathrm{~g} / \mathrm{cm}^{3}\right)$, $\mathrm{CaMg}\left(\mathrm{CO}_{3}\right)_{2}\left(\rho-2.87 \mathrm{~g} / \mathrm{cm}^{3}\right) \mathrm{NaAlSiO}_{4}\left(\rho=2.6 \mathrm{~g} / \mathrm{cm}^{3}\right), \mathrm{Al}_{2} \mathrm{Si}_{2} \mathrm{O}_{5}(\mathrm{OH})\left(\rho-3.1 \mathrm{~g} / \mathrm{cm}^{3}\right)$ and $\mathrm{CaCO}_{3}\left(p=2.7 \mathrm{~g} / \mathrm{cm}^{3}\right)$. Were uranium dioxide used in the tests, hydrates of uranium oxide presumably would also be suspended in the water. Hydration will reduce the effective densities of the suspended solids. A lower bound on the density of the suspended solids was therefore set to be $1 \mathrm{~g} / \mathrm{cm}^{3}$. The upper bound on the density is determined by the ability of gas sparging to keep the solids suspended. Without a surface active agent present it is difficult for simple gas sparging to keep solids of densities greater than about $6 \mathrm{grams} / \mathrm{cm}^{3}$ suspended in water [36].

Data presented in Chapter II show that solutes can either increase or decrease the surface tension of water and that the effect varies linearly with solute mass. Consequently the surface tension of the liquid phase is takeli to be:

$$
\sigma_{1}= \begin{cases}\sigma(w)(1-S) & \text { for } \epsilon<0.5 \\ \sigma(w)(1+S) & \text { for } \epsilon \geq 0.5\end{cases}
$$


where

$$
\begin{aligned}
& o(w)=\text { surface tension of pure water } \\
& S \quad=\text { weight fraction of dissolved solids } \\
& \quad=\text { uncertain parameter with values uniformly distributed over the range of } 0 \text { to } 1 \text {. }
\end{aligned}
$$

\section{Uncertainty in Aerosol Size Distribution}

The size distribution of aerosols being injected into an overlying water pool is quite uncertain largely because there are no data to indicate if the aerosol formation process is affected by the water pool. Here, the aerosol size distribution is taken to be a lognormal distribution characterized by a mean and a geometric standard deviation. Microscopic examinations of aerosol collected in tests of melt interactions with concrete show that the acrosols are agglomerates with primary particles about $0.1 \mu \mathrm{m}$ in diameter. It would seem unlikely, then, that aerosols entering the water pool would be smaller than these primary particles. The mean size would, in fact, be somewha' larger since some particle agglomeration would be expected even over the short transport distances available in cases with a water pool present. Consequently, the lower bound on the mean aerosol size was selected to be $0.25 \mu \mathrm{m}$. The upper hound on the mean size was selected to be $2.5 \mu \mathrm{m}$ based on the larger sizes predicted to occur during the most intense phases of aeroso generation by core debris-concrete interactions as discussed in Chapter II.

The geometric standard deviation of the aerosol size distribution was selected to be uncertain between 1.6 to 3.2 based on the observations from tests with no water pool present. Arguments can be made to suggest that the water pool could affect the geometric standard deviation. There are, however, no data to support contentions that the size distribution of aerosols being injected into the water pool is either narrowed or broadened because a water pool is present. Nor are there data to support or refute contentions that the geometric standard deviation is correlated with the mean size of the aerosol. Consequently, the mean size and the geometric standard deviation are taken to be independent.

Aerosols are all assumed to have shape factors of 1 . This was done in the belief that water would condense in the interstices of agglomerates of primary aerosol particles. Surface tension forces exerted by the condensed water will tend to pull chain aggiomerates of aerosols into spheres [56].

\section{Uncertainty in Bubble Size}

The initia! sizes of bubbles entering the water pool are calculated from the Davidson-Schular equation for low viscosity fluids:

$$
D_{h}=c\left(\frac{6}{\pi}\right)^{1 / 3} \frac{v_{s}^{0.4}}{8^{0.2}} \mathrm{~cm}
$$

as described in Chapter II. The leading coefficient $\epsilon$ has a nominal value of 1.1. Various experimental studies have shown this value to vary at least over the range of 1 to 1.54 depending on the details of the geometry of orifices at which bubbles are formed [26]. It was assumed then that $\epsilon$ was uniformly distributed over this range. 
Analysis

A lower bound on the initial bubble size is defined by the Fritz equation:

$$
D_{h}=0.0105 \psi\left[o_{1} / g\left(\rho_{1}-\rho_{g}\right)\right]^{1 / 2}
$$

The coritact angle $\psi$ in this equation depends on whether water can "wet" the interfacial crust that separates water from molten core debris. If water cannot "wet" this surface $\psi-120^{\circ}$. If water can "wet" the surface $\psi$ approaches zero. Here a lower limit on $\psi$ is taken 10 be $20^{\circ}$.

An upper bound on the initial bubble size is taken to be defined by Taylor instabitity:

$$
D_{b}=2 C\left[o_{1} / g\left(p_{1}-p_{g}\right)\right]^{1 / 2}
$$

As discussed in Chapter II. the leading coefficient is taken to be uncertain and uniformly distributed over the range of 1.9 to 4 . The Levich criterion is applied also to define an upper bound on the initial bubble size and a bound on the bubble growth that can occur as butbles rise through the water pool.

\section{Uncertainty in Inertial Impaction}

Inertial impaction of derosols with the bubble walls is a factor in aerosol scrubbing only if gases within rising bubbles circulate. In highly contaminated systems like water pools overlying core debris that is interacting with concrete, it is by no means certain that gases will circulate or at what rate gases will circulate within rising bubbles. Consequently, the coefficient foi inertial impaction of aerosol particles described in Chapter II has been multiplied by an uncertain parameter with values uniformly distributed over the range 0 to 1 .

\section{Uncertainty in Bolling Heat Flux}

The boiling heat flux from the interfacial crust to the water is controversial. The hope [23] that a progressive fragmentation of the crust will result in very high heat fluxes to the water has not been rewarded in experiments done to date. Progressive fragmentation and very high heat fluxes are neglected here. There is some evidence [23] that when melt first begins to spread out of the pedestal region across the drywell floor in a Mark I containment, high heat fluxes do develop. This is, however, a very transient period of time. This transient may be quite important tor the analysis of attack on th: containment liner. For source term considerations, the quasi-steady state heat flux to the water pool that develops after the molten core debris has spread is of more interest. Based on the experimental data that have been accumulated to date, this quasi-steady heat flux is assumed here to be lognormally distributed with a mean of $50 \mathrm{~W} / \mathrm{cm}^{2}$ and a geometric standard deviation of 1.645 .

\section{Predictions of the Decontamination Factors}

A model of aerosol scrubbing by a water pool based on the phenomena described in Chapter II has been formulated. Details of the model are described elsewhere [18, 27]. In summary, the model uses a fourth order Runga-Kutta algorithm to solve the differential equation for aerosol scrubbing by sedimentation, diffusion and inertiai impaction. Scrubbing due to the collapse of bubbles in a subconled water pool is assumed to occur instantaneously. Step sizes are controlled in the algorithm so that no 
more than 10 percent of the aerosol is removed during bubble rise in a given computation cycle. The initial size of all bubbles entering the overlying water pool is taken to be the same. If buhbles grow to exceed the Levich criterion (see Chapter II), they are instantaneously divided into bubbles with half the volume dictated by the Levich criterion.

Aerosols are assumed to be lognormally distributed in size. The cumulative, mass-weighted, size distribution is taken to be:

$$
\operatorname{Pr}(d<D)=0.5(1+\operatorname{erf}(z))
$$

where

$$
\begin{aligned}
\operatorname{Pr}\left(d_{p}<D\right) & =\text { cumulative probability of the particle size being less than } D \\
z & =\ln (D / \mu) / \sqrt{2} \ln \sigma \\
\mu & =\text { mean size } \\
\sigma & =\text { geometric standard deviation } \\
\text { erf }(x) & =\text { error function of } x
\end{aligned}
$$

Calculations are conducted by dividing the initial aerosol size distribution into 20 equal mass "bins." The necessary inversion of the error function is done with a Newton-Raphson method. The behaviors of aerosol particles in each bin are assumed to be weil represented by a particle with the diamelar of the mass median particle diameter in the bin.

Calculations are done by randomly selecting values of the uncertain parameters according to their respective probability density functions. This is easily done for the uniform and $\log$-uniform distributions. The inversion of the error furction necessary for lognormally distributed parameters is, again, done with the Newton-Rapson method for locating rnots of non-linear equations. Random numbers needed for the selection of values of the uncertain parameters are obtained from a congruent sequential generator algorithm. Such algorithms are known to have a cyclical behavior. To avoid this. the random numbers were randomly "shuffled" using an algorithm by Knuth [57].

Results of the calculation are cast in terms of a decontamination factor (DF) defined by:

$$
D F=\frac{\text { Mass of aerosol entering the water pool }}{\text { Mass of aerosol emerging from the water pool }}
$$

This method of presentation eliminates some of the sensitivity of results to the uncertain initial and boundary conditions such as the mass of core melt on the drywell floor. Calculations were done using methods described in Reference 17 to generate uncertainty distributions for the decontamination factor. Typically about 500 calculations were done for each set of conditions. As is discussed in Appendix A. this number of calculations assures to at least a 95 percent confidence that 99 percent of the range of values of the decontamination factor has been sampled. 
The purpose of this work is to show that provision of water to the drywell of a Mark I boiling water reactor will reduce the magnitudes of the radionuclide releases from the plant even if the water fails to prevent containment failure. Details on the way water is to be provided to the drywell have not been specified. Possible variations in the supply of water include var lations in the depth and the temperature of the water to be maintained over the core debris that is interacting with the drywell concrete. Therefore, calculations were done for water pool depths of 30 and $50 \mathrm{~cm}$, and for water subcooling of $0,2,5,10,20,30,50$, and $70^{\circ} \mathrm{C}$. The calculated values of the decontamination factors for each of the sixteen sets of conditions were analyzed to construct at confidence levels of 50,90, and 95 percent the cumulative probability distribution functions for the decontamination factor. The detailed results are presented in tabular form in Appendix B. Cumulative probability distributions for two typical results are shown in Figure 11. These results are shown in the figure as plots of the natural logarithm of the decontamination factor as a function of the quantile of the cumulative distribution. Confidence bands of 95 and 50 percent are shown in the figure.

One of the most useful features of this type of analysis is that it permits separation of the phenomenological uncertainty from the stochastic uncertainty associated with the finite size of the samples taken of the distribution. It is apparent from the results shown in Figure 11 that the stochastic uncertainties in the results rbtained here are small in comparison to the phenomenological uncertainties in the vicinity of the mean. At the 95 percentile level and above the stochastic uncertainties are, in some cases, quite large. The confidence intervals to account for stochastic uncertainties could be narrowed by taking larger samples in the Monte Carlo sampling process.

Results obtained in the calculations for the median, the 10 percent quantile and the 90 percent quantile are summarized in Table 3 for specific confidence levels. Each entry in the table is a range of values whose width is determined by the specified confidence level.

The median decontamination factors (at 50 percent confidence level) for water pools 30 and $50 \mathrm{~cm}$ deep are shown as functions of pool subcooling in Figure 12. It is evident from this figure that subcooling greatly enhances the amount of decontamination that can be achieved by a water pool. Even for very shallow water pools with proper subcooling, median values of the decontamination factor in excess of 100 are achieved. That is, even with only a $30 \mathrm{~cm}$ deep water pool the radionuclide release from core debris interacting with concrete can be reduced by a factor 100 .

Very conservative views of the state of phenomenological uncertainty might be based on the 10 percent quantile of the uncertainty distribution. Even in this pessimistic case, factor of 10 reductions in the radionuclide release can be achieved with well-subcooled, shallow water pools (see Figure 13).

The calculations presented here are for water pools overlying core debris within the drywell. Should core debris penetrate the steel liner and flow into the reactor torus room, water would follow. Water maintained over core debris in the torus room would achieve similar reductions of the aerosol and radionuclide emissions as have been calculated here. The results described in this chapter are used in Chapter VI to analyze aerosol concentration in the Mark I drywell for a particular accident. 
Analysis

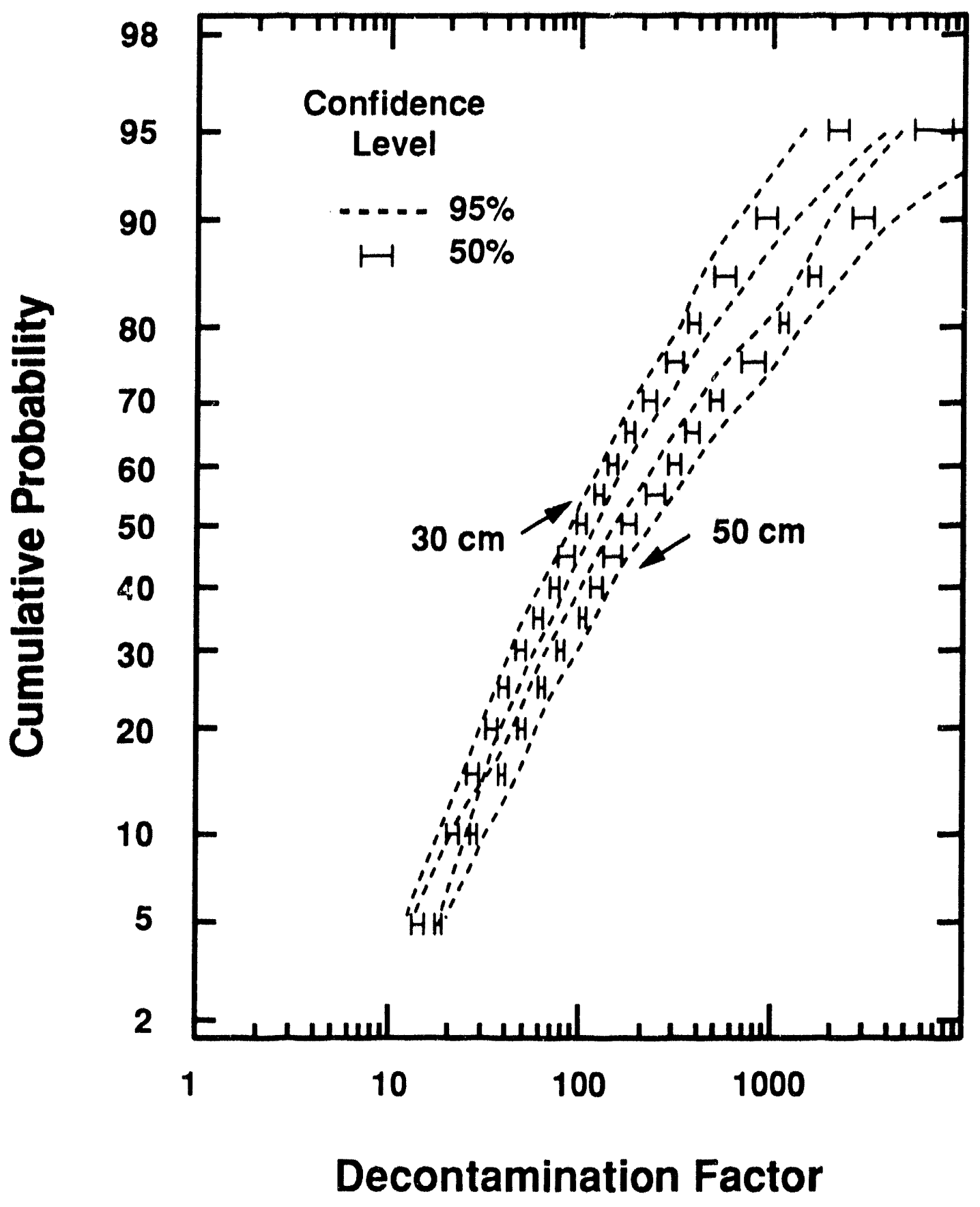

Figure 11 Cumulative probability distributions for the decontamination factors by water pools 30 and $50 \mathrm{~cm}$ deep and 20 degrees subcooled 
Analysis

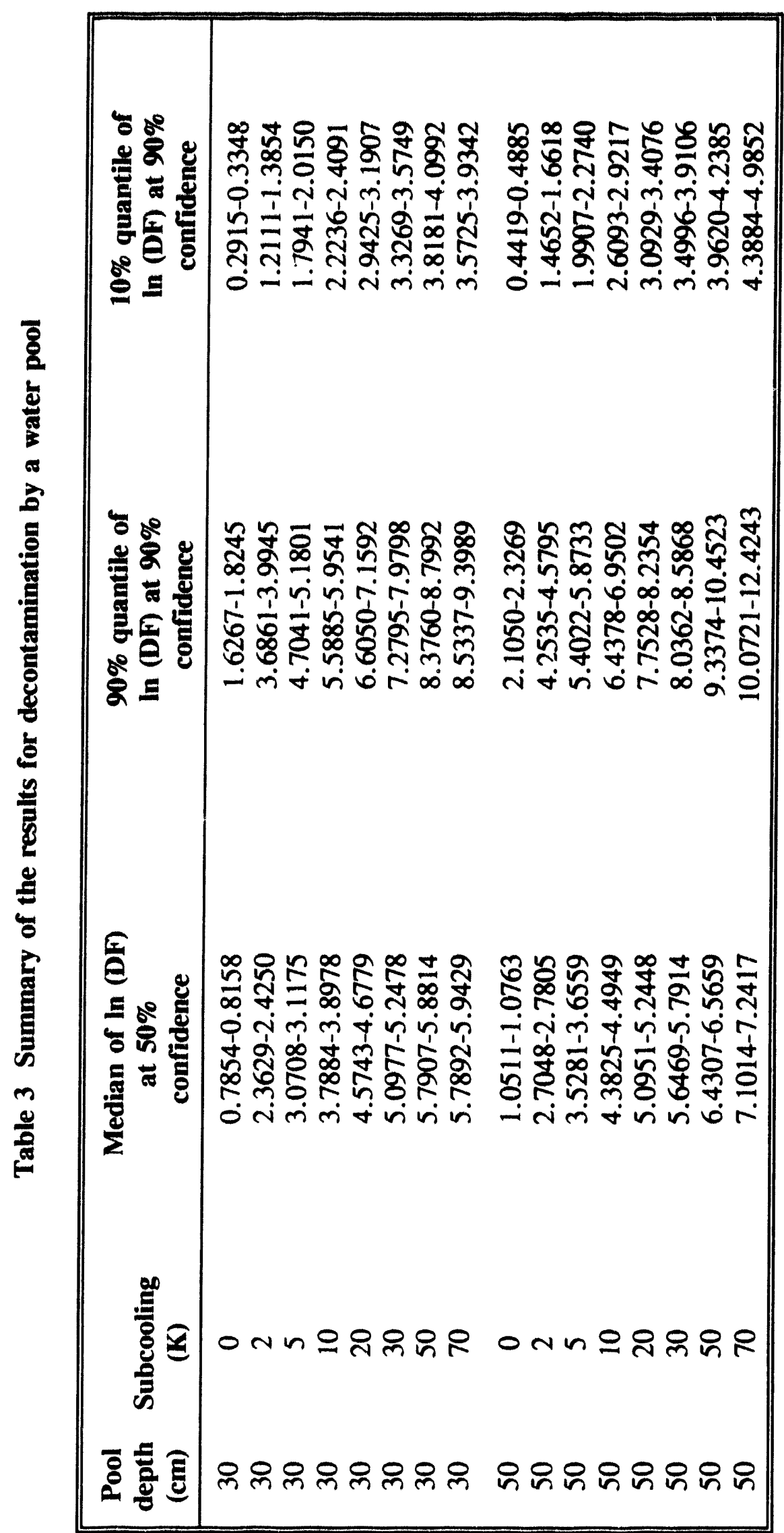


Analysis

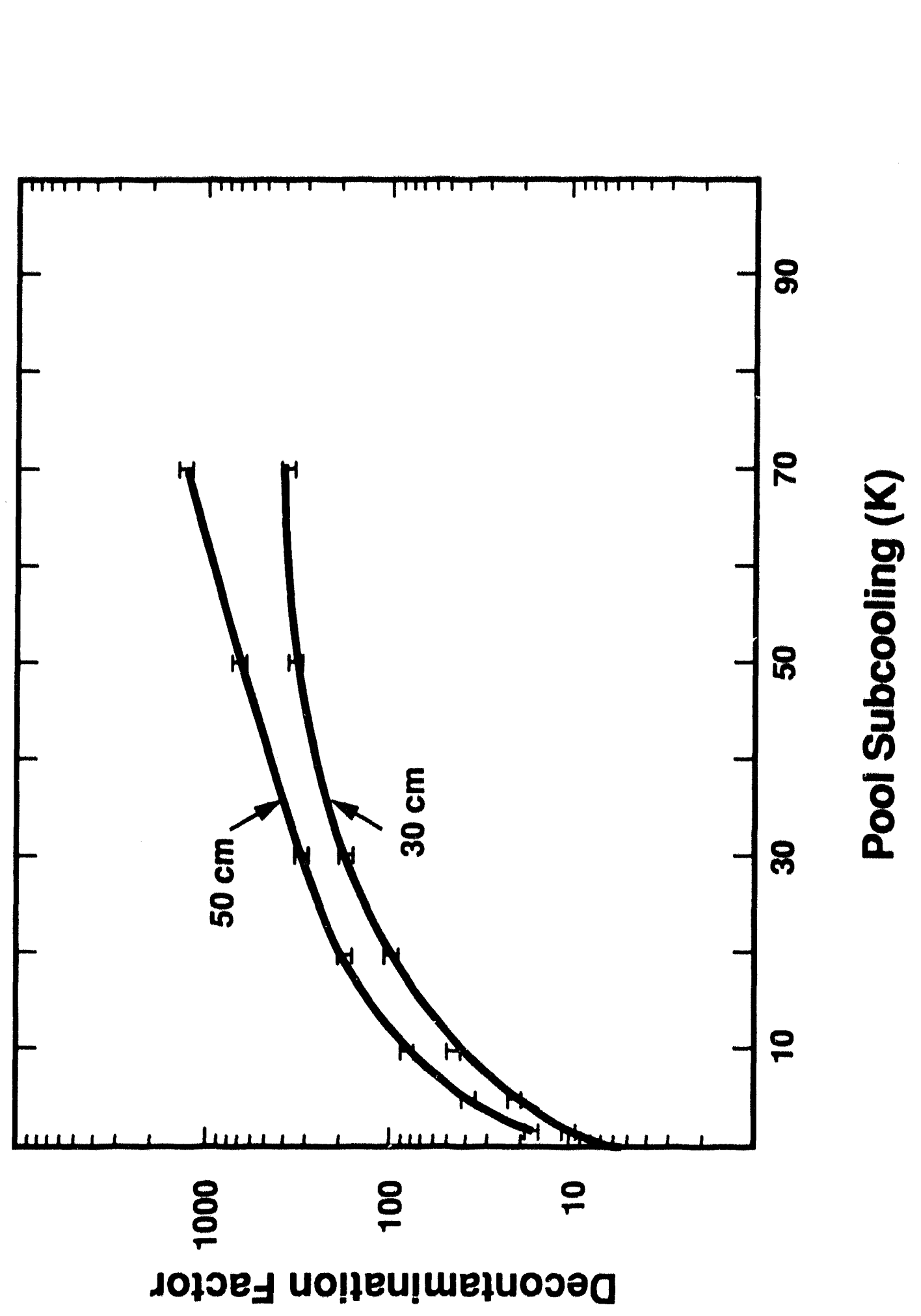

$y$

8

园

ำ

를

8

$\frac{1}{8}$

옳

5

8

롱

8

푸

늘

롤

$\theta$

$\stackrel{9}{\$}$

4

\&

른

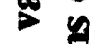

ㅍ.

욜

$\underset{2}{2}$ 
Analysis

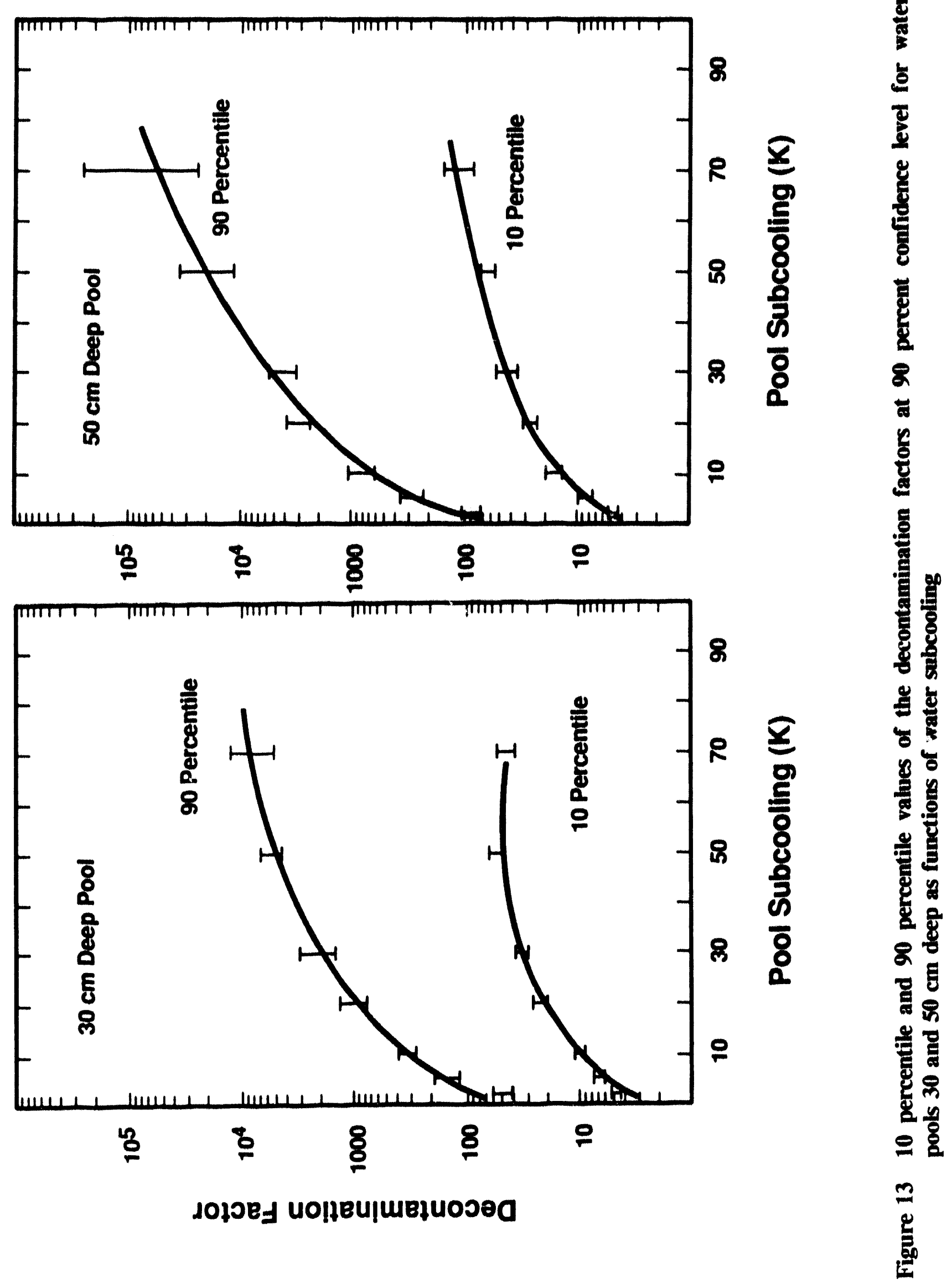




\section{Source Term Attenuation by Drywell Sprays}

\section{A. Background}

In the previous chapter, it was shown that water pools overlying core debris could reduce the aerosol production and radionuclide release from core debris interactions with concrete. Release of radioactive materials during core debris/concrete interactions is but one of the processes that can contaminate the atmosphere of the Mark I drywell and contribute to the inventory of radioactive materials that could escape the plant should the containment fail. Release of radioactive materials from the reactor coolant system when core debris penetrates the reactor vessel, revaporization of radionuclides deposited in the reactor coolant system and release of radionuclides from residual fuel in the reactor coolant system after vessel failure are other ways the atmosphere of the drywell becomes contaminated with radioactive materials. Water pools overlying core debris on the drywell floor will little affect these sources of radioactivity to the drywell atmosphere.

The drywells of Mark I containments are equipped with sprays. The sprays are intended primarily to be used to condense steam in design-basis loss of coolant accidents. The sprays might, however, be used to supply the water needed to maintain a water pool over core debris deposited in the drywell during severe reactor accidents. Falling water drops produced by the spray will trap aerosols suspended in the drywell atmosphere. The sprays could, then, be used to attenuate the source term of radioactive material injected into the drywell atmosphere by processes other than core debris interactions with concrete as well as scavenge aerosols produced by core debris/concrete interactions and not trapped in the water pool.

In this and the next chapter, a quantitative analysis of the decontamination of the drywell atmosphere by drywell sprays is presented. The presentation is, in outline, rather similar to that used to present analyses of the decontamination by an overlying water pool. Phenomena that affect spray performance are discussed in the balance of this chapter. In Chapter $V$ a detailed, quantitative analysis of spray performance is presented.

There is an important difference in the analyses of spray performance from the analyses of the decontamination by overlying water pools. Sprays can be operated for an indeterminant period of time. The decontamination that can be achieved by sprays is, then, unbounded whereas the decontamination by water pools is inherently limited by the depth of the pool and the rise velocities of aerosol-laden bubbles through the pool. That is, aerosols rising through an overlying water pool are exposed to the actions of the water pool for a fixed, predictable time. Aerosols in the drywell atmosphere can be exposed to the actions of spray droplets for times that can be known only if the schedule for spray operation is known. It would be presumptuous to assign a particular decontamination factor to the sprays if some mandated schedule for their operation does not exist.

The formal differential equation that describes aerosol mass in the containment atmosphere is:

$$
\frac{\mathrm{dM}}{\mathrm{dt}}=-\lambda \mathrm{M}+\dot{S}+\dot{R}
$$




\section{Attenuation}

where

$\mathrm{M}=$ aerosol mass suspended in the containment atmosphere

$\lambda=$ a coefficient for decontamination by sprays

$\dot{R}=$ rate of aerosol removal by mechanisms other than spray decontamination of the atmosphere

$\dot{\mathbf{S}}=$ rate at which aerosol mass is injected into the containment atmosphere

A more convenient method for the analysis of spray performance is to determine $\lambda$, the coefficient for decontamination by sprays. ${ }^{*}$ Specification of $\lambda$ provides a much more generically useful result than does specification of a decontamination factor obtained by assuming some arbitrary operation of the sprays. In the subsections below, it will be shown that $\lambda$ is not a constant. Rather, it has complicated functional dependencies on the aerosol trapping processes, the characteristics of the spray and the conditions under which the sprays operate.

*Regulatory descriptions of $\lambda$ use the definition [84]:

$$
\lambda=\frac{1.5 \mathrm{HF}}{\mathrm{V}}\left(\frac{\mathrm{E}}{\mathrm{D}}\right)
$$

where

$$
\begin{aligned}
& H=\text { fall distance } \\
& V=\text { containment volume } \\
& F=\text { water flow rate } \\
& \frac{E}{D}=\text { aerosol capture efficiency divided by droplet diameter }
\end{aligned}
$$

For $1000 \mu \mathrm{m}$ diameter droplets a recommended value [84] for $\left(\frac{E}{D}\right)$ is 10 meters $^{-1}$ until a decontamination factor of 50 (98 percent of the aerosol initially present has been removed) is reached. Then, the recommended value of $\left(\frac{E}{D}\right)$ is reduced to 1 meter $^{-1}$. Values of $\lambda$ given in this report in units of $\mathrm{hr}^{-1}$ may be converted into values of $\left(\frac{E}{D}\right)$ in units of meters by:

$$
\left(\frac{E}{D}\right)\left(\text { meters }^{-1}\right)=\frac{\lambda\left(\mathrm{hr}^{-1}\right) 0.01852}{Q}
$$

where $Q$ is the water flux into the containment atmosphere in units of $\mathrm{cm}^{3} \mathrm{H}_{2} \mathrm{O} / \mathrm{cm}^{2}-\mathrm{s}$. The reciprocal of $\lambda$ is the time in hours for sprays to reduce the aerosol concentration in the atmosphere by a factor of $e-2.7$ if there is no unsprayed volume. 


\section{B. Trapping of Aerosol Particles by Water Droplets}

Activation of drywell sprays in a Mark 1 boiling water reactor must be done manually. If the drywell sprays are activated during a severe reactor accident the sprays will affect the pressure, temperature and composition of the containment atmosphere. Sprays will cool the atmosphere and condense steam in the atmosphere. Stefan forces on aerosol particles during the condensation of steam will drive aerosol particles into falling water droplets. There will also be some modest thermophoretic forces on aerosol particles that will drive the particles into the water droplets.

The dynamic conditions immediately following spray actuation will be of short duration. Rather quickly a quasi-steady state will be established in which the pressure, temperature and composition of the containment atmosphere are nearly in equilibrium with the falling spray droplets. It is the source term reduction that can be achieved during this quasi-steady operation of the sprays that is of interest here. Though a significant amount of decontamination of the drywell can be anticipated during the initial phase of spray operation, this early decontamination driven by steam condensation is neglected here. Neglect of decontamination during the early period of spray operation is not a serious omission if containment failure is not coincident with actuation of the sprays.

Under the essentially steady-state conditions assumed here, falling water droplets still sweep aerosol particles from the containment atmosphere. The predominant modes by which falling water droplets trap aerosol particles are:

- impaction

- interception, and

- diffusion.

Impaction refers to the collision of water droplets with aerosol particles. As a droplet falls through the drywell atmosphere, a flow field develops around the droplet. This flow field will carry aerosol particles. Some aerosol particles will be too massive to respond to the sudden accelerations of gas flow in the vicinity of the falling droplet. Inertia will allow these particles to cross the streamlines of the flow field and to contact the water droplet. It is assumed here that contact between a water droplet and an aerosol particle is sufficient to cause the capture of the aerosol particle whether or not the aerosol material is soluble in the droplet. Surface tension and van der Waals forces are sufficient to hold even insoluble particles to the droplet.

Particles of an intermediate size may be able to respond to the accelerations in the gas flow field near the droplet. The centers of mass of these droplets will follow trajectories around the droplet. But, because the droplets are of finite size, they may still be intercepted by the droplet.

Very small particles will be able to follow the flow field around a falling droplet easily. These small particles also respond to impulses provided by collisions with gas molecules. Because of the stochastic nature of these collisions, there is an apparent diffusion of small aerosol particles. This diffusive motion can carry the particles across streamlines into the droplet surface. Again, surface tension and van der Waals forces assure the diffusing particles are trapped by the falling drop once contact is made. 


\section{Attenuation}

It is possible for aerosol particles and falling drops to be electrostatically charged. Coulombic forces between charged aerosols and charged droplets could attract or repel particles and drops depending on the relative signs of the charges. Radiation fields are, however, often used to discharge aerosol particles. Certainly under severe accident conditions both the drops and the aerosol particles in the Mark I drywell would be exposed to an intense radiation field. Electrostatic interactions are neglected here. No entirely satisfactory proof has been formulated to defend the decision to neglect clectrostatic effects (but, see References 59, 60).

The quantitative descriptions of aerosol collection by falling drops are based on the assumption that the drops are spheres. This seems to be an acceptable assumption for droplets formed by sprays in nuclear power plants. Water droplets falling through air needed to be larger than $0.1 \mathrm{~cm}$ to distort significantly from spherical $[26,61]$. The distortion of larger droplets and models for these distortions are described elsewhere [18].

Consider a sphere of diameter $D_{d}$ falling through space. After falling a distance $x$, the sphere will have swept out a volume of gas given by:

$$
\text { Volume }=\frac{\pi}{4} D_{d}^{2} x
$$

If the gas contains a concentration of $n(i)$ aerosol particles of diameter $d_{p}(i)$, then the falling sphere would have encountered:

$$
\frac{\pi}{4} D_{d}^{2} n(i) x
$$

of these aerosol particles in the absence of hydrodynamic forces on the particles. A convenient definition of the efficiency with which falling drops capture aerosol particles is the ratio of the actual number of particles captured to the number of particles in the volume swept by the falling sphere:

$$
\epsilon\left(D_{d}, d_{p}(i)\right)=4 \Delta N(i) / \pi D_{d}^{2} n(i) x
$$

where

$$
\begin{aligned}
\epsilon\left(D_{d}, d_{p}(i)\right)= & \text { droplet capture efficiency for aerosol particles of diameter } d_{p}(i) \\
\Delta N(i)= & \text { actial number of particles of diameter } d_{p}(i) \text { captured during a fall of distance } \\
& x .
\end{aligned}
$$

Hydrodynamic effects cannot be neglected in the analysis of aerosol capture by falling water drops. The efficiency with which droplets capture particles should depend on the nature of the gas flow around the droplet. Analytic results are available only for the limiting flow regimes of viscous flow (Reynolds number $=\operatorname{Re} \rightarrow 0$ ) and of potential flow $(\operatorname{Re} \rightarrow \infty)$. Pemberton [62] has argued that in view of the substantial size differences between aerosols of interest $\left(d_{p}(i)<10 \mu \mathrm{m}\right)$ and water droplets 
$\left(D_{\mathrm{d}}>100 \mu \mathrm{m}\right)$. flows around falling water droplets can be satisfactorily treated as potential flows. Others [63], however, have felt it necessary to consider some means fot interpolating between viscous and potential flow to predict real decontamination rates. Not everyone has agreed with the interpolation methods that have been proposed in the literature $[64]$.

Widely used expressions for the efficiency of aerosol capture as a result of impaction are:

a. Potential Elow Regime

$\epsilon$ (imp. pot $)=0 \quad$ for Stk $\leq 0.0833$

$\epsilon($ imp, pot $)=|S t k /(S t k+8)|^{2}$ for Stk $\geq 0.2$

$\mathrm{e}(\mathrm{imp}$, pot $)=8.57[\text { Stk } /(\text { Stk }+8)]^{2}($ Stk -0.08333$)$ for $0.08333<$ Stk $<0.2$

where 8 has been given values between 0.25 and 0.75 .

b. Viscous Flow Regime

$\epsilon$ (imp, visc $)=0 \quad$ for Stk $s 1.214$

$\epsilon($ imp, visc $)=\left[1+\frac{0.75 \ln (2 \text { Stk })}{(\text { Stk }-1.214)}\right]^{-2} \quad$ for Stk $>1.214$

c. Transition Flow Regime

$$
\epsilon(\text { imp, trans })=\frac{\epsilon(\text { imp, visc })+R e_{d} \in(i m p, p o t) / 60}{1+R e_{d} / 60}
$$

where

$$
\begin{aligned}
\text { Stk } & =d_{p}^{2} \rho_{p} U_{T} / 9 \mu_{g} D_{d} \chi \\
R_{d} & =U_{T} \rho_{g} D_{d} / \mu_{g} \\
\rho_{g} & =\text { density of the gas phase } \\
U_{T} & =\text { terminal velocity of the droplet } \\
\mu_{g} & =\text { viscosity of the gas phase } \\
\chi & =\text { dynamic shape factor for the aerosol particle. }
\end{aligned}
$$

Note that two models of particle capture by impaction are presented above. All real flows are in the transition regime between the viscous and potential flow limits. One model follows the argument by 


\section{Altenuation}

Pemberion |62| that real tlows of interest here are adequately approximated by potential flow and the impaction efficiency is given by e(imp, pot). The other model is hased on an interpolation between potential and viscous flow. The efficiency of acrosol capture by impaction is then given by e(imp. trans). Plots of e(imp, pol) and e(imp. (rans) are shown in Figure 14 for water droplets falling through air at I atmosphere pressure and $298 \mathrm{~K}$. Properties used for these calculations are shown in Table 4. The dynamic shape factor of the aerosol was taken to be I for the calculations used to prepare this figure

lixpressions for the efficiency of aerosol capture by interception are

i. Pocential How Regime

e(int. p(l) $)=3 \gamma d_{p} / D_{d}$

h. Viscous Fow Regims

E(int. visc) $=1.5\left(\gamma d_{p} / D_{d}\right)^{2} /\left(1+\gamma d_{p} / D_{d}\right)^{1 / 3}$

c. Transition Flow Regime

c(int, trans) $\frac{\epsilon\left(\text { int, visc) }+R_{\mathrm{d}} \in(\text { int, pot) } / 60\right.}{1+\operatorname{Re}_{\mathrm{d}} / 60}$

Where $\gamma$ is the collision shape factor for the aerosol particles.

The capture efficiency for the viscous flow regime is that recommended hy lee and Gieseke $|65|$ and differs somewhat from that often quoted $\epsilon$ (int. visc $)=1.5\left(\gamma d_{p} / D_{d}\right)^{2}$.

Again, note there are two models of interception efficiency presented above. These efficiencies--e(int, pot) and $\epsilon$ (int, trans) - -are shown as functions of aerosol particle size and droplet diameter in Figure 15. Also show'n in the figure is the efficiency of aerosol capture in the viscous flow limit.

Expressions available for the description of the efficiency of aerosol capture hy diffusion include:

$$
\begin{aligned}
& \epsilon(\text { dif })=3.18 \mathrm{Pe}^{-2 / 3} \\
& \epsilon(\text { dif })=(4 / \mathrm{Pe})\left(2+0.557 \mathrm{Re}_{\mathrm{d}}^{1 / 2} \mathrm{Sc}^{3 / 8}\right)
\end{aligned}
$$

where

$$
\begin{aligned}
& \mathrm{Pe}_{\mathrm{c}}=\text { Peclet number }=\mathrm{Re}_{\mathrm{d}} \mathrm{Sc} \\
& \mathrm{Sc}=\text { Schmidt number }=\mu_{\mathrm{g}} / \rho_{\mathrm{g}} / \rho_{\mathrm{p}}
\end{aligned}
$$




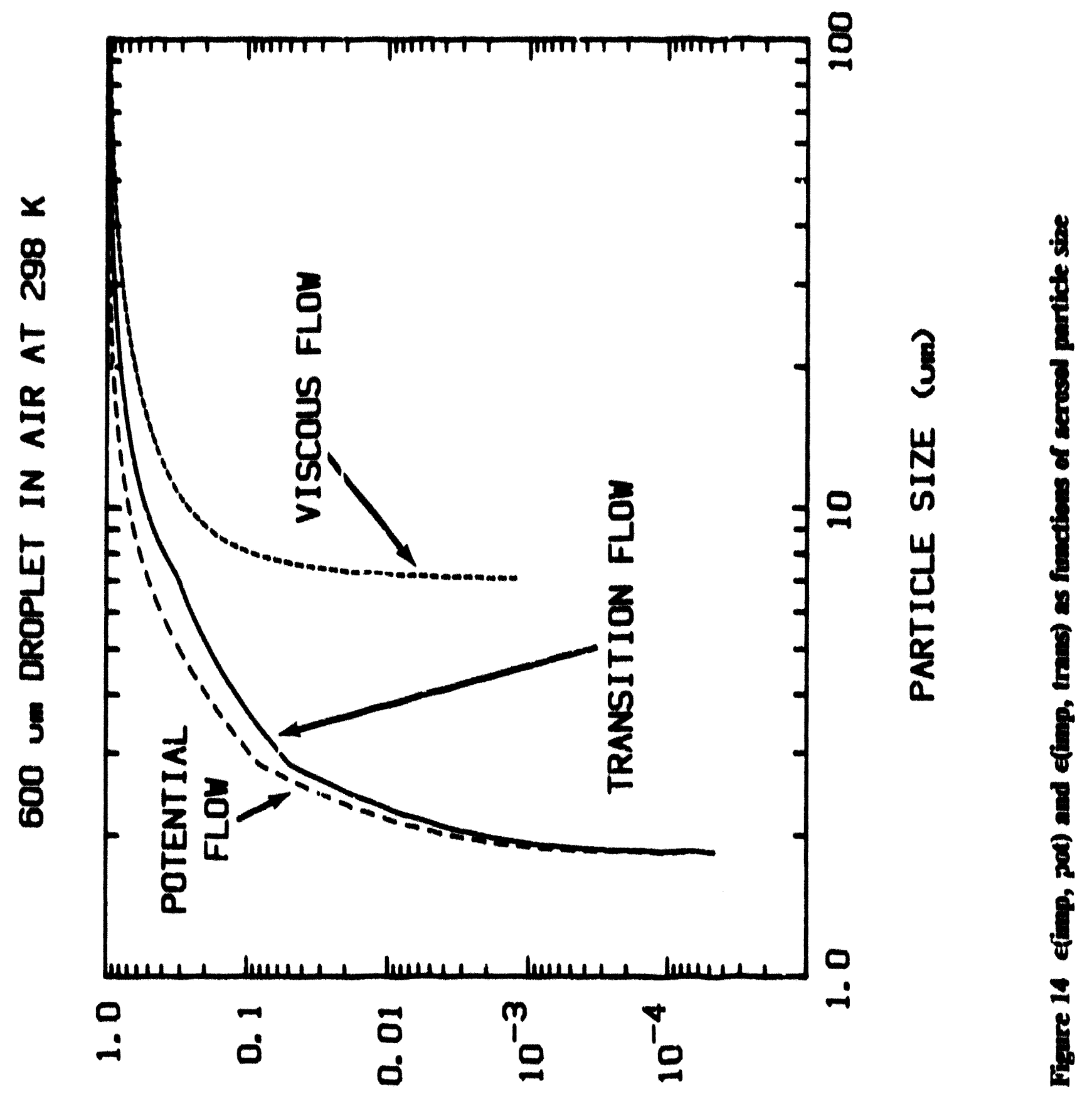

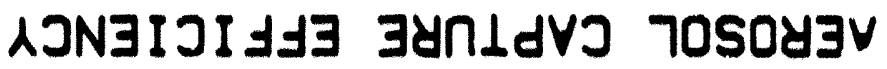


Atconuation

Table 4 Properties of water and air

\section{Water Density $\left(\mathrm{g} / \mathrm{cm}^{3}\right)$}

$$
\rho_{1}=0.849397+1.29812 \times 10^{-3} \mathrm{~T} \cdot 2.69223 \times 10^{-6} \mathrm{~T}^{2}
$$

Water Viscosity (Poises)

$$
\log _{10} \mu_{1}=\log _{10}(0.01002)+\frac{\left[1.3272(293-\mathrm{T})-1.52 \times 10^{-3}(\mathrm{~T}-293)^{2}\right]}{(\mathrm{T}-168)}
$$

Water Surface Tension (dyne/cm)

$$
\sigma_{1}=34.6(\mathrm{~T} / 704)^{-0.8373}
$$

Air Density $\left(\mathrm{g} / \mathrm{cm}^{3}\right)$

$$
\rho_{\mathrm{g}} \text { (air) }=0.352 \mathrm{P}(\mathrm{atms}) / \mathrm{T}
$$

Air Viscosity (Poises)

$$
\mu_{g}\left(\text { air },=2.3013 \times 10^{0.6} \cdot \mathrm{r}^{0.768}\right.
$$




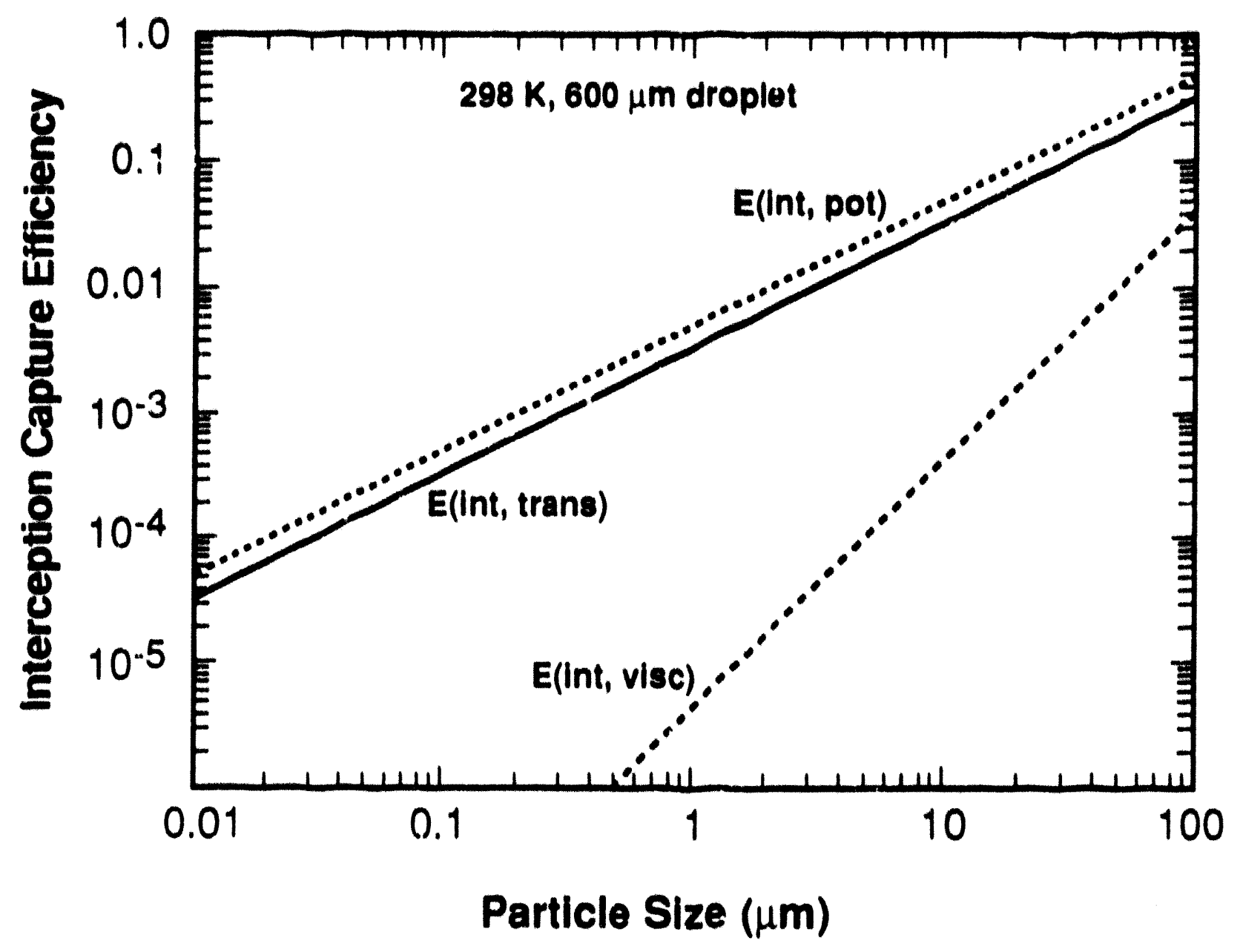

Figure $15 \epsilon$ (int, pot) and $\epsilon$ (int, trans) as a function of aerosol particle size for droplets in air at $298 \mathrm{~K}$ and $1 \mathrm{~atm}$ 
Attenuation

$$
\begin{aligned}
a_{\mathrm{p}} & =\text { diffusion coefficient for arrosol particles } \\
& =\overline{\mathrm{c}} \mathrm{kT} / 3 \pi \mu_{\mathrm{g}} \mathrm{d}_{\mathrm{p}} \\
\mathrm{k} & =\text { Boltzmann's constant }=1.38 \times 10^{-16} \mathrm{ergs} / \mathrm{K} \\
\overline{\mathrm{c}} & =\text { Cunningham slip correction } \\
\overline{\mathrm{c}} & =1+\left(\frac{2 \overline{1}}{\mathrm{~d}_{\mathrm{p}}}\right)\left[1.257+0.4 \text { exp }\left(-0.55 \mathrm{~d}_{\mathrm{p}} / \overline{1}\right)\right] \\
\overline{1} & =\text { mean free path in the gas phase } \\
\overline{1}(\mathrm{~cm}) & \approx 2.3 \times 10^{-8} \mathrm{~T}(\mathrm{~K}) / \mathrm{P}(\text { atm })
\end{aligned}
$$

Great confidence cannot be placed in any of these expressions for aerosol capture by diffusion. The expressions are based on isolated spherical collectors for aerosol particles. Spray droplets in the drywell atmosphere of a Mark I containment will not be isolated. There is substantial evidence that in arrays of spheres mass transport to a sphere is less than mass transport to an isolated sphere [65-66]. Detailed results are available only for cases involving two equal size spheres [66-68]. At the limit of $\mathrm{Pe} \rightarrow 0$ where the Sherwood number for an isolated sphere is 2, the Sherwood number for a sphere in a pair as a function of the septation between spheres is [68]:

Separation divided by the radius of the sphere

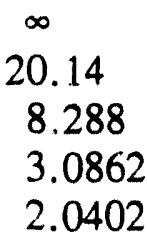

\section{Sherwood number $(\mathrm{Sh})$}

\subsection{0}

1.9056

1.7852

1.5232

1.3920

Thus, the deviation increases as the spheres become closer. The obvious limit is $S h=1.0$ when the spheres coalesce. The presence of a second sphere drastically affects the angular distribution of local Sherwood numbers around a sphere.

Useful results for rando,nly dispersed spheres with varying diameters do not appear to be available. It is apparent, however, that the wake behind a large, fast moving drop could affect diffusive collection of aerosol particles by smaller droplets. Small droplets, it will be seen, are quite important in the decontamination of containment atmospheres by sprays.

Often the various mechanisms of aerosol capture by spray droplets are considered to operate independently. The overall efficiency of the spray is then given by (additive model):

$$
\epsilon(\text { total })=\epsilon(\text { imp })+\epsilon(\text { int })+\epsilon(\text { dif })
$$


An alternate expression for the overall efficiency of decontamination by spray droplets is [69] (compound model):

$$
\epsilon^{\prime}(\text { total })=1-(1-\epsilon(\text { imp }))(1-\epsilon(\text { int }))(1-\epsilon(\text { dif }))
$$

This expression differs markedly from the previous expression only for capture of aerosols by large particles.

The overall efficiency of aerosol capture by water droplets is shown as a function of aerosol size and droplet size in Figure 16. Note that there is a minimum in the capture efficiency when is plotted against aerosol particle size. At this minimum, aerosols are too big to be significantly affected by Brownian motion responsible for aerosol capture by diffusion. Yet, the particles are still small enough that they have a high probability of avoiding capture by imp cction or interception.

A great deal of significance has been attached to the existence of this minimum. Though sprays may be effective agents for cleansing the atmosphere of general aerosols, they may be quite inefficient at removing aerosols with sizes in the vicinity of the minimum. This size, not coincidently, is the aerosol size likely to be injected into containment by sources subjected to other decontamination processes such as overlying water pools or transport through the reactor coolant system. It is also the aerosol particle size to be expected when vapors are released from the reactor coolant system are suddenly condensed in the cooler drywell. The concern is, of course, that these particles might be substantially resistant to scrubbing by sprays.

Note, however, that the location of the minimum is dependent on the droplet size. Droplets having diameters of about $200 \mu \mathrm{m}$ produce a minimum at a substantially different location than do droplets $600 \mu \mathrm{m}$ in diameter and larger. At least some of the concern over the minimum in the overall decontamination factor arises because models used to predict decontamination by sprays [70] use a single monodisperse droplet size. Modeling sprays with a range of droplet sizes would reduce, but not eliminate, the concern over aerosol particles resistant to capture by droplets.

\section{Characteristics of Sprays}

A comprehensive examination of spray systems in the drywells of Mark I boiling water reactors has not been attempted. A brief description of features of these spray systems pertinent to the analysis of aerosol removal is presented here. At least for the plants that were examined, the spray system consists of at least two headers. One header is located near the waist of the so-called inverted lightbulb containment about 8.5 meters above the drywell floor. The other header may be variously located. At the Brown's Ferry plants, the second header is located 15.8 meters above the drywell. At other plants there may be a header even higher in the drywell.

In all cases examined, the spray system must be manually actuated. In the case of the Brown's Ferry plants, interlocks prevent actuation of the spray unless the drywell is pressurized and the core is $2 / 3$ covered with water. Other characteristics of drywell sprays are listed in Table 5.

At the Brown's Ferry Units 1 and 2 sprays can provide 517 liters/second of water to the drywell. At Unit 3 sprays can provide 577 liters per second. Such high flow rates from drywell sprays may not be typical of all Mark I boiling water reactors. The containments of these reactors are designed for internal 
Attenuation
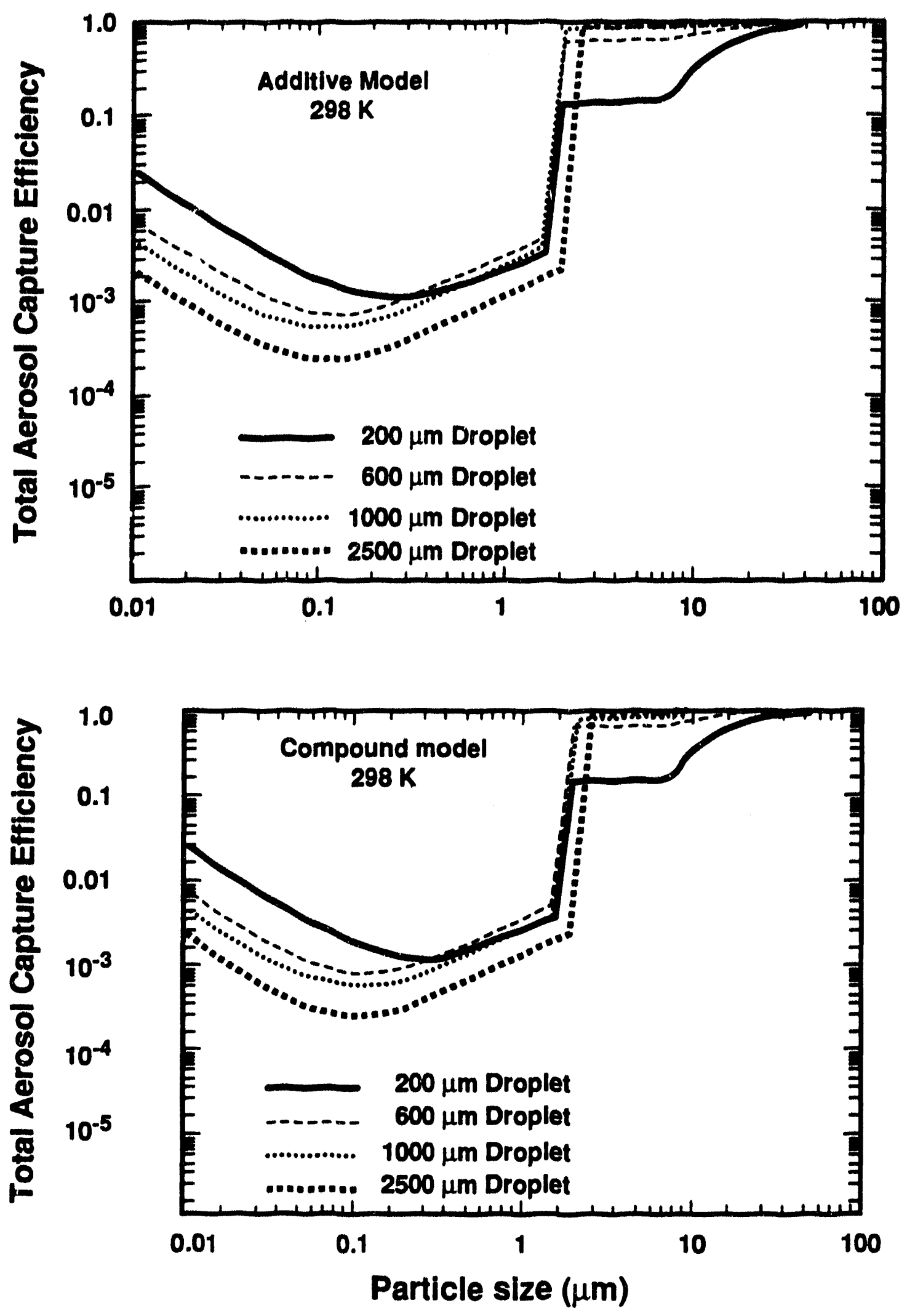

Figure 16 Overall capture efficiency as a function of aerosol particle size for various water drop sizes according to the additive and compound models described in the text 
Table 5 Characteristics of drywell sprays in some Mark I boiling water reactors

\begin{tabular}{|c|c|c|c|c|}
\hline Plant & $M W_{\text {th }}$ & $\begin{array}{l}\text { Drywell } \\
\text { volume } \\
\left(\mathbf{m}^{3}\right)\end{array}$ & $\begin{array}{l}\text { Wellwell } \\
\text { volume } \\
\left(\mathbf{m}^{3}\right)\end{array}$ & Spray system description \\
\hline Pilgrim 1 & 1998 & 4162 & 3398 & $\begin{array}{l}\text { Part of RHR; interlocks to prevent actuation } \\
\text { unless water level } 2 / 3 \text { of core height and drywell } \\
\text { pressure }>0.27 \text { atms-gauge }\end{array}$ \\
\hline $\begin{array}{l}\text { Oyster } \\
\text { Creek }\end{array}$ & 1930 & 5097 & 3596 & $\begin{array}{l}\text { Two independent systems. Automatic initiation } \\
\text { of one system on high drywell pressure and low } \\
\text { water level in core. Power from emergency } \\
\text { buses. }\end{array}$ \\
\hline $\begin{array}{l}\text { Nine Mile } \\
\text { Point } 1\end{array}$ & 1850 & 5037 & 3398 & $\begin{array}{l}\text { Independent system. One system automatically } \\
\text { initiated on high drywell pressure and low water } \\
\text { level. Second system connected to emergency } \\
\text { diesel generators and manually initated. }\end{array}$ \\
\hline Millstone 1 & 2011 & 4162 & 3540 & $\begin{array}{l}\text { Part of RHR. Manual initiation after core is } \\
\text { flooded. }\end{array}$ \\
\hline Fitzpatrick & 2436 & 4248 & 3398 & $\begin{array}{l}\text { Part of RHR. System can be manually initiated } \\
\text { after low pressure injection requirements are } \\
\text { met. }\end{array}$ \\
\hline $\begin{array}{l}\text { Hope Creek } \\
1 \& 2\end{array}$ & 3436 & 4786 & 3879 & Part of RHR. Manually initiated. \\
\hline $\begin{array}{l}\text { Vermont } \\
\text { Yankee }\end{array}$ & 1593 & 3794 & 3058 & Part of RHR. \\
\hline $\begin{array}{l}\text { Dresden } \\
2 \& 3\end{array}$ & 2527 & 4474 & 3313 & Part of RHR. \\
\hline $\begin{array}{l}\text { Quad Cities } \\
1 \& 2\end{array}$ & 2511 & 4474 & 3313 & $\begin{array}{l}\text { Part of RHR. Manual initiation permissible after } \\
\text { water level } 2 / 3 \text { of core height. }\end{array}$ \\
\hline Fermi 2 & 3430 & 4644 & 3681 & $\begin{array}{l}\text { Part of RHR. Manual initiation permissible after } \\
\text { low pressure injection requirements are met. }\end{array}$ \\
\hline $\begin{array}{l}\text { Duane } \\
\text { Arnold }\end{array}$ & 1658 & 3086 & 2662 & $\begin{array}{l}\text { Part of RHR. Manual initiation after low } \\
\text { pressure injection requirements are met. }\end{array}$ \\
\hline Cooper & 2381 & 3738 & 3115 & $\begin{array}{l}\text { Part of RHR. Manual initiation possible once } \\
\text { water level }>2 / 3 \text { of core height and drywell } \\
\text { pressure }>0.27 \text { atms-gauge. }\end{array}$ \\
\hline Monticello & 1670 & 3794 & 3058 & $\begin{array}{l}\text { Part of RHR. Manual initiation once low } \\
\text { pressure injection requirements are met. }\end{array}$ \\
\hline
\end{tabular}


Attenuation

Table 5 Characteristics of drywell sprays in some Mark I boiling water reactors (Concluded)

\begin{tabular}{|c|c|c|c|c|}
\hline Plant & $M W_{t h}$ & $\begin{array}{l}\text { Drywell } \\
\text { volume } \\
\left(\mathbf{m}^{3}\right)\end{array}$ & $\begin{array}{l}\text { Wetwell } \\
\text { volume } \\
\left(\mathbf{m}^{3}\right)\end{array}$ & Spray system description \\
\hline $\begin{array}{l}\text { Edwin Hatch } \\
1 \& 2\end{array}$ & 2436 & 4134 & 3143 & $\begin{array}{l}\text { Part of RHR. Manual initiation possible } \\
\text { after low pressure injection requirements } \\
\text { are met. }\end{array}$ \\
\hline $\begin{array}{l}\text { Brown's Ferry } \\
1,2, \& 3\end{array}$ & 3293 & 4502 & 3370 & $\begin{array}{l}\text { Part of RHR. Manual initiation after low } \\
\text { pressure injection requirements are met. }\end{array}$ \\
\hline Brunswick $1 \& 2$ & 2436 & 4644 & 3511 & $\begin{array}{l}\text { Part of RHR. Manual initiation after low } \\
\text { pressure injection requirements are met. }\end{array}$ \\
\hline
\end{tabular}

pressurization and are poorly suited to withstand pressurization by the external atmosphere. A concern has arisen that actuation of the sprays in the drywell may cool the drywell so much that it becomes externally pressurized. Some Mark I plants have been modified so that the drywell sprays can provide only about 50 liters of water per second.

Based on the examinations done for this work, two types of spray nozzles are used in the drywell sprays of Mark I boiling water reactors--Model 1-7G25 and 1-7G3 made by Spray Systems Co. A schematic diagram of the Model 1-7G25 spray nozzle is shown in Figure 17. The Model 1-7G3 is quite similar. Also shown in this figure is the spray pattern produced by the nozzle. About 65 percent of the water flow is within a central core region. The remaining 35 percent of the flow is within a coaxial annulus.

Flow rates through the nozzles as functions of water pressure are shown in Figure 18. The volumeweighted mean droplet sizes produced by the nozzles as a function of water pressure are shown in Figure 19.

More detailed droplet size data are not available for the Model 1-7G25 spray nozzle. Droplet size data have been obtained for the Model 1-7G3 nozzle [71]. These data were obtained by allowing droplets to fall into pools of liquid nitrogen and sieving the frozen particles. Some results are shown in Table 6. In comparison to photographic techniques, this method typically yields higher concentrations of fine droplets. This may be because it is able to measure droplets that cannot be resolved well by photographic methods. On the other hand, sieving may break particles and lead to erroneously high indications of fine droplet contributions to the distribution [72].

A surprising finding of the droplet size distribution measurements is that droplets obtained with "tap water" are somewhat smaller than droplets obtained with a sodium hydroxide-boric acid solution (see Figure 20). The concentrations of solutes $(3000 \mathrm{ppm}$ boron and $\mathrm{pH} 9.5)$ used in the experiments seem to be too low to produce changes in liquid properties that would account for the changes in droplet size distribution. Of course, it may be that solutes make frozen droplets less susceptible to breakage during sieving. 
Attenuation
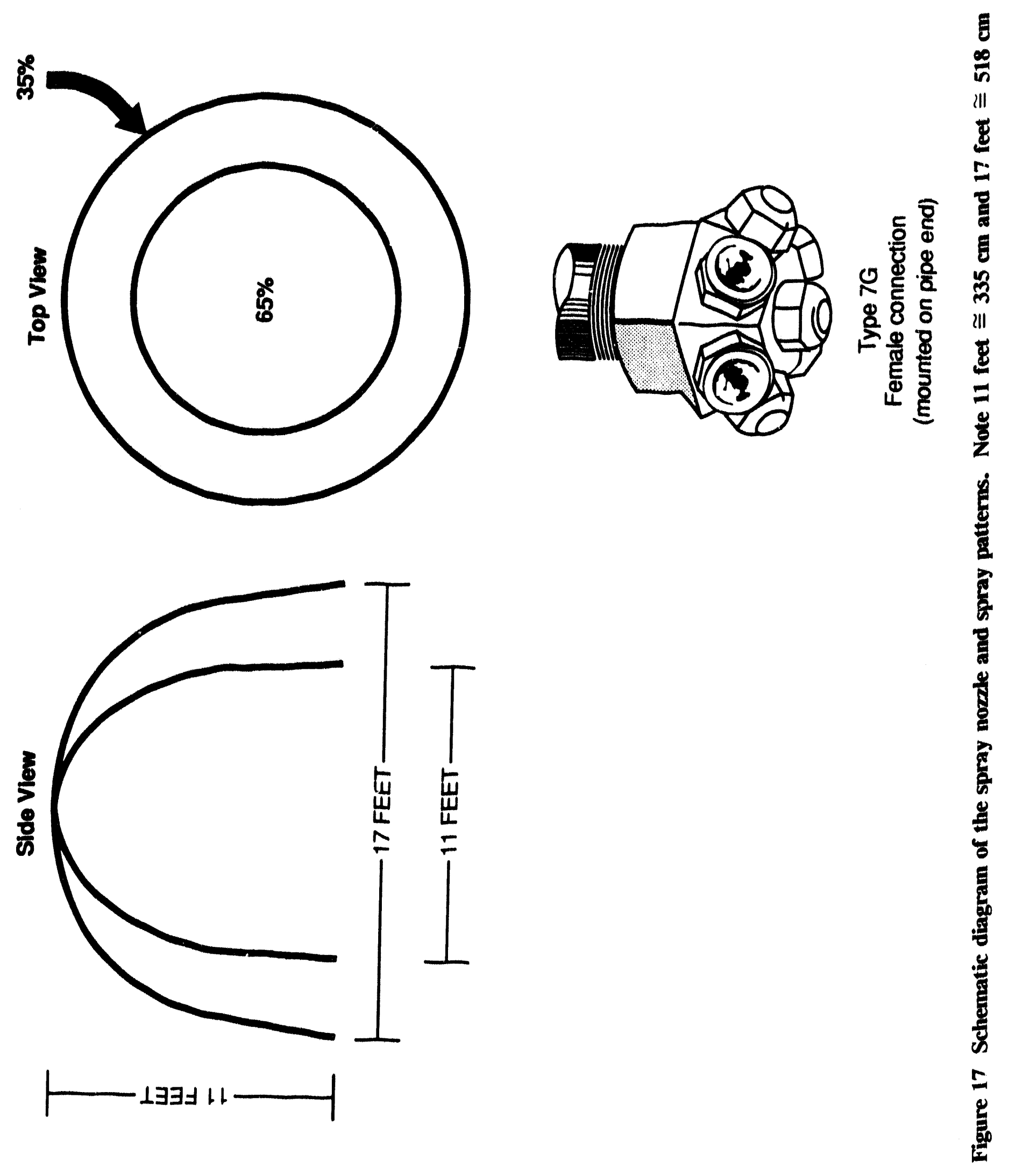
Attenuation

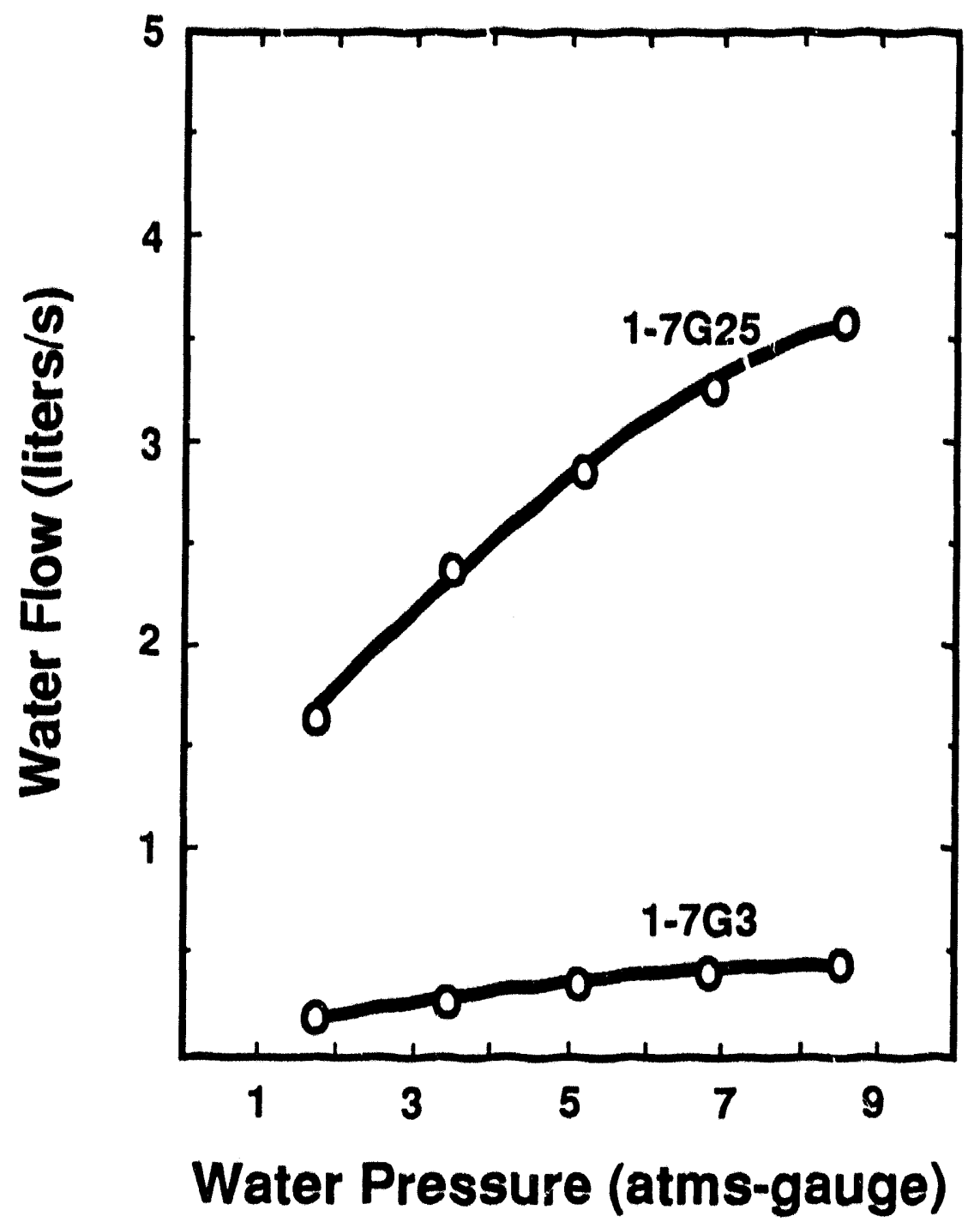

Figure 18 Volumetric flow rates through the Model 1-7G25 and Model 1-7G3 spray nozzles as functions of water pressure 
Attenuation

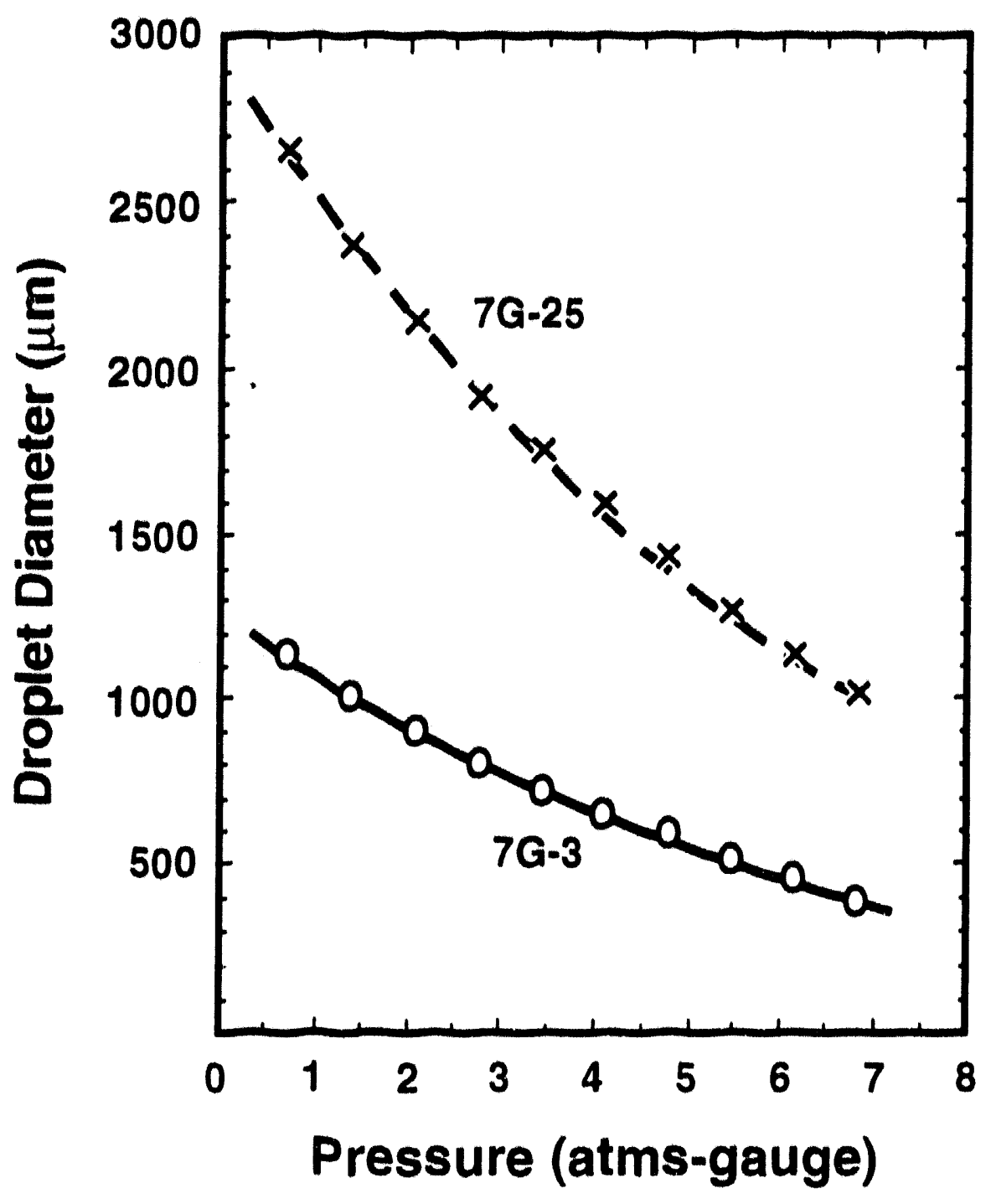

Figure 19 Volume-weighted mean droplet sizes produced by the Model 1-7G25 and Model 1-7G3 spray nozzles as functions of water pressure 
Attenuation

Table 6 Droplet size data for the Model 1-7G3 spray nozzle [71]

\begin{tabular}{|c|c|c|c|c|}
\hline \multirow[b]{2}{*}{$\begin{array}{c}\text { Screen } \\
\text { opening } \\
(\mu \mathrm{m})\end{array}$} & \multicolumn{4}{|c|}{ Mass on screen (g) in } \\
\hline & \multicolumn{2}{|c|}{ (Tap water) } & \multicolumn{2}{|c|}{$\begin{array}{l}\text { (boric acid-sodium } \\
\text { hydroxide solution) } \\
\end{array}$} \\
\hline 2360 & & & & \\
\hline 1700 & & & 154.3 & 0 \\
\hline $14 M$ & & & 154.3 & 77.2 \\
\hline 1180 & 77.2 & & 231.5 & 77.2 \\
\hline 1000 & 77.2 & 77.2 & 77.2 & 77.2 \\
\hline 850 & 231.5 & 154.3 & 231.5 & 231.5 \\
\hline 710 & 231.5 & 77.2 & 540.1 & 540.1 \\
\hline 600 & 385.8 & 231.5 & 925.8 & 848.7 \\
\hline 500 & 540.1 & 462.9 & 1311.6 & 1388.7 \\
\hline 355 & 1080.1 & 1234.4 & 2468.8 & 3008.9 \\
\hline 300 & 462.9 & 617.2 & 1080.1 & 1234.4 \\
\hline 250 & 462.9 & 462.9 & 462.9 & 462.9 \\
\hline 125 & 231.5 & 154.3 & 462.9 & 771.5 \\
\hline pan & 308.6 & 231.5 & 231.5 & 308.6 \\
\hline
\end{tabular}


Attenuation

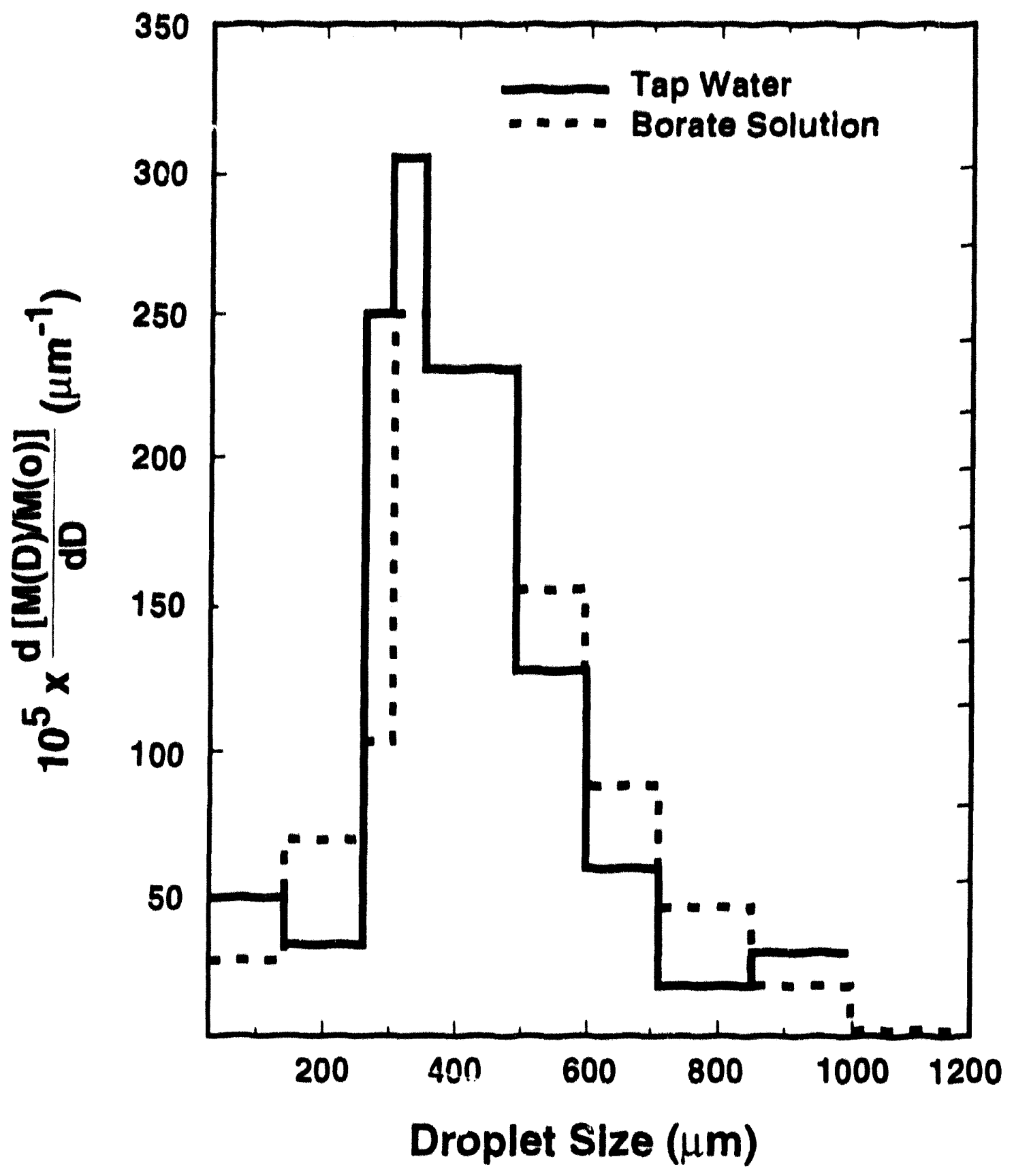

Figure 20 Droplet size distribution data for the Model 1-7G3 spray nozzle 


\section{Attenuation}

\section{Droplet Terminal Velocities}

The databace available for the terminal velocities of water droplets is not large [26]. Most data are for the terminal velocities of raindrops in air. Far fewer data have been obtained for the much finer drops produced by containment sprays. Most data are for terminal velocities in air at normal conditions. There appear to be no data for terminal velocities of water droplets in drywell atmospheres under severe reactor accident conditions.

Three correlations for the terminal velocities of water droplets are:

- Model A Ul41

$$
\begin{gathered}
\left.\operatorname{Re}_{\mathrm{T}}=\exp \mid-3.126+1.01 \ln \mathrm{N}_{\mathrm{D}}-0.01912\left(\ln \mathrm{N}_{\mathrm{D}}\right)^{2}\right] \\
\text { for } 2.4<\mathrm{N}_{\mathrm{D}}<10^{7}: 0.1<\operatorname{Re}_{\mathrm{T}}<3550
\end{gathered}
$$

where

$$
\begin{aligned}
& \operatorname{Re}_{\mathrm{T}}=\text { terminal Reynolds number }=\mathrm{U}_{\mathrm{T}} \rho_{\mathrm{g}} \mathrm{D}_{\mathrm{d}} / \mu_{\mathrm{g}} \\
& \mathrm{N}_{\mathrm{D}}=\text { Bust number }=4 \rho_{\mathrm{g}}\left(\rho_{\mathrm{I}}-\rho_{\mathrm{g}}\right) \mathrm{g} \mathrm{D}_{\mathrm{d}}^{3} / 3 \mathrm{H}_{\mathrm{g}}^{2} \\
& \mathrm{C}_{\mathrm{D}}=\text { drag coefficient }=\mathrm{N}_{\mathrm{D}} / \operatorname{Re}_{\mathrm{T}}{ }^{2}
\end{aligned}
$$

- Model B [26]

$$
\operatorname{Re}_{\mathrm{T}}= \begin{cases}1.62 \mathrm{E}_{\mathrm{o}}^{0.755} \mathrm{M}^{-0.25} & \text { for } 0.5<\mathrm{E}_{\mathrm{o}} \leq 1.84 \\ 1.83 \mathrm{E}_{\mathrm{o}}^{0.555} \mathrm{M}^{-0.25} & \text { for } 1.84<\mathrm{E}_{\mathrm{o}} \leq 5.0 \\ 2.00 \mathrm{E}_{\mathrm{o}}^{0.5} \mathrm{M}^{-0.25} & \text { for } \mathrm{E}_{\mathrm{o}}>5.0\end{cases}
$$

and for $E_{0}<0.5$, 


$$
\begin{aligned}
R_{1}= & N_{D} / 24-1.7569 \times 10^{-4} N_{D}^{2}+6.9252 \times 10^{-7} N_{D}^{3} \\
& +-2.3027 \times 10^{-10} N_{D}^{4} \\
& N_{D}<73 \text { and } \operatorname{Re}_{T}<2.37 \\
\log _{10} R_{T}= & -1.7095+1.33438 \log _{10} N_{D}-0.11591\left(\log _{10} N_{D}\right)^{2} \\
& 73<N_{D}<580 \\
\log _{10} R_{T}= & -1.81391+1.34671 \log _{10} N_{D}-0.12427\left(\log _{10} N_{D}\right)^{2} \\
& +0.006344\left(\log _{10} N_{d}\right)^{3} \quad N_{D}>580
\end{aligned}
$$

where

$$
\begin{aligned}
& M=\text { Morton number }=g \mu_{g}{ }^{4}\left(\rho_{1}-\rho_{g}\right) / \rho_{g}{ }^{2} \sigma_{l}^{3} \\
& E_{o}=\text { Eotvos number }=g\left(\rho_{1}-\rho_{g}\right) D_{d} / \sigma_{l}
\end{aligned}
$$

- Madel C [26]

$$
\operatorname{Re}_{T}= \begin{cases}0.766 E_{0}^{0.66} M^{-0.28} & \text { for } E_{0} \leq 164 M^{1 / 6} \\ 1.37 E_{0}^{0.55} M^{-0.26} & \text { for } E_{0}>164 M^{1 / 6}\end{cases}
$$

Model $\mathrm{C}$ appears to be appropriate only for droplets much larger than those of interest here. Predictions of the terminal velocities of water drops falling through air at 1 atms and $298 \mathrm{~K}$ obtainfd with Models $A, B$, and $C$ are compared in Figure 21. Clearly, predictions of terminal velocities obtaned with Model $\mathrm{C}$ are quite different than predictions obtained with Models $\mathrm{A}$ and $\mathrm{B}$. Model $\mathrm{C}$ is nct used in analyses described below'.

The essential result shown in Figure 21 is that larger droplets fall through the atmosphere at higher velocities than smaller droplets. Thus, the larger droplets will sweep out not just aerosols but also the smaller water drops. From the discussion of the mechanisms of aerosol capiure by water drops, it is 
Attenuation

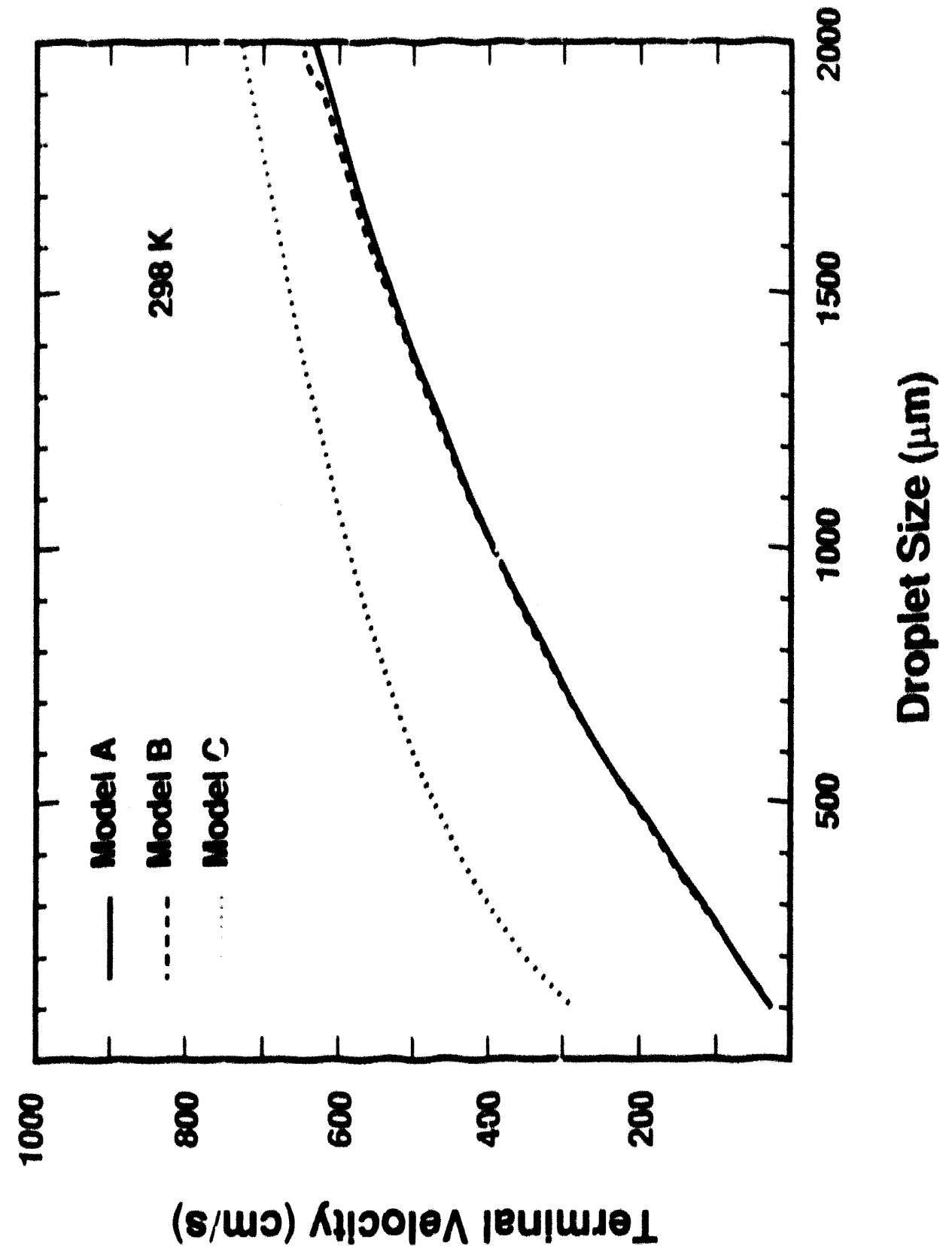


evident that the small droplets play a very important role in the decontamination of an atmosphere by sprays.

\section{E. Droplet Trajectories}

Droplet trajectories in the immediate vicinity of the spray nozale are complicated. Directional orifices of the Model 1-7G25 and the Model 1-7G3 spray nozzles greatly complicate analysis of these trajectories. Small droplets emerging from these orifices quickly lose their horizontal components of motion. They fall downward through streams of larger droplets that still have significant components of horizontal motion. There are then opportunities for droplets to collide and for small droplets to coalesce. Were each spray nozzle well isolated there would not be a critical need to analyze the trajectories of water droplets and possible collisions of droplets. The droplet si is: data discussed above were obtained for the drops about 3 meters below the nozzle where all dr sps had reached steady, downward motion. The drop size data reflect collisions and the loss of small droplets from the spray distribution. But, nozzles are not iso'ated. There is a deliberate effort made in the spray systems to overlap the spray patterns from adjacent nozzles to achieve complete coverage of the drywell annulus cross section. Overlap creates additional opportunities for droplet-droplet collisions and the loss of small droplets. Collisions among droplets from different spray nozzles are not reflected in the dioplet size data cited above. It would be expected that the contributions of small droplets to the spray are cetiainly rio larger than is indicated by the data obtained for the isolated nozzle. The matter is, however, not entirely obvious. As discussed below, particularly energetic co!lisions of droplets possibie near the nozzles will not result in coalescence of the droplets. The drops may bounce or even splatter into smaller droplets.

A detailed analysis of droplet trajectories and the possibilities of droplet collisions is not attempted here. There do not appear to be data needed for such an ana 'sis. The analysis would be complicated by the coupling of atmospheric and liquid motions near the nozzle where the volume fraction of droplets is high. Instead, analyses of aerosol capture are restricted to the region of droplet motion where horizontal movement of the drops at least on some suitable time average bus has ceased. Certainly, this is "conservative" in the sense that aerosol trapping does occur in the region where droplets have horizontal motion. Some compensation for this conservatism can be achieved by considering the fall distance of the droplets to be uncertain by the length of the curvilinear arc they traverse when they have horizontal components of motion. The treatment adopted here is non-conservative in that the initial concentrations of small droplets may be too high. Some compensation for this is achieved by recognizing that the droplet size distributions are uncertain, especially with regard to the fraction of fine droplets.

\section{F. Droplet Agglomeration}

Because of drag, there is relative motion among droplets of different sizes falling through the drywell atmosphere. Large droplets falling faster than small droplets can sweep out the small droplets. Consider $N_{0}$ droplets with a distribution of sizes such that initially there are $f(i) N_{0}$ droplets with diameters between $D_{d}(i)$ and $D_{d}(i+1)$. For calculational purposes, it is convenient to assume that all droplets in the $i^{\text {th }}$ size class, that is droplets with diameters between $D_{d}(i)$ and $D_{d}(i+1)$, have the same diameter. As the droplets fall and droplet-droplet collisions occur a real distribution of sizes will develop within a size class. Assume the aerodynamic properties of a size class $i$ are well represented by a droplet with radius $R(i)$. In general, the volumetric properties of the $i^{\text {th }}$ size class will not be well represented by this droplet. Let the volumetric properties of the size class be represented by a droplet 


\section{Attenuation}

of radius S(i). As droplets fall and strike or are struck oy other droplets these representative droplet radii change.

Since all horizontal motions have been postulated to have ceased, the drywell can be treated as one dimensional. Mass balance requires that at any horizontal plane in the drywell:

$$
\sum_{i=1}^{N} n(i, x) V(i) \frac{4}{3} \pi S(i)^{3}=Q
$$

where

$$
\begin{aligned}
n(i, x) & =\begin{array}{l}
\text { number of concentration of droplets of size class } i \text { at a position } x \text { below the spray } \\
\text { nozzle }
\end{array} \\
V(i) & =\text { terminal velocity of a droplet of radius } R(i) \\
S(i) & =\text { volume characteristic ridius of droplets in size class } i \\
Q & =\text { volume flux of water into the drywell produced by sprays } \\
N & =\text { number of size classes }
\end{aligned}
$$

Consider a subvolume of the drywell defined by planes at $\mathrm{x}$ and $\mathrm{x}+\mathrm{dx}$. A number balance of droplets of size class $\mathrm{j}$ in this region is:

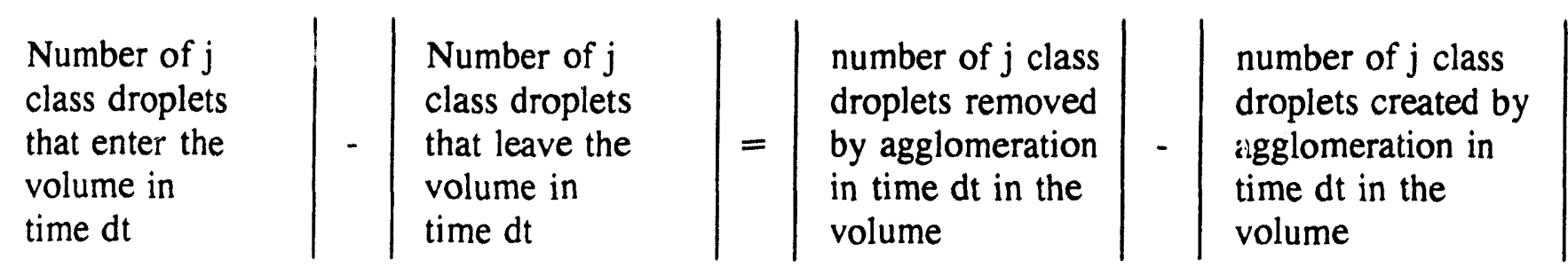

or

$$
[n(j, x)-n(j, x+d x)] V(j) A d t=\Delta N(j)-\psi(j)
$$

where

$$
\begin{aligned}
\Delta \mathrm{N}(\mathrm{j}) & =\text { number of } \mathrm{j} \text { class droplets removed by agglomeration in the volume in time } \mathrm{dt} \\
\mathrm{H}(\mathrm{j}) & =\text { number of } \mathrm{j} \text { class droplets created by agglomeration in the volume in time } \mathrm{dt} \\
\mathrm{A} & =\text { cross-sectional area of drywell that is sprayed }
\end{aligned}
$$


A single droplet of size class $i$ such that $R(i)>R(j)$, falling a distance $d x$, will encounter

$$
\Delta n(i, j)=\pi(R(i)+R(j))^{2} n(j, x) \frac{[V(i)-V(j)]}{V(i)} d x
$$

droplets of size class $\mathrm{j}$. During the period $\mathrm{dt}$, the number of $\mathrm{i}$ class droplets that enter the volume is given by:

$$
n(i, x) V(i) A d t
$$

If the efficiency with which a collision of $i$ and $j$ class droplets results in agglomeration is $\epsilon(i, j)$, then the number of $\mathrm{j}$ class droplets lost by sweepout by larger $\mathrm{i}$ class droplets is:

$$
\Delta N(i>j)=\sum_{i=j+1}^{N} \epsilon(i, j) \pi[R(i)+R(j)]^{2} n(j, x) n(i, x)[V(i)-V(j)] A d t d x
$$

By analogous arguments the number $\mathrm{j}$ class droplets lost by collisions with smaller droplets is:

$$
\Delta N(j>k)=\sum_{k=1}^{j-1} \epsilon^{\prime}(j, k) \pi[R(j)+R(k)]^{2} n(j, x) n(k, x)[V(j)-V(k)] A d t d x
$$

where $\epsilon^{\prime}(j, k)$ includes an additional term that indicates whether the agglomeration of an $i$ class droplet and a $\mathrm{k}$-class droplet creates a droplet that is outside the size range of the $\mathrm{j}$ class.

Were all the droplets within a size class to have exactly the same diameter, then, under the idealized assumptions made here, there would be no collisions of droplets from the same size class. Because droplets within a size class are not all the same size, and because rather large size ranges are used to define a class, there can be collisions of droplets within the same size class. Coalescence of two droplets within a size class may yield a droplet with a diameter outside the boundaries of the size class. Such a collision and coalescence reduces the population of the size class by two. On the other hand, collision and coalescence of two droplets within a size class may yield a slightly larger droplet whose diameter leaves it within the size class. The population of the size class is only reduced by one.

Considering the limits for a size class, the expression for the loss of $j$-class druplets by collision with other $\mathrm{j}$-class droplets can be constructed by analogy with expressions for collisions of droplets from different size classes. Recognizing that a collision can remove two droplets from the size class, rather than just one droplet as in other terms of the equation, yields: 
Attenuation

$$
\Delta N(j=j)=\epsilon^{\prime \prime}(j, j) \frac{\pi}{2}\left[D_{d}(j+1)+D_{d}(j)\right]^{2} n(j, x)^{2} \Delta V(j) A d x d t
$$

where

$$
\begin{aligned}
\Delta V & =V\left(D_{d}(j+1)\right)-V\left(D_{d}(j)\right) \\
V\left(D_{d}(j)\right) & =\text { terminal velocity of a droplet of diameter } D_{d}(j)
\end{aligned}
$$

The efficiency term, $\epsilon^{\prime \prime}(j, j)$, includes an expression for the probability that a collision results in coalescence and a term that indicates if the droplet produced by coalescence is outside the size limits for the $\mathrm{j}$-size class.

The total number of $\mathrm{j}$-class droplets lost by collisions in the spatial interval from $\mathrm{x}$ to $\mathrm{x}+\mathrm{dx}$ is:

$$
\Delta N(j)=\Delta N(i>j)+\Delta N(j>k)+\Delta N(j, j)
$$

Formation of $\mathrm{j}$-class droplet by collisions of droplets in size classes $\mathrm{k}$ and $\ell$ such that $\mathrm{j}>\mathrm{k}>\ell$ can be analyzed in a similar fashion to yield:

$$
\begin{aligned}
\Psi(j)= & \sum_{k=2}^{j-1} \sum_{\ell=1}^{k-1} \epsilon^{\prime}(k, \ell) \pi[R(k)+R(\ell)]^{2} n(k, x) n(\ell, x)[V(k)-V(\ell)] A d t d x \\
& +\sum_{k=1}^{j-1} \epsilon^{\prime}(k, k) \frac{\pi}{4}\left[D_{d}(k+1)+D_{d}(k)\right]^{2} n(k, x)^{2} \Delta V(k) A d t d x
\end{aligned}
$$

Then, from a number balance on droplets of size class $\mathrm{j}$ : 


$$
\begin{aligned}
\frac{-d n(j, x)}{d t}= & \sum_{i=j+1}^{N} \epsilon(i, j) \pi[R(i)+R(j)]^{2} n(j, x) n(i, x) \frac{[V(i)-V(j)]}{V(j)} \\
& +\sum_{k=1}^{j-1} \epsilon^{\prime}(j, k) \pi[R(j)+R(k)]^{2} n(k, x) n(j, x) \frac{[V(j)-V(k)]}{V(j)} \\
& +\epsilon^{\prime \prime}(j, j) \frac{\pi}{2}\left[D_{d}(j+1)+D_{d}(j)\right]^{2} n(j, x)^{2} \frac{\Delta V(j)}{V(j)} \\
& -\sum_{k=2}^{j-1} \sum_{\ell=1}^{k-1} \epsilon^{\prime}(k, \ell) \pi[R(k)+R(\ell)]^{2} n(\ell, x) n(k, x) \frac{[V(k)-V(\ell)]}{V(j)} \\
& -\sum_{k=1}^{j-1} \epsilon^{\prime}(k, k) \frac{\pi}{4}\left[D_{d}(k+1)+D_{d}(k)\right]^{2} n(k, x)^{2} \frac{\Delta V(k)}{V(j)}
\end{aligned}
$$

Differential equations of this type for $\mathrm{j}=1$ to $\mathrm{N}$ were solved by an explicit, Eulerian method to obtain the steady-state spatial distribution of droplet sizes. Term-by-term examinations were necessary to account for the changes in the water volume and droplet cross-sectional area within each size class. Values of $R(j)$ and $S(j)$ for each size class were adjusted at the end of each spatial step to reflect these changes in the population of the size class. Mass conservation was enforced by adjusting $\mathrm{N}_{0}$ such that:

$$
\frac{\mathrm{N}_{0} \sum_{i=1}^{N} n(i, x) V(i) \frac{4}{3} \pi S(i)^{3}}{\Omega}=Q
$$

where

$$
\Omega=\sum_{i=1}^{N} n(i, x)
$$

\section{G. Droplet-Droplet Interaction Efficiency}

Collision of water droplets, even at low, terminal, velocities, does not ensure that the droplets will coalesce. This is especially true for droplet-droplet collisions that are not "head-on" [73-78]. A commonly cited expression for the efficiency of collisions at terminal velocities to result in coalescence is [73]:

$$
\epsilon(i, j)=\frac{R(i)^{2}}{[R(i)+R(j)]^{2}} \quad \text { for } R(i)>R(j)
$$




\section{Attenuation}

The minimum efficiency according to this description is 0.25 . Experimental evidence indicates that lower efficiencies can occur [74]. Collision efficiencies calculated based on various theoretical arguments for a $500 \mu \mathrm{m}$ droplet are shown in Figure 22. As the small droplet involved in the collisions is increased in sizc, the above expression becomes an upperbound for the theoretically calculated efficiencies. An approximate lower bound for these efficiencies is taken to be:

$$
\epsilon(i, j)= \begin{cases}1-8 R(j) / R(i) & \text { for } R(j) / R(i)<0.12 .5 \\ 0 & \text { otherwise }\end{cases}
$$

\section{H. Droplet-Structure Interactions}

The drywells of Mark I boiling water reactors are notorious for their congestion. An obvious issue, then, in predicting the performance of drywell sprays is the effectiveness of droplets when they hit structures and equipment within the drywell. Droplets can be imagined to bounce off structures and continue to be effective as agents for cleansing the drywell atmosphere of aerosols. Droplets might coalesce with liquid films on surfaces and thereby be removed from the drywell atmosphere. Droplets may drip off surfaces, and droplets may splatter when they strike surfaces. Baker et al. [79] have reviewed the literature concerning the possible behaviors of droplets impacting surfaces. They conclude that regimes of behavior can be defined based on the droplet Weber number, We:

$$
W e=D_{d} \rho_{l} U_{T}^{2} / \sigma_{l}
$$

At Weber numbers of 5 and less, droplets striking a surface bounce [80]. The recoiled droplet retains only about 6 percent of its initial kinetic energy [81]. At Weber numbers between about 5 and about 65 water droplets spread over surfaces they impact or coalesce with a pre-existing water film. At higher Weber numbers the droplets that hit a wetted surface begin to splash [81-83]. The amount of material splashed back into the atmosphere increases with Weber number. About 50 percent of the incident water mass for droplets with median diameters of 1000 to $500 \mu \mathrm{m}$ is splashed at a Weber number of about 1500. At a Weber number of about 3000 , essentially 100 percent of the incident water mass is splashed back into the atmosphere.

Based on these correlations in terms of the Weber number, larger drops in the spray distribution would be expected to coalesce with water films on structure surfaces. Droplets smaller than about $400 \mu \mathrm{m}$ could bounce off the surfaces.

As water films collect on a surface, drips will form. Baker et al. [79] predicted that the major droplet formed by dripping from a s ace would have a diameter determined by Taylor instability to be:

$$
D_{d}(\text { drip })=\sqrt[3]{\frac{\sigma}{\rho_{1} g}}
$$


Attenuation

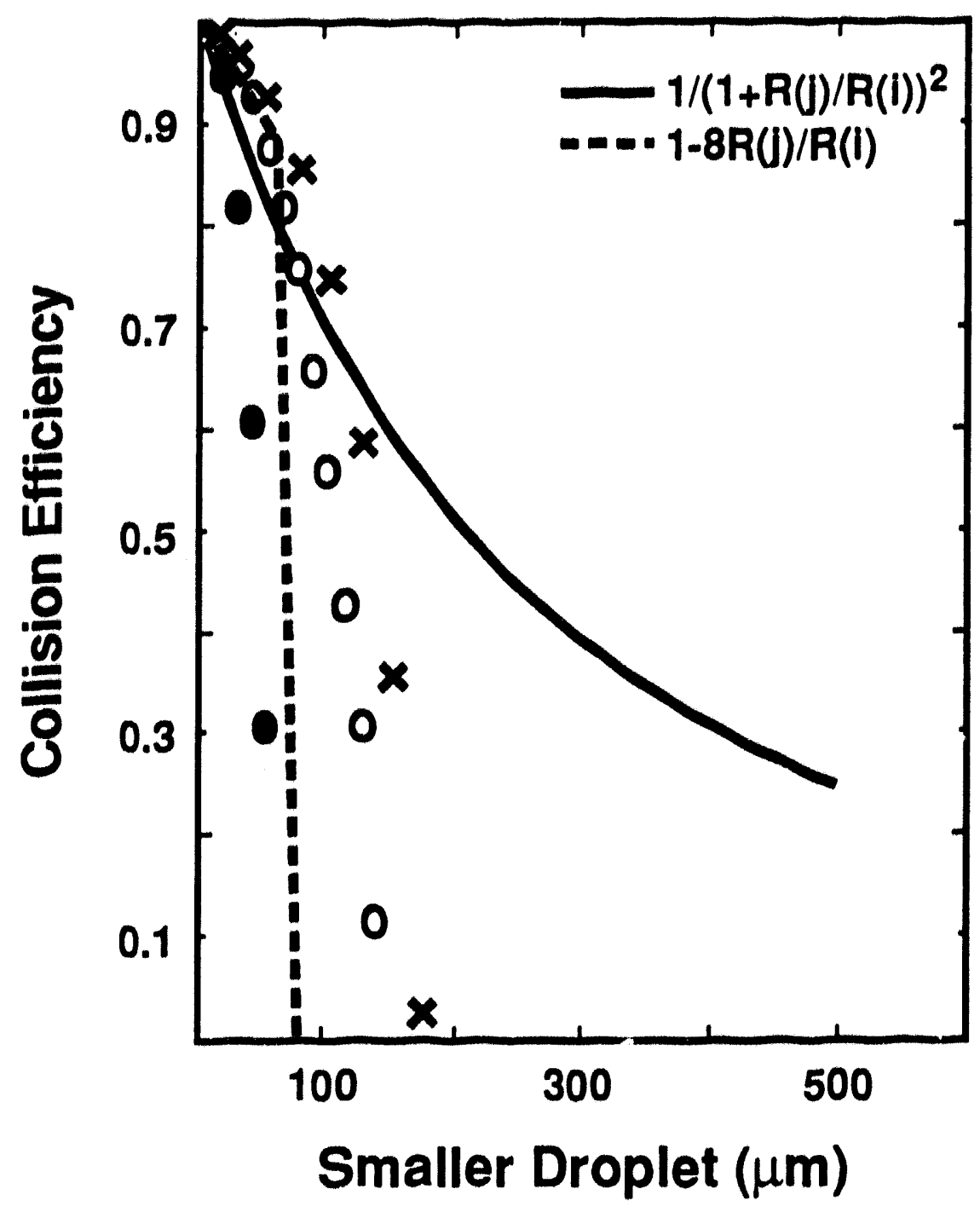

Figure 22 Comparison of the usual collision efficiency (bold line) to theoretical an alyses [73] of the collision efficiency of a $500 \mu \mathrm{m}$ droplet (symbols) and an alternate model (dashed line) described in the text 


\section{Attenuation}

Such drops $\left(D_{d} \sim 8500 \mu m\right)$ are huge in comparison to spray drops and would be expected to be largely ineffective at sweeping aerosols from drywell atmosphere. Baker et al. indicated, however, that when the major drop detached from the surface, filaments of liquid ruptured and 4 or 5 smaller droplets were formed. These smaller droplets should be more effective at aerosol removal from the drywell atmosphere than the major drop. On a volumetric basis, however, their contribution to the spray flow is small. At steady state, assuming the smaller droplets were $1000 \mu \mathrm{m}$ in diameter, these small drops would replace only about 4 percent of the water flow through the containment atmosphere lost by interactions with structures. This, of course, is well within the uncertainty in the estimate of water lost by droplet interactions with surfaces.

It appears at this juncture that water droplets striking surfaces should be considered to be lost from the spray. The uncertainty in this position with respect to small droplets that bounce off surfaces may be adequately reflected in the uncertainty in the size distribution of droplets. 


\section{Analysis of Source Term Attenuation by Drywell Sprays}

A Monte Carlo uncertainty analysis of the performance of drywell sprays is described in this chapter. The approach to uncertainty and its quantifiration as well as the mathematical methods used in this analysis are entirely similar to those described in Chapter III concerning the analysis of decontamination by an overlying waterpool. Here, however, the rate constant for spray decontamination, $\lambda$, rather than the total decontamination is taken as the uncertain quantity. Values of the rate constant are sampled from its uncertainty distribution using a model of the phenomena and processes described above and Monte Cario sampling of uncertain quantities in the models. The set of sampled values of the rate constant is analyzed using the non-parametric statistics described in Appendix A. This analysis is used to construc: an estimate of the uncertainty distribution of $\lambda$. Again, because only a firite sample is taken, the estimated uncertainty distribution is known only to a specified confidence level. As in the uncertainty analysis of decontamination by an overlying pool, stochastic uncertainty associated wit. the finite sample sizes and phenomenological uncertainty are distinguished and separately quantified.

A key step in the uncertainty analysis is the identification of uncertain aspects of the prediction of spray performance obtained with models of phenomena and processes described in the previous chapter. These uncertainties are summarized in Table 7. They are individually discussed in the subsection below. Ranges assigned to each of the uncertain quantities are described and probability density functions for values within the ranges are defined. The model of spray performance and its predictions are described in a subsequent subsection of this chapter.

\section{A. Specific Uncertainties Considered}

The principle objective of this section is to discuss uncertain quantities that arise in the description of spray performance in terms of the phenomena and processes presented in Chapter IV. These uncertain quantities are summarized in Table 7 . For each of the uncertain quantities a range is specified for values this quantity can adopt. The bases for these ranges are presented, in many cases, in Chapter IV as part of the discussion of phenomena and processes. Only when some elaboration is thought necessary is further justification or description of the ranges presented here. Probability density functions for values of the uncertain quantities within their specified ranges are assigned here following the same set of rules described in Chapter III in connection with the uncertainty analysis of decontamination by an overlying water pool.

\section{Uncertainty in Drywell Pressure and Temperature}

Pressures and temperatures in the drywell atmosphere can affect the performance of sprays as a mechanism for removal of aerosols. Actions of the sprays also affect pressures and temperatures in the drywell. Certainly, sprays can condense steam from the atmosphere and cool structures within the drywell. How much pressure reduction can be achieved by the sprays depends on the details of the accident in question. The extent to which non-condensible gases such as $\mathrm{CO}, \mathrm{CO}_{2}$ and $\mathrm{H}_{2}$ are produced during the accident and the temperature of water used to feed the sprays will greatly affect pressures and temperatures in the drywell. Pressure and temperature conditions in the drywell vary widely among the many varieties of severe accidents hypothesized to be possible in a Mark I boiling water reactor. These conditions also vary in the course of a given hypothetical accident sequence. 


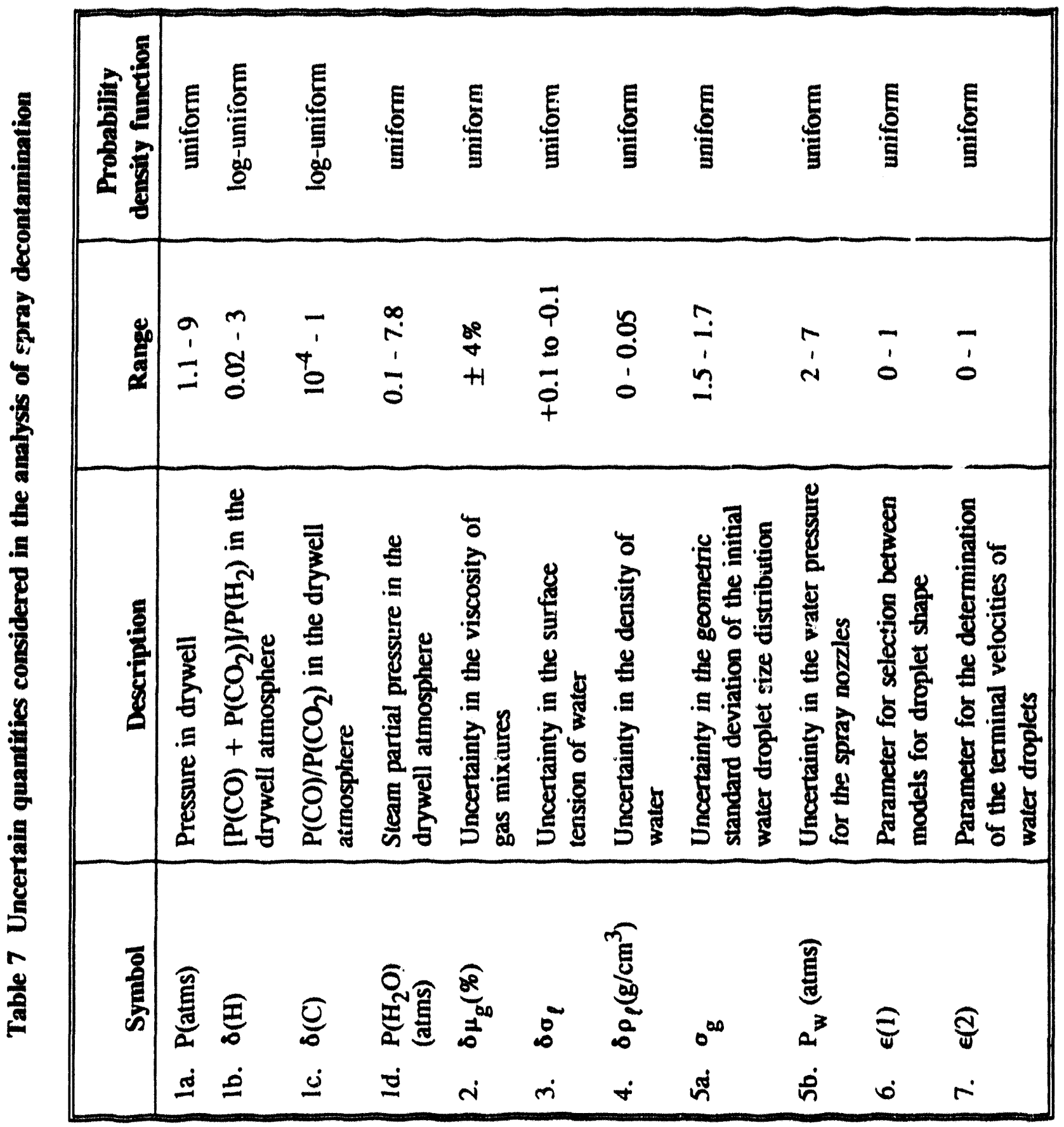




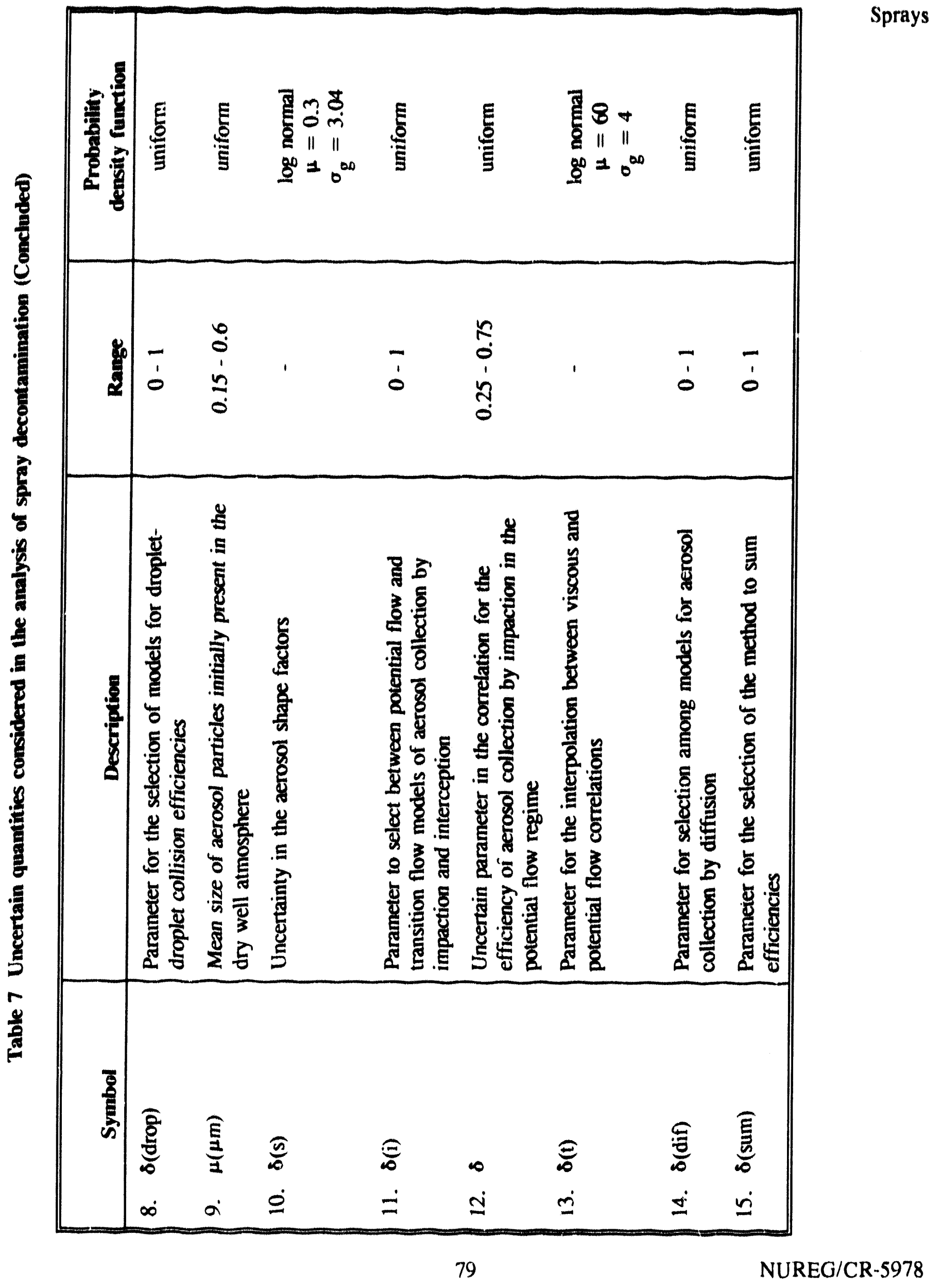


Sprays

A detailed analysis of the ranges of pressure and temperature in the drywell is beyond the scope of this work. A more bounding analysis is undertaken here.

It is clear that pressures in excess of the containment failure pressure are not of interest. The pressure boundary of a Mark I containment is very strong. Based on "as-designed" analyses, containment failure pressure may be in excess of 10 atmospheres. There may have been, however, some degradation of the strength of the containment structures over the years (for example corrosion of the liner in the sand buffer) and there is the omnipresent difficulty of flaws in construction. Consequently, 9 atmospheres is taken to be the limiting pressure of interest for the analysis of spray performance. Tre lnwer bound on the pressure in the drywell is taken to be 1.1 atmospheres.

With sprays in operation, the atmospheric temperature will be such that the partial pressure of water is in equilibrium with liquid water. The temperature can be found from:

$$
\ln \mathrm{P}\left(\mathrm{H}_{2} \mathrm{O}\right)=\frac{-7938.16}{\mathrm{~T}}+88.912-12.1215 \ln \mathrm{T}+0.011079 \mathrm{~T}
$$

where $\mathrm{P}\left(\mathrm{H}_{2} \mathrm{O}\right)$ is the partial pressure of steam in atmospheres and $\mathrm{T}$ is the Kelvin scale temperature. Again, temperatures are not allowed to exceed the temperature of containment failure which is here taken to be $53.3 \mathrm{~K}$ [8] which is significantly above the typical design temperature of $411 \mathrm{~K}$.

The partial pressure of steam in the atmosphere is estimated to be between 0.1 and 7.8 atmospheres. The partial pressure of nitrogen in the atmosphere is taken to always be T/298 atmospheres. The sum of this partial pressure and the partial pressure of steam is constrained to be less than the total pressure.

The remaining source of pressure within the drywell is taken to be the non-condensible gases $\mathrm{H}_{2}, \mathrm{CO}$, and $\mathrm{CO}_{2}$ produced during core degradation and core debris interactions with concrete.

The relative contributions $\mathrm{H}_{2}, \mathrm{CO}$, and $\mathrm{CO}_{2}$ make to the atmospheric composition depend on the extent to which hydrogen is produced in the course of core degradation and the type of concrete used in the construction of the drywell floor. Concretes composed of siliceous aggregates may contain as little as 1 weight percent carbon dioxide. Concrete composed of calcareous aggregates (dolomite or limestone) may contain as much as 36 weight percent $\mathrm{CO}_{2}$. All concretes contain 5 to 8 weight percent water. Then, the gases evolved during core debris-concrete interactions may have the partial pressure ratio

$$
\left[\mathrm{P}(\mathrm{CO})+\mathrm{P}\left(\mathrm{CO}_{2}\right)\right] / \mathrm{P}\left(\mathrm{H}_{2}\right)=8(\mathrm{H})
$$

as high as 3 in the case of concretes with calcareous aggregate or as low as 0.05 in the case of siliceous aggregates. The same partial pressure ratio in the drywell atmosphere may be even lower if the production of hydrogen during core degradation is included.

Carbon monoxide and hydrogen are produced during core debris interactions with concrete when carbon dioxide and steam from the concrete react with the metallic constituents remaining in the core debris. 
The extent to which carbon dioxide is reduced chemically to carbon monoxide (and steam is reduced to hydrogen) depends on the chemistry of the metallic phase of core debris. When zirconium is present in the core debris, chemical reduction of the carbon dioxide is very nearly compiete. The ratio of the partial pressure of carbon monoxide to the partial pressure of carbon dioxide in the drywell atmosphere evolves to quite high values:

$$
\frac{1}{\delta(\mathrm{C})}=\frac{\mathrm{P}(\mathrm{CO})}{\mathrm{P}\left(\mathrm{CO}_{2}\right)} \cdot 10^{4}
$$

Once the highly electronegative elements in the debris such as zirconium are consumed by chemical reactions, iron becomes the most reactive constituent remaining in the core debris. The ratio of the partial pressure of carbon monoxide to the partial pressure of carbon dioxide in the drywell atmosphere will evolve toward one:

$$
\frac{1}{\delta(\mathrm{C})}=\frac{P(\mathrm{CO})}{\mathrm{P}\left(\mathrm{CO}_{2}\right)} \cdot 1
$$

Classic analyses of core degradation in Mark I boiling water reactors, such as those analyses done with the Source Term Code Package [85], often indicate that core debris interacting with concrete initially contains large amounts of metallic core debris--certainly larger amounts of zirconium than in core debris than in core meltdown accidents in pressurized water reactors. The larger amounts of n etallic zirconium occur, if for no other reason, because boiling water reactors use significant amounts of zirconium for the channel boxes in! the core as well as cladding on the fuel.

Recently, alternative depictions of the core degradation process in boiling water reactors have been hypothesized. Ott and coworkers at the Oak Ridge National Laboratory [86] have suggest that core debris is expelled from the reactor coolant system in a segregated manner. The first molten materials expelled are metals which may be rich in molten zirconium. This expulsion is followed by the slow draining of molten reactor fuel. Like the more classic analysis, this scenario would initially involve very extensive carbon dioxide and steam reduction. Later in time, once all the highly reactive metals were consumed, the reduction of carbon dioxide and steam would be small.

A third hypothesis is that molten metals are not majur contributors to the molten core debris expelled into the drywell. The metals including unoxidized cladding on the fuel are assumed to melt early in the accident, drain out of the core region and freeze on structures. Because of the low decay heating rates in these metals, they do not remelt unless they come in contact with molten fue!. Molten fuel is assumed to pour from the core region much as it did at Three Mile Island, penetrate the reactor vessel and interact with the concrete in the drywell flcor. Except for a brief period during the first contact of molten fuel with concrete, the extent to which this oxiusic core debris can chemically reduce carbon dioxide and steam liberated from the concrete is small throughout the ex-vessel phase of the accident.

At this juncture, it is by no means clear which of the above core degradation scenarios is correct. Consequently, the parameter $\delta(C)$ is taken to be uncertain and to be log-uniformly distributed over the range of 1 to $10^{-4}$. Then, the composition of the gas phase can be defined to be: 
Sprays

$$
\begin{gathered}
\mathrm{P}\left(\mathrm{N}_{2}\right)=T / 298 \mathrm{atms} \\
\mathrm{P}\left(\mathrm{l}_{2}\right)=\Delta /(1+\delta(\mathrm{H})) \\
\mathrm{P}(\mathrm{CO})=\delta(\mathrm{H}) \Delta /(1+\delta(\mathrm{H}))(1+\delta(\mathrm{c})) \\
\mathrm{P}\left(\mathrm{CO}_{2}\right)=\delta(\mathrm{C}) \delta(\mathrm{H}) \Delta(1+\delta(\mathrm{H})(1+\delta(\mathrm{C}))
\end{gathered}
$$

where

$$
\begin{aligned}
\Delta & =\mathrm{P} \cdot \mathrm{T} / 298 \cdot \mathrm{P}\left(\mathrm{H}_{2} \mathrm{O}\right) \\
\mathrm{P} & =\text { ital pressure } \\
\mathrm{P}\left(\mathrm{H}_{2} \mathrm{O}\right) & =\text { partial pressure of steam } \\
\delta(\mathrm{H}) & =\left[\mathrm{P}(\mathrm{CO})+\mathrm{P}\left(\mathrm{CO}_{2}\right)\right] / \mathrm{P}\left(\mathrm{H}_{2}\right) \\
\delta(\mathrm{C}) & =\mathrm{P}\left(\mathrm{CO}_{2}\right) / \mathrm{P}(\mathrm{CO})
\end{aligned}
$$

\section{Uncertainty in the Viscosity of Gas Mixtures}

The viscosity of the ambient gas phase has a pervasive effect of the behavior of water droplets in free fall and the ability of water droplets to trap aerosols. The gas phase in the drywell of a Mark 1 containment will have a fairly complicated composition during the course of a severe accident. Initially, the drywell is inserted with nitrogen ( $<5$ percent oxygen). As the severe accident begins, the steam concentration in the atmosphere will increase. When core debris is expelled into the drywell, gases, products of concrete decomposition $\left(\mathrm{H}_{2} \mathrm{O}\right.$ and $\left.\mathrm{CO}_{2}\right)$ and the products of reaction of these gases with core debris $\left(\mathrm{H}_{2}\right.$ and $\mathrm{CO}$, respectively), will be added to the atmosphere. Hot steel in the atmosphere can catalyze reactions of hydrogen and carbon monoxide to form hydrocarbons such as methane, ethane, ethylene and acetylene. It is likely, however, that hydrocarbons will not reach concentrations highenough to affect significantly the viscosity of the gas phase. Here, the gas phase in the drywell is taken to be a mixture of $\mathrm{N}_{2}, \mathrm{H}_{2} \mathrm{O}, \mathrm{CO}_{2}, \mathrm{H}_{2}$, and $\mathrm{H}_{2} \mathrm{O}$. The viscosity of this gas mixture is calculated from the Herning-Zipperer formula [53]:

$$
\mu_{g}=\frac{\sum_{i}\left(\frac{P(i)}{P}\right) \mu_{g}(i) \sqrt{M w(i)}}{\sum_{i}\left(\frac{P(i)}{P}\right) \sqrt{M w(i)}}
$$

where the summation are over the major constituents of the gas phase and 
Sprays

$$
\begin{aligned}
P(i) & =\text { partial pressure of the } i^{\text {th }} \text { gas } \text {, hase constituent, } \\
\mu_{g}(i) & =\text { temperature-dependent viscosity of the } i^{\text {th }} \text { gas phase constituent when pure, and } \\
M w(i) & =\text { molecular weight of the } i^{\text {th }} \text { gas phase constituent. }
\end{aligned}
$$

The viscosities of pure gaseous species used in connection with the Herning-Zipperer formula are:

$$
\begin{aligned}
& \mu_{g}\left(\mathrm{~N}_{2}\right)=11.674 \times 10^{-6} \mathrm{~T}^{0.522602} /(1+87.143 / \mathrm{T}) \text { Poise } \\
& \mu_{g}\left(\mathrm{H}_{2} \mathrm{O}\right)=0.950 \times 10^{-6} \mathrm{~T}^{0.892912} /(1+207.219 / \mathrm{T}) \text { Poise } \\
& \mu_{g}\left(\mathrm{H}_{2}\right)=1.5765 \times 10^{-6} \mathrm{~T}^{0.705712} /(1-3.378 / \mathrm{T}) \text { Poise } \\
& \mu_{g}\left(\mathrm{CO}_{2}\right)=15.957 \times 10^{-6} \mathrm{~T}^{0.45721 ? /(1+246.744 / \mathrm{T}) \text { Poire }} \\
& \mu_{g}(\mathrm{CO})=14.151 \times 10^{-6} \mathrm{~T}^{0.502012} /(1+117.178 / \mathrm{T}) \text { Poise }
\end{aligned}
$$

The Herning-Zipperer formula has been shown to predict within about 2 percent the viscosities of $\mathrm{H}_{2}-\mathrm{CO}$ gas mixtures at $298 \mathrm{~K}$ [25]. It has been shown to predict within about 4 percent the viscosities of air-steam mixtures [18]. For these two cases, the predictions of the Herning-Zipperer formula were biased toward higher values than were observed, but there is no assurance that this would be the case either for other binary gas mixtures or more complicated mixtures. Here the gas viscosity predictions of the Herning-Zipperer formula are taken to be uncertain to \pm 4 percent and to be uniformly distributed over this range

\section{Uncertainty in the Surface Tension of Water}

The surface tension of pure water is not particularly uncertain. Solutes in the water can change the water's surface tension. Changes in the surface tension of water caused by solutes can affect the distortion of the water droplets and the terminal velocities of the droplets. Sprays may contain solutes such as sodium hydroxide and boric acid deliberately added to affect lodine chemistry in the containment. When spra:s operate in the recirculation model, the spray water will accumulate both dissolved and suspended material.

As discussed above in Chapter II, dissolved species may increase or decrease the surface tension of water (see Figure 10, above). For solute concentrations likely to develop in severe accidents there ought not be more than a 10 percent increase or decrease in the surface tension caused by solutes. The surface tension of water used in the sprays is then taken to be

$$
\sigma_{p}=\sigma(w)\left(1+\delta \sigma_{p}\right)
$$


Sprays

where

$$
\begin{aligned}
\sigma_{\ell} & =\text { liquid surface tension } \\
\sigma(w) & =\text { temperature-dependent surface tension of pure water (see Table 4) }
\end{aligned}
$$

and $\delta \sigma_{\rho}$ is an uncertain parameter uniformly distributed over the range of 0.1 to +0.1 .

\section{Uncertainty in the Density of Water}

The density of pure water is also not particularly uncertain. Materials dissolved and suspended in the water will affect the liquid density used in the calculations of spray performance. The density of the liquid is taken to be:

$$
\rho_{\ell}=\rho(w)\left(1+\delta \rho_{p}\right)
$$

where $\rho(w)$ is the temperature dependent density of pure water and $\delta \rho_{\ell}$ is an uncertain parameter uniformly distributed over the range of 0 to 0.05 .

\section{Uncertainty in the Initial Droplet Size}

The complexities of spray trajectories near the spray nozzles as well as some overlap of spray patterns from adji-nt nozzles forces the introduction of some artificiality in the analysis of spray performance. The scrubbing of the drywell atmosphere is considered to begin only after droplets have traversed an arc and lost all horizontal components of motion. During this travel there is, in reality, opportunity for droplets to contact aerosol particles. There are also opportunities for droplets to coalesce and to distort the size distribution of droplets that emerges from individual nozzles. Even the size distribution of droplets emerging from the nozzles is uncertain. One cannot be absolutely confident in the distributions determined by the freeze-and-sieve technique since particle breaking during the sieving process may lead to over-emphasis of the contributors made by very fine droplets. Furthermore, it was found that solutions containing modest concentrations of boric acid and sodium hydroxide produce different droplet size distributions than does tap water. As spray operation continues during severe reactor accidents, it is quite likely that water drawn into the spray system will become much more heavily contaminated with both solutes and suspended particles than the boric acid-sodium hydroxide solutions used in the tests. It is, of course, unknown if these solutes and suspended particles will cause further changes in the size distribution of droplets produced by individual nozzles.

Under reactor accident conditions, it is by no means obvious that it will be possible to operate the sprays at their design flow rates. Or, it may be that in the heat of the moment that a severe nuclear reactor accident is likely to cause, that drywell sprays may be operated at beyond design flow rates. The spray nozzles here are known to produce droplets with volume mean diameter that vary with the flow rate.

At a given flow rate, it appears that the principle uncertainty in the droplet size distribution is in the contribution to this distribution made by droplets with diameters less than the mean size. The experimentally determined droplet-size distributions only approximately fit log normal distributions. This may be because the data are not sufficiently abundant or precise. It is convenient here to assume 
the distributions do fit a $\log$ nornal distribution. It is further assumed that the effects of the processes that might affect the droplet size distribution produced by a nozzle are to narrow the spread in the distribution by sweeping out the finer droplets without greatly affecting the volume weighted mean size. Thus, for this work, the volume weighted mean droplet size is taken to be known precisely in terms of its dependence on water flow (see Figures 18 and 19). Fitting the mass fraction data obtained by freezeand-sieve technique to a log rormal distribution yields geometric standard deviation values of $1.60 \pm 0.10$. This same range of geometric standard deviation values is assumed to apply to the number distribution of the droplets. The mean size of the number distribution is, then, given by:

$$
\mu(\text { number })=\mu(\text { volume }) \exp \left[-3 \ln ^{2} \sigma_{g}\right]
$$

\section{Uncertainty in the Droplet Shape}

Only the largest water droplets of interest here distort significantly from spherical during fall through the drywell atmosphere. Typically, only droplets larger than $0.1 \mathrm{~cm}(1000 \mu \mathrm{m})$ distort significantly. The Pruppacher and Board model [61] considers distortion only of droplets larger than $0.1 \mathrm{~cm}$. This model is designated model $A$ here. A more complicated model that considers distortion of droplets when the Eotvos number, $E_{0}$, is greater than 0.4 is designated model B [18]. An uncertain parameter, $\epsilon(1)$, which is uniformly distributed over the interval 0 to 1 is used to select between these models. Model A from Pruppacher and Board is used when $\epsilon(1)$ is less than 0.5. Model B is use t otherwise. Note, that the distorted geometry is involved only in the caiculations of impaction and interception of aerosols by water drops and the sweepout of water droplets. The distorted geometry is not used for calculations of the terminal velocity of droplets. Correlations used here to calculate terminal velocities implicitly include the effects of droplet distortion.

\section{Uncertainty in the Droplet Terminal Velocities}

The limited data base on the terminal velocities of water droplets does not extend into the extreme conditions of temperature, pressure, and atmospheric composition likely to develop in the Mark I drywell under severe accident conditions. Two applicable correlations of droplet terminal velocities were described in the previous chapter. It is assumed that these correlations can be extrapolated to predict terminal velocities in drywell atmospheres. The correlations considered here are:

Correlation A: A best fit to droplet terminal velocities in air.

$$
\operatorname{Re}_{\mathrm{T}}(\mathrm{A})=\exp \left[-3.126+1.013 \ln \mathrm{N}_{\mathrm{D}}-0.01912\left(\mathrm{ln} \mathrm{N}_{\mathrm{D}}\right)^{2}\right]
$$

where

$$
\begin{aligned}
\mathrm{N}_{\mathrm{D}} & =4 \rho_{\mathrm{g}}\left(\rho_{\ell}-\rho_{\mathrm{g}}\right) \mathrm{g} \mathrm{D}_{\mathrm{d}}^{3 / 3} \mu_{\mathrm{g}}{ }^{3} \\
\mathrm{Re}_{\mathrm{T}} & =\mathrm{U}_{\mathrm{T}} \rho_{\mathrm{g}} \mathrm{D}_{\mathrm{d}} / \mu_{\mathrm{g}}
\end{aligned}
$$




\section{Sprays}

Correlation B: Used by others to extrapolate data [26].

$$
\begin{aligned}
& \operatorname{Re}_{T}(B)= \begin{cases}1.62 E_{o}^{0.755} M^{-0.25} & \text { for } 0.5<E_{o} \leq 1.84 \\
1.83 E_{o}^{0.555} M^{-0.25} & \text { for } 1.84<E_{o} \leq 5.0 \\
2.0 E_{o}^{0.5} M^{-0.25} & \text { for } E_{O}>5.0\end{cases} \\
& \operatorname{Re}_{T}(B)=N_{D} / 24-1.769 \times 10^{-4} N_{D}^{2}+6.952 \times 10^{-7} N_{D}^{3} \\
& -2.3027 \times 10^{-10} N_{D}^{4} \\
& \text { for } \mathrm{N}_{\mathrm{D}}<73 ; \mathrm{E}_{\mathrm{o}} \leq 0.5 ; \operatorname{Re}_{\mathrm{T}} \leq 2.37 \\
& \log _{10} \operatorname{Re}_{\mathrm{T}}(\mathrm{B})=-1.7095+1.33438 \log _{10} \mathrm{~N}_{\mathrm{D}}-0.11591\left(\log _{10} \mathrm{~N}_{\mathrm{D}}\right)^{2} \\
& \text { for } 73<N_{D} \leq 580 ; E_{o} \leq 0.5 ; 2.37<\operatorname{Re}_{T}(B) \leq 12.2 \\
& \log _{10} \operatorname{Re}_{T}(B)=-1.81391+1.34671 \log _{10} N_{D}-0.12427\left(\log _{10} N_{D}\right)^{2} \\
& +0.006344\left(\log _{10} N_{D}\right)^{3} \\
& \text { for } N_{D}>580 ; E_{o} \leq 0.5 ; 12.2<\operatorname{Re}_{\top}(B)<6350
\end{aligned}
$$

To account for the uncertainty in the extrapolation of these two correlations, an uncertain parameter $\epsilon(2)$, which is uniformly distributed over the range of 0 to 1 , is defined. The terminal Reynolds numbers of droplets in a calculation are found from:

$$
\operatorname{Re}_{\mathrm{T}}=\operatorname{Re}_{\mathrm{T}}(\mathrm{A}) \epsilon(2)+[1-\epsilon(2)] \operatorname{Re}_{\mathrm{T}}(\mathrm{B})
$$

\section{Uncertainty in Droplet-Droplet Interactions}

Sweepout of small spray droplets by larger spray droplets is an important phenomenon in the prediction of spray removal of aerosol particles. Small droplets can be more efficient at the capture of aerosol particles than larger droplets. Simple contact between two spray droplets does not necessarily result in the coalescence of the droplets into a larger droplet. Two limiting models for the efficiency with which collisions of water droplets lead to coalescence are described in Chapter IV: 
Model A:

$$
\epsilon(A)=\frac{R(i)^{2}}{[R(i)+R(j)]^{2}} \quad \text { for } R(j)<R(i)
$$

Model B:

$$
\epsilon(B)= \begin{cases}1-8 R(j) / R(i) & \text { for } R(j) / R(i)<0.125 \\ 0 & \text { for } R(j) / R(i) \geq 0.125\end{cases}
$$

An uncertain parameter, $\delta$ (drop), is defined here to have values uniformly distributed over the range from 0 to 1 . This parameter is used to evaluate the efficiency of droplet-droplet collisions from

$$
\epsilon= \begin{cases}\epsilon(\mathrm{A}) & \text { for } \delta \text { (drop) }<0.5 \\ \epsilon(\mathrm{B}) & \text { for } \delta \text { (drop) } 20.5\end{cases}
$$

\section{Uncertainty in the Aerosol Size Distribution}

The size distribution of the aerosols suspended in the drywell atmosphere will have an important bearing on the efficiency with which sprays can decontaminate the drywell atmosphere. Shown in Figure 23 are size distributions for aerosols in a Mark I drywell predicted with the Source Term Code Package [85] to arise in various, hypothetical severe reactor accidents. The size distributions are complicated. Mean sizes vary from fractions of a micrometer to nearly $10 \mu \mathrm{m}$. The size distributions predicted with the Source Term Code Package [85] do not reflect decontamination by a water pool overlying the core debris. The principle interest in this work is, in fact, to ascertain the additional decontamination that sprays can achieve on aerosols that have been subjected to the action of vater pools overlying core debris. As discussed in Chapter III of this document, aerosols that emerge from water pools have narrow size distributions centered around the minimum in the decontarnination efficiency size for the water pool. Therefore, size distributions for the aerosols to be considered for the analysis of spray effectiveness, while still uncertain, are quite different than the size distribution of aerosols found in past accident analyses. Based on the analyses of decontamination by a water pool clescribed above, the mean aerosol diameter is taken to be uniformly distributed over the range of 0.15 to $0.65 \mu \mathrm{m}$. The geometric standard deviation of the distribution is taken to be closely correlated with the mean size:

$$
\sigma_{g}=0.860+3.6 \mu
$$

where

$$
\begin{aligned}
\sigma_{\mathrm{g}} & =\text { geometric standard deviation } \\
\mu & =\text { mean of the aerosol size distribution in micrometers. }
\end{aligned}
$$




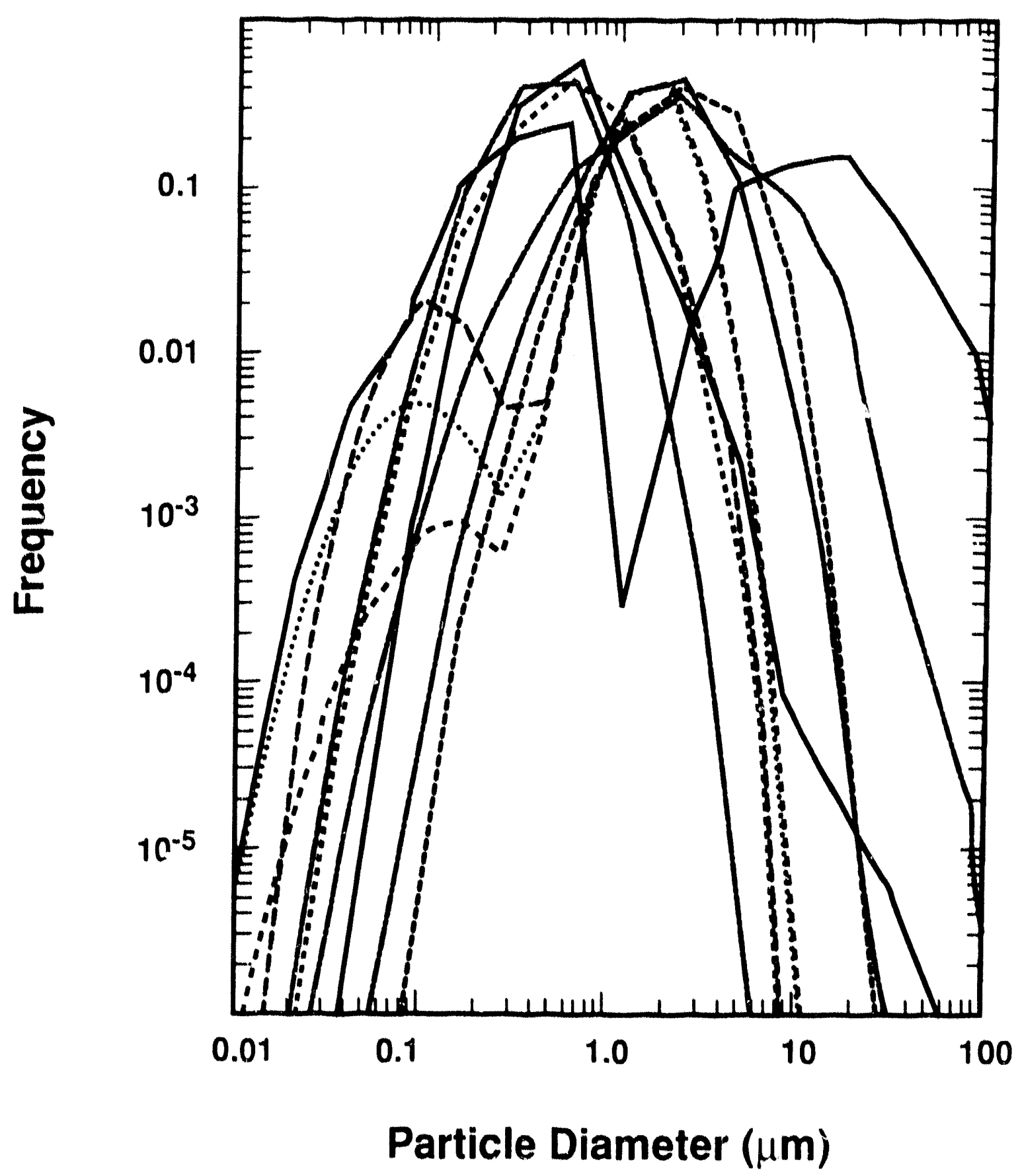

Figure 23 Size distributions of aerosols in the drywell of a Mark I boiling water reactor during various accidents as predicted with the Source Term Code Package [85] 


\section{Uncertainty in the Aerosol Shape Factors}

Models for the efficiency of aerosol capture by falling water droplets discussed in Chapter IV have been derived assuming the aerosol particles to be spheres. It is likely in the water vapor saturated envirunment that will exist once the sprays are activated that the aerosol particles will not deviate markedly from spherical. Water will condense within the concave interstices of particles composed of agglomerates of smaller particles. Surface tension forces generated by the condensed water will tend to draw particles making up any agglomerate into a spherical shape. The two shape factors of interest here, the dynamic shape factor, $\chi$, and the collision shape factor, $\gamma$, will be equal under these conditions [57]:

$$
\chi=\gamma
$$

But, because the spheridized agglomerates are not uniformly dense, their shape factors need not be equal to 1. Based on experiments with $\mathrm{U}_{3} \mathrm{O}_{8}$ and $\mathrm{Fe}_{2} \mathrm{O}_{3}$ aerosols [87], Kress has suggested that under high humidity conditions the shape factors will not exceed 3 [88]. The agglomerates of particles are, in fact, likely to have shape factors that approach the theoretical packaging limit of 1.1 .

For this work, the dynamic shape factor and the collision shape factor are taken to be equal. Values are uncertain and given by

$$
x=\gamma=1+\delta(s)
$$

where $\delta(s)$ is log-normally distributed with mean equal to 0.3 and a geometric standard deviation of 3.04. This uncertain distribution assures that shape factors are never selected to be less than 1 and that about 80 percent of the distribution lies between 1.2 and 1.9 .

\section{Uncertainty in Collection Efficiency by Impaction and Interception}

It was noted in the description of aerosol capture by impaction and interception that correlations are known only for the viscous and potential flow limits. Some have argued that because of the size disparity between aerosol particles of interest and droplets of interest that correlations for potential flow conditions are adequate for the description of impaction and interception under real flow conditions. Others have argued that some interpolation between correlations for viscous and potential flows is needed to describe impaction and interception under realistic flow conditions.

To account for the uncertainty reflected in the debate over the need to interpolate, a parameter $\delta(i)$ is defined and taken to be uniformly distributed over the range of 0 to 1 . Efficiencies of impaction and interception are then found from: 
Sprays

$$
\begin{gathered}
\epsilon(\text { imp })= \begin{cases}\epsilon \text { (imp,pot) } & \text { for } \delta(i) \leq 0.5 \\
\epsilon \text { (imp,trans) } & \text { for } \delta(i)>0.5\end{cases} \\
\epsilon(\text { int })= \begin{cases}\epsilon \text { (int,pot }) & \text { for } \delta(i) \leq 0.5 \\
\epsilon \text { (int,trans) } & \text { for } \delta(i)>0.5\end{cases}
\end{gathered}
$$

Note that the selections of the models for impaction and interception are completely correlated. The uncertainty being addressed with the parameter $\delta(i)$ is an uncertainty in the flow field. Once this value of $\delta(i)$ is selected to define the nature of the flow field, the correlations to be used for both impaction and interception are defined.

\section{Uncertainty in $\epsilon$ (imp,pot)}

The correlation given above for impaction efficiency under potential flow conditions irvolves an uncertain parameter $\delta$ :

$$
\epsilon(\text { imp,pot })= \begin{cases}0 & \text { for Stk } \leq 0.08333 \\ {\left[\frac{\text { Stk }}{\text { Stk }+\delta}\right]^{2}} & \text { for Stk } 20.2 \\ 8.57\left[\frac{\text { Stk }}{\text { Stk }+\delta}\right]^{2}(\text { Stk }-0.08333) & \text { for } 0.08333<\text { Stk }<0.2\end{cases}
$$

This parameter, $\delta$, was taken to be uncertain and to have values uniformly distributed over the range of 0.25 and 0.75 .

\section{Uncertainty in the Collection Efficiencies in the Transition Flow Regime}

The Langmuir interpolation [63] between the viscous and potential flow regimes is used in many models of aerosol collection by interception or impaction with water droplets. Fuchs [64] has criticized this interpolation, but has offered no better altci native. Here the Langmuir interpolation is generalized to be:

$$
\epsilon(\text { transition })=\frac{\epsilon(\text { viscous })+\epsilon(\text { potential }) \operatorname{Re} / \delta(t)}{1+\operatorname{Re} / \delta(t)}
$$


where

$$
\begin{aligned}
\epsilon(\text { transition }) & =\epsilon \text { (imp, trans) or } \epsilon \text { (int, trans }) \\
\epsilon(\text { viscous }) & =\epsilon \text { (imp, visc }) \text { or } \epsilon(\text { int, visc }) \\
\epsilon(\text { potential }) & =\epsilon \text { (imp, pot }) \text { or } \epsilon(\text { int, pot }) \\
\operatorname{Re} & =\text { Reynolds number }=U_{T} D_{d} \rho_{g} / \mu_{g}
\end{aligned}
$$

In the Langmuir interpolation $\delta(t)=60$. Here $\delta(t)$ is taken to be uncertain with values log-normally distributed with mean 60 and geometris standard deviation of 4 . Thus, the interpolation parameter has an uncertainty distribution centered around the Langmuir value, but has significant densities for somewhat higher and somewhat lower values.

\section{Uncertainty is Aerosol Collection by Diffusion}

Several possible models of aerosol collection by diffusion of particles across stream lines into water droplets. Diffusion is by far the most uncertain of the aerosol collection processes. Yet, for the particles of interest here, as it will be shown, diffusion is as important a collection mechanism as interception and more important than impaction. To account for the uncertainty in the description of the diffusion mechanism of aerosol capture a parameter, $\delta$ (dif), is defined and taken to have values uniformly distributed over the range of 0 to 1 . The efficiency of aerosol capture by diffusion is then taken to be:

$$
\epsilon(\text { dif })= \begin{cases}3.18 \mathrm{Pe}^{-2 / 3} & \text { for } 0<\delta(\text { dif }) \leq 0.5 \\ \left(\frac{4}{\mathrm{Pe}}\right)\left[2+\operatorname{Re}_{\mathrm{d}}^{1 / 2} \mathrm{Sc}^{3 / 8}\right] & \text { for } 0.5<\delta \text { (dif) } \leq 1.0\end{cases}
$$

Note that the term $0.557 \mathrm{Re}_{\mathrm{d}}{ }^{1 / 2} \mathrm{Sc}^{3 / 8}$ is the convective enhancement term in the third of these models. This term is itself uncertain both because of the flow regime and because of wake effects caused by adjacent droplets. Here, these uncertainties were thought to be adequately treated by consideration of other models with empirical coefficients.

\section{Uncertainty in the Summation of Efficiencies}

Two methods for summing collection efficiencies due to impaction, interception and diffusion are considered here. Selection of the method to be used in a particular calculation is based on the value of the uncertain parameter $\delta$ (sum) which is taken to have values uniformly distributed over the range of 0 to 1 . Then, 
Sprays

$$
\epsilon(\text { total })=\left\{\begin{array}{l}
\epsilon(\text { dif })+\epsilon(\text { imp })+\epsilon(\text { int }) \quad \text { for } 0<\delta(\text { sum }) \leq 0.5 \\
1-[1-\epsilon(\text { dif })][1-\epsilon(\text { imp })][1-\epsilon(\text { int })] \quad \text { for } 0.5<\delta(\text { sum }) \leq 1
\end{array}\right.
$$

\section{Other Uncertainties}

The formulation of the spray decontamination process adopted here yields results in terms of the fractional removal of aerosols. Consequently, the predictions are not especially sensitive to either the amount of core debris expelled into the drywell or its initial temperature. There is some sensitivity to the composition of the metallic phase of the core debris since this composition affects the composition of the drywell atmosphere as discussed above.

The water flux provided by sprays to the drywell atmosphere has a first order effect on spray performance. The water flux has not been defined. This water flux is treated here as a design variable rather than an uncertain quantity. Results presented here may be of some use in specifying the need for drywell sprays and the minimum useful levels of spray performance.

\section{B. Model Description}

The final steps in the uncertainty analysis of predictions of spray removal of aerosols involve the repeated evaluation of spray performance while sampling from the uncertain quantities that affect spray performance. The model used here for the evaluation of spray performance is based on the phenomena described in the previous chapier. Predictions obtained in the repeated evaluations with the model are accumulated and used to formulate estimates of the uncertainty distributions of the spray decontamination coefficient, $\lambda$.

Major steps in the calculation of spray performance are:

- select randomly the values of uncertain quantities.

- define the steady-state population and size distribution of water droplets in the drywell atmosphere,

- evaluate the rates at which droplets of various sizes capture particles of various sizes, and

- accumulate the results in terms of an overall rate of aerosol capture.

Uncertain parameters are selected using the same procedure as that involved in the uncertainty analysis of decontamination by a water pool. That is, for each uncertain quantity a random number is selected. The value of the uncertain quantity is found by solution of the equation:

$$
\text { rnd } \#=\operatorname{Pr}\left(x<x_{0}\right)
$$


where

$$
\begin{aligned}
\text { rnd } \# & =\text { random number } \\
x & =\text { value of the uncertain quantity } \\
x_{0} & =\text { selected value of the uncertain quantity }
\end{aligned}
$$

$\operatorname{Pr}\left(\mathrm{x}<\mathrm{X}_{\mathrm{o}}\right)=$ cumulative probability that $\mathrm{x}$ is less than or equal to $\mathrm{X}_{\mathrm{o}}$.

This equation is readily solved for all the probability density functions used here by a simple NewtonRaphson method. Again, random numbers used here were "shuffled" to avoid any periodicity in the congruent, sequential random number generator [58].

The method by which water will be supplied to the drywell has not been specified. The most likely method is to use the existing drywell sprays. In the case of the Brown's Ferry plant, there are two spray headers located 15.84 meters and 8.53 meters above the drywell floor. For the analyses done here, this was assumed to be the spray configuration. It was further assumed that half the available flux of water was supplied by each header. Thus, in defining the water droplet population density in the drywell atmosphere, there is half the total water flux between elevations 15.84 meters and 8.53 meters. Droplets in free fall between these elevations were allowed to coalesce. At 8.53 meters the remaining half of the water flux was injected. The injected droplets and the droplets from the upper header were allowed to coalesce during free fall to the drywell floor. The water injected at 8.53 meters had the same droplet size distribution as that injected at 15.84 meters.

The water flux that would be employed with the sprays is not defined. Here it was assumed that any of the spray water that hit the vessel or the drywell liner was not able to remove aerosols from the drywell atmosphere. (This water would, still, be able to contribute to the water pool overlying core debris on the drywell floor.) The existing spray system at Brown's Ferry is then able to supply a water flux of about $0.25 \mathrm{~cm}^{3} / \mathrm{cm}^{2}-\mathrm{s}\left(0.125 \mathrm{~cm}^{3} / \mathrm{cm}^{2}-\mathrm{s}\right.$ from each header). In other plants, such intense water fluxes may not be provided by the unmodified spray system. Further, accident management efforts may restrict the amounts of water supplied to the drywell. Consequently, calculations were done for water fluxes of:

$$
\mathrm{Q}=0.25,0.01 \text {, and } 0.002 \mathrm{~cm}^{3} \mathrm{H}_{2} \mathrm{O} / \mathrm{cm}^{2}-\mathrm{s}
$$

Again, half of the water flux was assumed to come from each header. Results presented below can be fit to simple polynomial expressions to interpolate or extrapolate to other values of the water flux.

The steady-state, spatial, size distributions of droplets in the drywell atmosphere were calculated using an explicit, Eulerian differential equation solver for the droplet growth equations described in Chapter IV. The initial size distribution of droplets was divided into 18 "bins." The size boundaries on these "bins" are listed in Table 8. The volumetric properties of droplets within a given bin were assumed to be represented initially by a droplet whose diameter is given by: 
Sprays

Table 8 Droplet size bins

\begin{tabular}{|c|c|}
\hline Bin \# & $\begin{array}{c}\text { Size range } \\
(\boldsymbol{\mu} \mathbf{m})\end{array}$ \\
\hline 1 & $2000-3000$ \\
2 & $1587-2000$ \\
3 & $1260-1587$ \\
4 & $1000-1260$ \\
5 & $794-1000$ \\
6 & $630-794$ \\
7 & $500-630$ \\
8 & $397-500$ \\
9 & $315-397$ \\
10 & $250-315$ \\
11 & $198-250$ \\
12 & $157-198$ \\
13 & $125-157$ \\
14 & $99-125$ \\
15 & $79-99$ \\
16 & $62-79$ \\
17 & $50-62$ \\
18 & $39-50$ \\
\hline
\end{tabular}




$$
D_{v}(i)=\left\{\left[D(i)^{3}+D(i+1)\right]^{3} / 2\right\}^{! / 3}
$$

where $D(i)$ and $D(i+1)$ are the upper and lower limits defining the $i^{\text {th }}$ bin. The hydrodynamic and aerosol capture properties of droplets in the $i^{\text {th }}$ bin were taken to be represented initially by a droplet whose diameter is given by:

$$
D_{h}(i)=\left\{\left[D(i)^{2}+D(i+1)^{2}\right] / 2\right\}^{1 / 2}
$$

Values of $D_{v}(i)$ and $D_{h}(i)$ were adjusted as the average volume and average surface area of droplets in a bin changed during free fall through the atmosphere.

Calculations of the spatial size distribution of droplets were done at spatial intervals such that the population of a given bin did not change by more than 25 percent. Spatial intervals were, then, much denser near the start of droplet fall than near the drywell floor. Spatial intervals were limited also to be larger than $1 \mathrm{~cm}$ and smaller than $20 \mathrm{~cm}$.

Capture of aerosol particles by falling droplets was also done using an explicit, Eulerian solver. The calculations of aerosol capture were done at the same spatial intervals used for the calculation of the droplet size distribution. Droplet size distributions at the end of an interval were assumed to exist over the entire interval. Calculations done, instead, with the droplet size distribution present at the top of an interval yielded very similar results.

For the calculation of aerosol capture, the aerosol size distribution was divided into 20 size bins. The size limits on these bins were selected so that initially each bin contained 5 percent of the aerosol mass. The dynamic properties of aerosols within a size bin were assumed to be well represented by a particle with the mass median diameter of particles in the size bin.

The capture rates were computed for aerosols in each size bin by droplets of each size class. That is, the decontamination coefficient for aerosols in the $\mathrm{j}^{\text {th }}$ size bin is defined by:

$$
-\frac{1}{M(j)} \frac{d M(j)}{d t}=\lambda(j)
$$

where $M(j)$ is the mass concentration of aerosol in the $\mathrm{j}^{\text {th }}$ size bin. The value of $\lambda(j)$ is determined by the capture efficiencies of droplets in all size classes and the fall distance:

$$
\lambda(j)=\sum_{i=1}^{18} \sum_{k} \frac{\Delta x(k)}{H} \pi R(i)^{2} n(i, x) V(i, x) \in(i, j)
$$


Sprays

where

$$
\begin{aligned}
& \Delta x(k)=\text { length of the kth spatial interval } \\
& \mathrm{n}(\mathrm{i}, \mathrm{x})=\begin{array}{l}
\text { number concentration of droplets in the } \mathrm{i}^{\text {th }} \text { size class at the bottom of the } \mathrm{k}^{\text {th }} \text { spatial } \\
\text { interval }
\end{array} \\
& \mathrm{V}(\mathrm{i}, \mathrm{x})=\text { terminal velocity of droplets in the } \mathrm{i}^{\text {th }} \text { size class } \\
& x=\sum_{j=1}^{k} \Delta x(j) \\
& \mathrm{H}=\text { total fall distance }=1584 \mathrm{~cm}=\sum_{\mathrm{k}} \Delta \mathrm{x}(\mathrm{k})
\end{aligned}
$$

Note, that droplets are assumed to be at their terminal velocities at the moment they start free fall through the drywell atmosphere. Aerosols are assumed to be well mixed in the drywell so the terminal velocities of the droplets are not adjusted in the above equation to be velocities relative to the settling velocities of the aerosol particles.

Results of the calculations were then summed to yield an overall aerosol decontamination coetficient:

$$
\frac{\mathrm{dM}}{\mathrm{dt}}=-\lambda \text { (overall) } \mathrm{M}=-\sum_{\mathrm{j}=\mathrm{i}}^{20} \lambda(\mathrm{j}) \mathrm{M}(\mathrm{j})
$$

where

$$
M=\sum_{j=1}^{20} M(j)
$$

The calculations of the overall spray decontamination coefficient were done fo: fixed amounts of aerosol in the drywell atmosphere and assuming that any unsprayed volume in the atmosphere was negligible. Neglect of the unsprayed volumes in a Mark I dryweil may, at first, be surprising. In the last section of this chapter it will be shown that the decontamination coefficients calculated here are readily corrected to account for unsprayed volumes if, as seems likely, the atmospheres in these volumes mix rapidly with the volumes subjected to the spray.

\section{Results of the Uncertainty Analysis}

The repeated evaluations of the spray performance model while sampling from the distributions of uncertain quantities yield a sample of the uncertainty distribution for the spray decontamination coefficient, $\lambda$. The samples obtained here were analyzed using the distribution-independent order 
statistics described in Appendix A. These analyses produced cumulative probability distributions for the spray decontamination coefficients. Because only a finite sample of an uncertainty distribution is available for the analyses, an estimate of the uncertainty distribution can be done only to a prescribed confidence level. Hert, as for the analysis of the decontamination by overlying water pools, confidence levels of 95,90 , and 50 percent are used. Thus, percentiles of the cumulative probability distribution are defined by ranges of values. The range can be interpreted for a confidence level of $\mathrm{C}$ percent (here $C=95,90$ or 50 percent) that there is a $C$ percent probability that the true value of $\lambda$ corresponding to the percentile of the distribution in question actually lies somewhere within the indicated range of values. There is a $100-\mathrm{C}$ percent probability that the true value of $\lambda$ corresponding to the percentile of the distribution lies outside (either above or below) the indicated range.

An example of the tabulated probability distribution for $\lambda$ is shown in Table 9. This particular example is for a case in which the total water flux is $0.25 \mathrm{~cm}^{3} / \mathrm{cm}^{2}$-s and the mass fraction of aerosol remaining in the drywell atmosphere is 0.9 . Percentile levels from 5 to 95 percent at 5 percent intervals for confidence levels of 95,90 and 50 percent are listed in the table. Note that the range of values of $\lambda$ that define a percentile level decreases in width as the level of confidence being demanded decreases. The width of the range at a given confidence level is a measure of the stochastic uncertainty that exists because only a finite sample of the uncertainty distribution was taken. The width of the range can be decreased by taking a larger sample. Unfortunately, the width of the range varies with about the square root of the sample size, so quite a large sample must be taken to dramatically reduce the range of values defining the percentile levels.

Example probability distributions are shown graphically in Figure 24 . The sample size chosen here (400 samples) was selected so there was a 95 percent confidence that 99 percent of the range of the uncertainty distribution of $\lambda$ was sampled. Ranges of values of $\lambda$ that define the percentile levels of the distribution are shown for 50 and 95 percent confidence. (That is, one can be 50 or 95 percent confident that the true value of $\lambda$ defining the percentile of the distribution in question lies within the range indicated.) It is evident from the figure that the stochastic uncertainty associated with this sample size is indeed quite small in comparison to the uncertainties in phenomenology, boundary conditions and initial conditions that dictate the range of the distribution for $\lambda$. It is also evident from results shown in Figure 24 that the decontamination coefficient does depend on the mass fraction of aerosol remaining in the atmosphere, $\mathrm{m}_{\mathrm{f}}$. That is, $\lambda$ decreases as decontamination progresses.

Tables showing the cumulative probability distributions for $\lambda$ in other cases are collected in Appendix $C$. Summaries of these results are shown in Tables 10-12. This summary indicates the 90 percentile and 10 percentile of the distribution at 90 percent confidence as well as the median or 50 percentile at 50 percent confidence for each calculated case. The rationale for focusing on these particular percentiles of the distributions is the same as the rationale described in connection with the distributions of decontamination factors for overlying water pools. Median values of $\lambda$ are representative of the spray performance, but analyses using median values are not likely to demand high confidence levels. The 90 and 10 percentile values of the distributions are reasonable upper and lower bounds on the cistributions for many purposes. Analyses using such upper and lower bounds are likely to also demand high confidence levels. 
Sprays

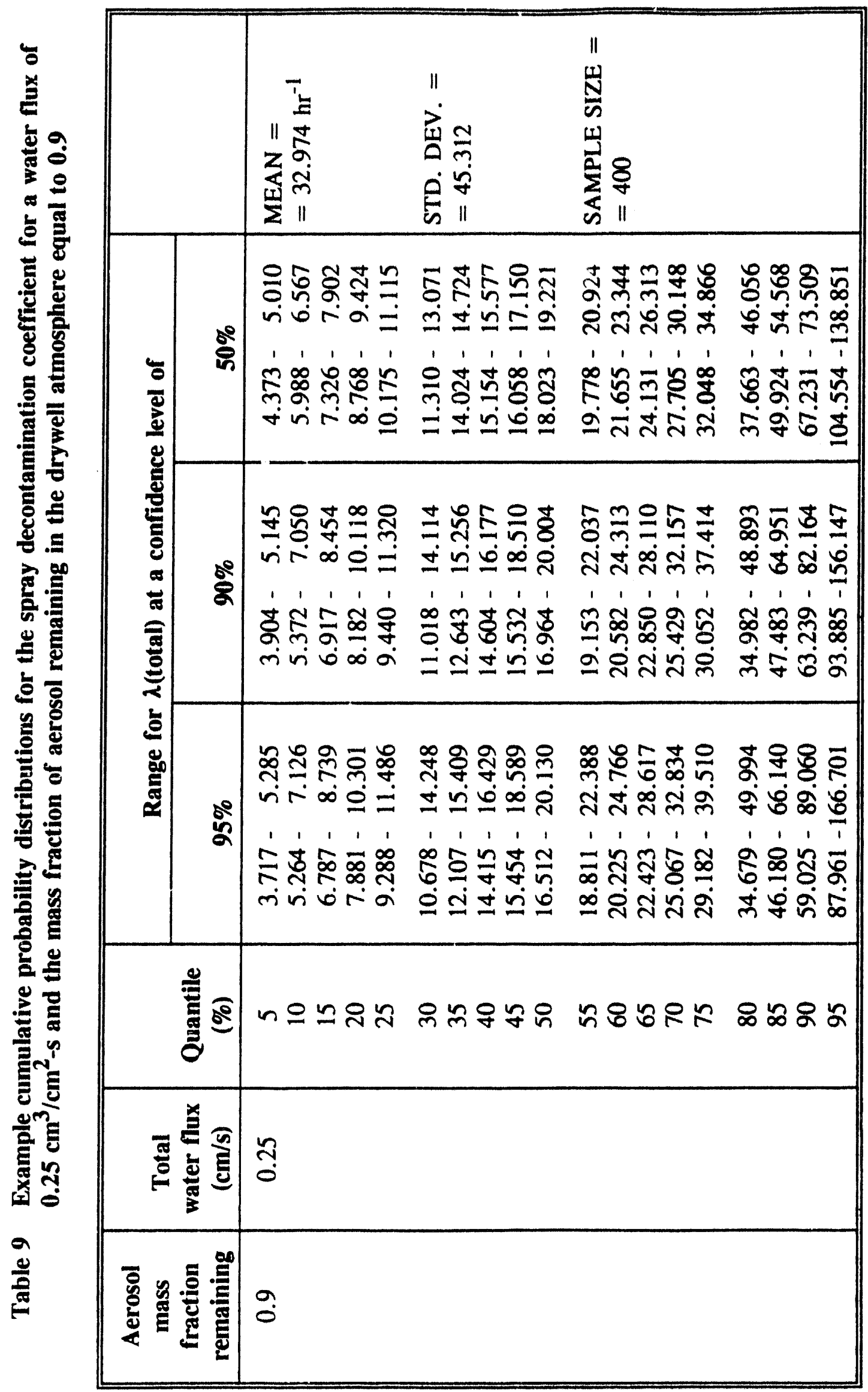




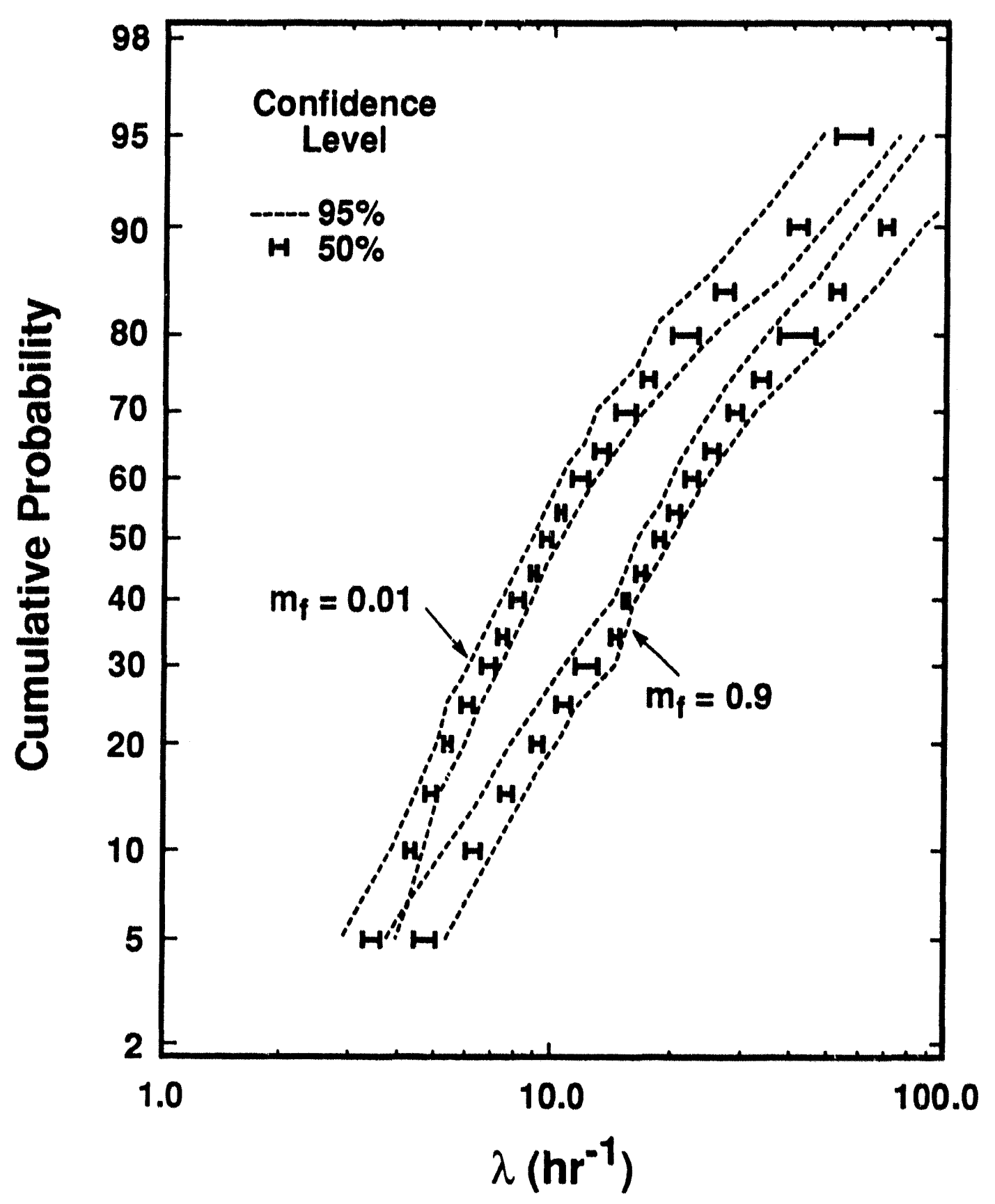

Figure 24 Cumulative probability distribution for $\lambda$ in the cases $Q=0.25 \mathrm{~cm}^{3} / \mathrm{cm}^{2}-\mathrm{s}, \mathrm{m}_{\mathrm{f}}=0.9$ and $\mathrm{m}_{\mathrm{f}}=0.01$ 
Sprays

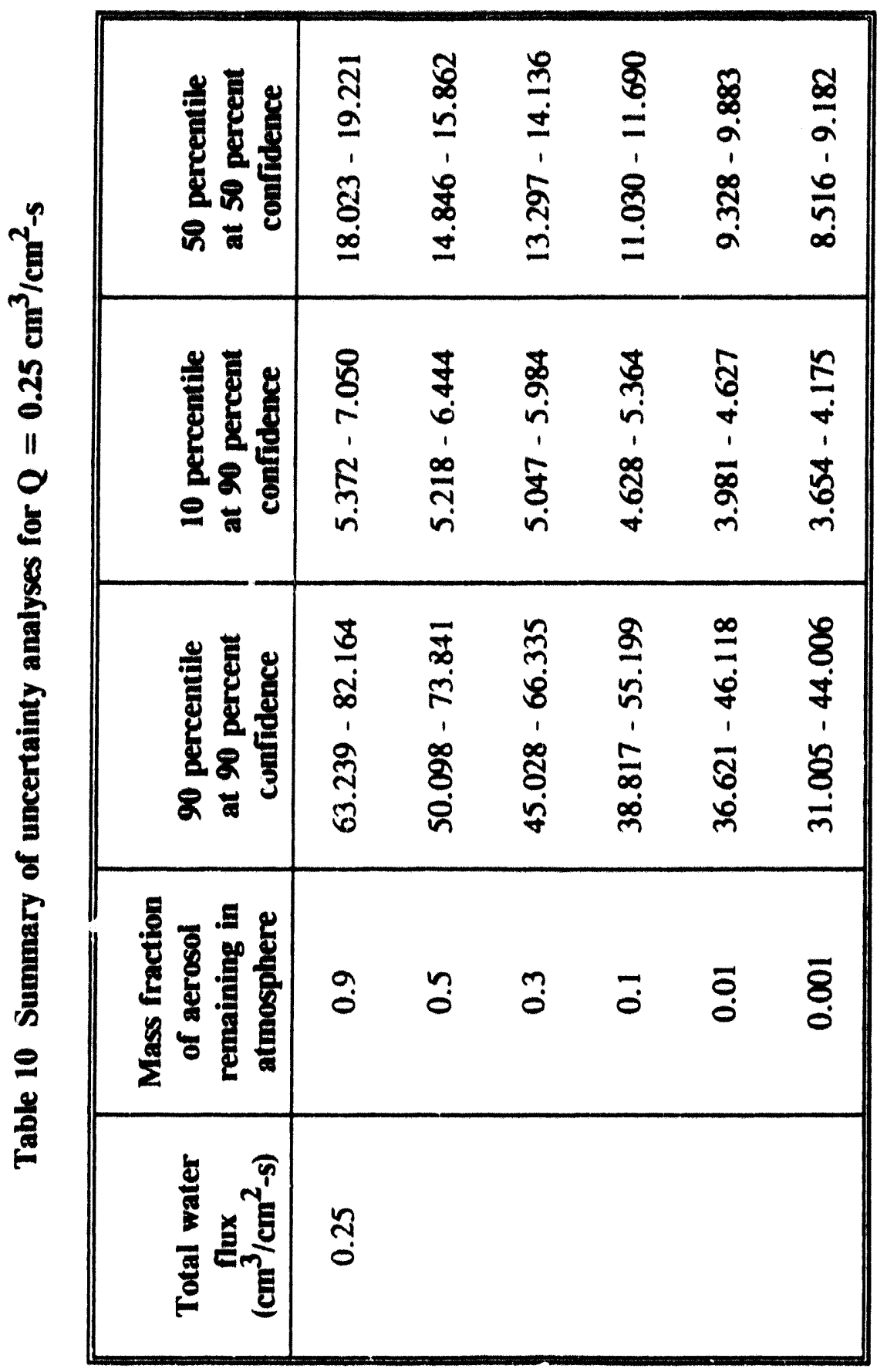


Sprays

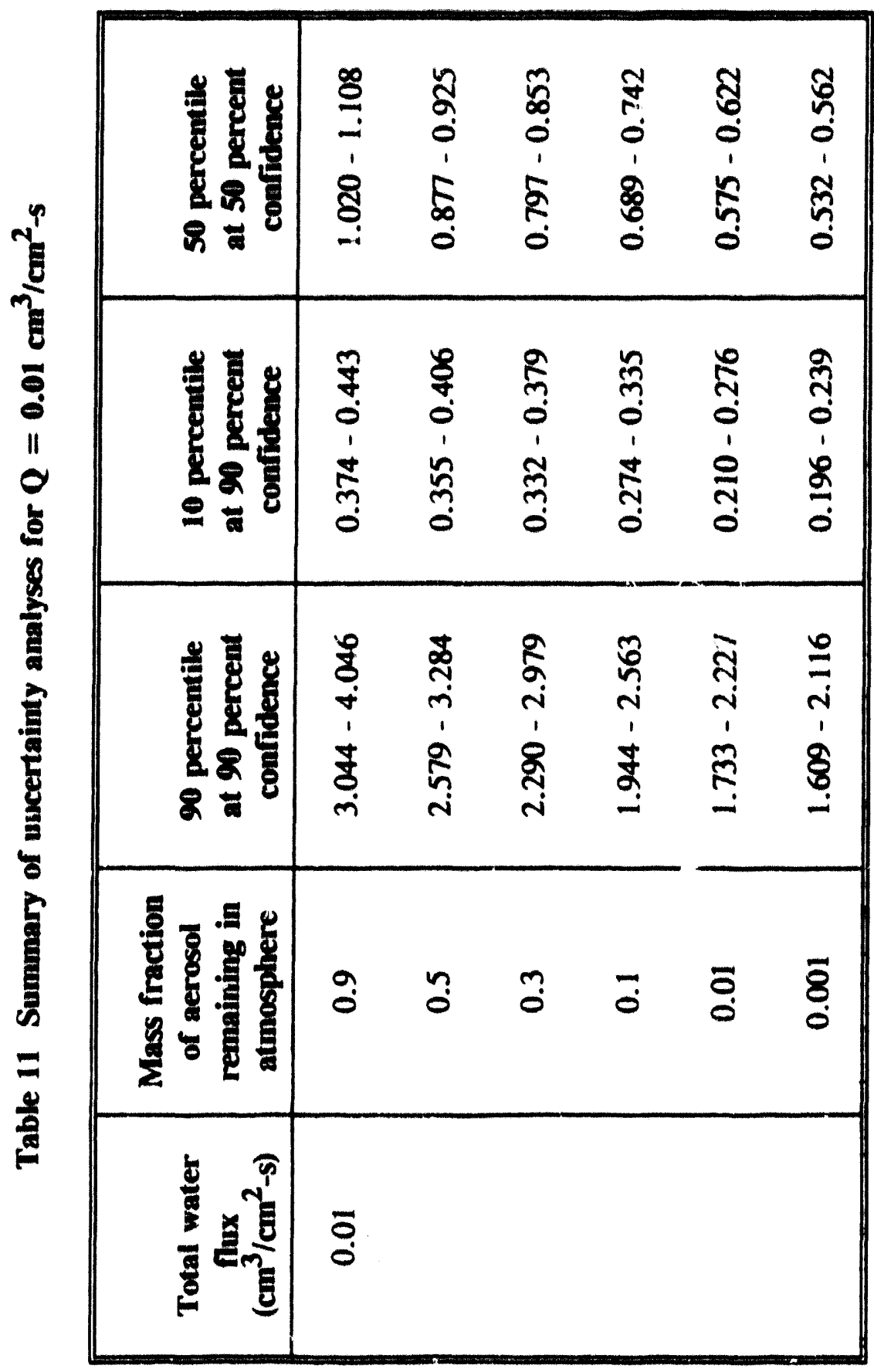


Sprays

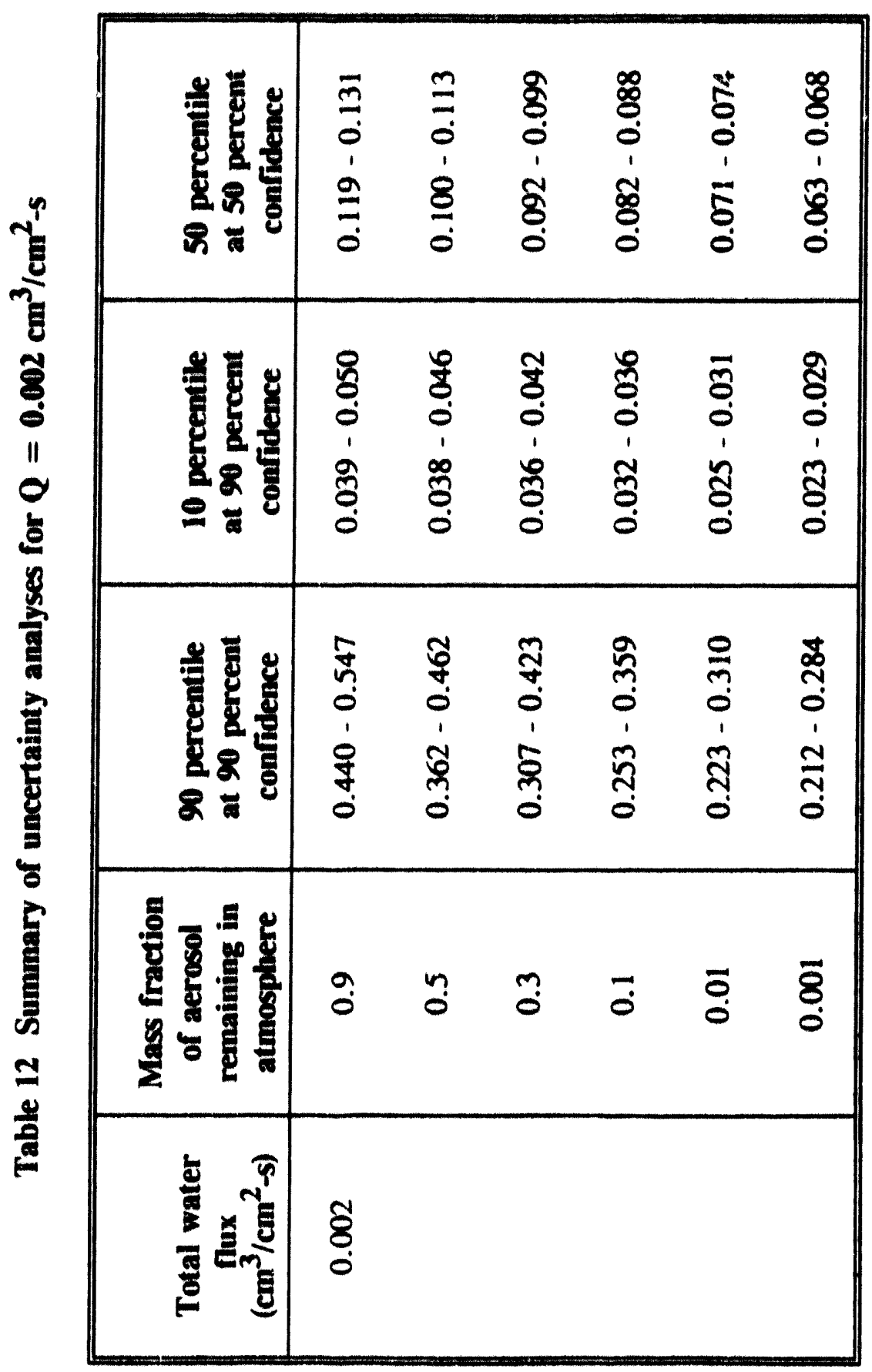


These spray decontamination coefficients derived here are not especially large. They may be compared, for instance, to values of $135 \mathrm{hr}^{-1}$ for $\mathrm{Q}=0.25 \mathrm{~cm}^{3} / \mathrm{cm}^{2}-\mathrm{s}, 5.4 \mathrm{hr}^{-1}$ for $\mathrm{Q}=0.01 \mathrm{~cm}^{3} / \mathrm{cm}^{2}-\mathrm{s}$ and $1.08 \mathrm{hr}^{-1}$ for $\mathrm{Q}=0.002 \mathrm{~cm}^{3} / \mathrm{cm}^{2}-\mathrm{s}$ derived from recommendations for analyses of spray performance [89]. The values of $\lambda$ found here are smaller because:

a. the aerosol particles that will pass through a water pool will be of a size that is inefficiently trapped by falling droplets, and

b. the water droplet size is not constant throughout the entire sprayed volume as was assumed when previous recommendations were developed.

Sprays will be far more efficient at scrubbing relatively large aerosol particles released into the containment without passing through a water pool. For further discussions of spray effectiveness at removing more general aerosol particles see Reference 18.

The median values of $\lambda$ are shown in Figure 25 as functions of the mass fraction of aerosol remaining in the containment atmosphere. The curves in this figure show that the spray decontamination coefficient decreases as decontamination of the atmosphere progresses. This occurs because spray droplets remove aerosol particles in a size-selective manner. That is, the spray not only attenuates the amount of aerosol present in the atmosphere, it also changes the size distribution of the aerosol that is remaining in the atmosphere. As decontamination progresses the remaining aerosol has a size distribution that evolves toward the size of minimum decontamination efficiency. The distribution is progressively narrowed around this size of minimum efficiency. As decontamination progresses, the remaining aerosol becomes lesis efficiently trapped by the spray droplets.

The variations in $\lambda$ with the mass fraction of aerosol remaining in the atmosphere, $m_{f}$, shown in Figure 25 and listed in Tables 1()-12, must be carefully used. There is a strong correlation among values of $\lambda$ at various values of $m_{f}$. That is, sets of vales of uncertain quantities that produce large values of $\lambda$ at $m_{f}=0.9$ are also likely' to produce relatively !'arge values of $\lambda$ at smaller values of $m_{f}$. This correlation among values of $\lambda$ is readily seen in the plot of samples of $\lambda\left(\mathrm{m}_{\mathrm{f}}=0.01\right)$ against values of $\lambda\left(m_{\mathrm{f}}=0.9\right)$ shown in Figure 2.6 .

Some of the correlation can be eliminated by considering $\lambda\left(m_{f}=0.9\right)$ and $\lambda\left(m_{f}\right) / \lambda\left(m_{f}=0.9\right)$ as the quantities of interest. The plot of $\lambda\left(m_{f}=0.01\right) / \lambda\left(m_{f}=0.9\right)$ against $\lambda\left(m_{f}=0.9\right)$ shown in Figure 27 reveals that much of the correlation has, indeed, been removed.

Samples of the spray decontamination coefficient were reanalyzed to obtain probability distribution functions for $\lambda\left(\mathrm{m}_{\mathrm{f}}\right) / \lambda\left(\mathrm{m}_{\mathrm{f}}=0.9\right)$ for $\mathrm{m}_{\mathrm{f}}=0.5,0.3,0.1,0.01$, and 0.001 (these values of $\mathrm{m}_{\mathrm{f}}$ correspond to decontamination factors of $2,3.3,10,100$, and 1000, respectively). The detailed distributions are collected in Appendix D. The results are summarized in Table 13.

Plots of $\lambda\left(m_{\mathrm{f}}\right) / \lambda\left(\mathrm{m}_{\mathrm{f}}=0.9\right)$ against $\mathrm{m}_{\mathrm{f}}$ for various values of the water flux, $\mathrm{Q}$, are shown in Figure 28. It is evident that the dependence of the spray decontamination ratio on $m_{f}$ is quite uncertain. The 90 percentile values show very little variation with $m_{\mathrm{f}}$. The 50 percentile and 10 percentile values show an initially sharp variation as $m_{f}$ goes from 0.9 to 0.1 . Thereafter, the ratio changes little with $m_{f}$. This behavior comes about because the initial size distributions for aerosols emerging from water pools into the drywell atmosphere can have mean sizes rather close to the size that is trapped with minimal 


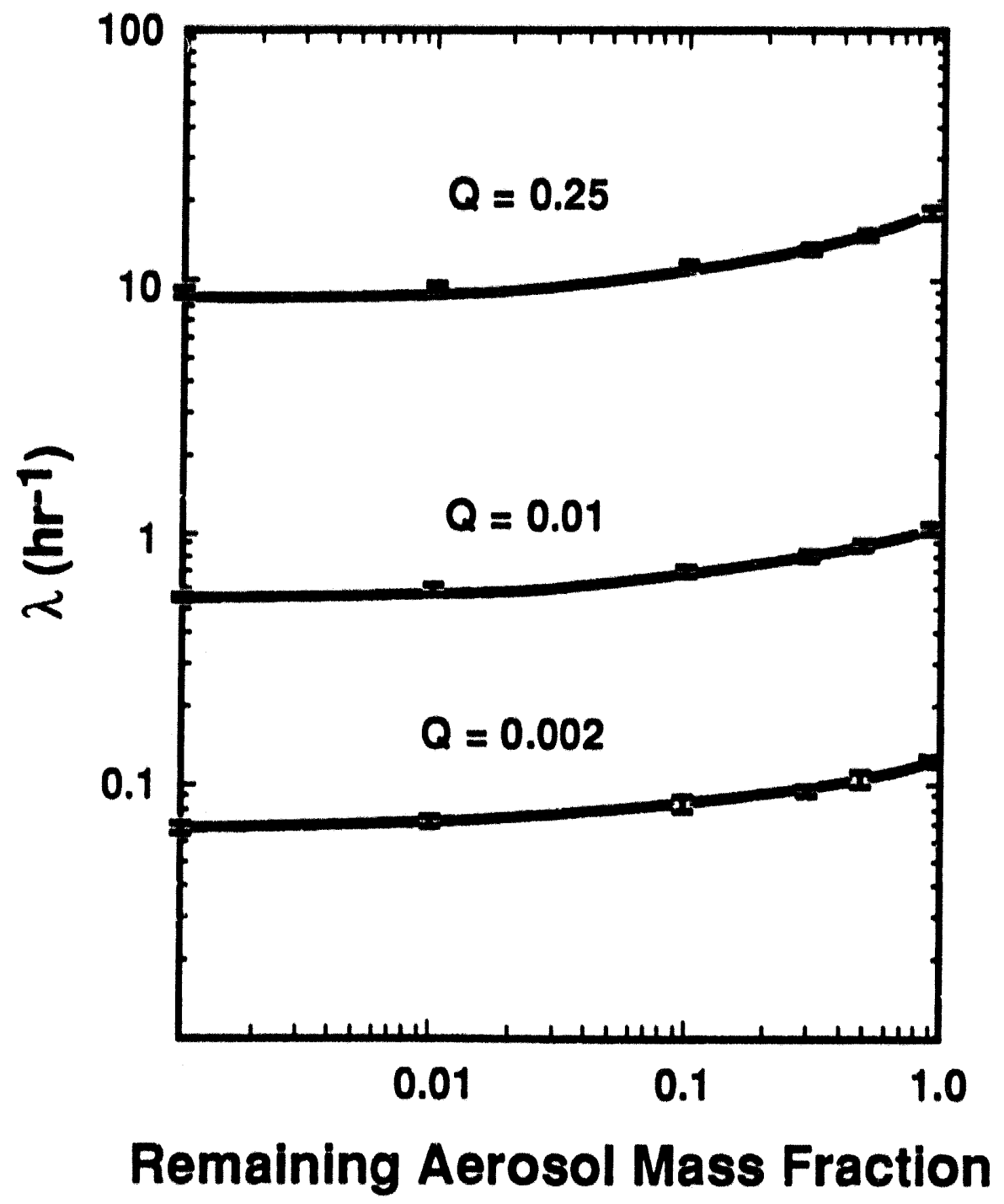

Figure 25 Median values of $\lambda\left(m_{f}=0.9\right)$ for $Q=0.25,0.01$ and $0.002 \mathrm{~cm}^{3} / \mathrm{cm}^{2}-\mathrm{s}$ as functions of $\mathrm{m}_{\mathrm{f}}$ 
Sprays

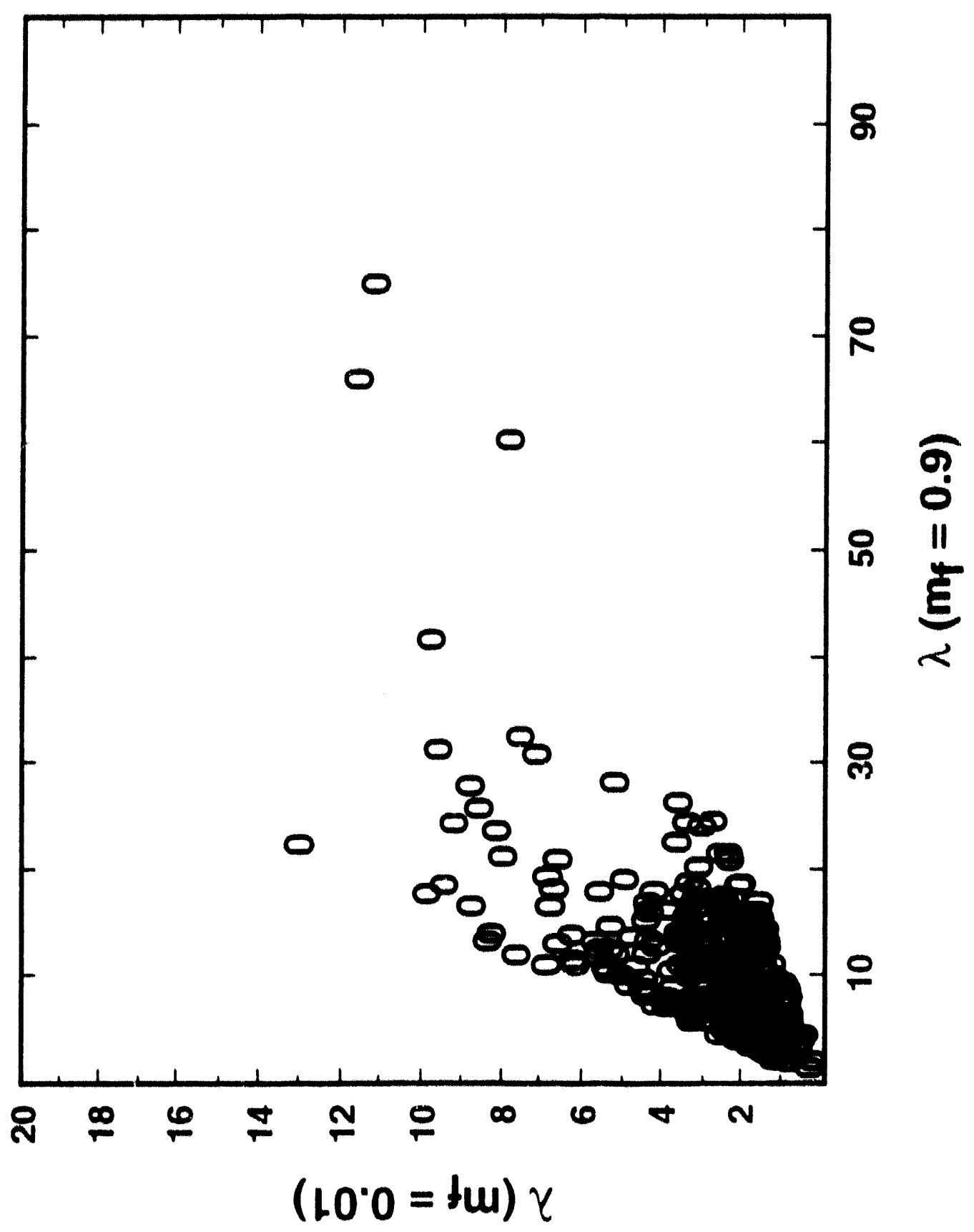

$\frac{8}{7}$

ปุ

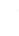

$\sigma$

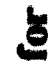

ร

II

E

5

8

8
$\frac{8}{5}$
$\frac{8}{8}$
$\frac{8}{8}$
$\frac{8}{8}$

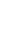

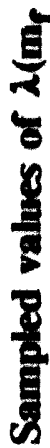

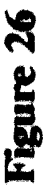


Sprays

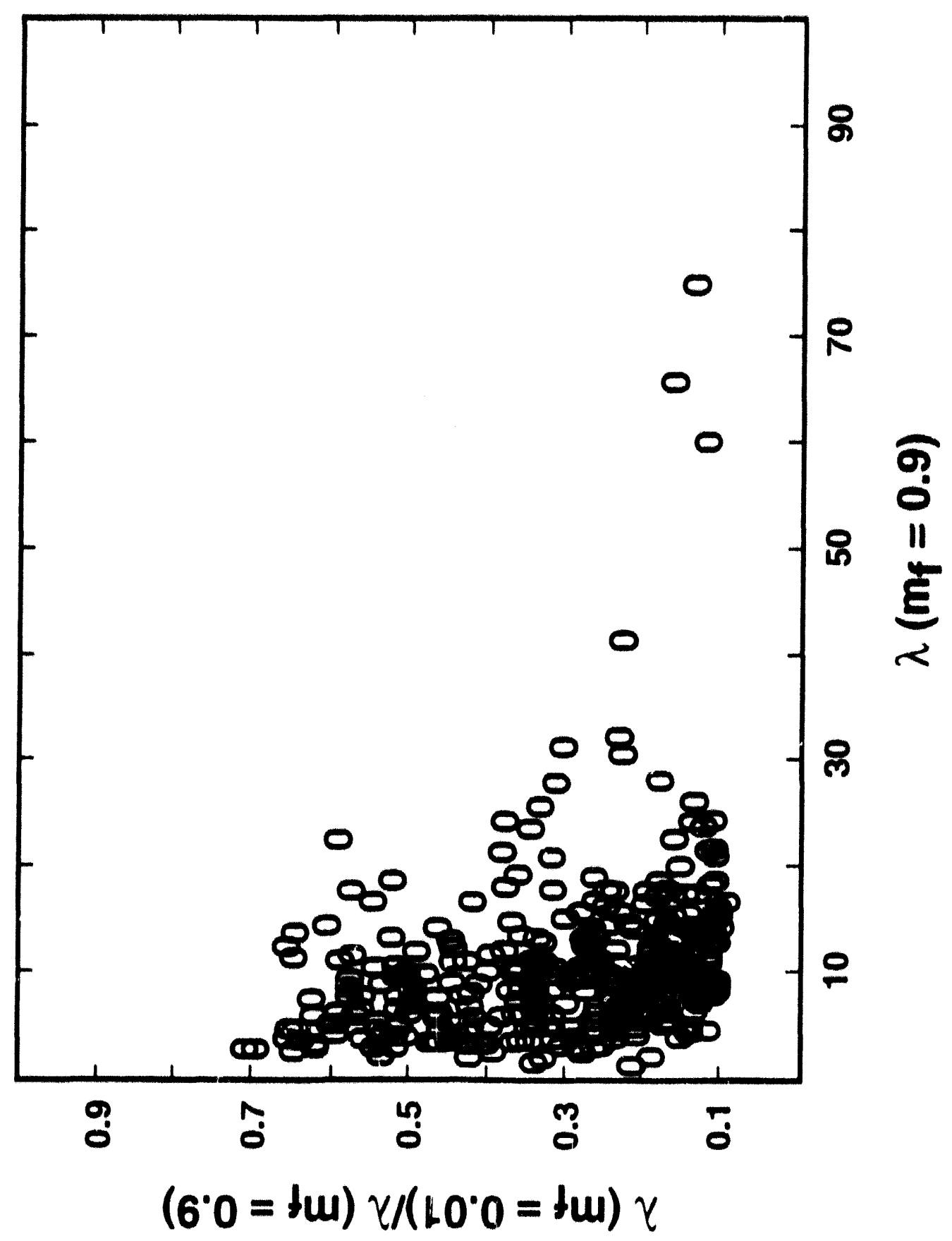




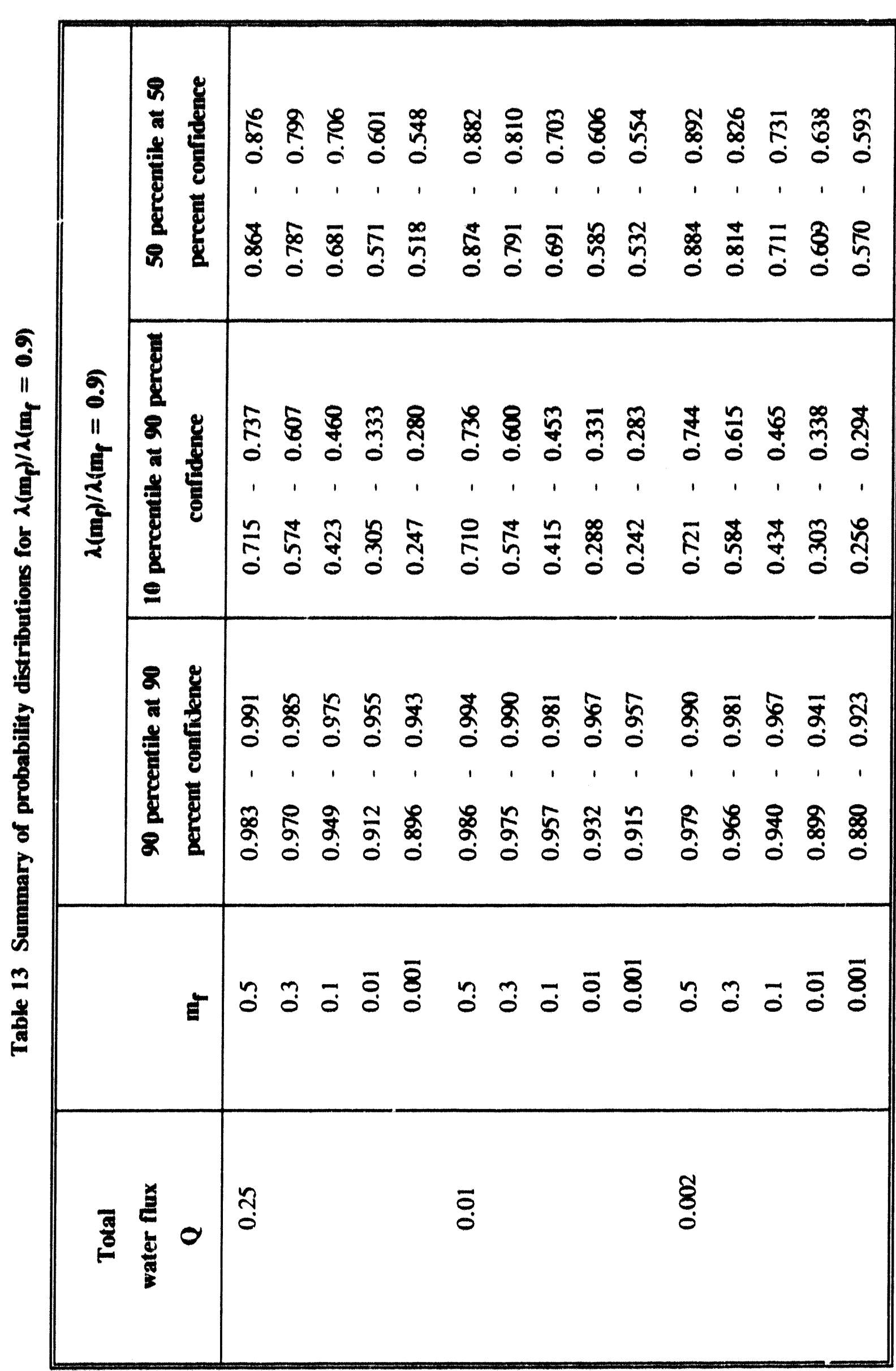

Sprays 
Sprays
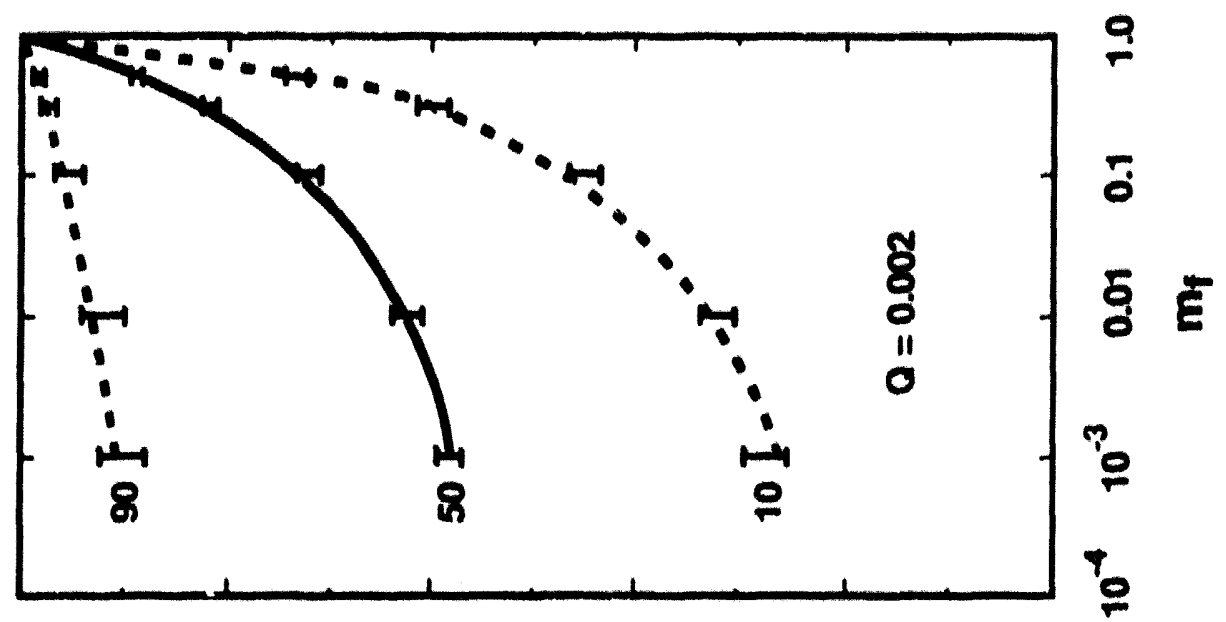

5

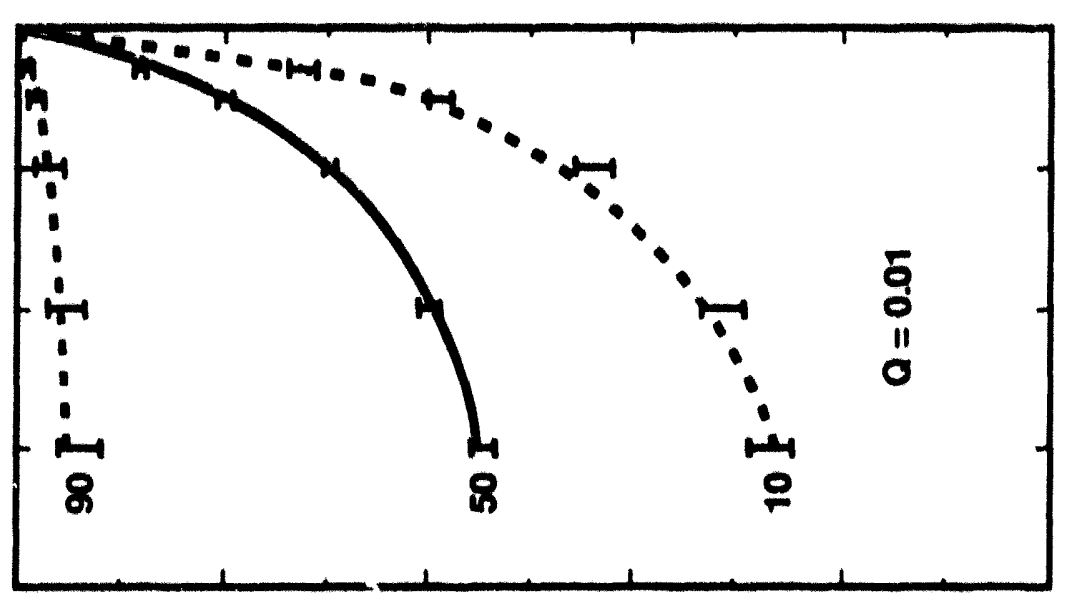

$?$

:

5

บุำ

115

? $\theta$ s

표

?

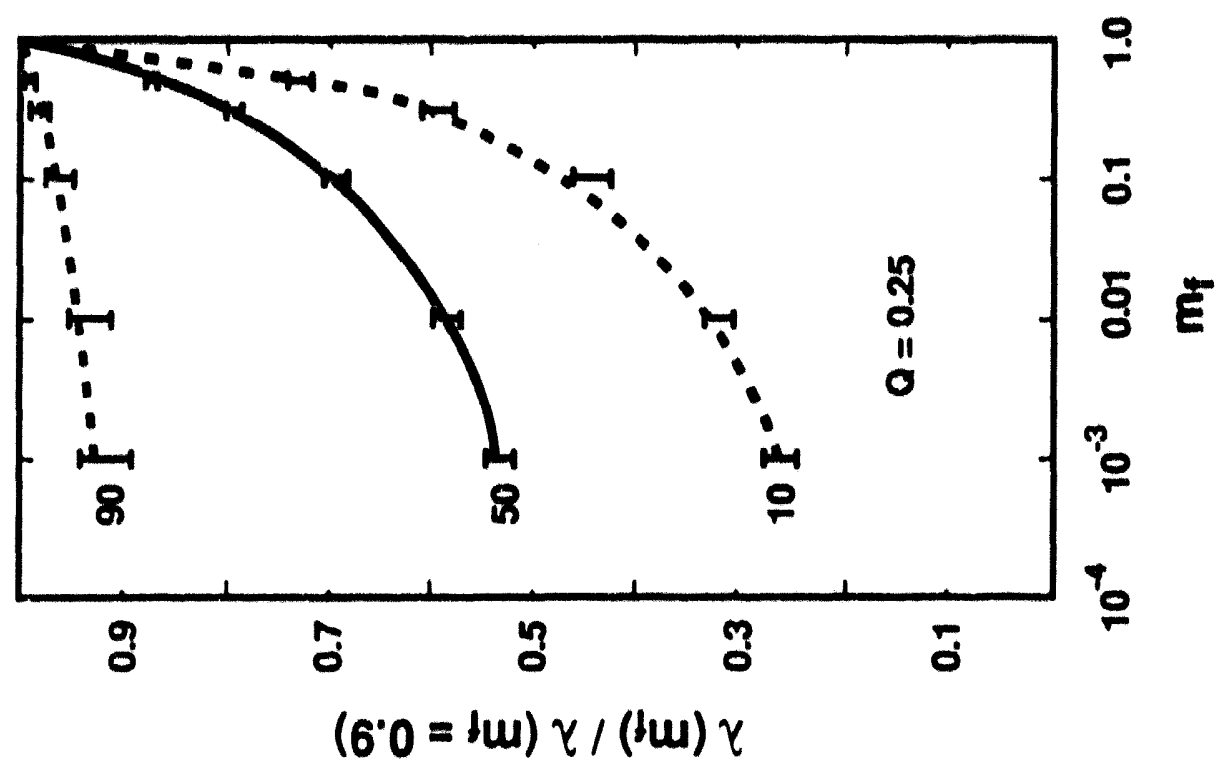

8

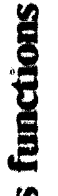


efficiency by spray droplets. Also, relative to aerosols injected into the drywell without passing through the water pool. the aerosols hypothesized here to be in the drywell initially have narrow size distributions. After some small amount of decontamination, an aerosol remaining in the drywell atmosphere is very narrowly distributed around the size of minimum trapping efficiency by the spray. Thereafter. there is only a small variation in the efficiency of aerosol trapping as decontamination progresses.

The values of the ratio $\lambda\left(m_{f}\right) / \lambda\left(m_{f}=0.9\right)$ may be compared to the recommendation [84] that the decontamination coefficient attributed to sprays be reduced by a factor of 10 once the decontamination factor exceeds $50\left(m_{f} \leqslant 0.02\right)$. It is e ident from the results shown in Figure 28 that such a sharp reduction in the decontamination coef cient would be quite a conservative estimate of the rate of atmosphere dcontamination. Even at the 10 percentile level, the decontamination coeficient has fallen by only about a factor of 3 from its initial value once the decontamination factor exceeds $50\left(m_{f} \leqslant 0.02\right)$.

A plot of $\lambda\left(m_{f}=0.9\right)$ against the water flux to the drywell atmosphere, Q. is shown in Figure 29. $\lambda\left(m_{f}=0.9\right)$ is not just linearly dependent on the water flux. As $Q$ increases the rate of water droplet coalescence to form larger water droplets that less efficiently trap aerosols increases more rapidly than the rate of droplet-particle interactions. It is also evident from results shown in this figure that spray decontamination of the small aerosol particles considered here is not very efficient. A principle interest of analyses done here is the rapid decontamination of the drywell atmosphere even if the drywell has been ruptured. At the highest water fluxes considered here, spray decontamination factors are large-enough to provide significant decontamination of the atmosphere over short periods of time ( $<15$ minutes). At water fluxes less than about $0.08 \mathrm{~cm}^{3} / \mathrm{cm}^{2}-\mathrm{s}$, spray decontamination coefficients become so small that significant additional decontamination of the atmosphere (DF 10) could be achieved only if drywell liner $\mu$ netration were delayed or the rupture of the drywell were small so the contaminated atmosphere is exposed to the spray for protracted periods.

Median values of $\lambda\left(m_{f}\right) / \lambda\left(m_{f}=0.9\right)$ are plotted in Figure 30 against the water flux to the drywell atmosphere. This ratio has only a very weak dependence on the magnitude of the water flux to the atmosphere.

\section{Effects of Unsprayed Volumes}

All of the discussions to this point have assumed implicitly that the entire aerosol-laden gas phase is exposed to the direct actions of spray droplets. This is certainly not the case in the Mark I boiling water reactor. Certainly, the volume within the pedestal support wall is not subjected to the spray. Also. spray headers are not at the top of drywell. In the case of the Brown's Ferry plant, spray headers are located at elevations 15.84 and 8.53 meters above the floor. The top of the drywell is $32.03 \mathrm{~m}$ above the floor.

It is likely that there will be very rapid mixing of the unsprayed volumes in the drywell with the volumes that are exposed to the actions of the spray. Displacement of gas by the falling spray as well as temperature differences between sprayed and unspray ed volumes will assure this mixing. If it is assumed that this mixing is rapid in comparison to the rate of decontamination, the spray decontamination coefficients are readily adjusted to account for the unsprayed volumes: 


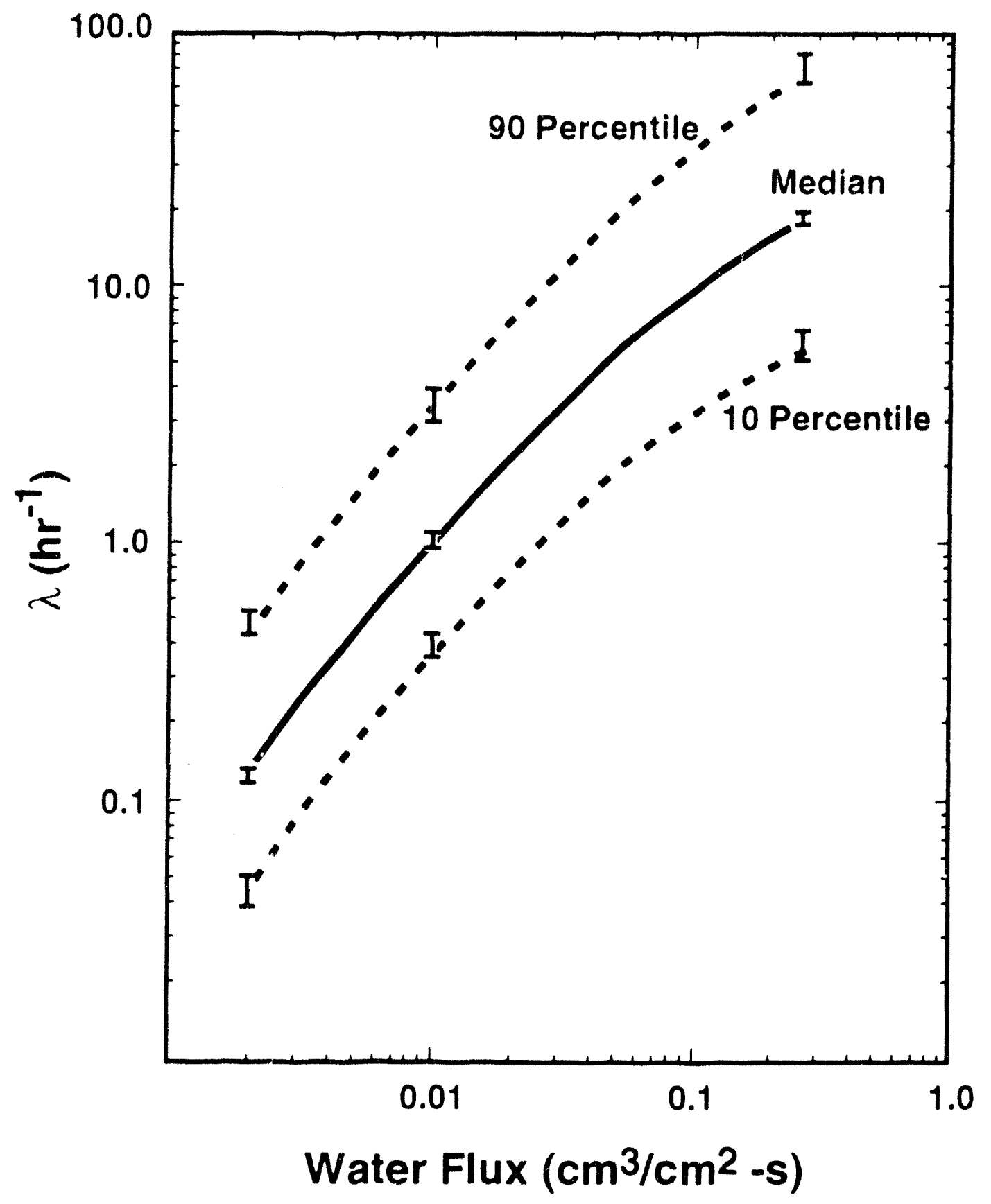

Figure $29 \lambda\left(m_{f}=0.9\right)$ as a function of water flux, $Q$ 


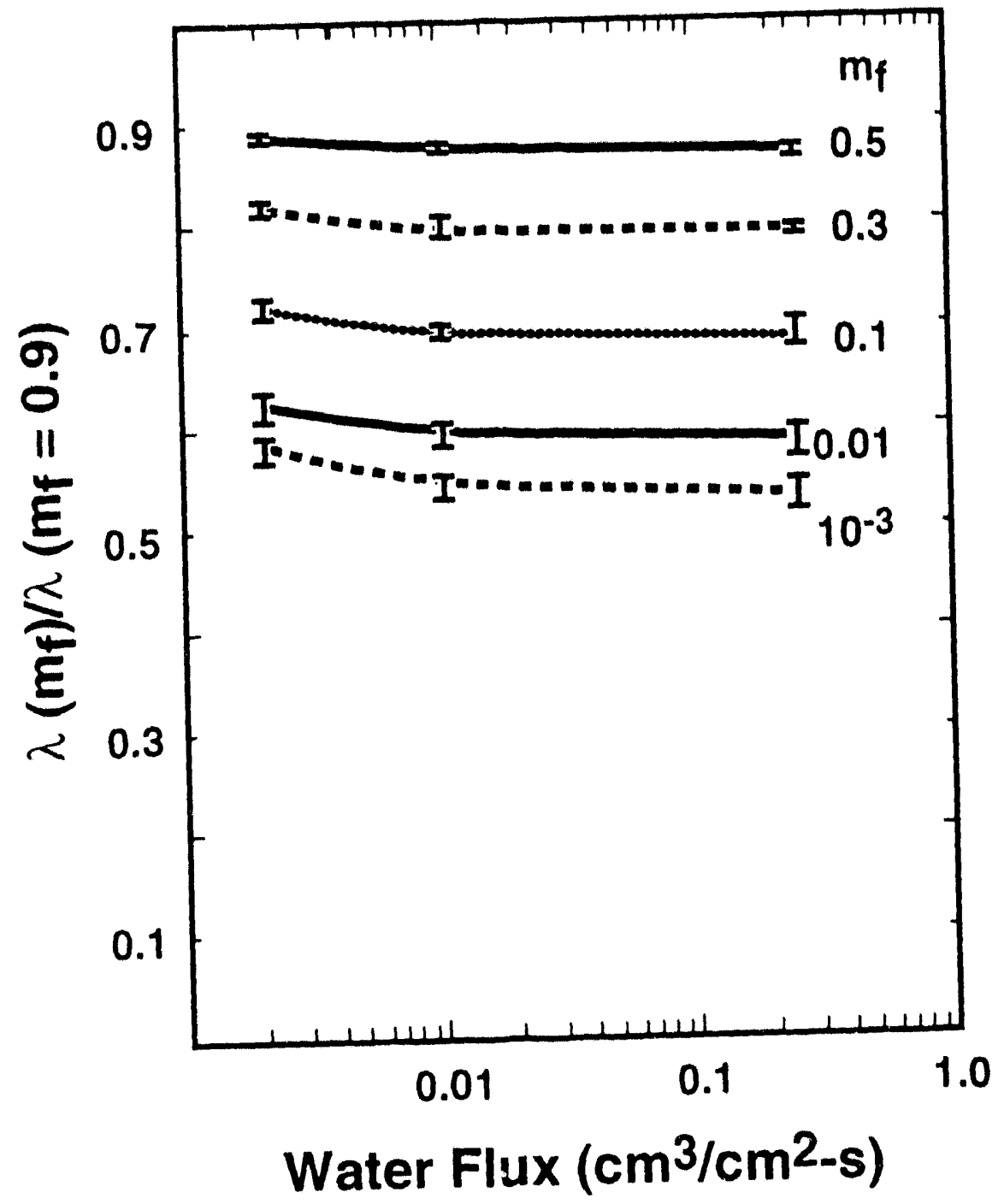

Figure 30 Median values of $\lambda\left(m_{f}\right) / \lambda\left(m_{f}=0.9\right)$ as functions of water flux, $Q$, for $m_{f}=0.5,0.3$, $0.1,0.01$, and 0.001 
Sprays

$$
\lambda(\text { real })=\lambda\left(Q, m_{f}\right) /(1+\alpha)
$$

where

$$
\begin{aligned}
\lambda(\text { real }) & =\begin{array}{l}
\text { the apparent decontamination coefficient for the drywell spray including the } \\
\text { effects of unsprayed volumes }
\end{array} \\
\lambda\left(\mathrm{Q}, \mathrm{m}_{\mathrm{f}}\right) & =\text { decontamination coefficient calculated here for the sprayed volume } \\
\alpha & =\mathrm{V} \text { (unsprayed) } / \mathrm{V} \text { (sprayed) }
\end{aligned}
$$

The ratio of sprayed to unsprayed volume is not easily calculated with confidence. For the Brown's Ferry plant the ratio of unsprayed volume to sprayed volume is about 2.6. Other values of this value might be found for other plants. The ratio is large-enough that the quantitative estimates of spray capabilities are affected. Qualitative conclusions that have been drawn above are not greatly affected.

\section{E. Simple Correlation of the Results}

The detailed, mechanistic analyses presented above and in the previous chapter provide quantitative predictions of the decontamination of the drywell atmosphere that can be achieved by sprays and the uncertainties that ought to be ascribed to these predictions. From these results, a reader can easily derive a qualitative indication of the effects sprays in the drywell might have on severe accident source terms. More quantitative insight could be obtained from simple correlations of the results in a form suitable for routine calculations. The results obtained above for $\lambda\left(m_{f}=0.9\right)$ may be correlated with a polynomial expression in the water flux to the drywell atmosphere, $Q$. The results for $\lambda\left(m_{\mathrm{f}}\right) / \lambda\left(\mathrm{m}_{\mathrm{f}}=0.9\right)$ may be correlated in terms of $\mathrm{Q}$ and the mass fraction of aerosol remaining in the drywell atmosphere, $m_{f}$. Such correlations, derived by least-squares analyses, are developed here for the median values at 50 percent confidence, the 90 percentile values at 90 percent confidence, and the 10 percentile values at 90 percent confidence. The curreiations are:

- Median (50 Percentile) Values at 50 Percent Confidence

$$
\begin{aligned}
\lambda\left(\mathrm{m}_{\mathrm{f}}=0.9\right) & =\mathrm{Q}\left[51.073+5759.2 \mathrm{Q}-22662 \mathrm{Q}^{2}\right] \\
\lambda\left(\mathrm{m}_{\mathrm{f}}\right) / \lambda\left(\mathrm{m}_{\mathrm{f}}=0.9\right) & =\left(0.50730-0.02055 \log _{10} \mathrm{Q}\right)(1-\mathrm{z})+\mathrm{z}
\end{aligned}
$$

where $z=\left(m_{f} / 0.9\right)^{0.491736}$ 
- 90 Percentile Values at 90 Percent Confidence

$$
\begin{gathered}
\lambda\left(\mathrm{m}_{\mathrm{f}}=0.9\right)=\mathrm{Q}\left[218.705+14133.3 \mathrm{Q}-55379.6 \mathrm{Q}^{2}\right] \\
\lambda\left(\mathrm{m}_{\mathrm{f}}\right) / \lambda\left(\mathrm{m}_{\mathrm{f}}=0.9\right)=\left(0.90531+0.00708 \log _{10} \mathrm{Q}\right)(1-\mathrm{z})+\mathrm{z}
\end{gathered}
$$

where $z=\left(m_{f} / 0.9\right)^{0.207615}$

- 10 Percentile Values at 10 Percent Confidence

$$
\begin{gathered}
\lambda\left(\mathrm{m}_{\mathrm{f}}=0.9\right)=\mathrm{Q}\left[17.446+2434.05 \mathrm{Q} \cdot 9617.81 \mathrm{Q}^{2}\right] \\
\lambda\left(\mathrm{m}_{\mathrm{f}}\right) / \lambda\left(\mathrm{m}_{\mathrm{f}}=0.9\right)=\left(0.27608-0.00284 \log _{10} \mathrm{Q}\right)(1-\mathrm{z})+\mathrm{z}
\end{gathered}
$$

where $z=\left(m_{\mathrm{f}} / 0.9\right)^{0.73410}$

Note that values of the decontamination coefficient derived from correlation should be corrected for the effects of unsprayed volumes in the drywell. If rapid mixing of the atmospheres of the sprayed and unsprayed volumes occurs, the correction is given by:

$$
\lambda=\lambda \text { (correlation) } /(1+\alpha)
$$

where

$$
\lambda=\text { corrected value of the spray decontamination coefficient }
$$

$\lambda($ correlation $)=$ value of the spray decontamination coefficient derived from any of the above correlations

$$
\alpha=V(\text { unsprayed }) / \mathrm{V} \text { (sprayed) }
$$

$V($ unsprayed $)=$ volume of the drywell that is not directly affected by the spray

$\mathrm{V}($ sprayed $)=$ volume of the drywell through which spray droplets fall.

These correlations will be utilized in an example accident analyses in Chapte: VI of this report. 
Sprays

\section{Accident Analyses}

The analyses of decontamination by an overlying water pool and the analyses of the decontamination coefficient of sprays presented above certainly indicate that some substantial source term reduction can be achieved if water is present in the Mark I boiling water drywell during a severe reactor accident. It is useful to have a quantitative indication of the magnitude of source term reduction by applying the results presented above to a specific reactor accident. Recent probablistic risk assessments [2] have shown that the risk dominant accidents in a particular Mark I boiling water reactor are anticipated transients without scram (ATWS) and station blackout accidents in which off-site and on-site AC power fails. The ex-vessel phases of thest two classes of hypothetical accidents are rather similar (see for instance Figure 4). Analyses here focus, then, on the ATWS type accident.

The predicted rates of aerosol generation by core debris interactions with concrete during an ATWS accident with no water in the drywell are shown in Figure 4. Aerosol generation is very intense for the first 2 to 3 hours of ex-vessel core debris interactions. At the maximum shown in Figure 4, aerosol generation rates reach nearly $1000 \mathrm{~g} / \mathrm{s}$. Once reactive zirconium metal in the core debris has been consumed by chemical reactions, the core debris temperature falls rapidly and the rate of aerosol production drops to 1 to $2 \mathrm{~g} / \mathrm{s}$.

Were the aerosols produced by the core debris interactions with concrete unable to settle or deposit in the Mark I drywell, aerosol concentrations shown by the curve marked "no mitigation" in Figure 31 would develop during the accident. Ten hours after the onset of core debris interactions with concrete aerosol, concentrations reach about $457 \mathrm{~g} / \mathrm{m}^{3}$. Most of the particulate materials suspended in the drywell atmosphere are products of concrete vaporization or are constituents of steel. Mixed with these materials can be a substantial amount of radionuclides from the core debris.

Aerosols lofted into the drywell atmosphere will, of course, agglomerate, deposit, and settle within the drywell. Barring some resuspension process," settled and deposited particles are removed from the inventory of aerosol that could escape into reactor building in the event the drywell integrity is lost by any mechanism (overpressurization, overheating or direct attack by the melt on the dry'well liner). Some indication of the magnitude of the effects of settling and deposition on aerosol concentrations is shown in Figure 31 by the curve marked "natural mitigation. " Natural mitigation processes reduce the peak aerosol concentration in the drywell from about $460 \mathrm{~g} / \mathrm{m}^{3}$ to about $46 \mathrm{~g} / \mathrm{m}^{3}$. At 10 hours after the start of core debris/concrete interactions, aerosol concentration in the drywell is only $0.75 \mathrm{~g} / \mathrm{m}^{3}$. The safety advantages of delaying drywell failure so that there is time for the natural mitigation processes to operate are apparent from these results.

Even when natural mitigation processes are considered, it is evident that substantial masses of radioactive material may be available for release if the drywell fails. It is of interest, then, to see what additional attenuation of the potential source term might be produced by water in the drywell. Both the effects of a water pool overlying the core debris and the effects of sprays are demonstrated below. For these demonstrations, aerosol concentrations are compared to the concentrations that would be present were

\footnotetext{
*Aerosols that settle onto the core debris could, presumably, revaporize. There has heen no attempt to take this into account in preparing Figure 31 .
}

NUREG/CR-5978 


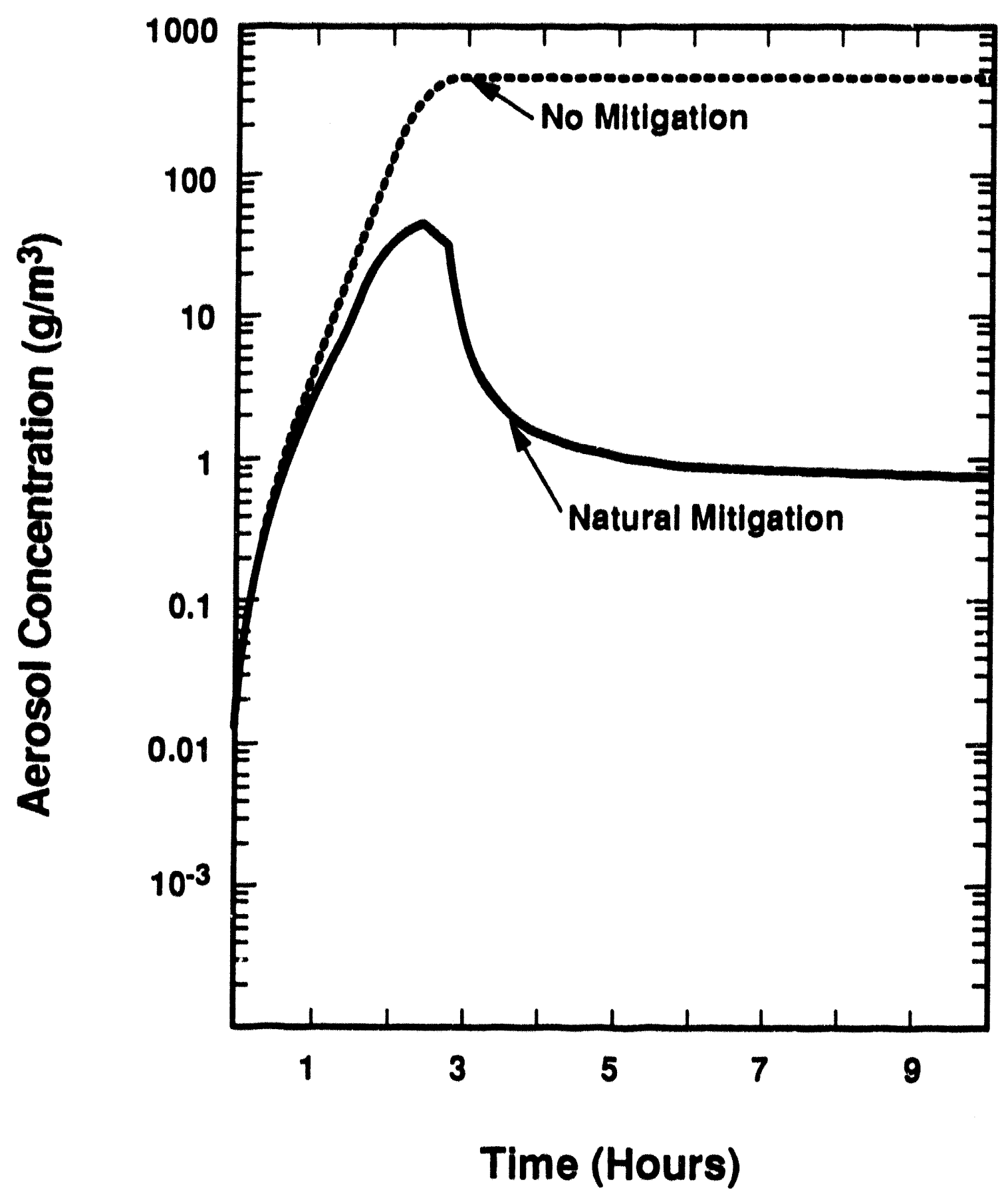

Figure 31 Aerosol concentrations in the drywell during an ATWS accident with no water present. The dashed curve marked "no mitigation" indicates concentrations that would exist if natural processes such as settling and deposition are neglected. The solid curve marked "natural mitigation" was calculated including these natural deposition processes. 


\section{Sprays}

there no natural mitigation by settling and deposition of aerosols. This type of comparison makes it more apparent how much aerosol mass is prevented from being available for release irrespective of the time at which a rupture in the drywell occurs.

First, the effect of an overlying water pool on the mass of aerosol available for release is considered. Only the decontamination effects of the water pool are considered here. Any effects an overlying water pool might have on reducing temperatures of the core debris, and consequently reducing the rates of aerosol generation, have been neglected here. The case of a $50 \mathrm{~cm}$ deep water pool subcooled by $20^{\circ} \mathrm{C}$. is shown in Figure 32. The 90 percentile, median and 10 percentile aerosol concentrations are shown in this figure. (These aerosol concentrations correspond, of course, to the 10,50, and 90 percentile pool decontamination factors, respectively.) The median decontamination factor produced by the $50 \mathrm{~cm}$ deep pool is about 180. Even in the very pessimistic case represented by the 90 percentile aerosol concentration, the water pool provides a decontamination factor of about 26. The 10 percentile aerosol concentration corresponds to a decontamination factor prodsced by the overlying water pool of almost 3000 .

Subcooling of the water fool is important in achieving high levels of decontamination. Results are shown in Figure 33 for the case of a $50 \mathrm{~cm}$ deep water pool with only $2^{\circ} \mathrm{C}$ subcooling. The median decontamination factor in this case is only about 16. The 10 and 90 percentile aerosol concentrations correspond to decontamination factors by the water pool of about 8.3 and about 4.8 , respectively.

Increasing the depth of the water pool will, of course, increase the extent of decontamination. The effect is not, however, especially large until depths in excess of about I meter are reached. Such water pool depths could be produced in the Mark I drywell only by filling the wetwell with water.

It might be argued that subcooling, even by only 20 degrees, necessary to achieve large decontamination coefficients by water pools might be difficult to maintain early in the ex-vessel phase of an accident when inost of the aerosol release occurs. Or, it might be contended that the violence of the early stages of core debris interactions with concrete could disrupt the water pool so that evolved streams of aerosolladen gas are not efficiently scrubbed. Evidence from tests of combined core debris-concrete-coolant interactions done to date $[16,22,46,51,52]$ indicate that any violent disruption of the water pool takes place only for a brief period. Extrapolation of these results to reactor accident conditions is, of course, uncertain. Furthermore, recent tests $[51,52]$ suggest that there can be episodic eruptions of melt into a well-established water pool that might, in extreme cases, result in, at least, localized disruption of the water pool. For these reasons the incremental decontamination of the drywell by sprays is of interest. Spray would, of course, also scrub from the atmosphere aerosols that were not exposed to the overlying water pool.

To illustrate the effects of sprays, it is assumed that a $50 \mathrm{~cm}$ deep water pool, subcooled by only $2^{\circ} \mathrm{C}$, is maintained over the core debris and that the decontamination efficiency of this pool is at the pessimistic 10 percentile level. Aerosol concentrations in the drywell atmosphere with sprays operating at a water flux of $0.25 \mathrm{~cm}^{3} / \mathrm{cm}^{2}-\mathrm{s}$ are shown in Figure 34 . The spray was assumed to contact only 28 percent of the containment volume. (Note that the drywell volume during the ex-vessel stage of the accident includes the volume of the reactor coolant system and the reactor vessel). The median aerosol concentration curve show'n in this figure has a maximum aerosol concentration of $3.4 \mathrm{~g} / \mathrm{m}^{3}$. This corresponds to an overall decontamination factor of about 134. After 10 hours of core debris interactions with concrete, the aerosol concentration is reduced to about $5.3 \times 10^{-3} \mathrm{~g} / \mathrm{m}^{3}$. The overall 


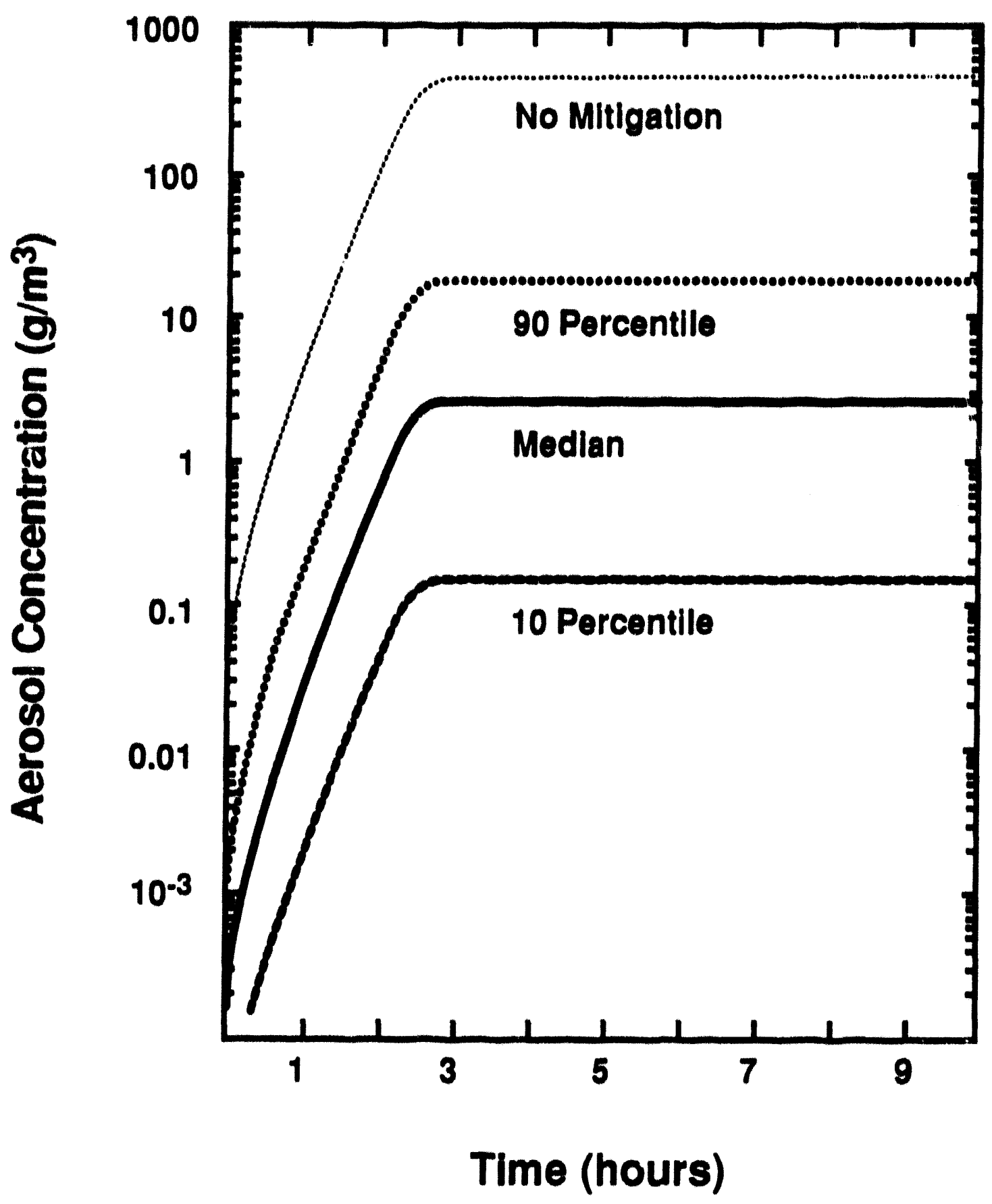

Figure 32 Aerosol concentrations in the drywell when a $50 \mathrm{~cm}$ deep water pool subcooled by $20^{\circ} \mathrm{C}$ is maintained over the core debris. The median (solid line), 90 percentile (dashed line) and 10 percentile (dotted line) concentrations are compared to concentrations for the case when no water pool is present. 


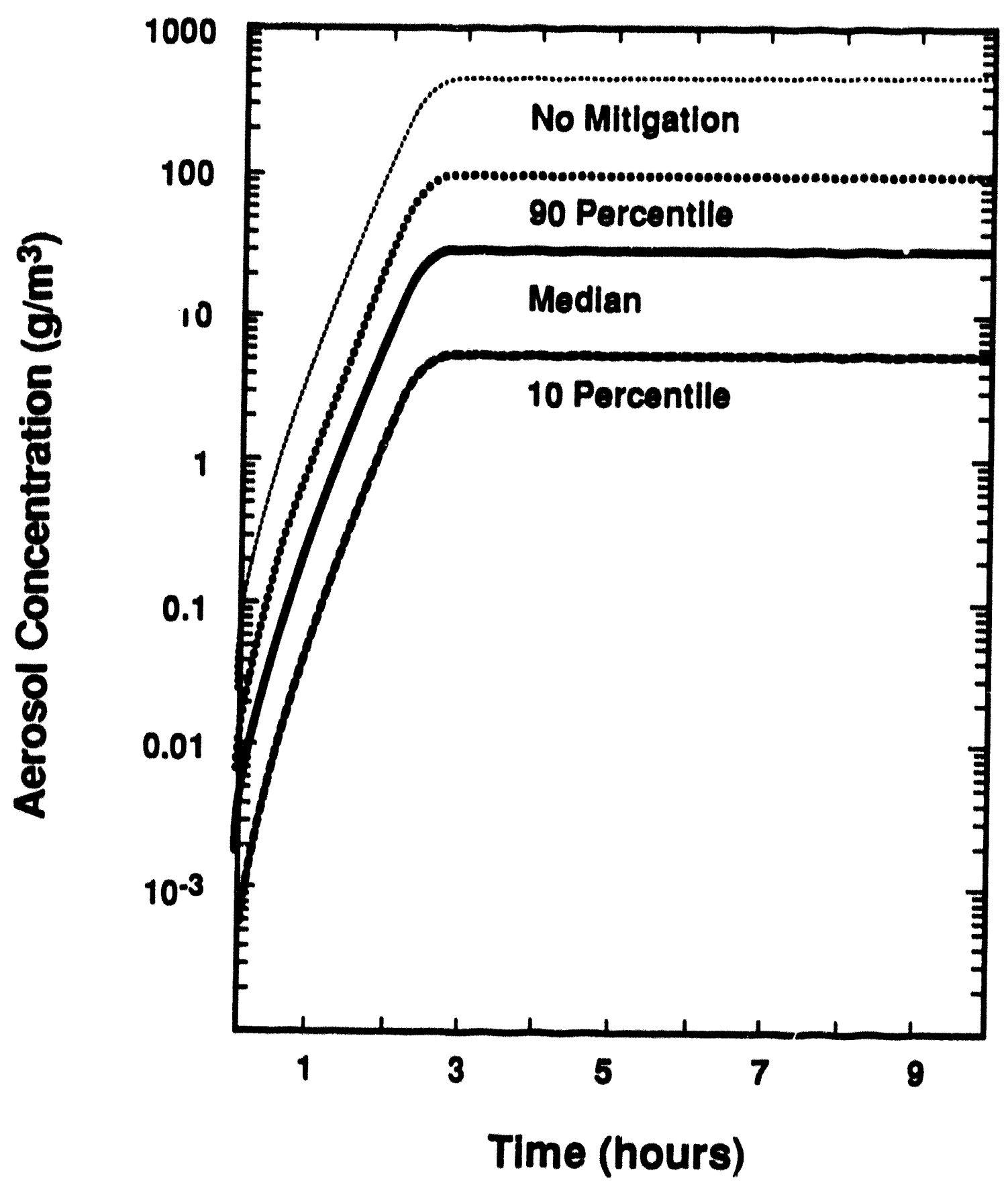

Figure 33 Aerosol concentrations in the drywell when a $50 \mathrm{~cm}$ deep water pool subcooled by only $2^{\circ} \mathrm{C}$ is maintained over the core debris. The median (solid line), 90 percentlle (dashed line) and 10 percentlle (dotted line) concentrations are compared to concentrations for the case of no water pool present. 


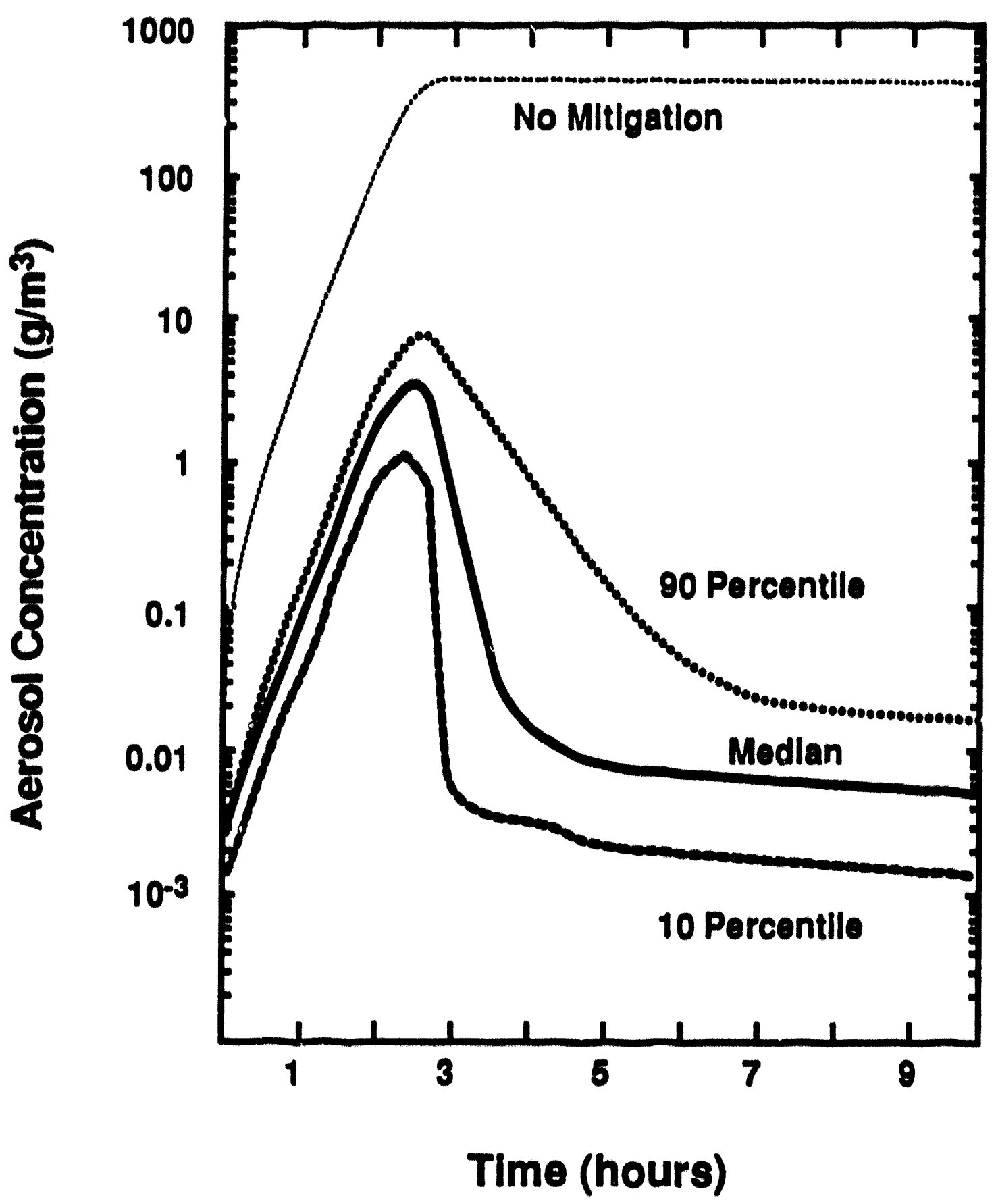

Figure 34 Effects of sprays on aerosol concentrations in the drywell atmosphere. A $50 \mathrm{~cm}$ deep water pool, subcooled by $2^{\circ} \mathrm{C}$ was assumed to be present. Sprays were assumed to supply a water nux of $0.25 \mathrm{~cm}^{3} / \mathrm{cm}^{2}-\mathrm{s}$. 
Sprays

decontamination factor at this time is about $8.6 \times 10^{4}$. The apparent, overall, decontamination factor increases with time because aerosols suspended in the drywell atmosphere continue to be exposed to the spray. Though sprays do not have as immediate effect on aerosol concentrations as water pools, the effects of sprays accumulate with time. Delaying drywell failure or limiting drywell failure to a small leak greatly improves the effectiveness of sprays at source term mitigation.

Reduction in the spray flow rate, of course, redices spray effectiveness. Results are shown in Figure 35 for a spray operating at a water flux of only $0.01 \mathrm{~cm}^{3} / \mathrm{cm}^{2} \cdot \mathrm{s}$ and other conditions the same as they were for calculations used to prepare Figure 34. The median aerosol concentration curve has a maximum at about $13.5 \mathrm{~g} / \mathrm{m}^{3}$. The 10 and 90 percentile concintrations reach maxima of about 9.8 and $14.9 \mathrm{~g} / \mathrm{m}^{3}$. Late in the course of the core debris interactions with concrete the 90,50 and 10 percentile aerosol concentrations are calculated to be about $7.4,1.6$, and $0.0368 / \mathrm{m}^{3}$, respectively.

The relatively high concentrations of aerosol that are calculated here to exist even with the spray operating (albeit at lower water fluxes) arise because aerosol particles are too small to be efficiently removed by spray droplets. At these higher concentrations, the aerosols would agglomerate. As this agglomeration progresses, the efficiency of particle removal by sprays would improve in comparison to what has been calculated here neglecting particle agglomeration. Nevertheless, it is evident that low water flux spray operations do not greatly augment the decontamination effect achieved by water pools overlying core debris. Certainly, low water flux spray operation does not produce a prompt decontamination that would be important for source term mitigation after drywell failure.

To summarize the findings of the accident analysis, a comparison of the effects of various mitigation processes is shown in Figure 36. Shown in this figure are aerosol concentrations in the drywell during an ATWS accident considering:

1. no mitigation processes,

2. mitigation by natural processes of settling and agglomeration,

3. natural processes supplemented by the effects of a $50 \mathrm{~cm}$ deep $20^{\circ} \mathrm{C}$ subcooled water pool (median value of the decontamination factor), and

4. natural processes supplemented by the effects of both the water pool and sprays operated at $0.25 \mathrm{~cm}^{3} / \mathrm{cm}^{2}$-s (median value of the decontamination factor).

By far the biggest reduction in the aerosol mass produced promptly in the first 1 or 2 hours is that provided by the water pool. The incremental effect of sprays in this early period is not espeically large. Sprays, and to a lesser extent the "natural" aerosol removal processes, have, howcver, an accumulating effect on aerosol concentrations. With continued operation sprays continue to decontaminate the atmosphere. Depending on when drywell failure occurs, these example calculations indicate that the combination of a subcooled water pool and high water flux sprays could reduce the amount of radioactivity released after drywell failure by factors of 4000 to over $10^{5}$. 
Sprays

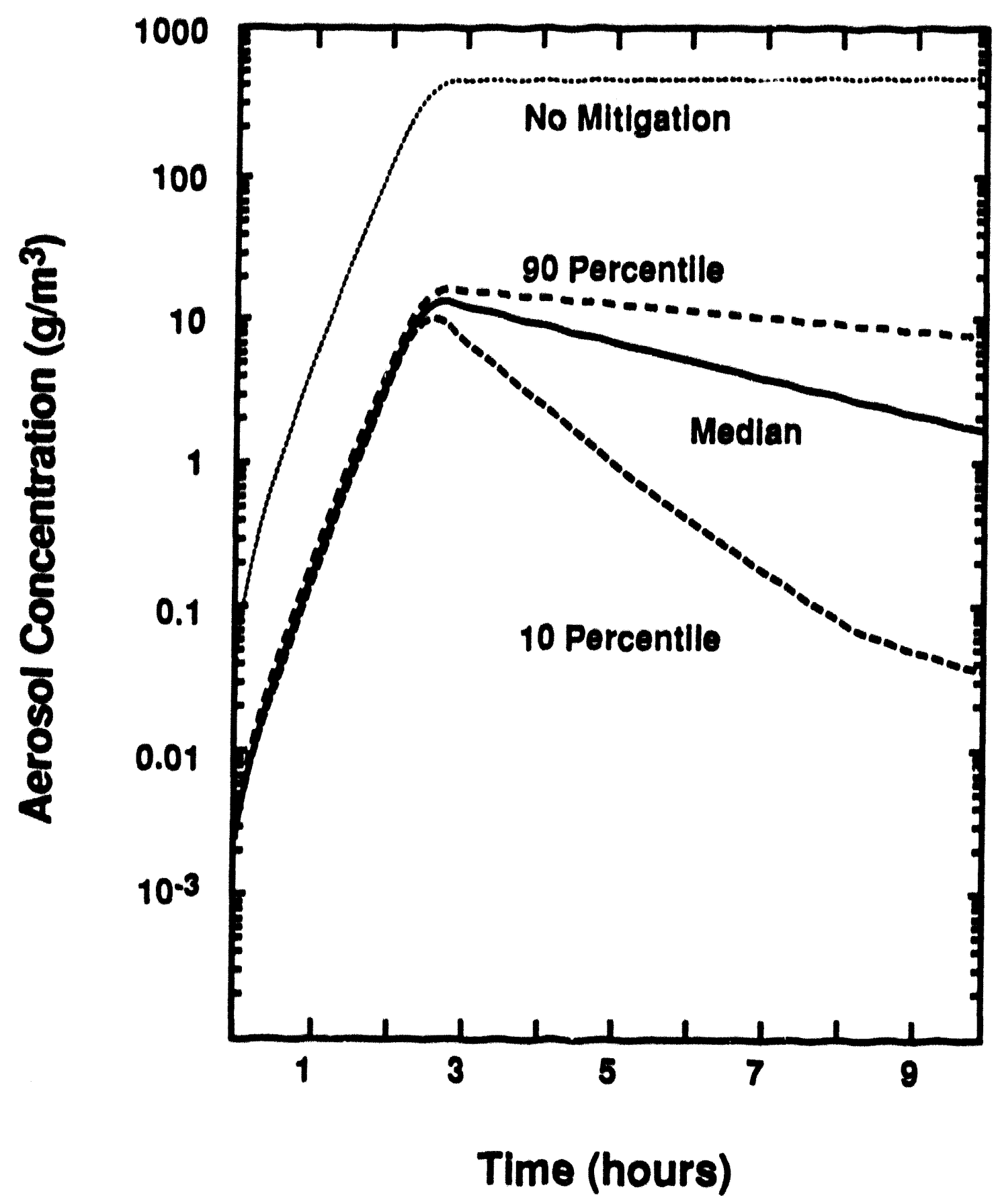

Figure 35 Effects of sprays operated at a water flux of $0.01 \mathrm{~cm}^{3} / \mathrm{cm}^{2}-\mathrm{s}$ on aerosol concentrations in the drywell. $A$ water pool $50 \mathrm{~cm}$ deep and $2{ }^{\circ} \mathrm{C}$ subcooled was assumed to be present. 


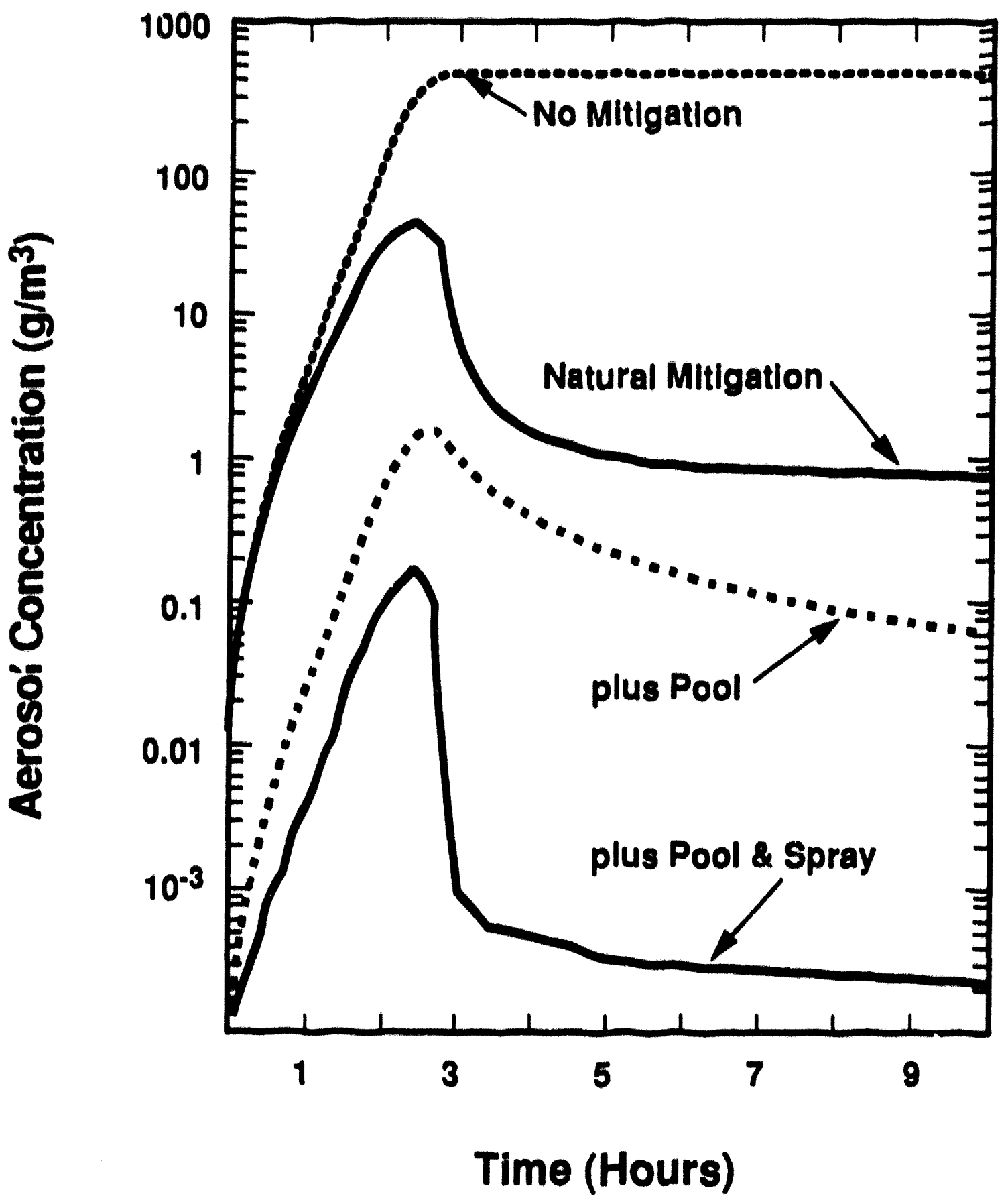

Figure 36 Comparison of aerosol concentrations considering various mitigation processes. The dotted curve was calculated neglecting any miltigation, the curve marked natural mitigation was calculated by aerosol settling and deposition. The other curves were calculated considering mitigation by a $50 \mathrm{~cm}$ deep $20^{\circ} \mathrm{C}$ subcooled water pool alone and in conjunction with a spray operated at $0.25 \mathrm{~cm}^{3} / \mathrm{cm}^{2}-\mathrm{s}$. 


\section{Conclusions}

The principal conclusion that can be reached from the analyses presented in this report is that water in the Mark I drywell can reduce substantially the reactor accident source term in the event of drywell rupture. That is, water in the drywell can reduce the risks of severe reactor accidents even if the water cannot prevent or delay the rupture of the drywell. Water can reduce the amount of radioactive material suspended in the the drywell atmosphere and available for release should containment fail by direct melt attack, overpressurization or as result of excessive temperatures.

Attenuation of the releases of radioactive materials by an overlying water pool during core debris interactions with concrete is the most important process by which drywell water reduces the severe accident source term. The key to achieving high levels of decontamination by shallow water pools in the Mark I drywell is substantial subcooling of the water. If median values of the uncertain decontamination factors calculated for water pools are considered, then releases of radioactivity during core debris, concrete interactions can be reduced by a factor of about 180 with a $50 \mathrm{~cm}$ deep watcr pool that is kept subcooled by about $20^{\circ} \mathrm{C}$. Allowing the pool to become saturated reduces the source term mitigation to about a factor of 16. More pessimistic views of the uncertainties in the predictions of decontamination by a water pool overlying core debris still indicates that a $50 \mathrm{~cm}$ deep pool with $20^{\circ} \mathrm{C}$ subcooling can reduce releases of radioactive materials during core debris interactions with concrete by factors of about 26.

Whereas water pools overlying core debris in the Mark I drywell only affect the radionuclide releases during core debris interactions with concrete, drywell sprays can attenuate radionuclide inventories in the diywell atmosphere from all sources. That is, drywell sprays can reduce the inventory of radionuclides suspended in the containment atmosphere as a result of core debris/concrete interactions, revaporization, and releases from residual fuel in the reactor coolant system. Drywell sprays lose effectiveness as aerosol particles become small. Only at high water fluxes do the sprays significantly augment the prompt attenuation by water pools of radionuclide releases during core debris/concrete interactions. Protracted exposure of aerosols to the action of sprays can produce very large reductions in the amounts of radioactive material available for release in the event of drywell rupture.

Simple correlations of the results obtained here can be used to prepare estimates of decontamination by water pools and sprays in the Mark 1 drywell at prescribed levels of conservatism and confidence.

A decision to assure water is present in the drywell during a severe reactor accident to protect the integrity of the drywell liner would have the derivative benefit of reducing the magnitude of radionuclide release to the reactor building should the drywell fail. Most of the potential attenuation of the severe accident source term comes from a water pool overlying the core debris interacting with concrete. Admission of water to the drywell by sprays could augment the source term attenuation. The augmentation provided by the sprays could be important if:

- the drywell water pool could not be kept subcooled,

- there was extensive, late, release of coarse aerosols from residual fuel in the reactor vessel directly to the drywell atmosphere, or

- there was extensive revaporization of deposited fission products from the reactor coolant system after reactor vessel failure. 


\section{References}

1. U.S. Nuclear Regulatory Commission, Reacto: Safety Study: An Assessment of Accident Risks in U.S. Commercial Nuclear Power Plants, WASH1400, NUREG-75/14, 1975.

2. Office of Nuclear Kegulatory Research, Severe Accident Risks: An Assessment for Five U.S. Nuclear Power Plants, NUREG-1150, Vols, 1 and 2, U.S. Nuclear Regulatory Commission (Second Draft for Peer Review), Washington, D.C., June 1989.

3. A. T. Wassel, A. F. Mills, D. C. Bugby, and R. Oehlberg, Nuclear Engineering and Design, 90 (1985) 87.

4. P. C. Owczarski, A. K. Postma, and R. L. Schrek, Technical Bases and User's Manual for SPARC-A Suppression Pool Aerosol Removal Code, NUREG/CR-3317, PNL-4742, Pacific Northwest Laboratory, Richland, WA, 1983.

5. P. N. Clough, S. A. Ramsdale, and P. N. Smith, "Aerosol Decontamination Factors in Pools Overlying Molten Core-Concrete-Code Modeling," Proceedings OECD(NEA) CSNI Specialists' Meeting on Core Debris/Concrete Interactions, EPRI Electric Power Research Institute, Palo Alto, CA, February 1987.

6. L. G. Griemann, F. Famous, A. Wold-Tinsai, D. Ketalaar, T. Lin, and D. Bluhm, Reliability Analysis of Steel Containment Strength, NUREG/CR-2442, 1984.

7. R. S. Denning et al., Radionuclide Release Calculations for Selected Severe Accident Scenarios, NUREG/CR-4624, BMI-2139, Vol. 1, Battelle's Columbus Division, Columbus, Ohio, July 1986.

8. Office of Nuclear Reactor Regulation, Estimates of Early Containment Loads From Core Melt Accidents, NUREG-1079, U.S. Nuclear Regulatory Commission, Washington, D.C., December 1985.

9. D. H. Cook et al., Station Blackout at Brown's Ferry Unit One - Accident Sequence Analysis, NUREG/CR-2182, Oak Ridge National Laboratory, Oak Ridge, TN, November 1981.

10. D. H. Cook et al., Loss of DHR Sequence at Brown's Ferry Unit One - Accident Sequence Analysis, NUREG/CR-2973, Oak Ridge National Laboratory, Oak Ridge, TN, May 1983.

11. G. A. Greene, K. R. Perkins, and S. A. Hodge, "Mark I Containment Drywell - Impact at Core/Concrete Interactions on Containment Integrity and Failure of the Drywell Liner, " IAEA-SM281/36, pp. 429-442, Source Term Evaluation for Accident Conditions, International Atomic Energy Agency, 1986.

12. Approximate Source Term Methodology for Boiling Water Reactors, FAI/86-1, Fauske and Associates, Inc., Burr Ridge, IL, December 1986. 
13. J. J. Weingardt and K. D. Bergeron, TAC2D Studies of Mark I Containment Drywell Shell MeltThrough, NUREG/CR-5126, SAND88-1407, Sandia National Laboratories, Albuquerque, NM, August 1988.

14. N. T. Pratt et al., Assessment of Severe Accident Prevention and Mitigation Features: BWR. Mark I Containment Design, NUREG/CR-4920, BNL-NUREG-52070, Vol. 1. Brookhaven National Laboratory. Upton, NY, March 1988.

15. T. G. Theofanous, W. H. Amarasooriya, H. Yan, and U. Ratman, The Probability of Liner Failure in a Mark I Containment, NUREG/CR-5423. University of California, Santa Barbara, CA, July 1989.

16. R. E. Blose et al., Swiss 1 and 2: Sustained Interaction of Molten Stainless Steel and Concrete in the Presence of Water. NUREG/CR-4727, SAND85-1546, Sandia National Laboratories, Albuquerque, NM, July 1987.

17. D. A. Powers and J. L. Sprung, A Simplified Model of Aerosol Scrubbing by a Water Pool Overlying Core Debris Interacting With Concrete, NUREG/CR-5901, SAND92-1422, Sandia National Laboratories, Albuquerque, NM, October 1992.

18. D. A. Powers and S. B. Burson, A Simplified Model of Aerosol Removal by Containment Sprays, NUREG/CR-5966, SAND92-2689, Sandia National Laboratories, Albuquerque, NM, December 1992.

19. D. A. Powers and R. C. Schmidt, "Analysis of Revaporization of Deposited Radionuclides," in Evaluation of Accident Risks Volume 2. Appendices, Part 5. Supporting Calculations, NUREG/CR-4551, Rev. 1, Sandia National Laboratories, Albuquerque, NM, draft available in NRC Public Document Room.

20. D. A. Powers and J. E. Brockmann, "An Analysis of Aerosol Transport Through a Ruptured Stean Generator Tube," in Evaluation of Accident Risks Volume 2. Appendices, Part 5. Supporting Calculations, NUREG/CR-4551, Rev. 1, Sandia National Laboratories, Albuquerque, NM, draft available in NRC Public Documents Room.

21. D. A. Powers, "A Probabilistic Method for the Evaluation of Severe Accident Source Term Uncertainties," pp. 1173-1178, Vol. 2, Probabilistic Safety Assessment and Management, G. Apostolakis, editor, Elsevier, 1991.

22. E. R. Copus, "Quick Look Data Report - WETCOR-1 Test," Sandia National Laboratories, Albuquerque, NM, October 1991.

23. DOE/ARSAP, Technical Support for the Debris Coolability Requirements for Advanced Light Water Reactors in the Utility/EPRI Light Water Reactor Requirements Document, DOE/ID-10278, Fauske and Associates, Inc., Burr Ridge, IL, June 1990. 
References

24. R. J. Lipinski et al., Uncertainty in Radionuclide Release Under Specific LWR Accident Conditions, Vols. I-IV, SAND84-410, Sandia National Laboratories, Albuquerque, NM, May 1984.

25. D. A. Powers, J. E. Brockmann, and A. W. Shiver, VANESA: A Mechanistic Model of Radionuclide Release and Aerosol Generation During Core Debris Interactions With Concrete, NUREG/CR-4308, SAND85-1370, Sandia National Laboratories. Albuquerque, NM, July 1986.

26. R. Clift, J. R. Grace, and M. E. Weber, Bubbles, Drops, and Particles, Academic Press, 1978.

27. D. A. Powers, An Analysis of Radionuclide Behavior in Water Pools During Accidents at the Annular Core Research Reactor, SAND91-1222, Sandia National Laboratories, Albuquerque, NM, April 1992.

28. J. E. Brockmann, F. E. Arellano, and D. A. Lucero, Validation of Models of Gas Holdup in the CORCON Code, NUREG/CR-5433, SAND89-1951, Sandia National Laboratories, Albuquerque, NM, December 1989.

29. W. Fritz, Physik, 36(1965)379.

30. F. G. Blottner, Hydrodynamics and Heat Transfer Characteristics of Liquid Pools With Bubble Agitation, NUREG/CR-0944, SAND79-1132, Sandia National Laboratories, Albuquerque, NM, November 1979.

31. J. F. Davidson and B.O.G. Schuler, Trans. Inst. Chemical Eng., 38 (1960) 335.

32. I. A. Vakhrushev and G. I. Efremor, Chemical Technology Fuels Oils (USSR), 5/6 (1970) 376.

33. J. R. Grace, T. Wairegi, and T. H. Nguyen, Trans. Inst. Chemical Eng., 54 (1976) 167.

34. V. G. Levich, Physicochemical Hydrodynamics, Prentice Hall Publishing Co., 1962.

35. J. E. Brockmann, "Ex-Vessel Releases: Aerosol Source Terms in Reactor Accidents," Progress in Nuclear Energy, 19 (1987) 7.

36. Chemicai Engineers' Handbook, 4th Edition, R. H. Perry, C. H. Chilton, and S. D. Kirkpatrick, editors, McGraw-Hill Book Co., 1963.

37. Handbook of Chemistry and Physics, 45th Edition, R. C. Weast, editor-in-chief, The Chemical Rubber Publishing Co., Cleveland, OH, 1964.

38. D. A. Powers and F. E. Arellano, Large-scale, Transient Tests of the Interactions of Molten Steel With Concrete, NUREG/CR-2282, SAND81-1753, Sandia National Laboratories, Albuquerque, NM, January 1982.

39. L. A. Kent, Water Release From Heated Concrete, NUREG/CR-2279, SAND81-1732, Sandia National Laboratories, Albuquerque, NM, March 1982. 
40. J. F. Muir, Response of Concrete Exposed to a High Heat Flux on One Surface, SAND77-1467, Sandia National Laboratories, Albuquerque, NM, 1977.

41. H. J. Sutherland, Nuclear Technology, 46 (1979) 350.

42. E. R. Copus et al., Core-Concrete Interactions Using Molten Urania With Zirconium on a Limestone Concrete Basemat: The SURC-1 Experiment, NUREG/CR-5443, SAND90-0087. Sandia National Laboratories, Albuquerque, NM, April 1992.

43. E. R. Copus and D. R. Bradley, Interactions of Hot Solid Core Debris With Concrete, NUREG/CR-4558, SAND85-1789, Sandia National Laboratories, Albuquerque, NM, June 1986.

44. E. R. Copus et al., Experimental Results of Core-Concrete Interactions Using Molten 2 Steel With Zirconium, NUREG/CR-4794, SAND86-2638, Sandia National Laboratories, Albuquerque, NM, July 1990.

45 E. R. Copus et al., Core-Concrete Interactions Using Molten Steel With Zirconium on a Basaltic Basemat: The SURC-4 Experiment, NUREG/CR-4994, SAND87-2008, Sandia National Laboratories, Albuquerque, NM, April 1989.

46. W W. Tarbell et al., Sustained Concrete Attack by Low-Temperature, Fragmented Core-Debris, NUREG/CR-3024, SAND82-2476, Sandia National Laboratories, Albuquerque, NM, July 1987.

47. D. A. Powers and F. E. Arellano, Direct Observation of Melt Behavior During High Temperature Melt/Concrete Interactions, NUREG/CR-2283, SAND81-1754, Sandia National Laboratories, Albuquerque, NM, January 1982.

48. D. A. Powers et al., Exploratory Study of Molten Core Material/Concrete Interactions, SAND772042, Sandia National Laboratories, Albuquerque, NM, February 1978.

49. S. S. Kutateladze and I.G. Malenkov, High Temperature, 14 (1976) 703.

50. D. R. Bradley et al., CORCON-Mod3: An Integrated Computer Model for Analysis of Molten Core-Concrete Interactions: User's Manual, NUREG/CR-5843, SAND92-0167, Sandia National Laboratories, Albuquerque, NM, April 1993.

51. M. Fischer et al., "MACE Scoping Test Data Report," ACE-TR-D3, Argonne National Laboratory, Argonne, IL, March 1991.

52. R. E. Blose, D. A. Powers, E. R. Copus, J. E. Brockmann, R. B. Simpson, and D. A. Lucero, Core-Concrete Interactions with Overlying Water Pool: WETCOR-1, NUREG/CR-5907, SAND92-1563, Sandia National Laboratories, Albuquerque, NM, March 1993.

53. F. Herning and L. Zipperer, Gas Wasserfach, 79 (1936) 49-73. See also P. K. Tondon and S. C. Saxena, Indian J. Pure Appl. Phys., 6 (1968) 475. 
References

54. T. G. Theofanous, "Dealing With Phenomenological Uncertainties in Severe Accident Assessments and Probabilistic Risk Analyses," Proceedines 3rd Intemational Topical Meetine on Nuclear Power Plant Thermal Hydraulics and Operations. November 14-17, 1988, Seoul, South Korea, 1989.

55. W. E. Kastenberg et al., Findings of the Peer Review Panel on the Draft Reactor Risk Reference Document. NUREG-1150, NUREG/CR-5113, UCID-21345, Lawrence Livermore National Laboratory, Livermore, CA, May 1988.

56. I. Cook and S. Unwin, Nuclear Science and Engineering, 24 (1986) 107.

57. J. E. Brockmann, "Range of Possible Dynamic and Collision Shape Factors," Appendix F in R. J. Lipinski et al., Uncertainty in Radionuclide Release Under Specific LWR Accident Conditions Volume II. TMLB' Analysis, SAND84-410, Vol. 2, Sandia National Laboratories, Albuquerque, NM, February 1985.

58. D. E. Knuth, Seminumerical Algorithms, Second Edition, Addison-Wesley Publishing Co., 1981.

59. L. D. Reed, H. Jordan, and J. A. Gieseke, L.Aerosol Science 8 (1977) 457.

60. W. C. Hinds, Aerosol Technology - Properties Behavior and Measurement of Airbome Particle, John Wiley and Sons, 1982.

61. H. R. Proppacher and R. V. Beard, Quarterly J.R. Meteorological_Sociaty, 26 (1970) 247.

62. C. S. Pemberton, L Air Pollution, 3 (1960) 168.

63. I. Langmuir, L. Meteorology, 5 (1948) 175.

64. N. A. Fuchs, The Mechanics of Aerosols, Pergamon Press, 1964.

65. K. W. Lee and J. A. Gieseke, L.Aerosol Science, 11 (1980) 335.

66. R. Tal, D. N. Lee, and W. A. Sirigano, Int'LJ.Heat Mass Transfer, 27 (1984) 1953.

67. K. Aminzadeh, T. R. Altaha, A. R. H. Cornish, M. S. Kolansky, and R. Pfeffer, Int'l J. Heat Mass Transfer, 17 (1974) 1425.

68. A. R. N. Cornish, Trans. Instn. Chem. Engrs., 43 (1965) 332.

69. D. Rimberg and Y-M. Peng, "Aerosol Collection by Falling Droplets," Air Pollution Control and Design Handbook, Part 2, Chapter 27, P. N. Cheremisinoff and R. A. Young, editors, Marcell Dekker, Inc., 1977.

70. K. E. Washington et al, Reference Manual for CONTAIN 1.1 Code for Containment Severe Accident Analysis, NUREG/CR-5715, SAND91-0835, Sandia National Laboratories, Albuquerque, NM, July 1991. 
71. T. B. Powers and D. L. Reid, Size Distribution of Drops from Cortainment Spray Nozzles, NUREG/CR-0608, PNL-2840, Pacific Northwest Laboratory, Richlarid WA, 1979.

72. G. Herdan, Small Particle Statistics, Butterworths, 1960.

73. D. M. Whelpdale and R. List, LGeophysics Research, 76 (1971) 2836.

74. N. Arbel and Z. Levin, Pure and Applied Geophysics, 115 (1977) 869.

75. A. M. Podrystosky and A. A. Shraiber, Eluid Mechanics - Soviet Research, I (1978) 152.

76. A. M. Podrystosky and A. A. Shraiber, Int'lJ. Multiphase Flow, 10 (1984) 195.

77. S. G. Bradley and C. D. Stow, L.Atmospheric Science, 36 (1979) 494.

78. V. A. Arkhipor, L.Appl. Mech, and Tech. Phys., 24 (1983) 371.

79. L. Baker, Jr., M. Pilch, and W. W. Tarbell, "Droplet Structure Interactions in Direct Containment Heating," Transactions ANS, 57 (1988) 323.

80. R. M. Sct.otland, Disc. Faraday Society, 30 (1960) 72.

81. L. S. Christensen, Bounce, Coalescence, and Splash of Water Drops, Master's thesis, University of Nevada, Reno, Nevada, 1960.

82. C. K. Mutchler, Water Resources Research, I (1971) 1024.

83. C. D. Stow and R. D. Stainer, L. Metr. Soc. Japan, 55 (1977) 518.

84. U.S. Nuclear Regulatory Commission, Standard Review Plan for the Review of Safety Analysis Reports for Nuclear Power Planis, NUREG-800, Section 6.5.2, December 1988.

85. J. A. Gieseke et al., Source Term Code Package: A User's Guide, NUREG/CR-4587, Battelle Columbus Laboratory, Columbus, Ohio, July 1986.

86. L. J. Ott, "Advanced Severe Accident Models for BWR Applications, " Proc. $15^{\text {th }}$ Light Water Reactor Safety Research Information Meeting, Gaithersburg, MD, 1988.

87. R. Adams, "Behavior of $\mathrm{U}_{3} \mathrm{O}_{8}, \mathrm{Fe}_{2} \mathrm{O}_{3}$ and Concrete Aerosols in a Condensing Steam Environment," Proc. Eleventh Water Reactor Safety Research Meeting, Volume 3, page 129, NUREG/CR-0048, U.S. Nuclear Regulatory Commission, Washington, D.C., January 1984.

88. T. S. Kress as cited in Reference 57. 


\section{Appendix A: Statistics of Order Distributions}

The statistical methods used to develop the probability distributions described in the text are derived in this appendix. The derivations used here follow directly from derivations presented by Hogg and Craig [1].

Consider a random variable $X$. Assume this random variable to have a continuous, positive probability density function $f(x)$ over the interval from $a$ to $b$ such that $a<b$. The cumulative probability distribution function for $X$ is $F(X)$ and is given by:

$$
F(X)=\int_{-\infty}^{X} f(x) d x=\int_{a}^{X} f(x) d x
$$

such that

$$
\int_{-\infty}^{+\infty} f(x) d x=1=\int_{a}^{b} f(x) d x
$$

The probability density function, $f(x)$ or equivalently the cumulative probability distribution function $F(x)$, are unknown for the problems posed in the text of this report. The objective of the Monte Carlo sampling is to obtain a sample of the random variable $X$ from which some estimate of $f(X)$ or $F(X)$ can be made.

At the conclusion of the Monte Carlo sampling for a given problem, a set of $n$ possible values of the random variable $X$ is available:

$$
\left\{x_{1}, x_{2}, x_{3} \cdots x_{n-1}, x_{n}\right\}
$$

These sampled values can be arranged in increasing order--say, for example, $X_{1}, X_{n-1}, X_{2} \ldots X_{n}, X_{3}$. The values can then be relabelled $\mathrm{Y}_{\mathrm{i}}$ such that $\mathrm{Y}_{\mathrm{i}}<\mathrm{Y}_{\mathrm{i}+1}$ :

$$
\left\{Y_{1}, Y_{2}, Y_{3} \cdots Y_{n-1}, Y_{n}\right\}
$$

This ordered set of the sampled values of the random variable is the "order statistic" for the sample of size $n$. The joint probability density function for this order statistic is labelled $g\left(Y_{1}, Y_{2}, Y_{3} \ldots Y_{n-1}\right.$, $\mathrm{Y}_{\mathrm{n}}$ ) and is given by: 
Appendix $A$

$$
g\left(Y_{1}, Y_{2}, Y_{3}, \ldots Y_{n-1}, Y_{n}\right)=\left\{\begin{array}{l}
n ! f\left(y_{1}\right) f\left(Y_{2}\right) f\left(Y_{3}\right) \ldots f\left(Y_{n-1}\right) f\left(Y_{n}\right) \\
\text { for } Y_{i}<Y_{i+1} \text { for } i=1 \text { to } n-1 \\
0 \text { otherwise }
\end{array}\right.
$$

This follows directly because there are $n$ ! ways that it might have been necessary to arrange the sampled values of $\mathrm{X}$ in order to formulate the statistic.

A new statistic $Z$ can be formulated from:

$$
Z_{i}=F\left(Y_{i}\right)
$$

where $F\left(Y_{\mathfrak{i}}\right)$ is the cumulative probability distribution function for the random variable $X$. The Jacobian for this transformation of $Y$ into $Z$ is:

$$
\begin{aligned}
& J=\left|\begin{array}{ccc}
\frac{d Y_{1}}{d Z_{1}} & 0 \ldots \ldots \ldots \ldots .0 \\
0 & \frac{d Y_{2}}{d Z_{2}} \ldots \ldots \ldots .0 \\
0 & 0 & \frac{d Y_{3}}{d Z_{3}} \ldots \ldots 0 \\
0 & 0 & 0 \ldots \ldots \cdot \frac{d Y_{n}}{d Z_{n}}
\end{array}\right|=\frac{d Y_{1}}{d Z_{1}} \frac{d Y_{2}}{d Z_{2}} \frac{d Y_{3}}{d Z_{3}} \cdots \frac{d Y_{n}}{d Z_{n}} \\
& =\frac{1}{d Z_{1} d Z_{2} d Z_{3}} \frac{d Z_{n}}{d Y_{1}} \frac{d Y_{2}}{d Y_{3}} \cdots \frac{d Y_{N}}{d y^{\prime}}
\end{aligned}
$$

Since $Z=F(Y)$ and $d Z_{j} / d Y_{i}=f\left(Y_{i}\right)$ :

$$
J=\frac{1}{f\left(Y_{1}\right) f\left(Y_{2}\right) f\left(Y_{3}\right) \cdots f\left(Y_{n}\right)}
$$


Then, the joint probability density function for the $\mathrm{Z}$ statistic is:

$$
\begin{aligned}
h\left(Z_{1}, Z_{2}, Z_{3} \cdots Z_{n}\right) & =J g\left(Y_{1}, Y_{2}, Y_{3} \cdots y_{n}\right) \\
& =n !
\end{aligned}
$$

The probability density function of a particular $Z_{K}$ is:

$$
\begin{aligned}
& h\left(Z_{K}\right)= \\
& \left.=\int_{0}^{z_{2}} \cdots \int_{0}^{z_{K}}\left[\int_{K}^{1} \ldots\left[\int_{n-2}^{1}\left[\int_{n-1}^{1} n\left(z_{1}, z_{2}, z_{3}, \ldots, z_{n}\right) d z_{n}\right] d z_{n-1}\right] \ldots d z_{K+1}\right] d z_{K-1}\right] \ldots d z_{1} \\
& \left.=\int_{0}^{Z_{2}} \cdots \int_{0}^{z_{K}}\left[\int_{Z_{K}}^{1} \ldots\left[\int_{n-2}^{1} n !\left(1-z_{n-1}\right) d z_{n-1}\right] \ldots . d z_{K+1}\right] d z_{K-1}\right] \ldots d z_{1} \\
& =\int_{0}^{z^{2}} \cdots \int_{0}^{Z_{K}} \frac{n !}{(n-K) !}\left(1-z_{K}\right)^{n-K_{d}} Z_{K-1} \ldots d z_{1} \\
& =\frac{n !}{(K-1) !(n-K) !} Z_{K}^{K}\left(1-Z_{K}\right)^{n-K}
\end{aligned}
$$

Now, for some probability $p$ such that $0<p<1$, the solution for

$$
F(x)=p
$$

is $\xi_{p}=x . \quad \xi_{p}$ is the $p^{\text {th }}$ quantile of the cumulative distribution function. The order statistic for the sample of size $n$ of the random variable $X$ can be characterized by the probability that $Y_{K}<\xi_{p}$ or

$$
\operatorname{Pr}\left(\mathrm{Y}_{\mathrm{K}}<\xi_{\mathrm{p}}\right)=\operatorname{Pr}\left(\mathrm{Z}_{\mathrm{K}}<\mathrm{p}\right)
$$


Appendix A

From the probability density function of $\mathrm{Z}_{\mathrm{K}}$ :

$$
\begin{aligned}
\operatorname{Pr}\left(Z_{K}<p\right) & =\int_{0}^{p} h\left(Z_{K}\right) d Z_{K}=\int_{0}^{p} \frac{n !}{(K-1) !(n-K) !} z_{K}^{K}\left(1-Z_{K}\right)^{n-K_{d}} Z_{K} \\
& =\frac{n !}{K !(n-K) !} p^{K}(1-p)^{n-K}+\frac{n !}{(K+1) !(n-K-1) !} p^{K+1}(1-p)^{n-K-1}+\ldots+p^{n} \\
& =\sum_{i=K}^{n} \frac{n !}{i !(n-i) !} p^{i}(1-p)^{n-i}=\operatorname{Pr}\left(Y_{K}<\xi_{p}\right)
\end{aligned}
$$

This result is sufficient to provide a basis to bracket critical values of the unknown distribution function $F(X)$ from the order statistic $Y[2]$. Note that

$$
\operatorname{Pr}\left(Y_{i}<\xi_{p}\right)=\operatorname{Pr}\left(Y_{j}<\xi_{p}\right)+\operatorname{Pr}\left(Y_{i}<\xi_{p}<Y_{j}\right)
$$

and that

$$
\operatorname{Pr}\left(Y_{i}<\xi_{p}<Y_{j}\right)=\operatorname{Pr}\left(Y_{i}<\xi_{p}\right)-\operatorname{Pr}\left(Y_{j}<\xi_{p}\right)
$$

The joint probability density function of $Z_{i}=F\left(Y_{i}\right)$ and $Z_{j}=F\left(Y_{j}\right)$ for $i<j$ is:

$$
\begin{aligned}
& h_{i j}\left(z_{i}, z_{j}\right)= \\
& =\int_{0}^{Z_{i}} \cdots \int_{0}^{Z_{i} Z_{j}} \ldots \ldots \int_{Z_{j-2}}^{Z_{j}} \int_{Z_{j}}^{1} \cdots \int_{n-1}^{1} n ! d z_{n} \ldots d Z_{j+1} d Z_{j-1} \ldots d Z_{i+1} d z_{1} \ldots d Z_{i-1} \\
& =\frac{n !}{(i-1) !(j-i-1) !(n-j) !} z_{i}^{i-1}\left(z_{j}-z_{i}\right)^{j-i-1}\left(1-z_{j}\right)^{n-j} \\
& \text { for } 0<Z_{i}<Z_{j}<1
\end{aligned}
$$

The niost interesting of the joint probabiiities is that of $Z_{1}$ and $Z_{n}$. Then,

$$
h_{1 n}\left(z_{1}, z_{n}\right)=n(9 n-1)\left(z_{n}-z_{1}\right)^{n-2} \text { for } 0<z_{1}<z_{n}<1
$$


Then, the probability that the sample of $X$ exceeds some fraction $p$ of the range of values of $X$ is given by:

$$
\begin{aligned}
\left.\operatorname{Pr} \mid F\left(Y_{n}\right)-F\left(Y_{1}\right) \geq p\right] & =\operatorname{Pr}\left[Z_{n}-Z_{1} \geq p\right] \\
& =\int_{0}^{1-p+Z_{1}} \int_{1}^{1} n(n-1)\left(Z_{n}-Z_{1}\right)^{n-2} d Z_{n} d Z_{1} \\
& =1-n p^{n-1}+(n-1) p^{n}=C
\end{aligned}
$$

$\mathrm{C}$ is then the confidence level that a sample of $\mathrm{n}$ values spans a fraction $\mathrm{p}$ of the distribution.

Some values of the confidence level $\mathrm{C}$ for various values of $\mathrm{n}$ and $\mathrm{p}$ are shown in Table A-1.

Table A-1 Sample size necessary to span a fraction of the uncertainty distribution, p, at a confidence Level C

\begin{tabular}{||ccccc|}
\hline $\begin{array}{c}\text { Confidence } \\
\text { level } \\
(\%)\end{array}$ & \multicolumn{4}{c|}{ Sample size to span $p=$} \\
\hline 90 & 37 & 0.95 & 0.99 & 0.999 \\
95 & 46 & 93 & 478 & 3888 \\
99 & 64 & 130 & 661 & 6635 \\
99.9 & 88 & 180 & 919 & 9228 \\
\hline
\end{tabular}

An example is used to illustrate how the characterization of the distribution improves with the sample size. For this example, samples of 100,500,1000, and 3000 values were taken from a lognormal distribution with a mean of 1.48 and a geometric standard deviation of 2.546 . The samples were ordered and subjected to the non-parametric statistical analyses described above. Cumulative probability distributions derived from the samples at the 95 percent confidence level are shown in Figures A-1 to A-4. These are conventional cumulative probability plots. The known distribution is shown as a solid line in the figures for comparison purposes. These results show that median values are derived fainly accurately from samples of just 100 values if the distribution is not too complicated. Samples of about 1000 values are needed to get accurate values at the 5 percent and 95 percent quantiles.

The principal advantage of the Monte Carlo method and the non-parametric order statistic analysis adopted here is that the number of samples that must be taken to characterize a distribution is independent of the number of uncertain quantities that arise in calculations of the type described in the 
Appendix A

100 Sample Case

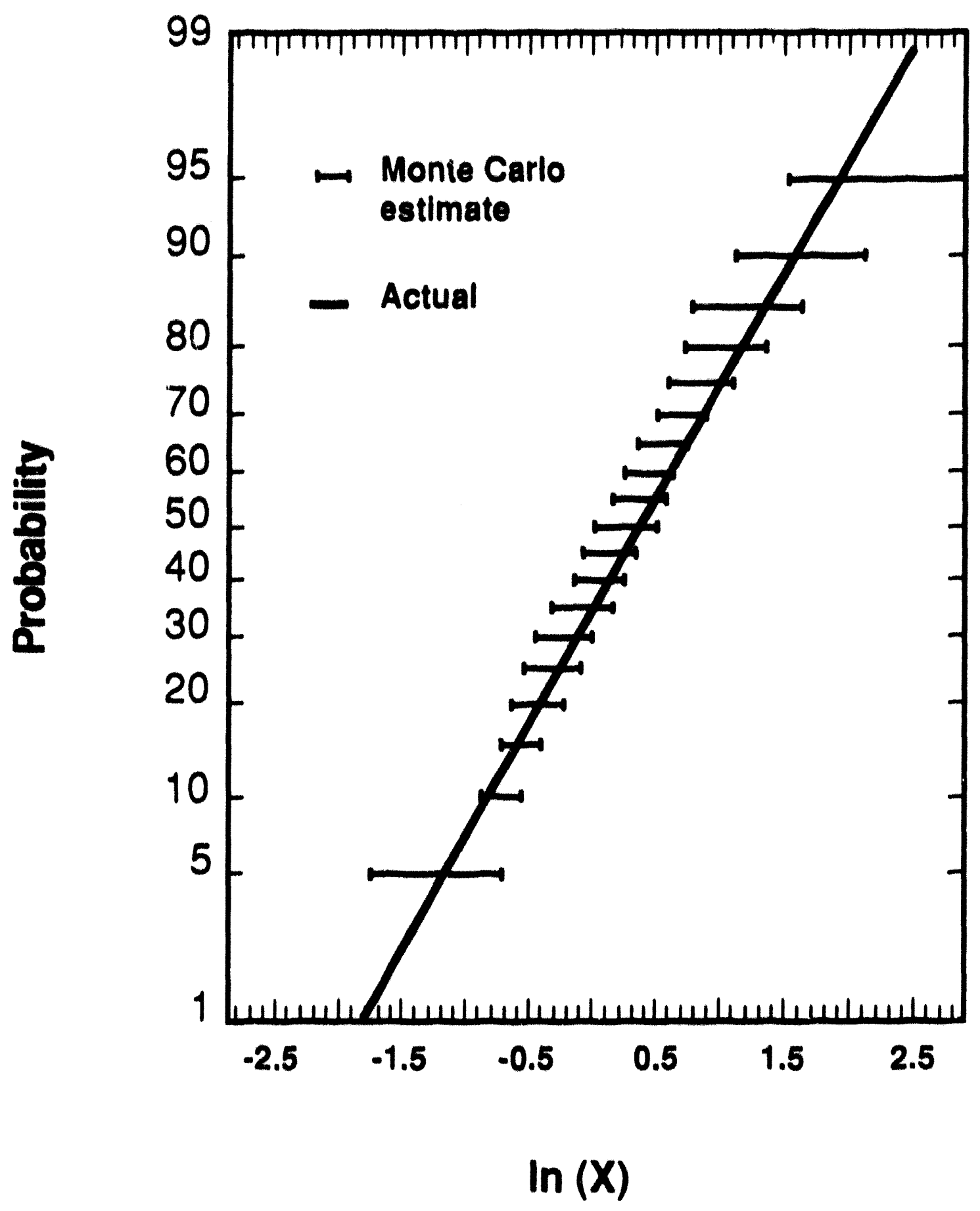

Figure A-1 95 percent confidence intervals for quantiles of the example distribution derived from a 100 value sample. The actual underlying distribution is shown by the continuous liue. 
Appendix A

\section{Sample Case}

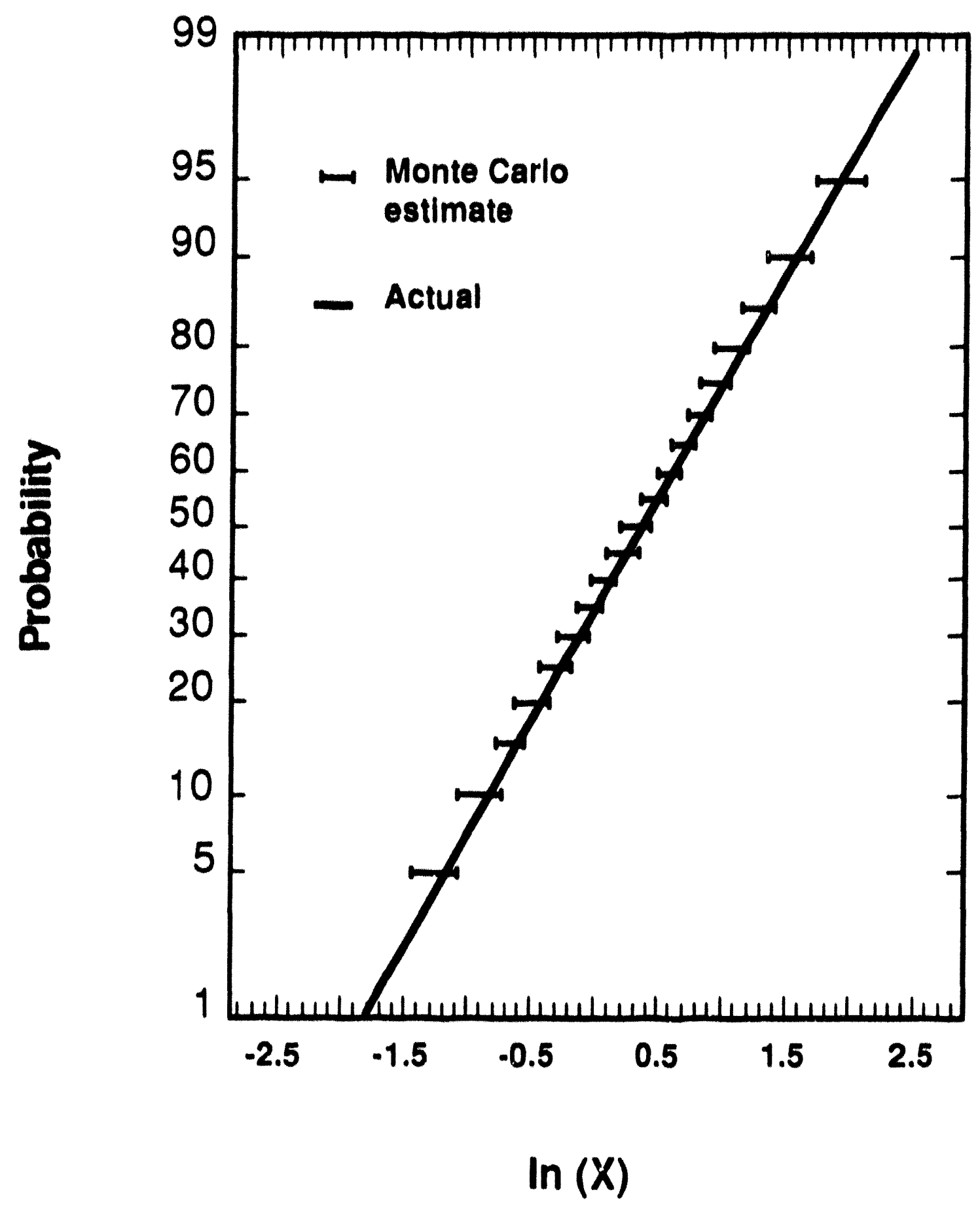

Figure A-2 95 percent confidence intervals for quantiles of the example distribution derived from a 500 value sample. The actual underlying distribution is shown by the continuous curve. 
Appendix A

\section{Sample Case}

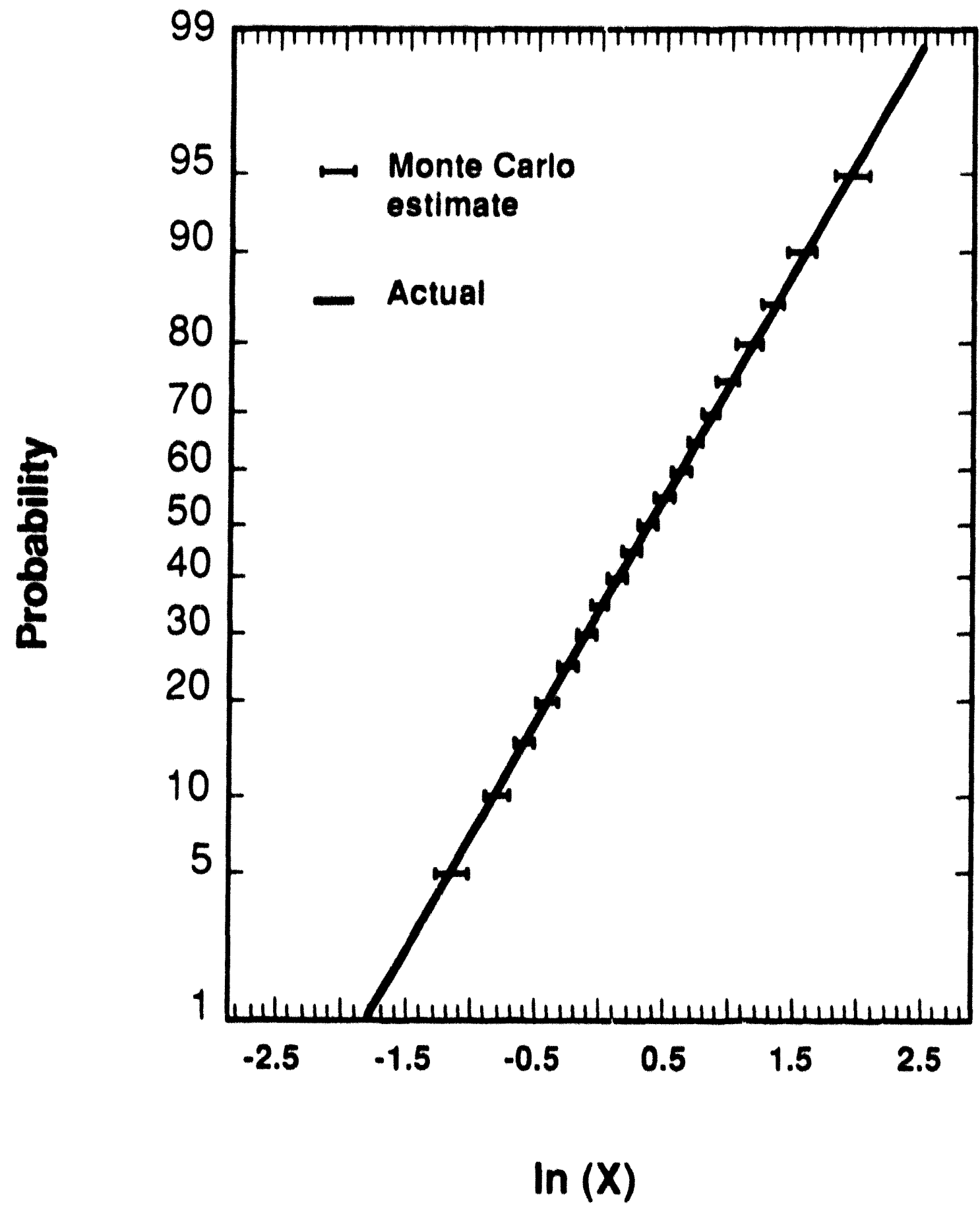

Figure A-3 95 percent confidence intervals for quantiles of the example distribution derived from a 1000 value sample. The actual underlying distribution is shown by the continuous curve. 


\section{Sample Case}

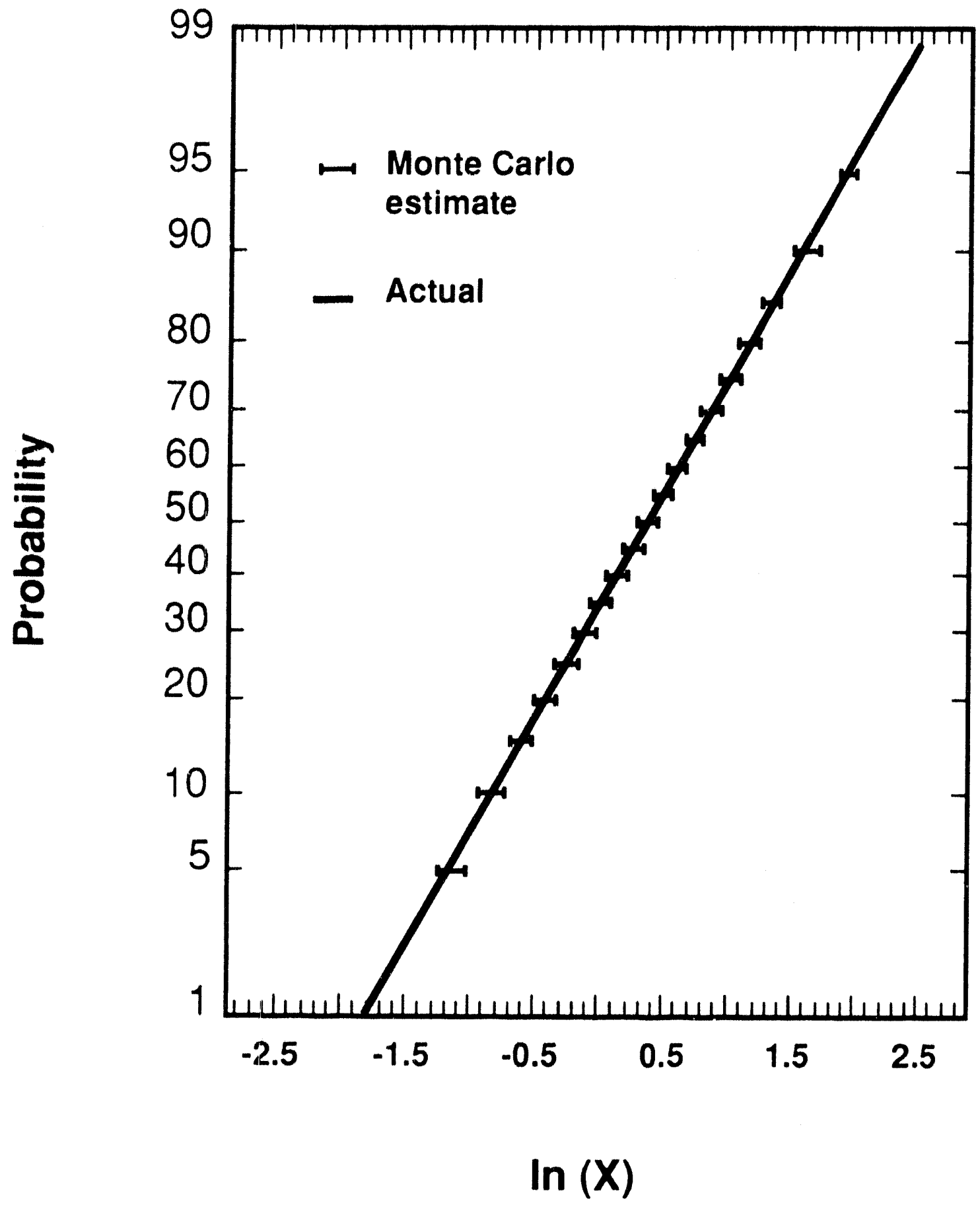

Figure A-4 95 percent confidence intervals for quantiles of the example distribution derived from a 3000 value sample. The actual underiying distribution is shown by the continuous ciorve. 


\section{Appendix A}

text. The values listed in Table A-1 can be compared to the number of calculations of values that would be required in a deterministic analysis. For instance. a simple two-level factorial analysis of a problem with 16 uncertain variables would require

$$
2^{16}=65536
$$

calculations. A far more complete characterization of the distribution is obtained at fairly high confidence levels with only a few hundred calculations following the Monte Carlo method.

\section{References:}

1. R. V. Hogg and A. T. Craig. Introduction to Mathematical Statistics, MacMillan Co.

2. The factorials found in these equations can be accurately calculated for values greater than 10 from:

$$
\begin{gathered}
\ln n !=\left(n+\frac{1}{2}\right) \ln (n+1)-n-1+\frac{1}{2} \ln (2 \pi)+\frac{1}{12(n+1)}-\frac{1}{360(n+)^{3}} \\
+\frac{1}{1260(n+1)^{5}}-\frac{1}{1680(n+1)^{7}}
\end{gathered}
$$

See

M. Abramowitz and I. A. Stegan, Handbook of Mathematical Functions, Dover Publications, 1970. 


\section{Appendix B: Detailed Results of the Uncertainty Analyses of Decontamination by an Overlying Water Pool}

Results of the Monte Carlo uncertainty analyses for decontamination by an overlying water pool are collected in this appendix. Results are for water pools 30 and $50 \mathrm{~cm}$ deep subcooled by $0,2,5,10$, 20, 30, 50, and $70^{\circ} \mathrm{C}$. The results are shown as cumulative probability distributions at confidence levels of 50.90, and 95 percent as defined in Appendix A. Tabulated results are shown in the enclosed tables for quantiles of the distribution from 5 to 95 percent at 5 percent intervals. Mean values and standard deviaitons are also shown in the tables. 
Appendix B

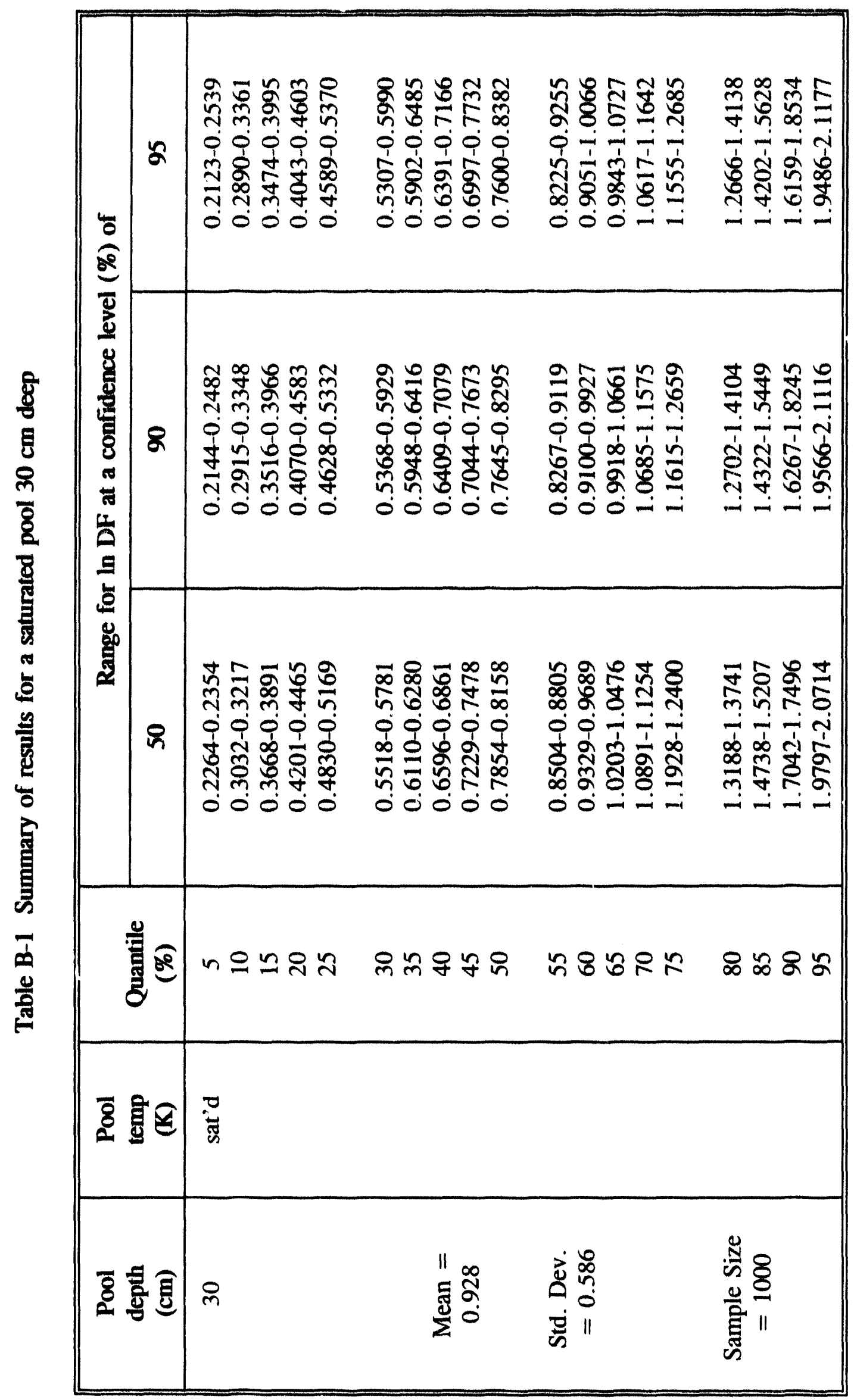


Appendix B

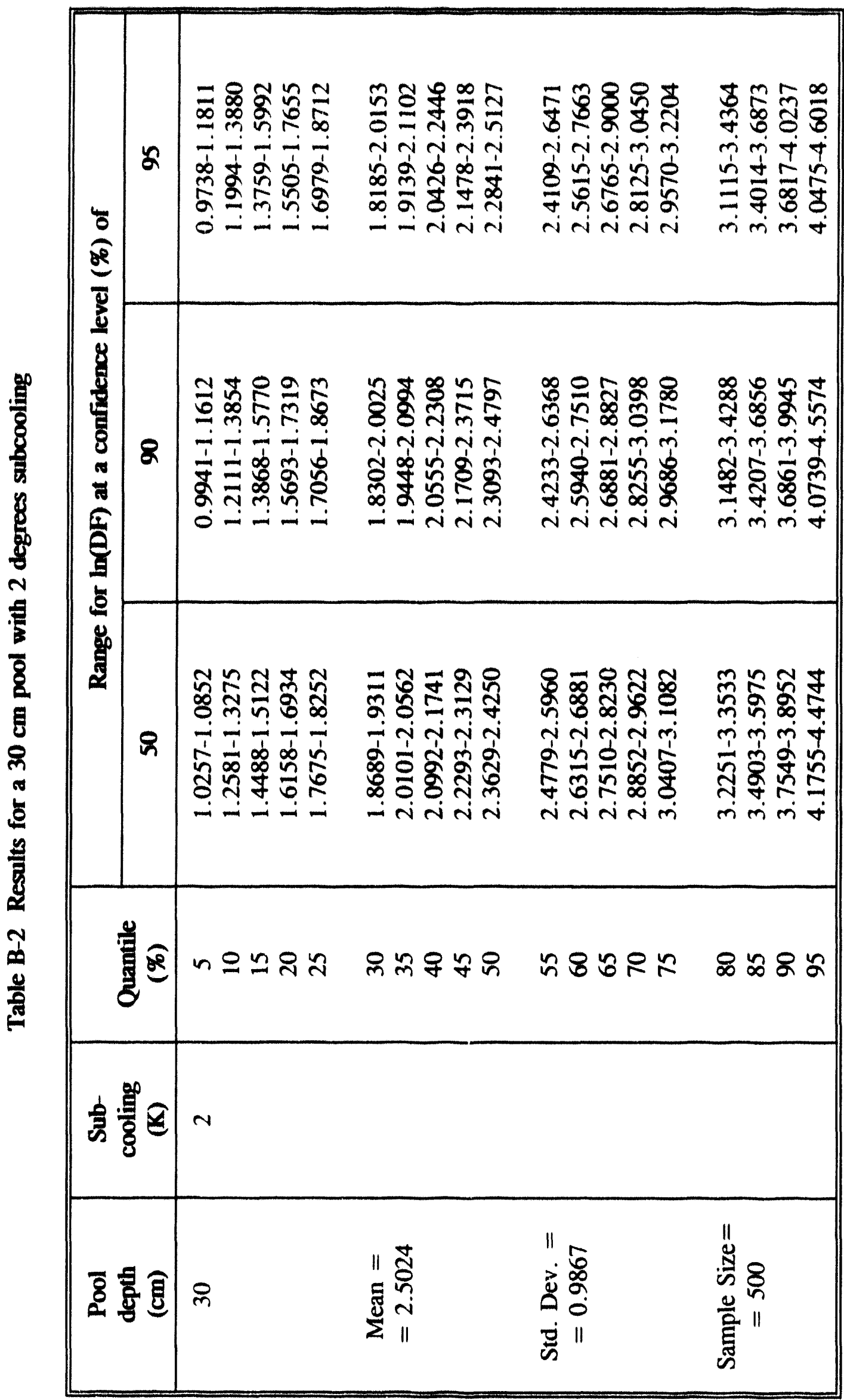


Appendix B

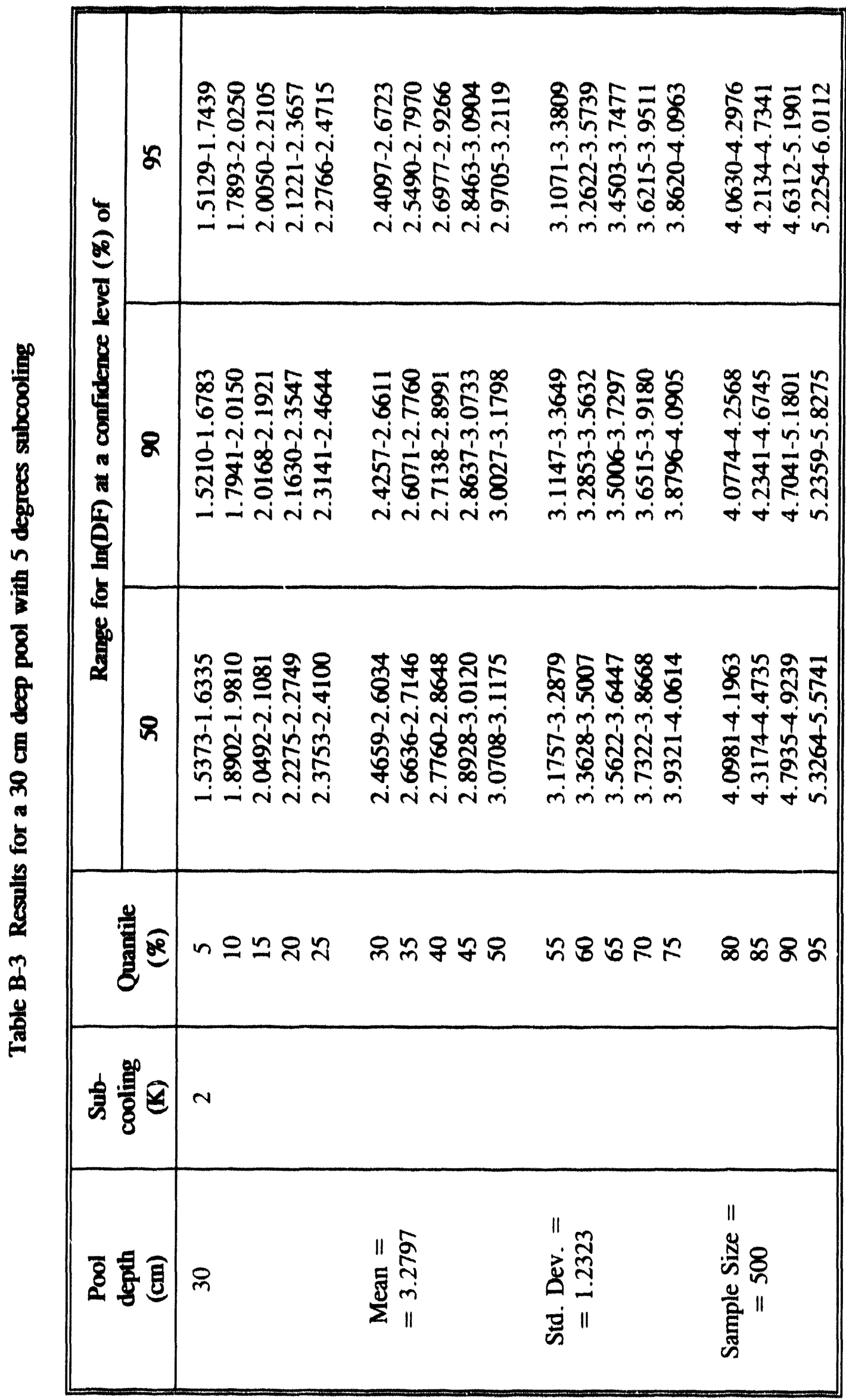


Appendix B

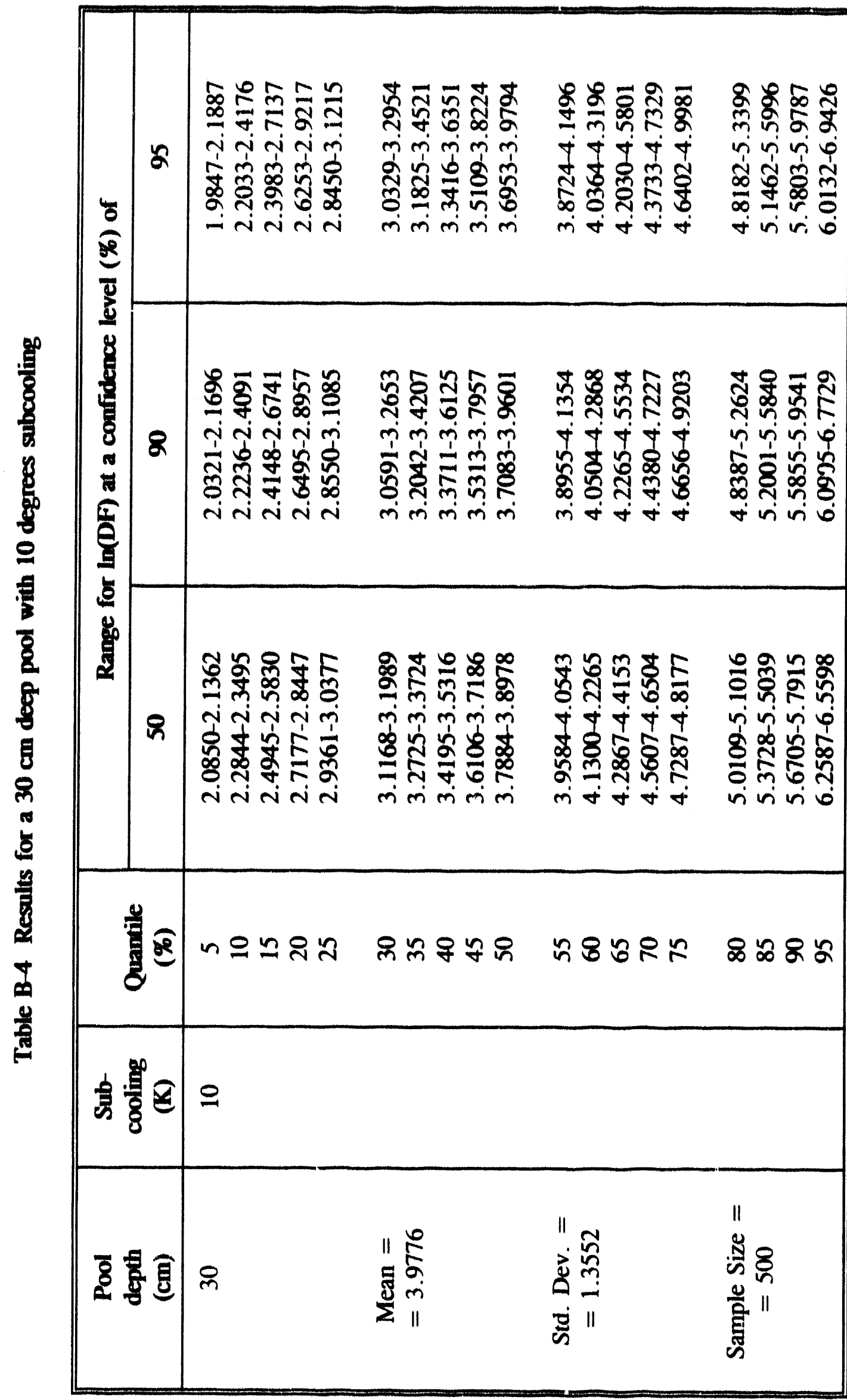


Appendix B

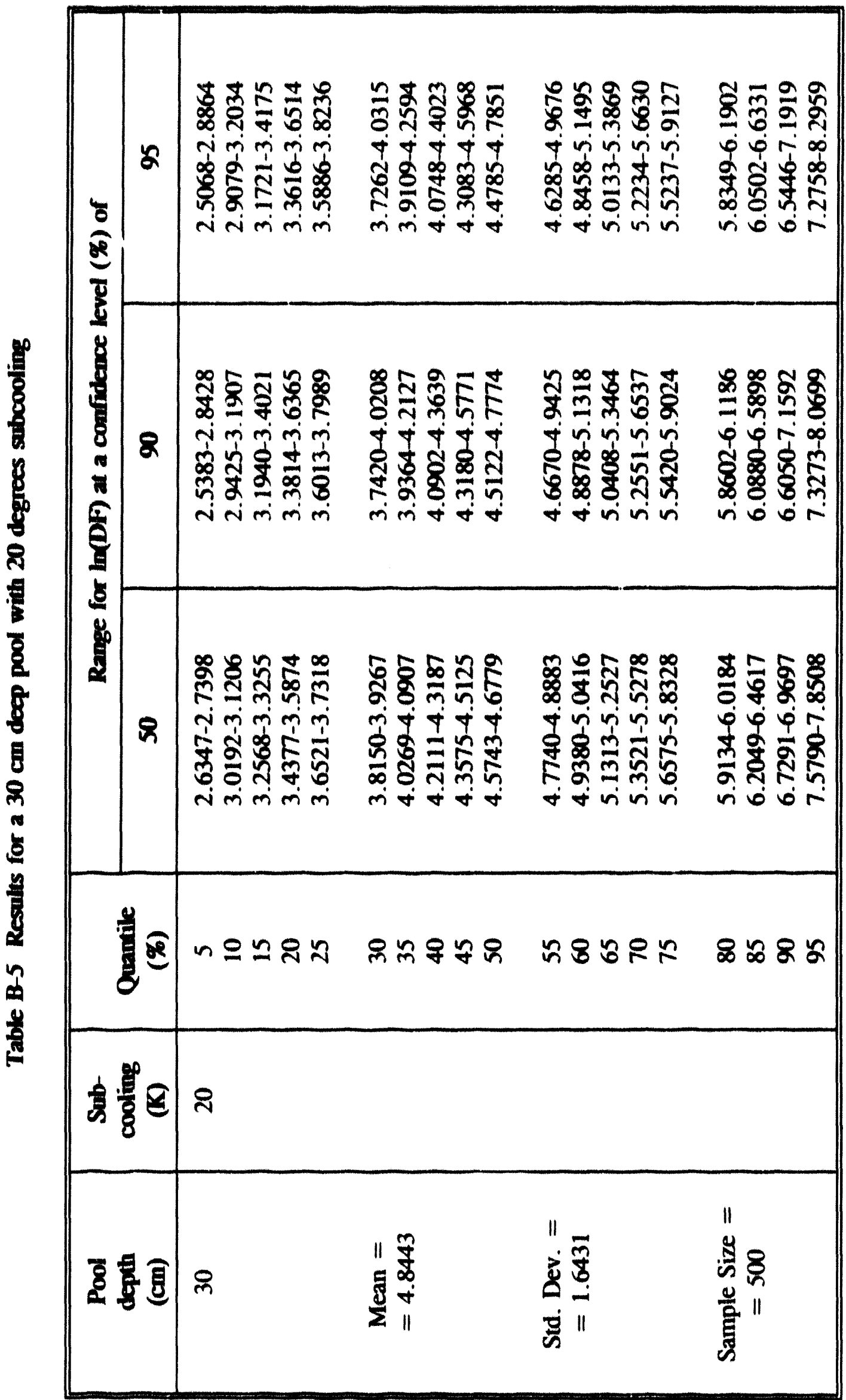


Appendix B

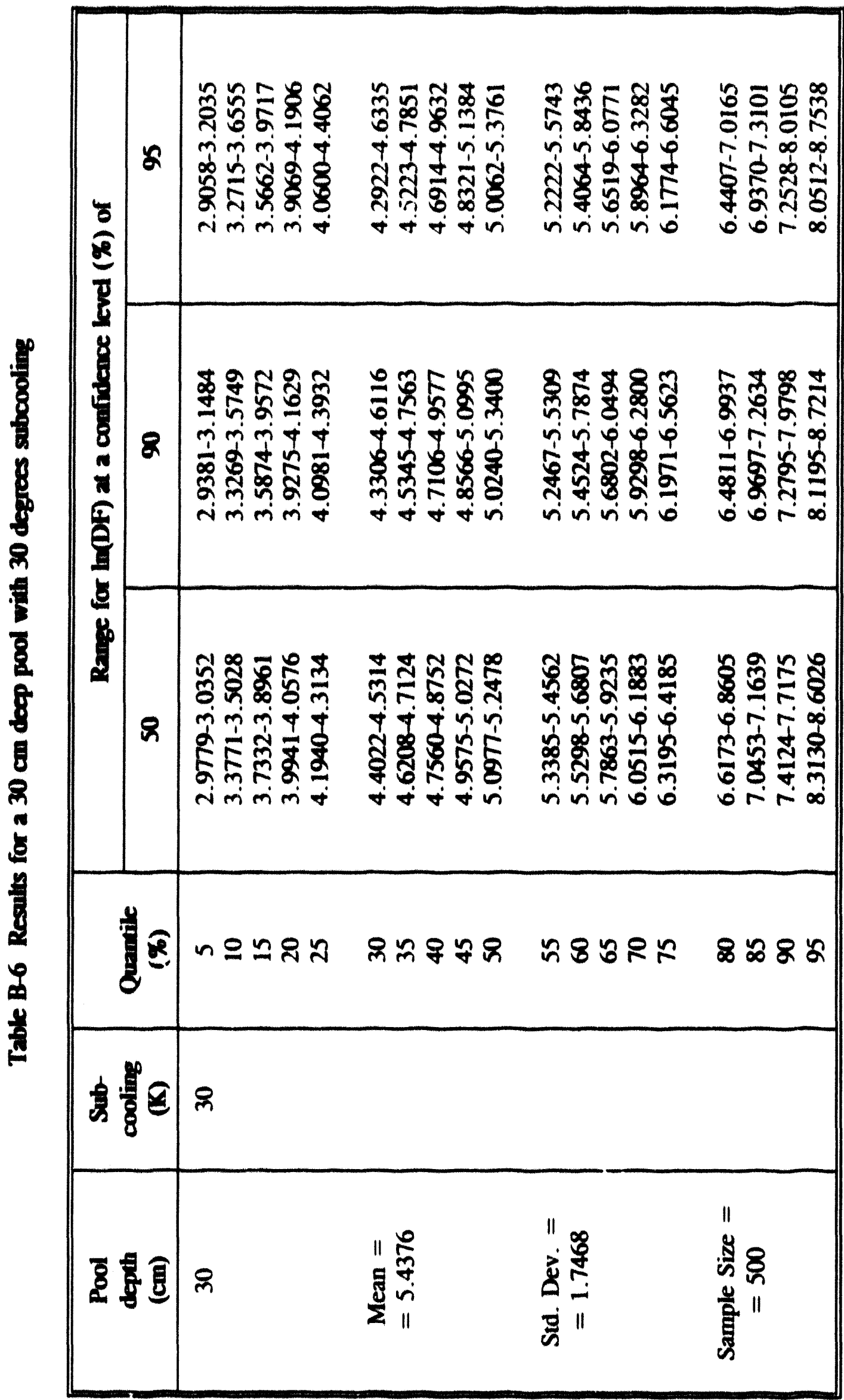

B-7 
Appendix B

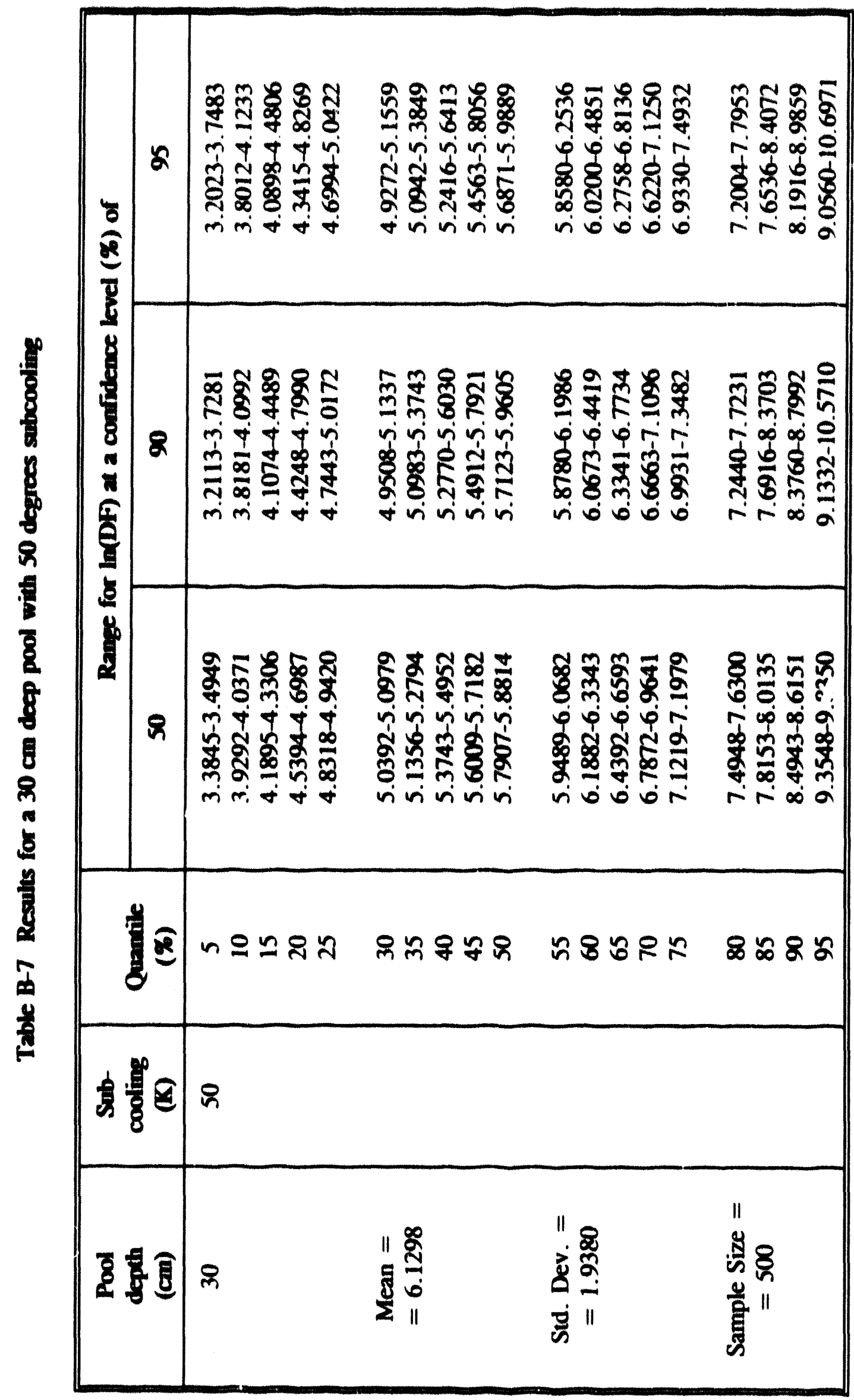


Appendix B

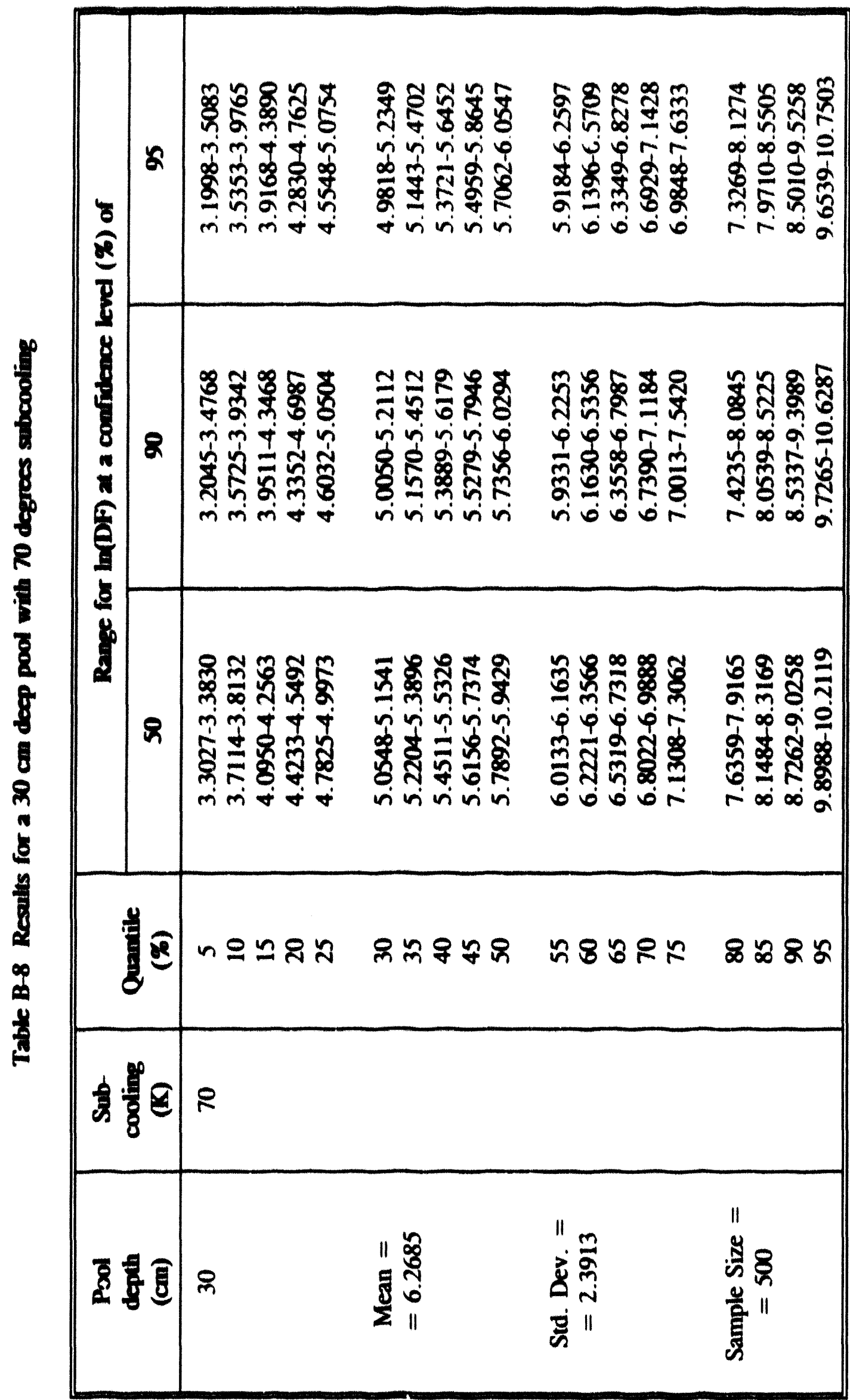


Appendix B

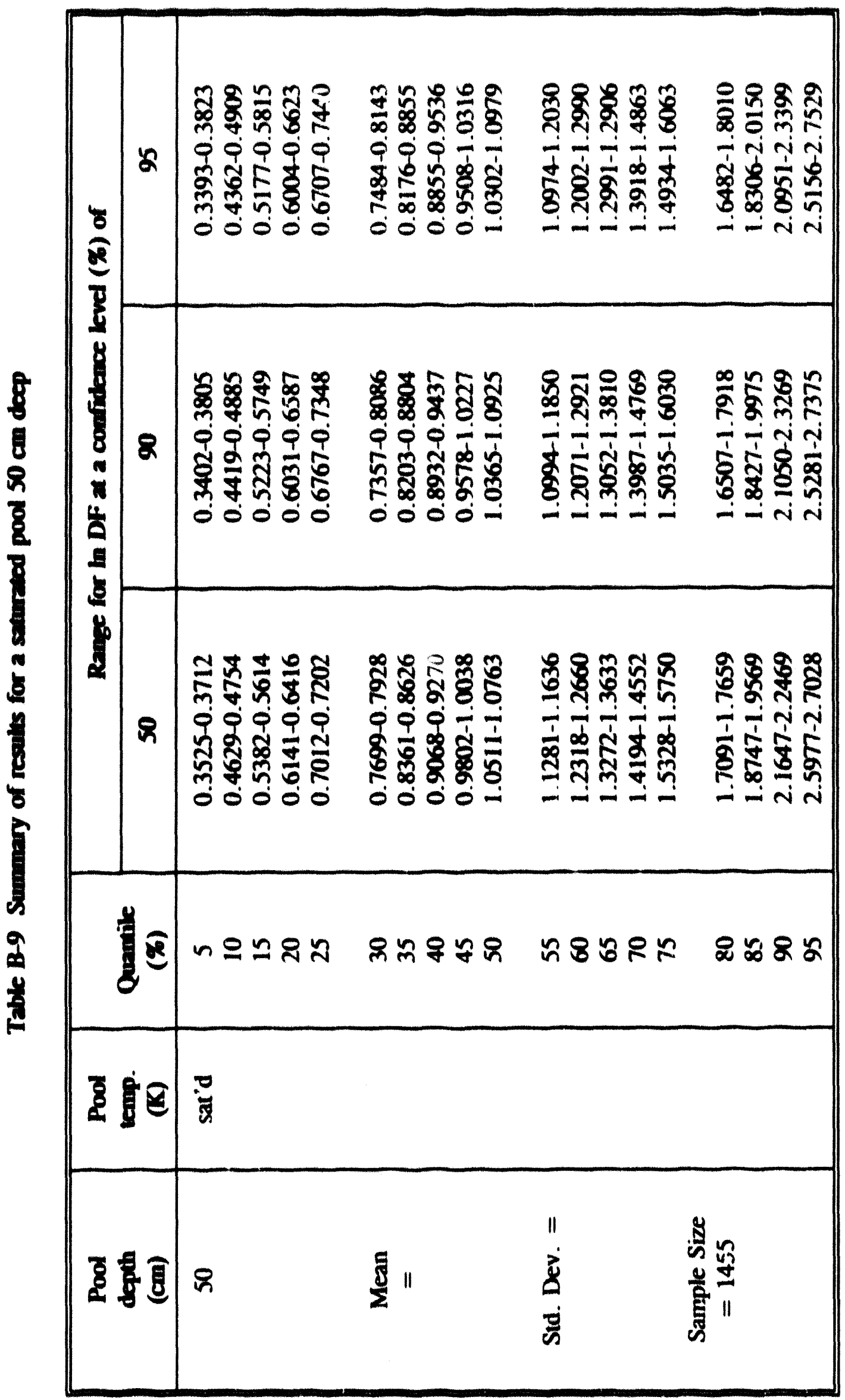


Appendix B

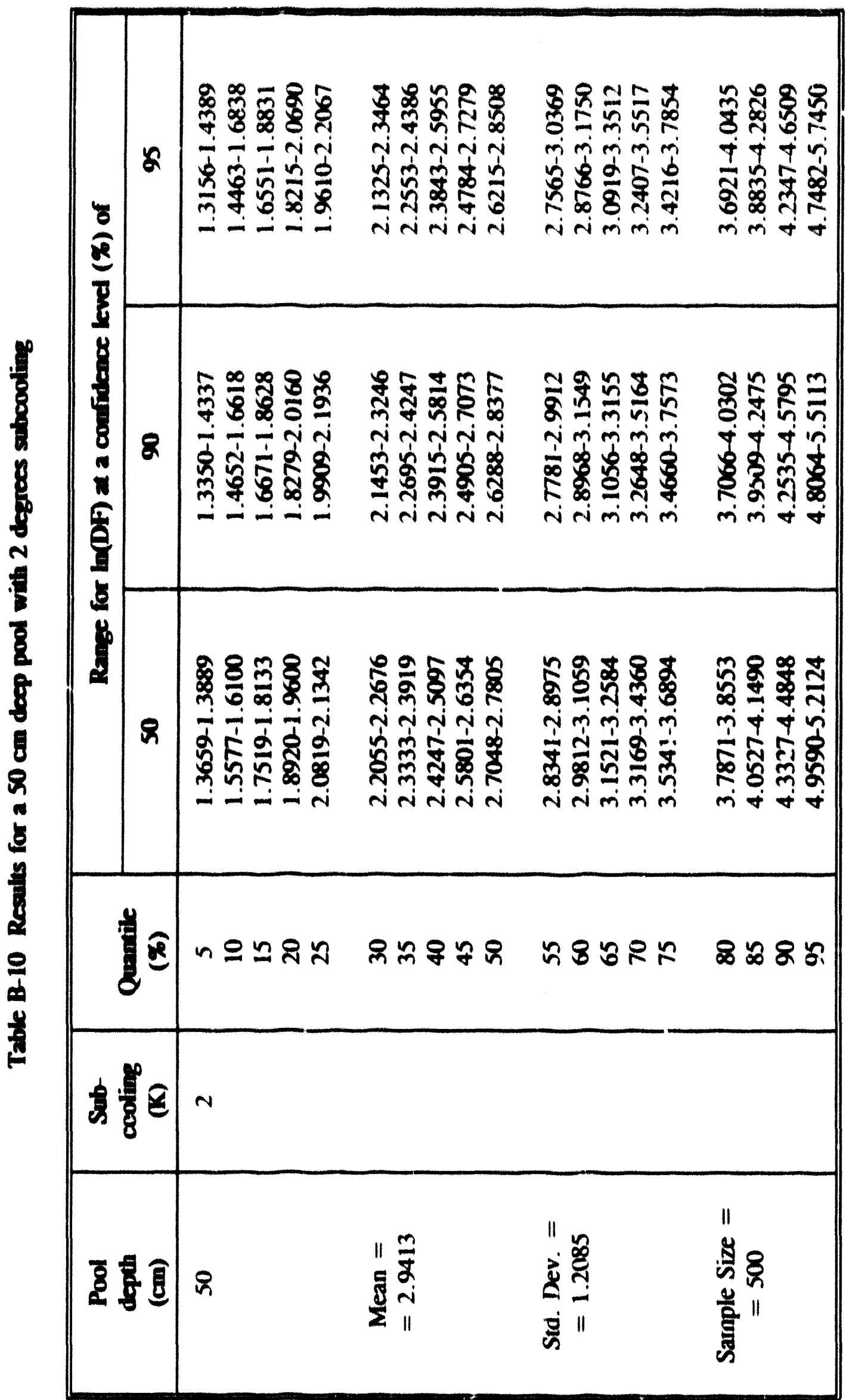

B. 11 
Appendix B

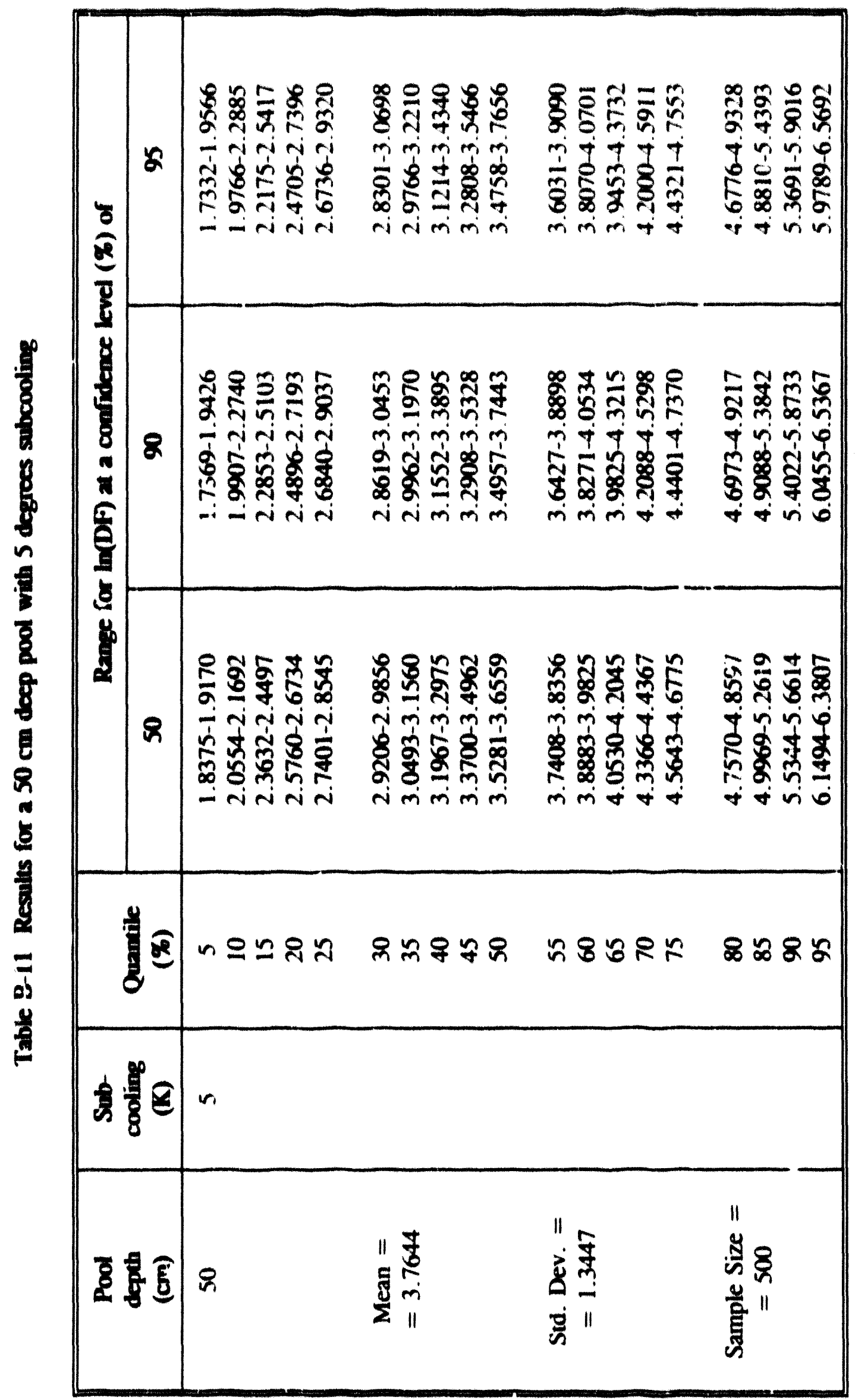


Appendix B

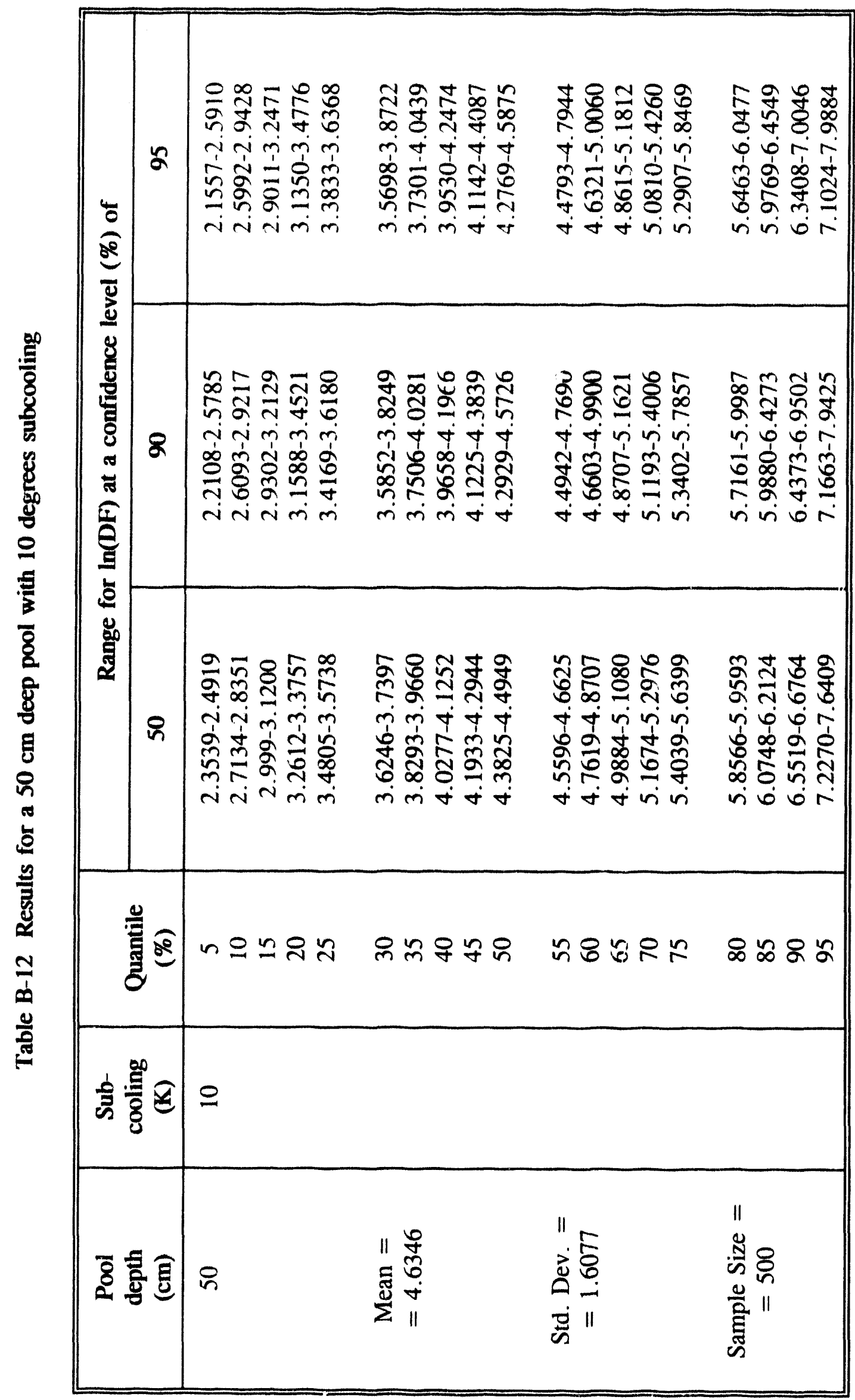

B-13 
Appendix B

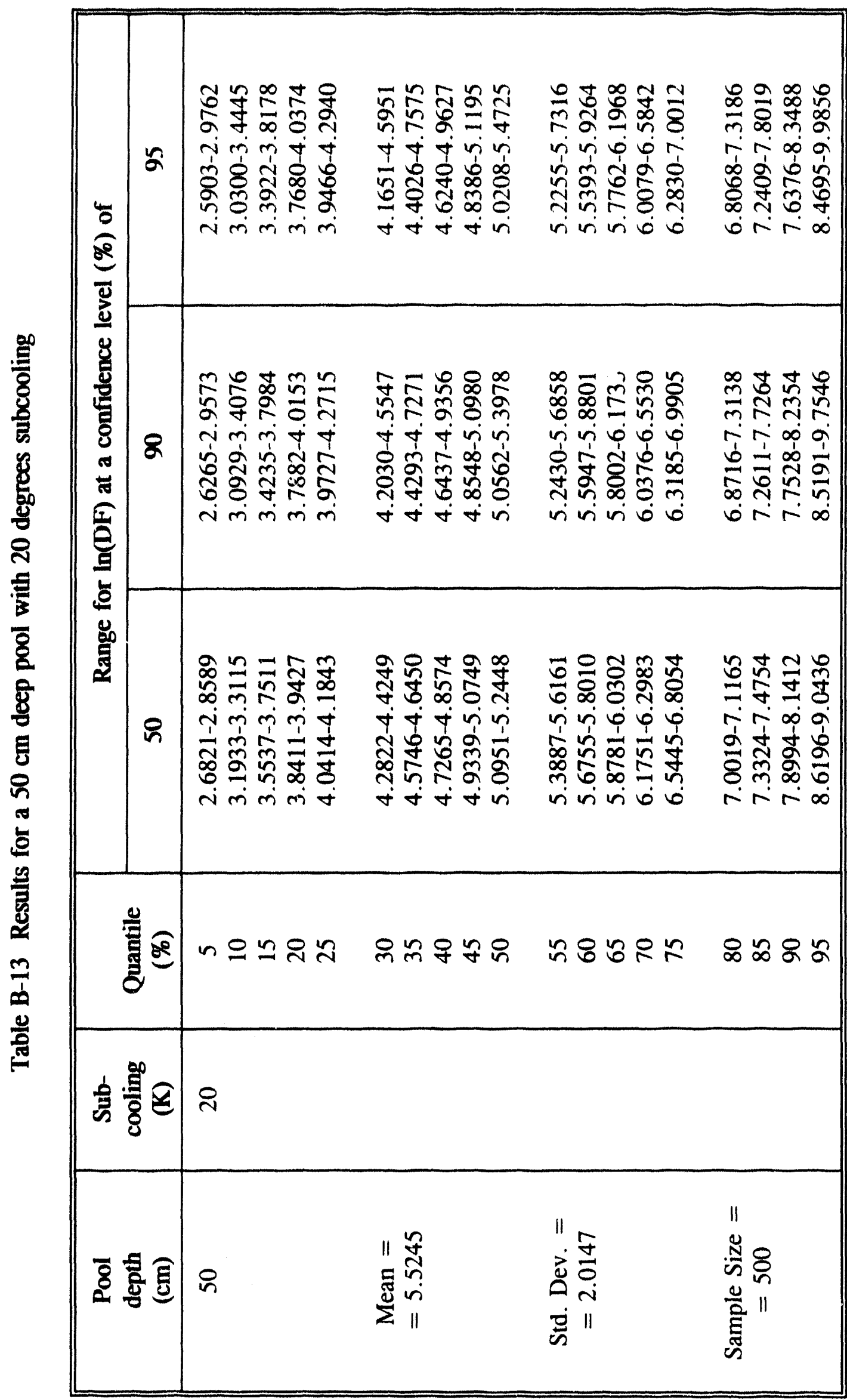


Appendix B

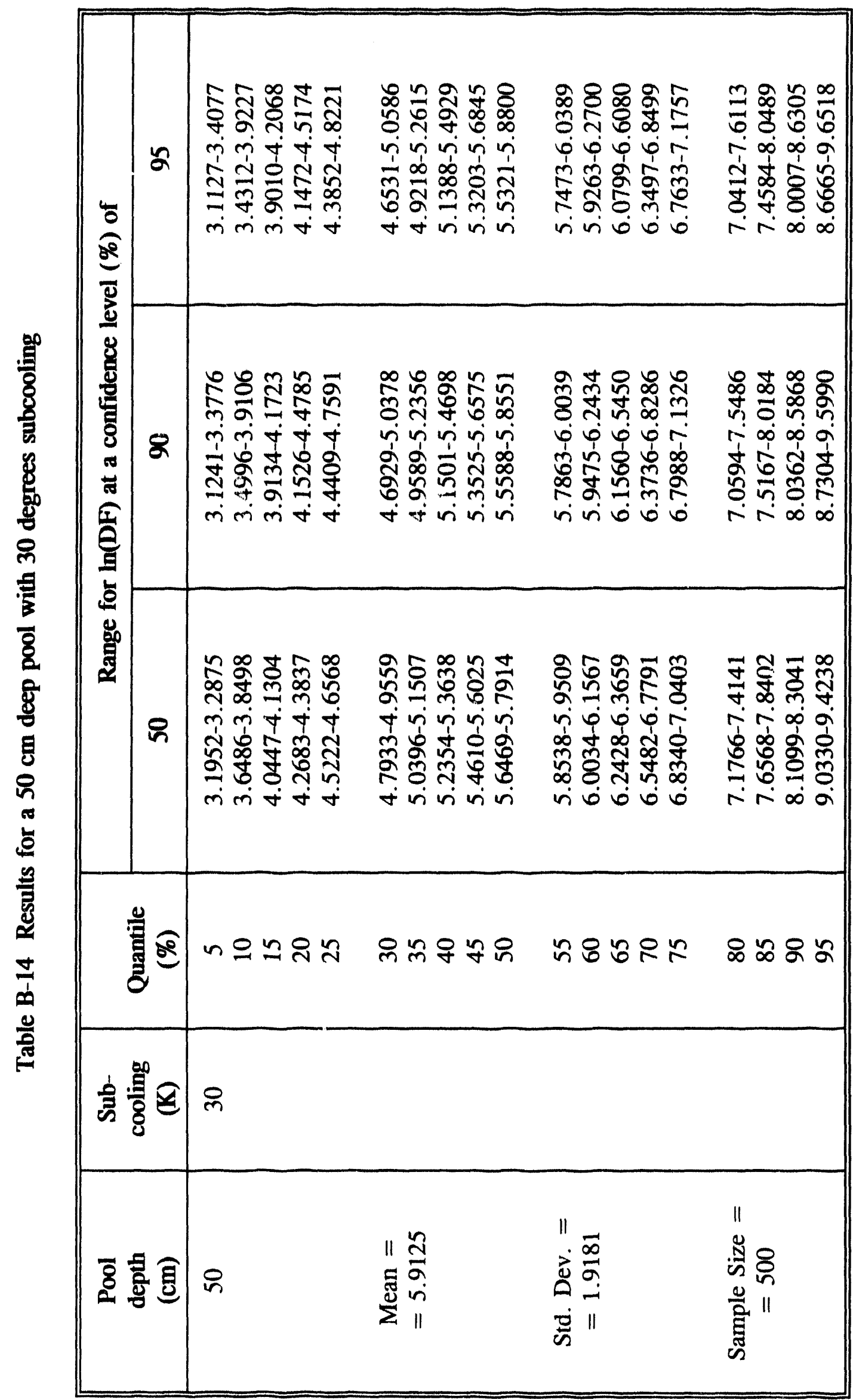


Appendix B

\begin{tabular}{|c|c|c|c|c|c|}
\hline \multirow{3}{*}{ 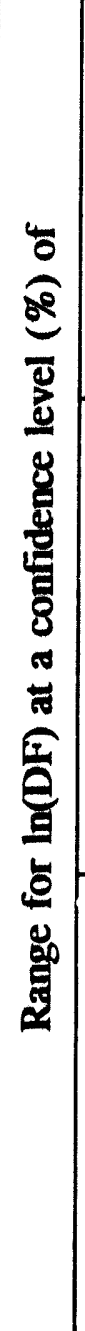 } & 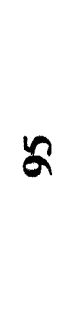 & 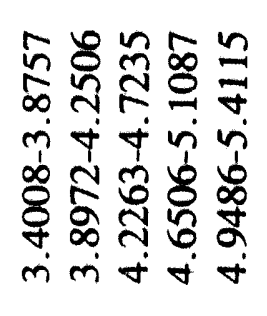 & 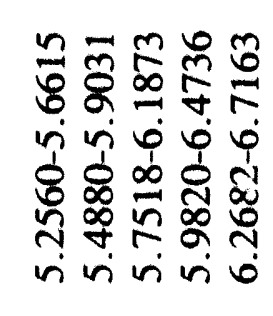 & 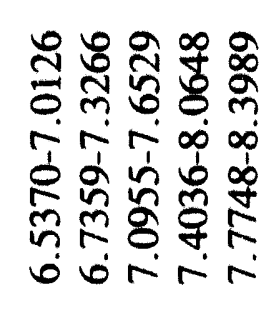 & 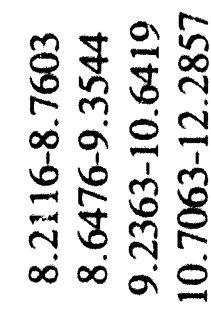 \\
\hline & 8 & 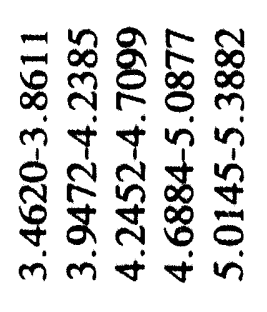 & 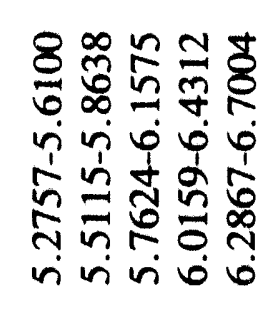 & 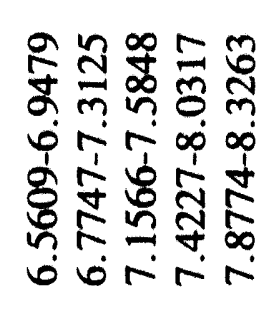 & 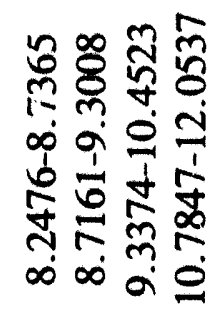 \\
\hline & n & 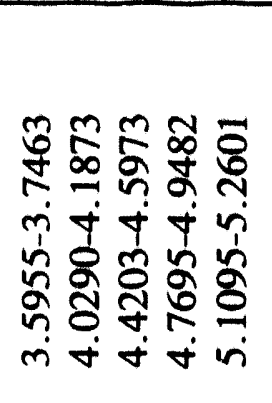 & 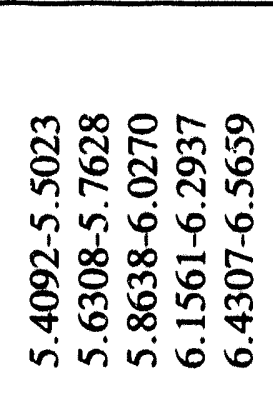 & 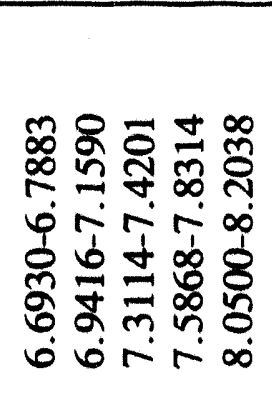 & 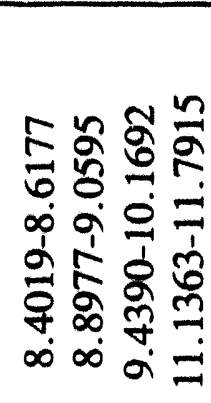 \\
\hline \multicolumn{2}{|c|}{ 营 } & $n ㅖ$ & 유 n̊ \& & ๓ $ே ே ゚ ッ$ & ৪ ஃ ス \\
\hline \multicolumn{2}{|c|}{ 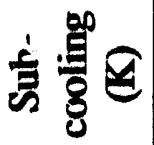 } & 오 & & & \\
\hline \multicolumn{2}{|c|}{ రి } & in & 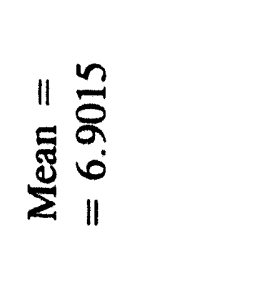 & $\begin{array}{l}\| \vec{b} \\
\vec{i} \\
\vec{i} \\
\vec{i} \\
\dot{\vec{n}} \|\end{array}$ & 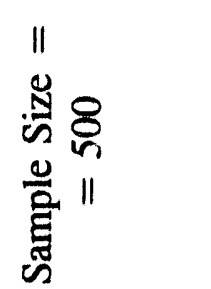 \\
\hline
\end{tabular}


Appendix B

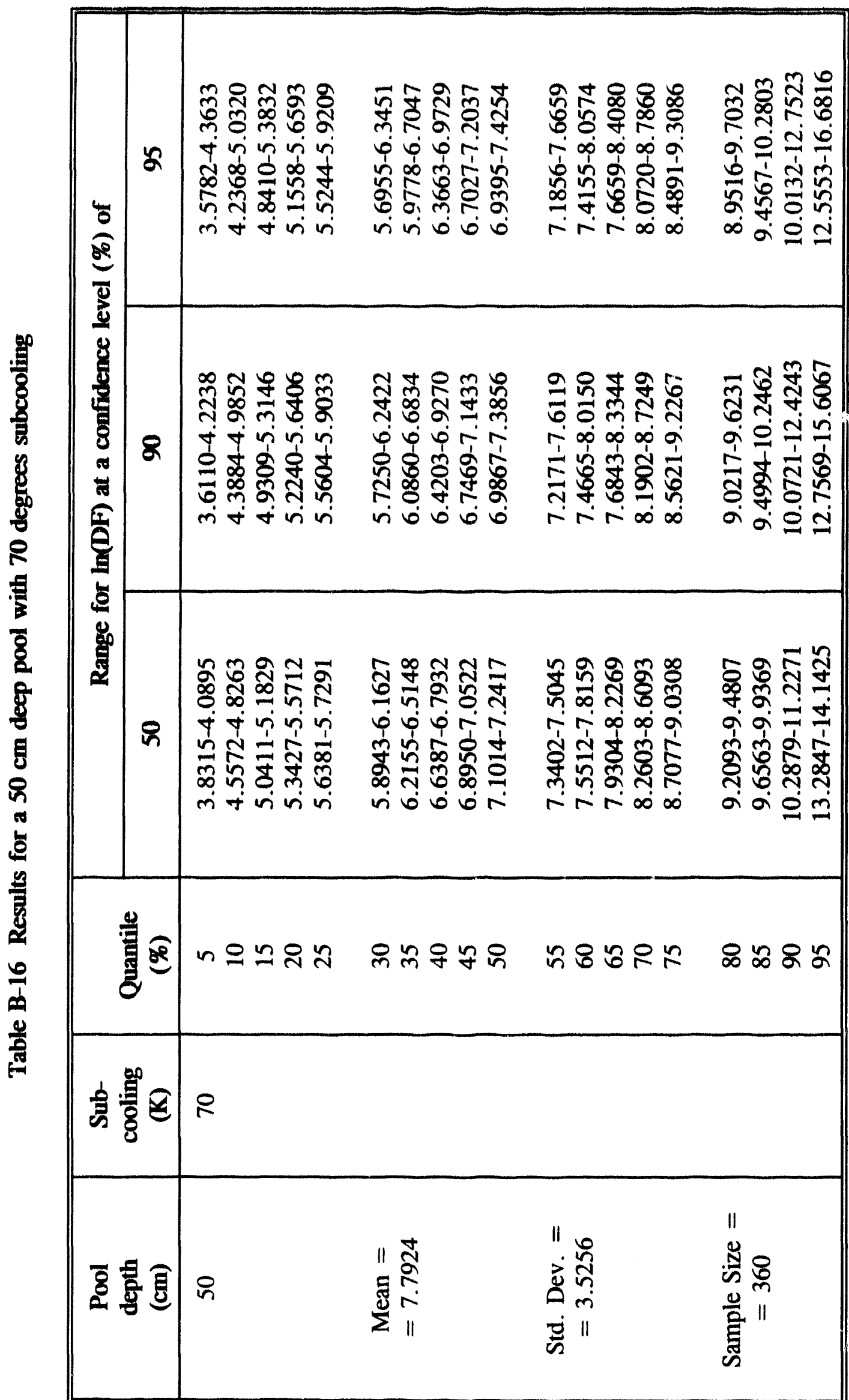




\section{Appendix C: Uncertainty Distributions for the Spray Decontamination Coefficient}

Detailed uncertainty distributions for the spray decontamination coefficient, $\lambda\left(\mathrm{hr}^{-1}\right)$, are presented in the tables of this appendix. Uncertainty distributions were calculated for total water fluxes of $0.002,0.01$, and $0.25 \mathrm{~cm}^{3} \mathrm{H}_{2} \mathrm{O} / \mathrm{cm}^{2}$-s and fractions of the initial aerosol remaining in the atmosphere of $0.9,0.5$, $0.3 .0 .1,0.01$, and 0.001 . The distributions are calculated for confidence levels of 50, 90, and 95 percent. That is, percentiles of a cumulative probability distribution are defined by a range of values of $\lambda$. Ranges such that there is a 50,90 , or 95 percent confidence that the true value of $\lambda$ characteristic of the specified percentile lies within the range are given. Percentiles of 5 to 95 percent at 5 percent intervals are tabulated. Means and standard deviations for the distributions are also given, though for these distributions neither of these quantities is especially useful. 
Appendix C

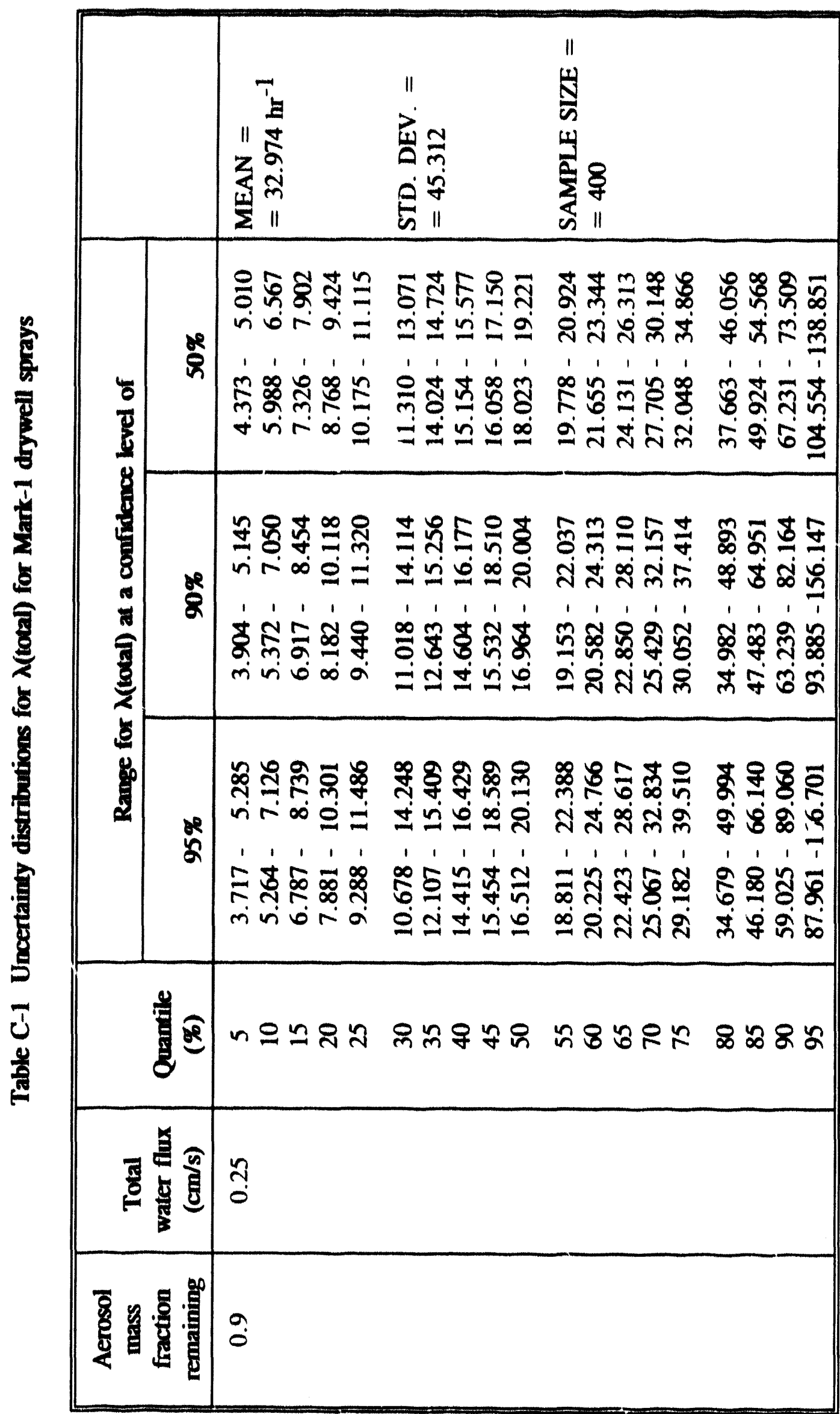


Appendix C

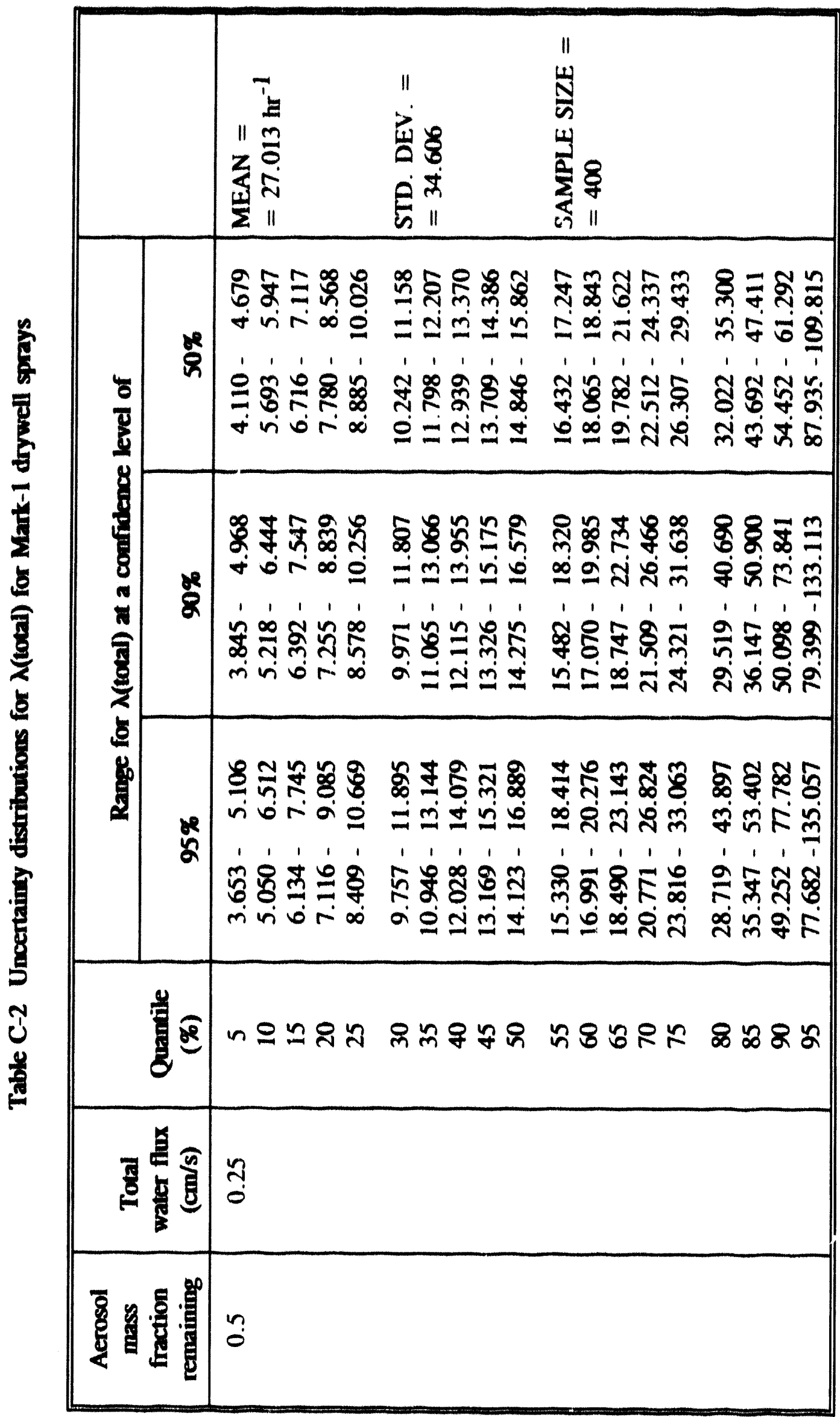


Appendix C

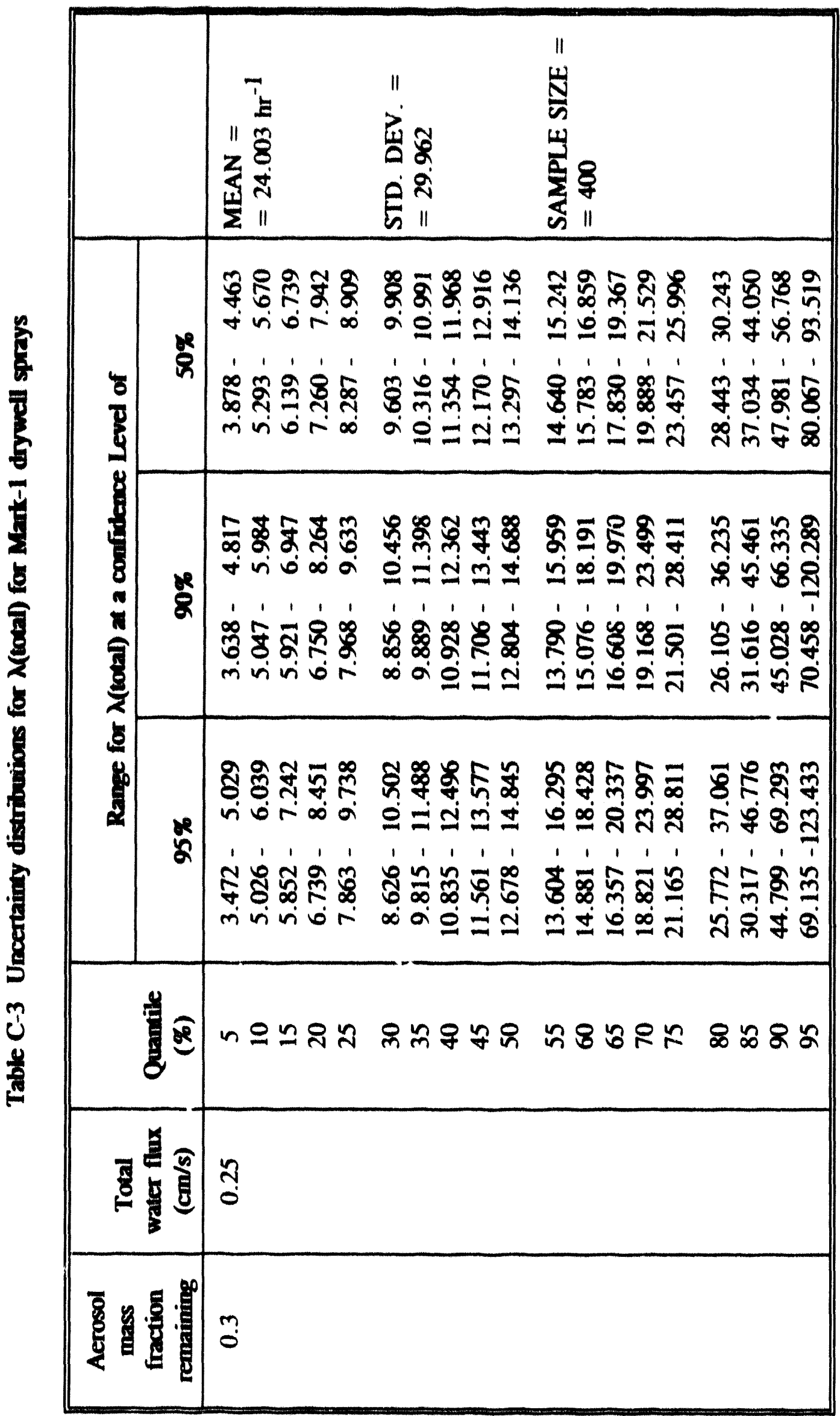


Appendix $\mathrm{C}$

\begin{tabular}{|c|c|c|c|c|}
\hline & 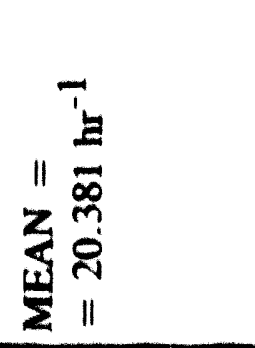 & 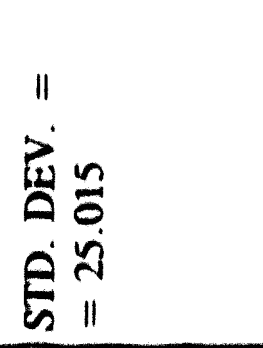 & 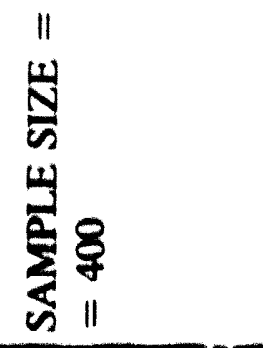 & \\
\hline$\frac{5}{5}$ & 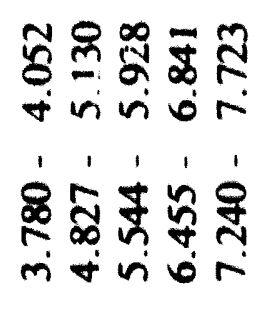 & 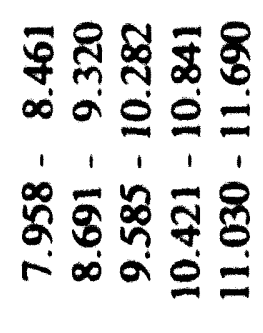 & 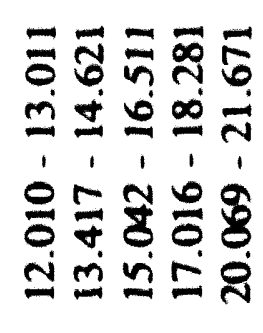 & 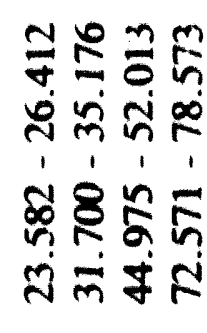 \\
\hline 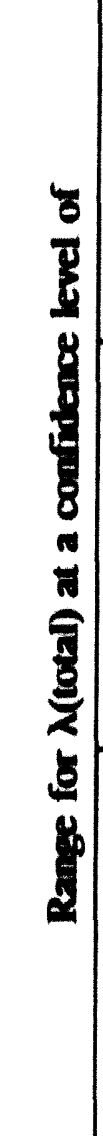 & 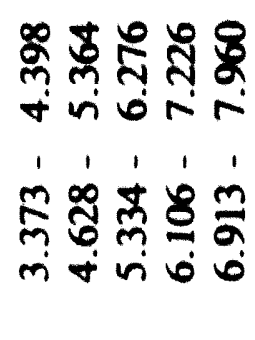 & 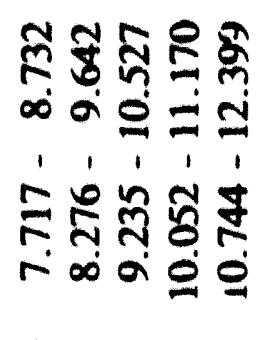 & 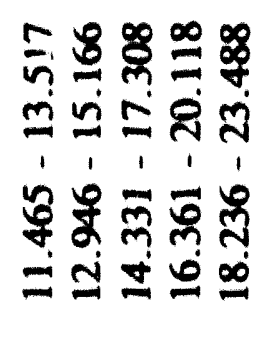 & 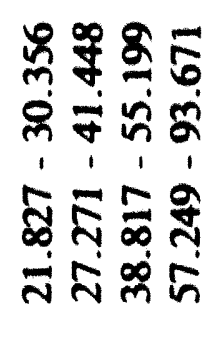 \\
\hline 8 & 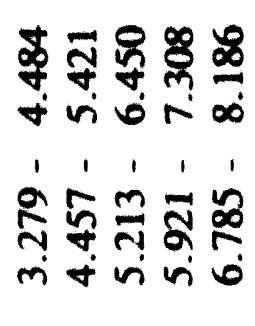 & 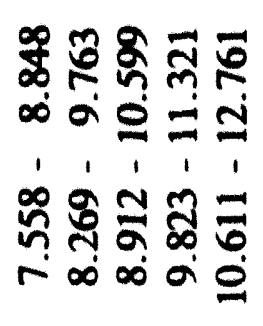 & 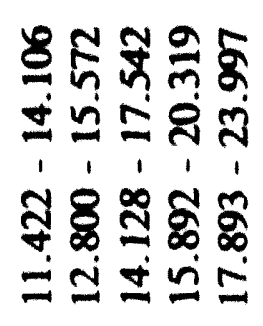 & 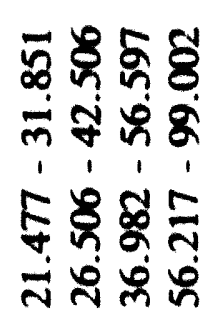 \\
\hline 8 & n으믁ㄱㄱ & 윴 & ๓ & \& ஃ \& \\
\hline 종 & $\stackrel{\check{n}}{0}$ & & & \\
\hline 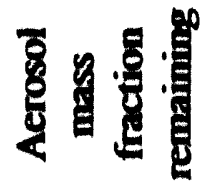 & $\overrightarrow{0}$ & & & \\
\hline
\end{tabular}


Appendix C

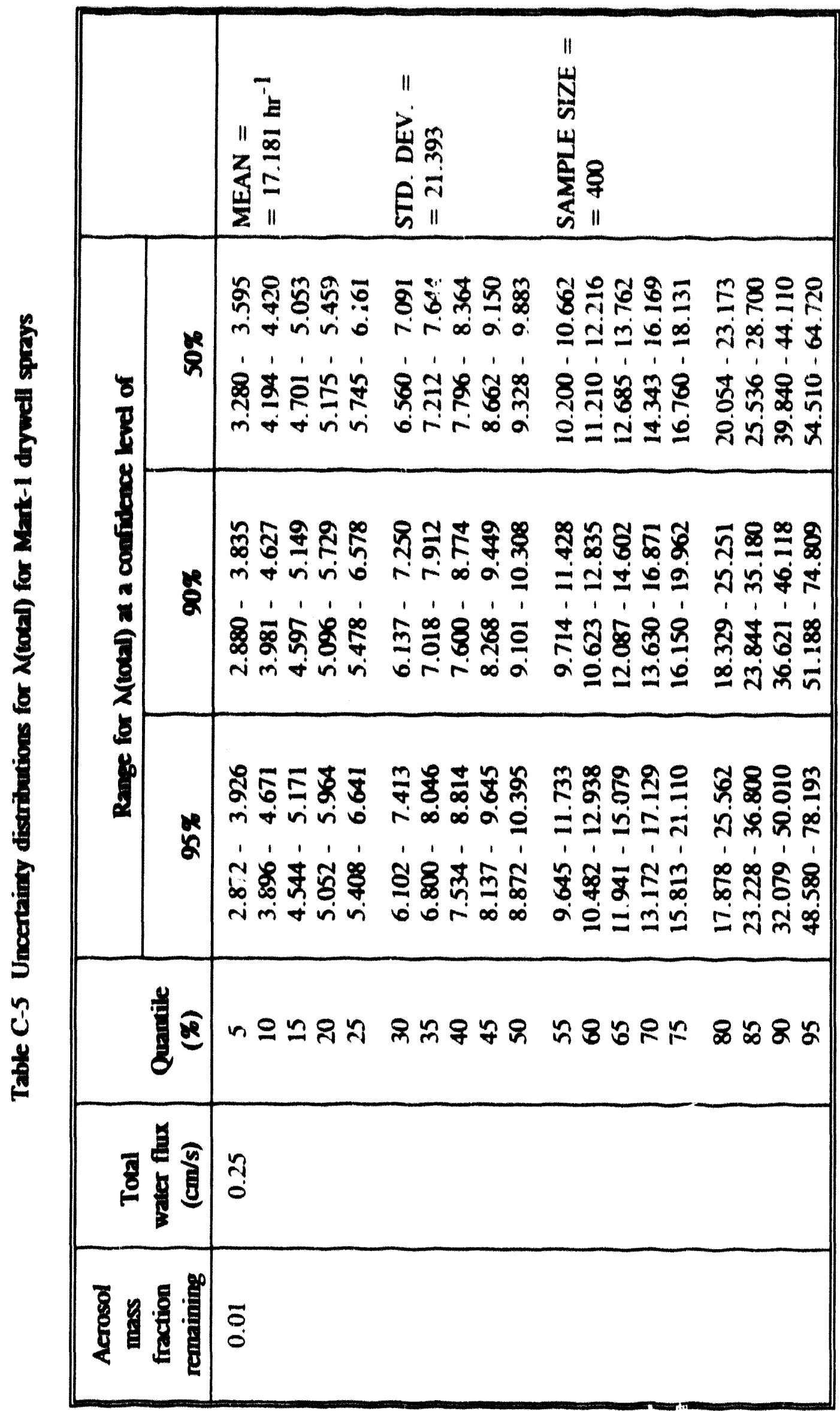




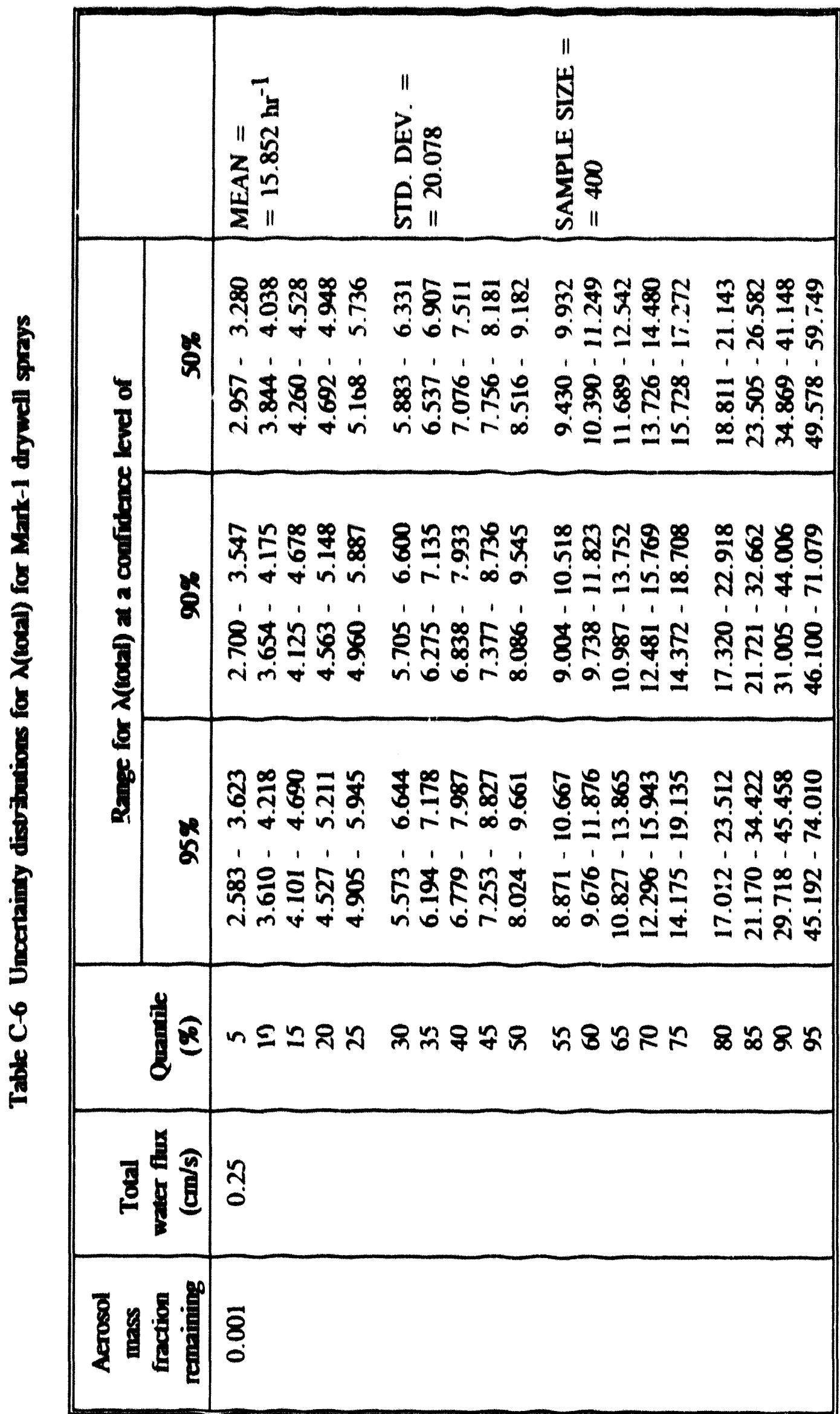


Appendix $\mathrm{C}$

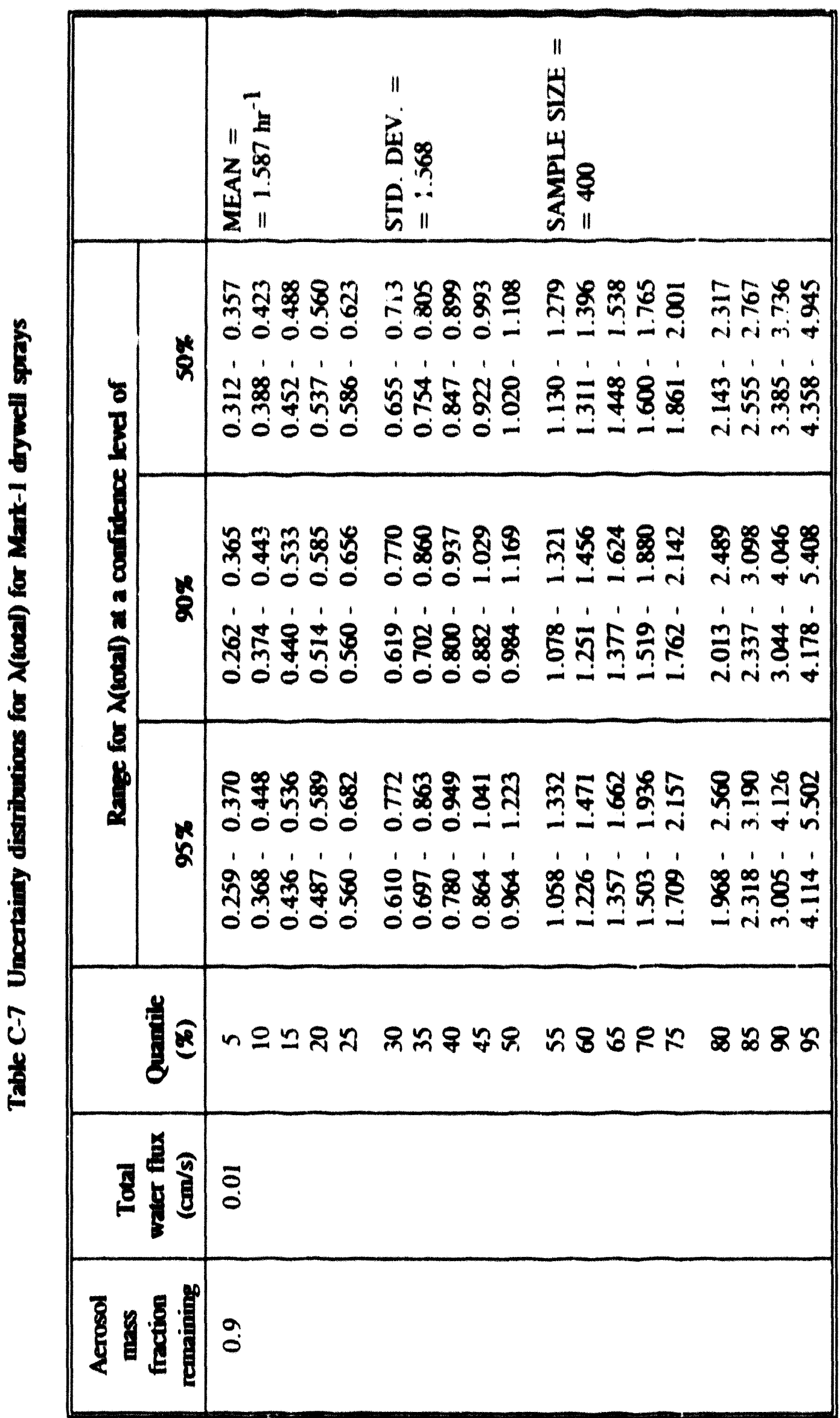


Appendix C

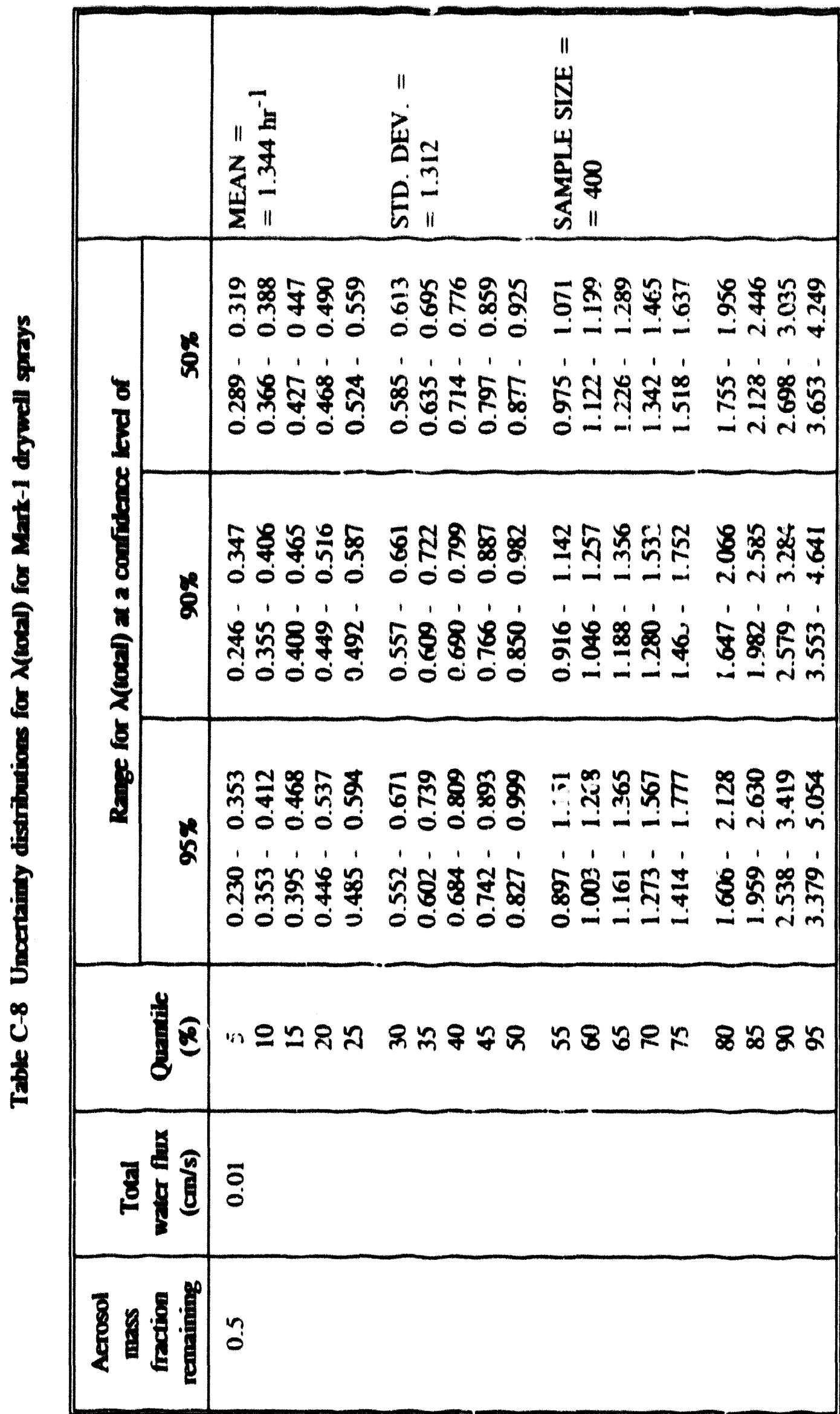




\section{Appendix C}

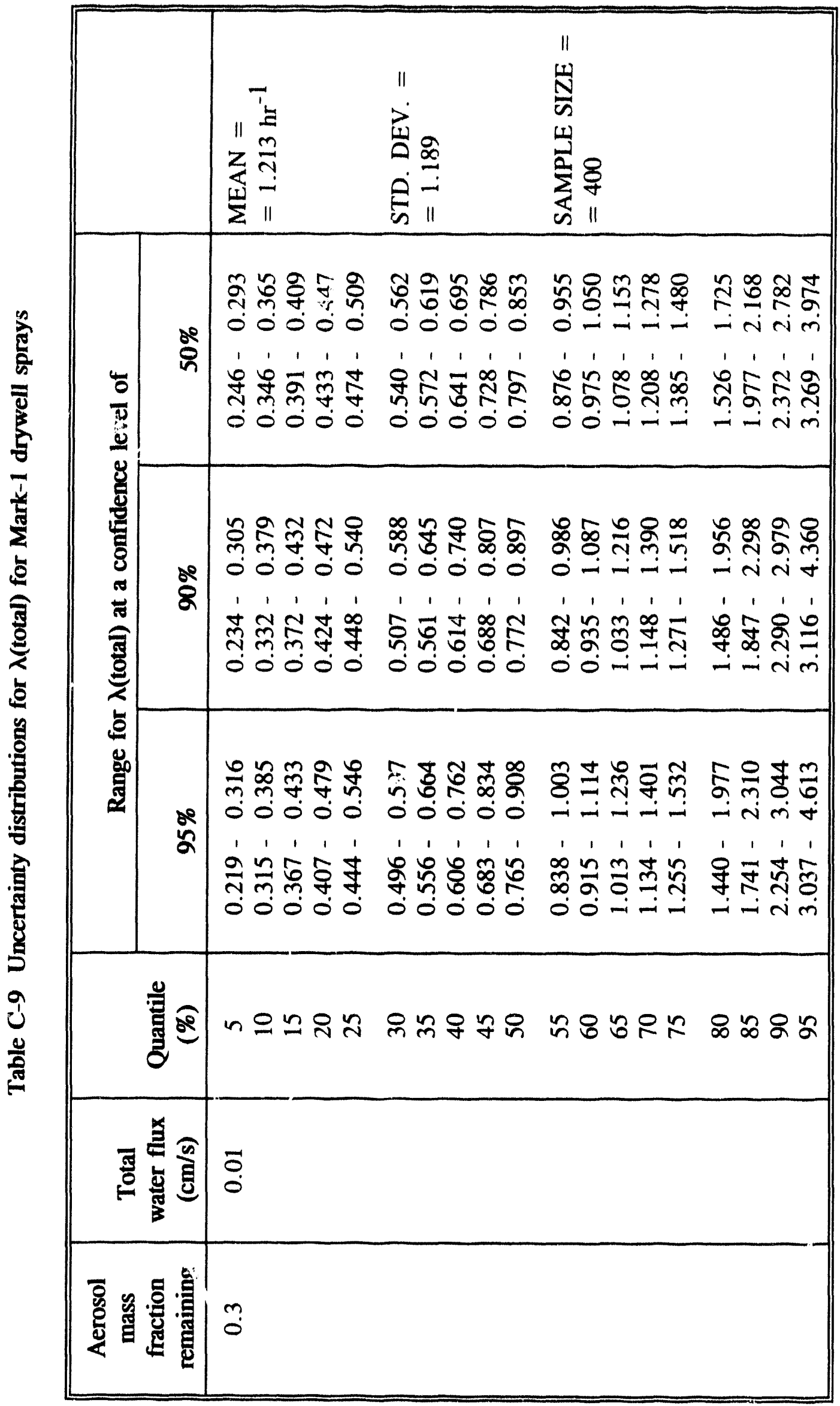


Appendix C

\begin{tabular}{|c|c|c|c|c|c|}
\hline & & 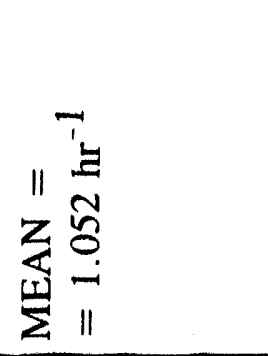 & 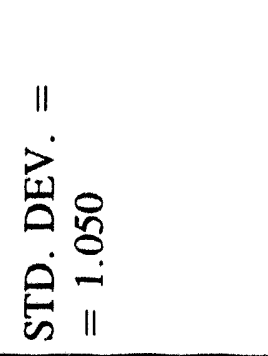 & 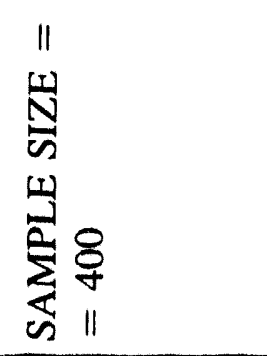 & \\
\hline \multirow{3}{*}{ 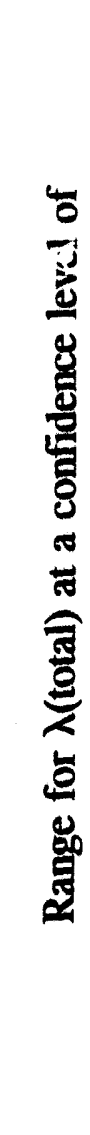 } & $\stackrel{\circ}{\circ}$ & 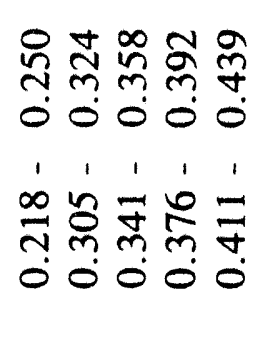 & 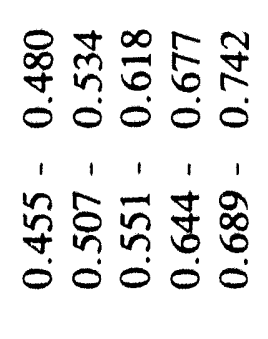 & 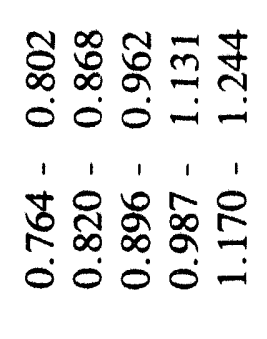 & 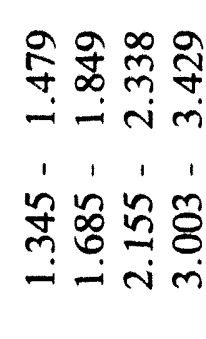 \\
\hline & छ̊ & 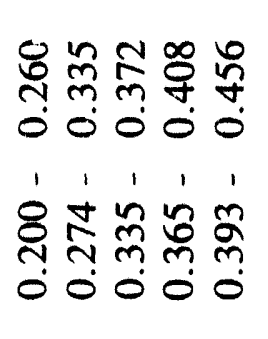 & 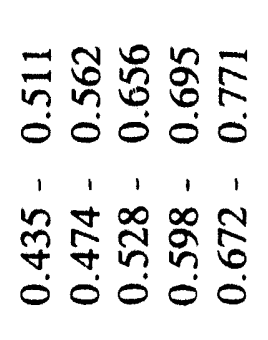 & 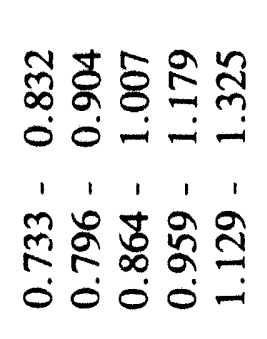 & 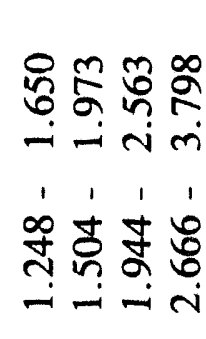 \\
\hline & $\begin{array}{l}\text { ô } \\
\text { a }\end{array}$ & 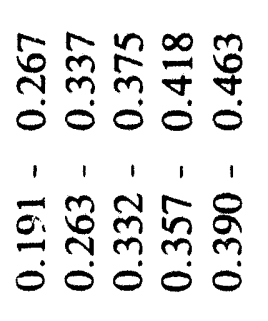 & 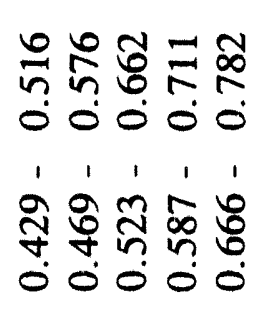 & 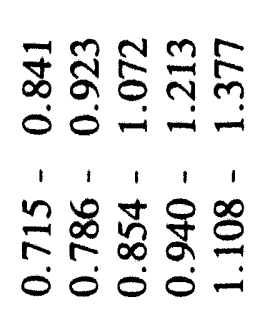 & 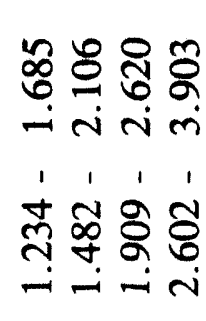 \\
\hline & 惫 & n으으요 & 品年古 & n̊ำํำ & ৪ஃタর \\
\hline & 兑 & $\ddot{\sigma}$ & & & \\
\hline $\begin{array}{l}\overline{0} \\
\text { 总 } \\
\text { 尊 }\end{array}$ & 兽 & $\overline{0}$ & & & \\
\hline
\end{tabular}




\section{Appendix C}

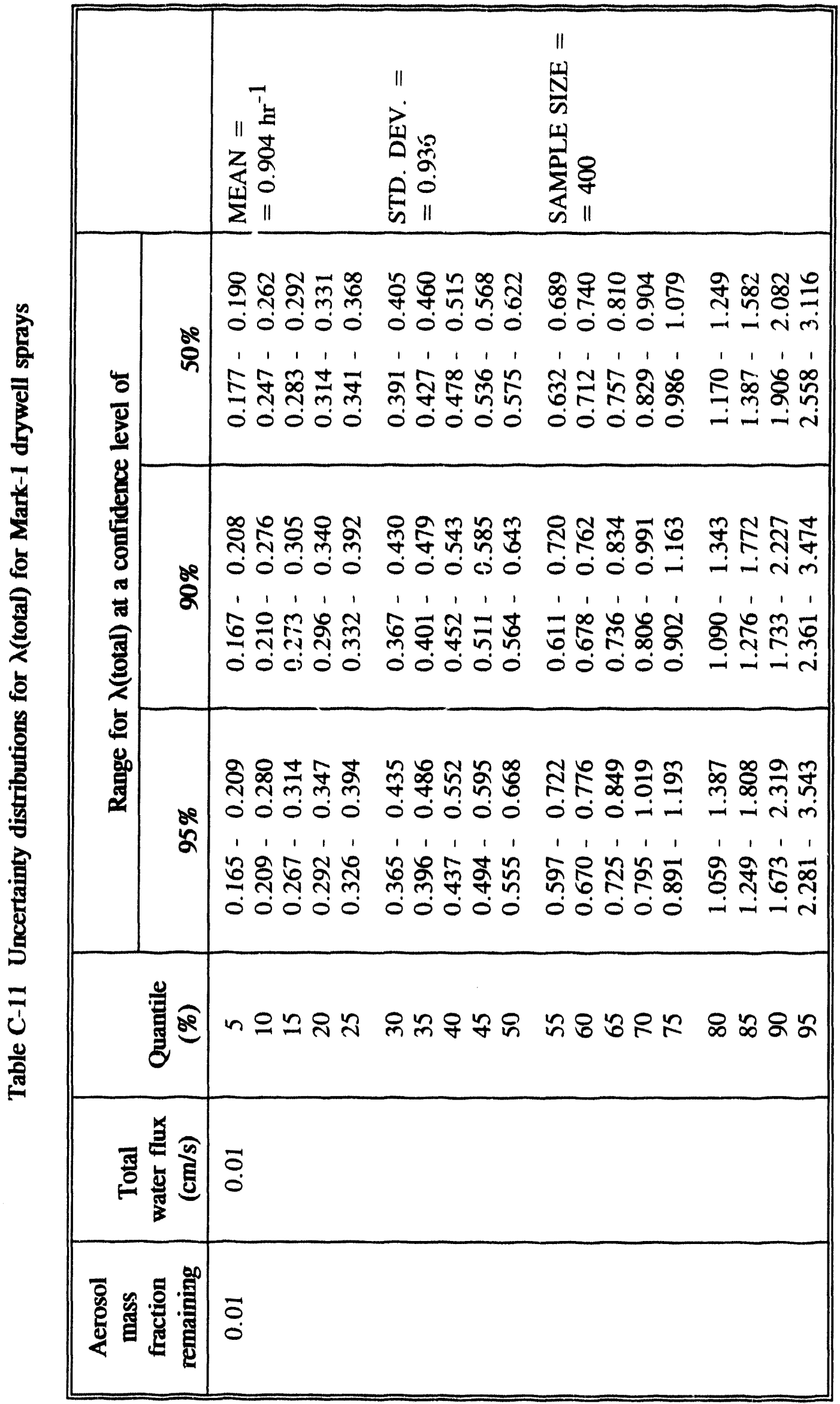


Appendix C

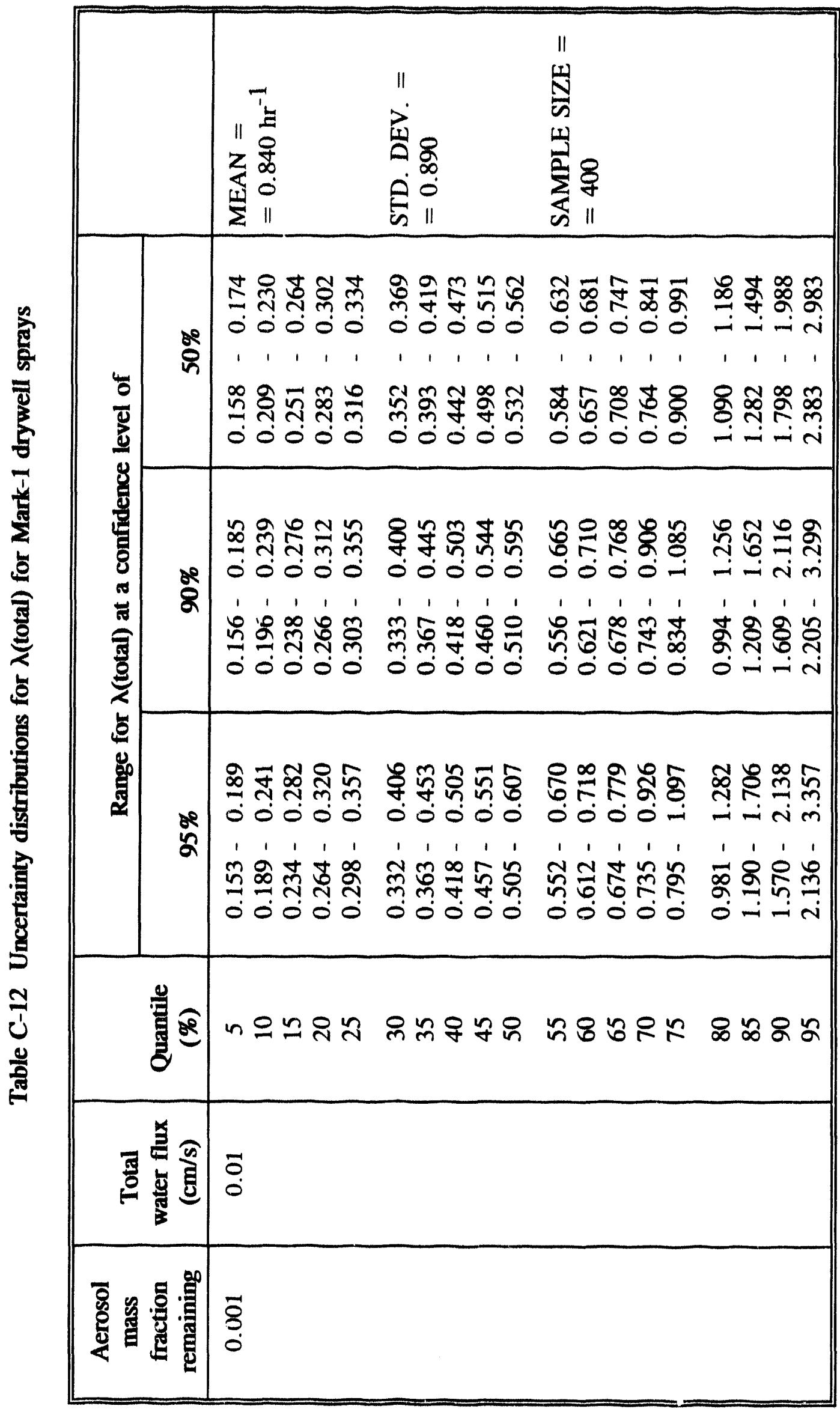




\section{Appendix C}

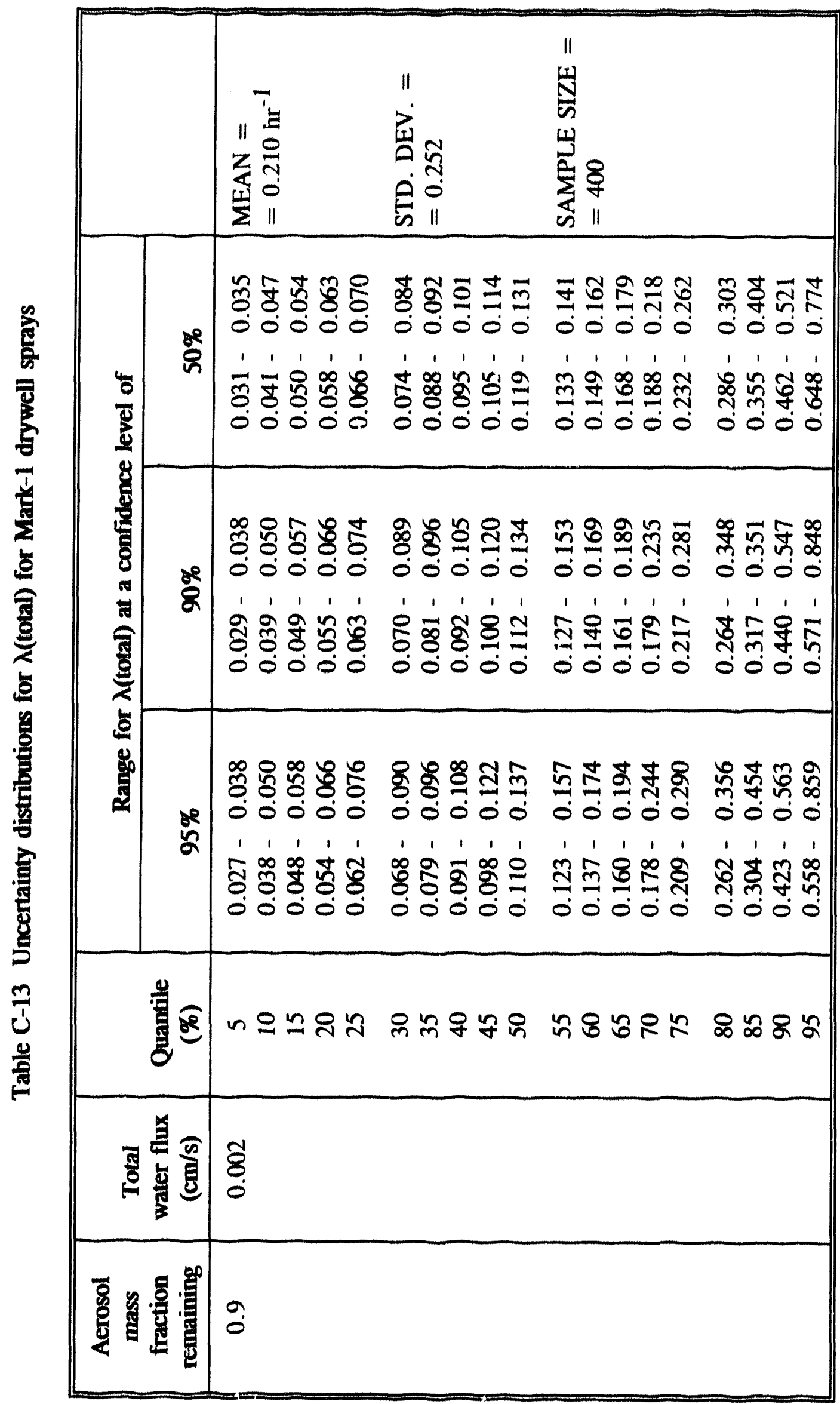


Appendix C

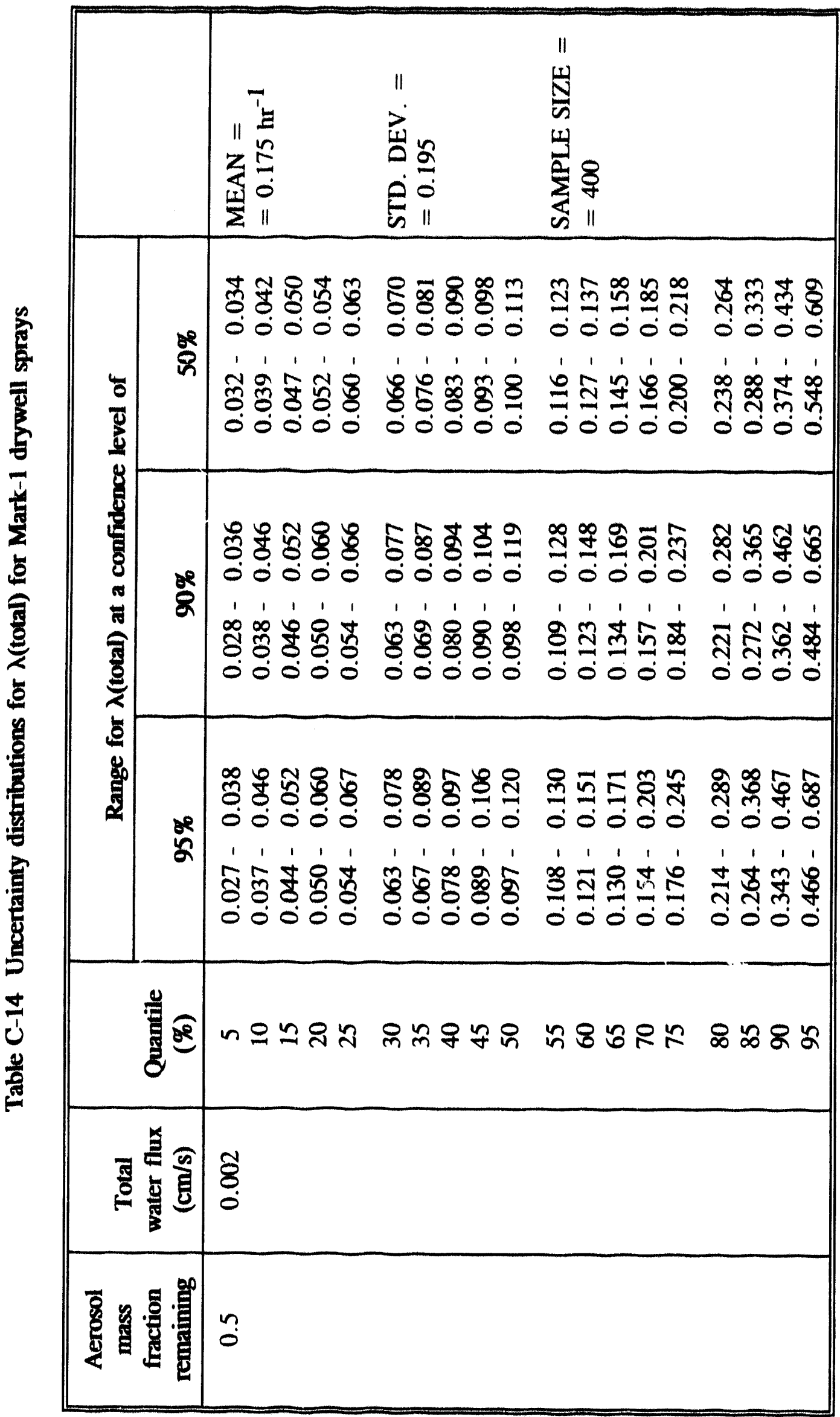


Appendix C

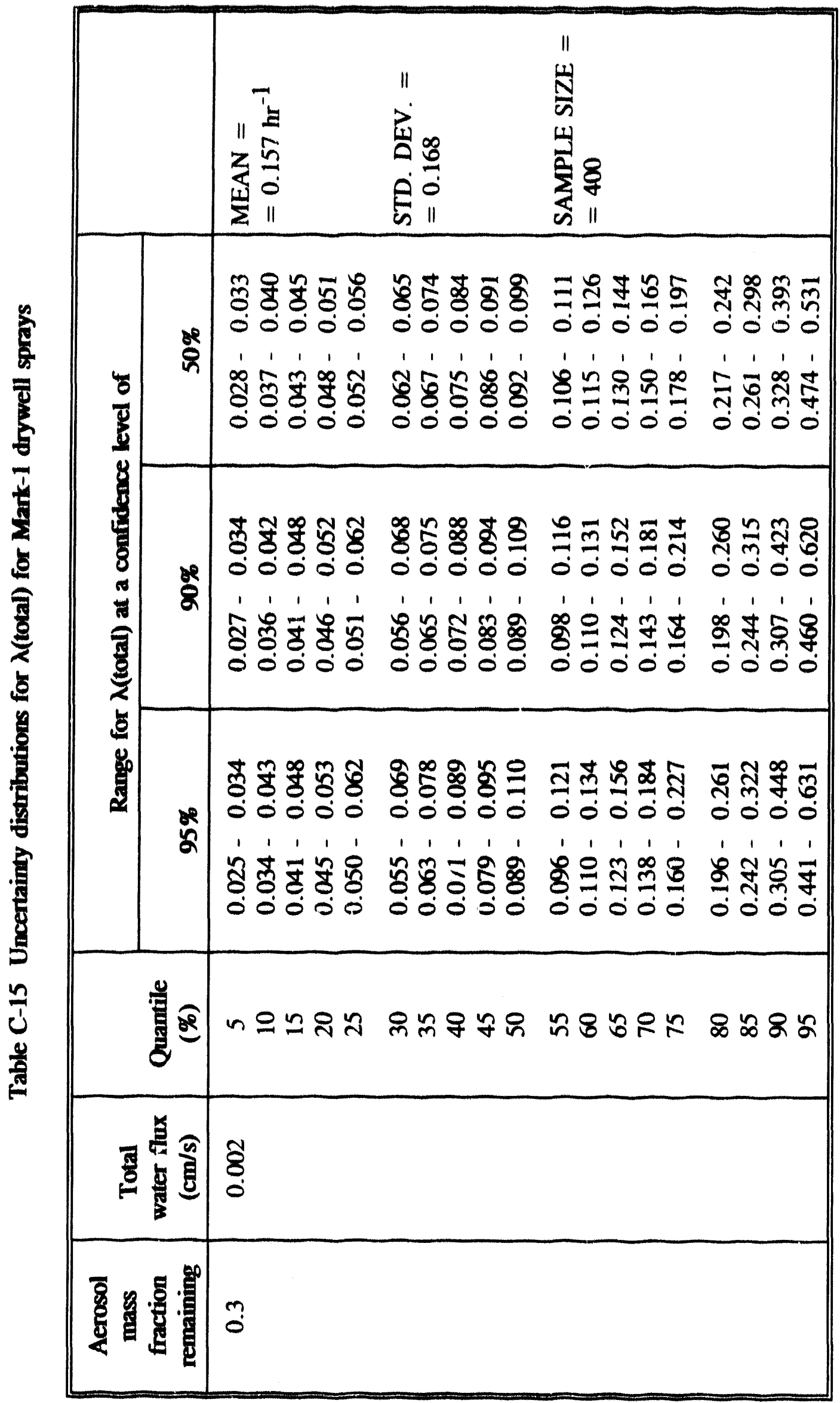


Appendix C

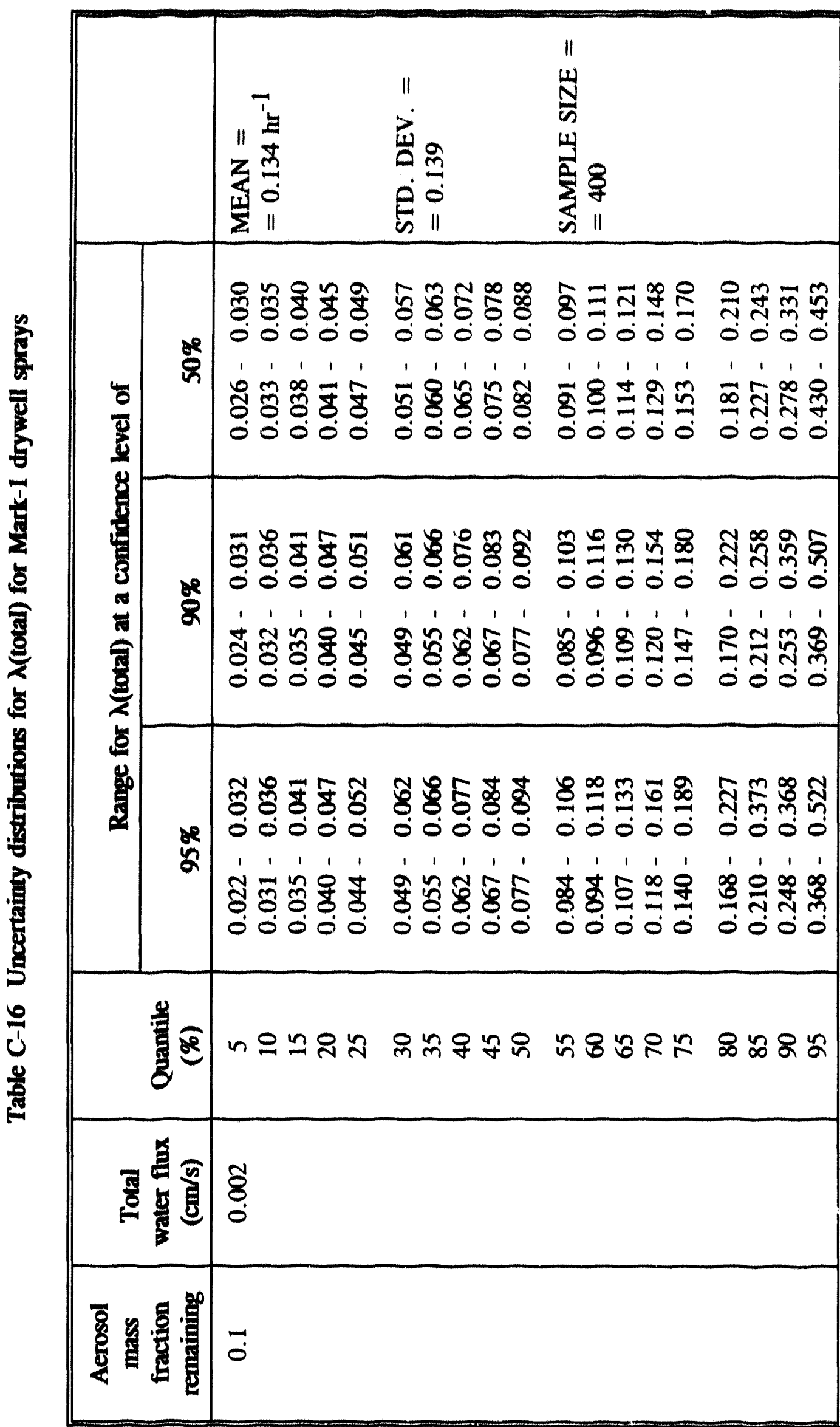


Appendix C

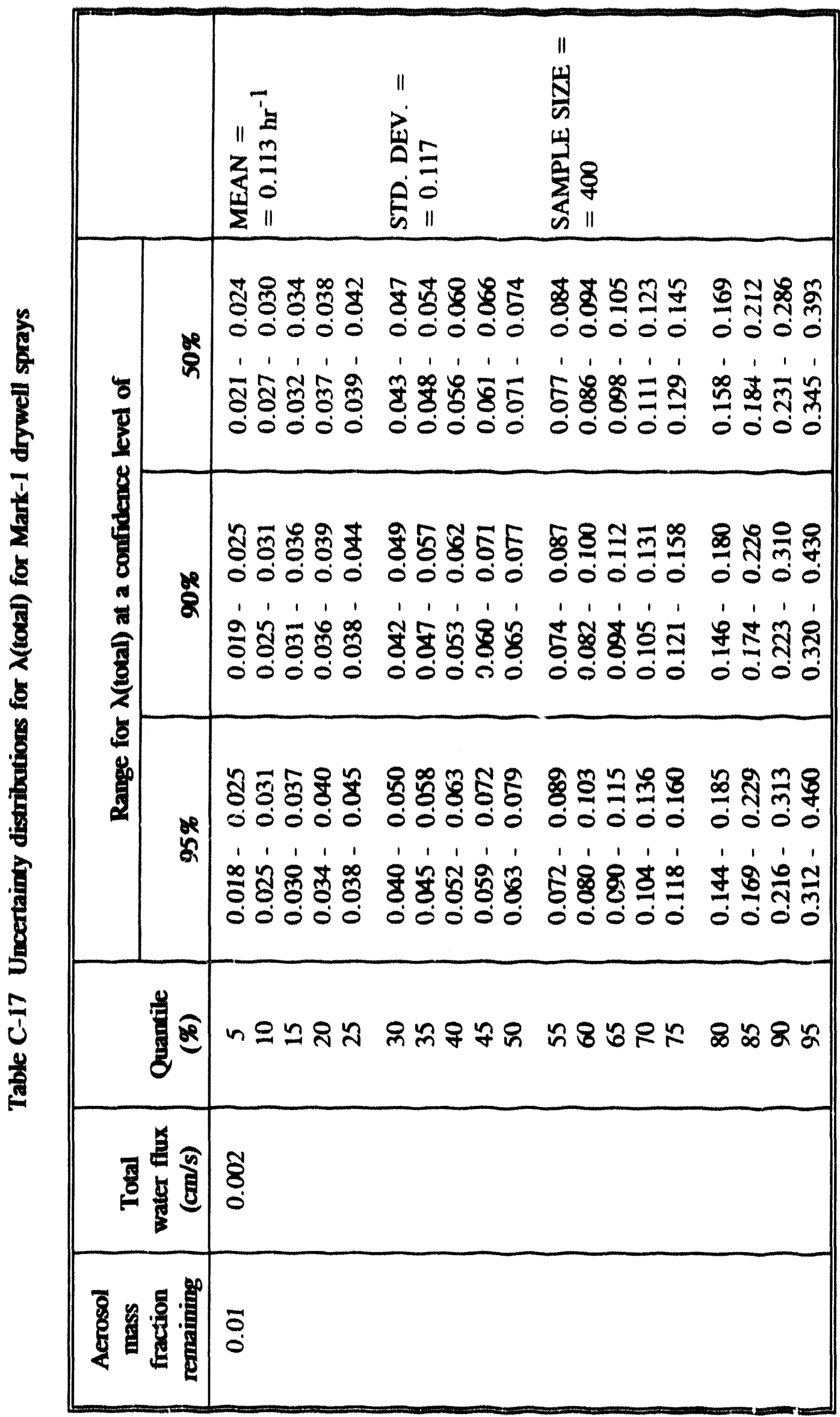


Appendix C

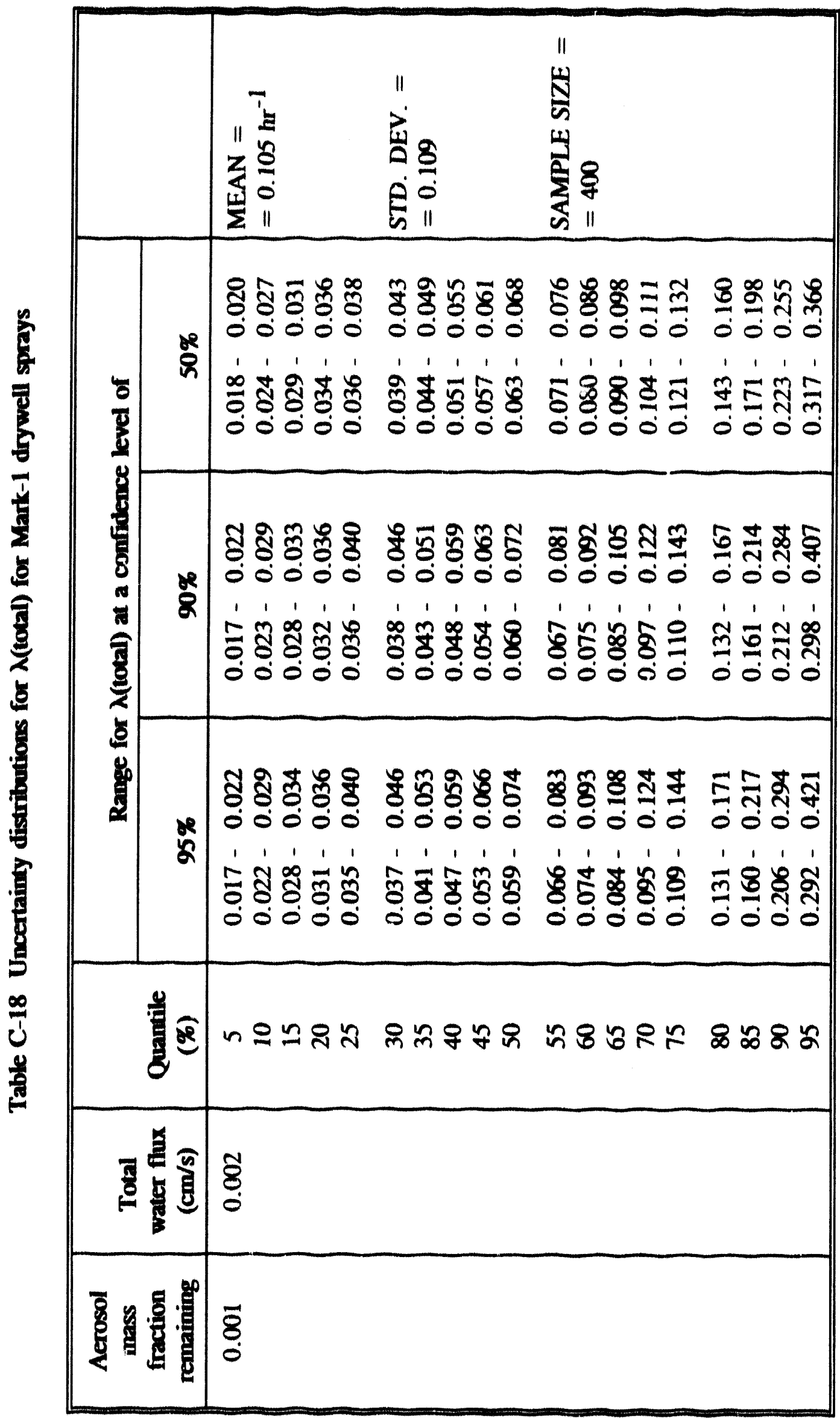




\section{Appendix D: Cumulative Probability Distributions for $\lambda\left(m_{f}\right) / \lambda\left(m_{f}=0.9\right)$}

Correlations among the values of the spray decontamination coefficients for various values of the mass fraction of aerosol remaining in the containment, $m_{f}$, make results of the uncertainty analyses difficult to use. Much of this correlation can be eliminated by selecting as the uncertain variables for a given water flux $\lambda\left(m_{f}=0.9\right)$ and $\lambda\left(m_{f}\right) / \lambda\left(m_{f}=0.9\right)$ for $m_{f}=0.5,0.3,0.1,0.01$. and 0.001 . Samples of the spray decontamination coefficient were reanalyzed in terms of these variables. Deatiled cumulative probability distributions for the variables $\lambda\left(m_{f}\right) / \lambda\left(m_{f}=0.9\right)$ for $Q=0.25,0.01$, and $0.002 \mathrm{~cm}^{3} / \mathrm{cm}^{2}-\mathrm{s}$ are shown in the tables in this appendix. The form and the contents of these tables are rather similar to the tables in Appendix $C$. showing detailed probability distributions for the spray decontamination coefficients. 
Appendix D

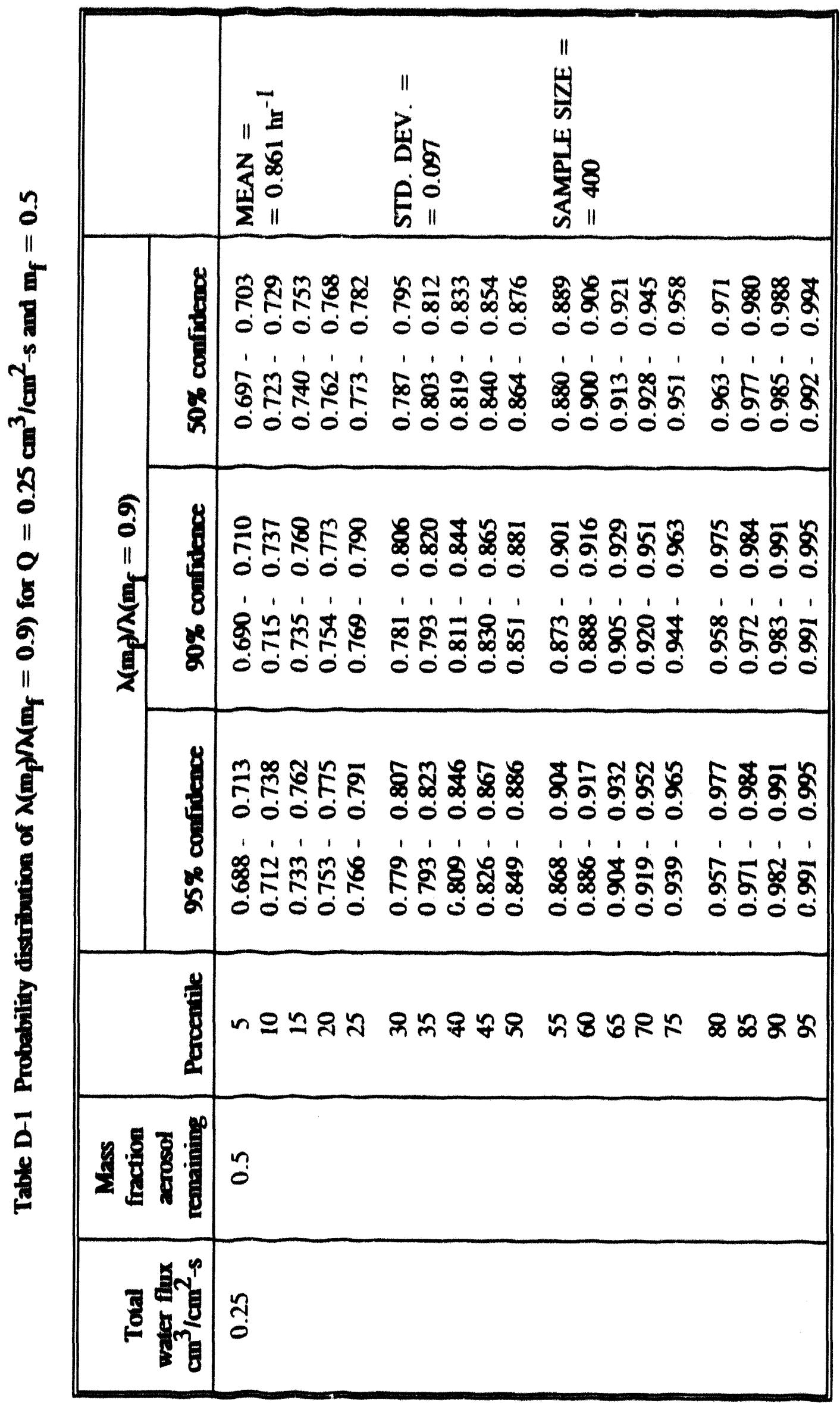


Appendix D

\begin{tabular}{|c|c|c|c|c|}
\hline & 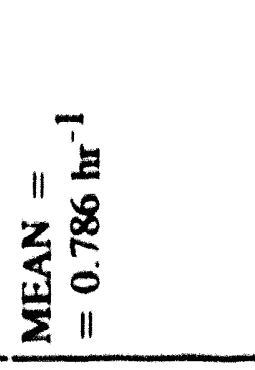 & 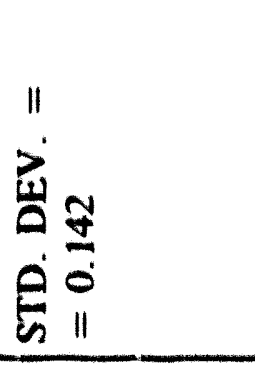 & 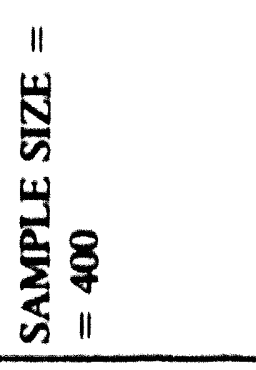 & \\
\hline $\begin{array}{l}8 \\
5 \\
8 \\
8 \\
8 \\
8\end{array}$ & 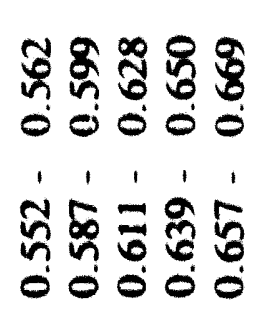 & 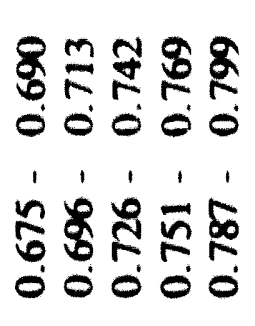 & 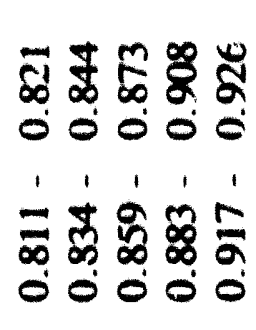 & 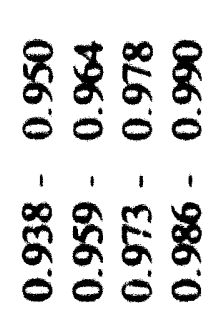 \\
\hline 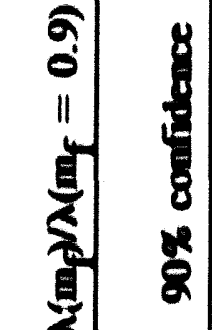 & 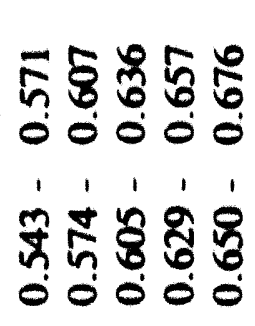 & 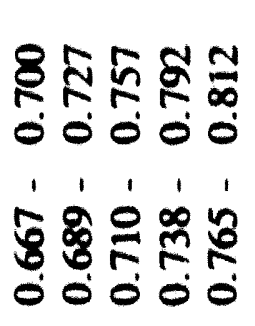 & 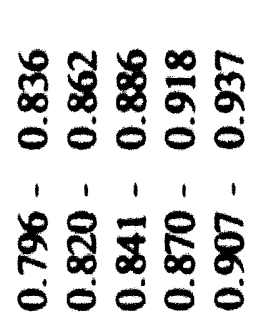 & 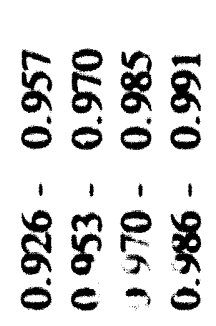 \\
\hline $\begin{array}{l}8 \\
\frac{8}{2} \\
8 \\
8 \\
2 \\
2\end{array}$ & 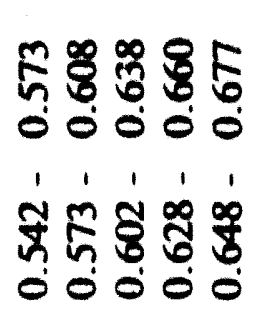 & 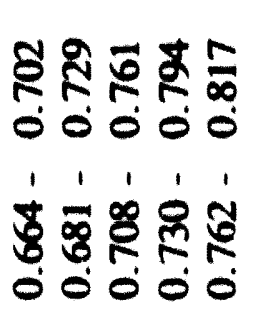 & 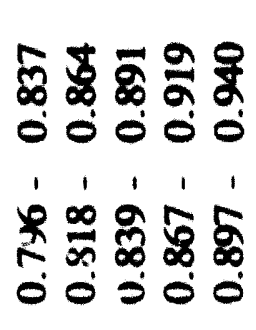 & 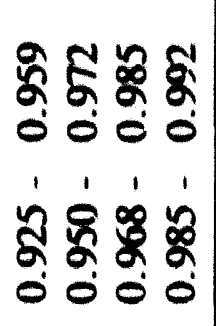 \\
\hline $\begin{array}{l}8 \\
8 \\
8\end{array}$ & ๓ะッス & 只んチ そタ & 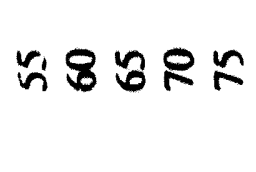 & வ ஃ \& と \\
\hline 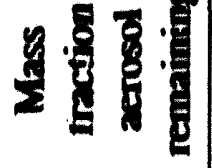 & $\stackrel{m}{o}$ & & & \\
\hline 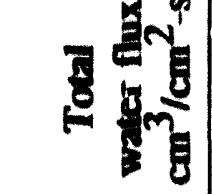 & $\stackrel{y}{y}$ & & & \\
\hline
\end{tabular}


Appendix D

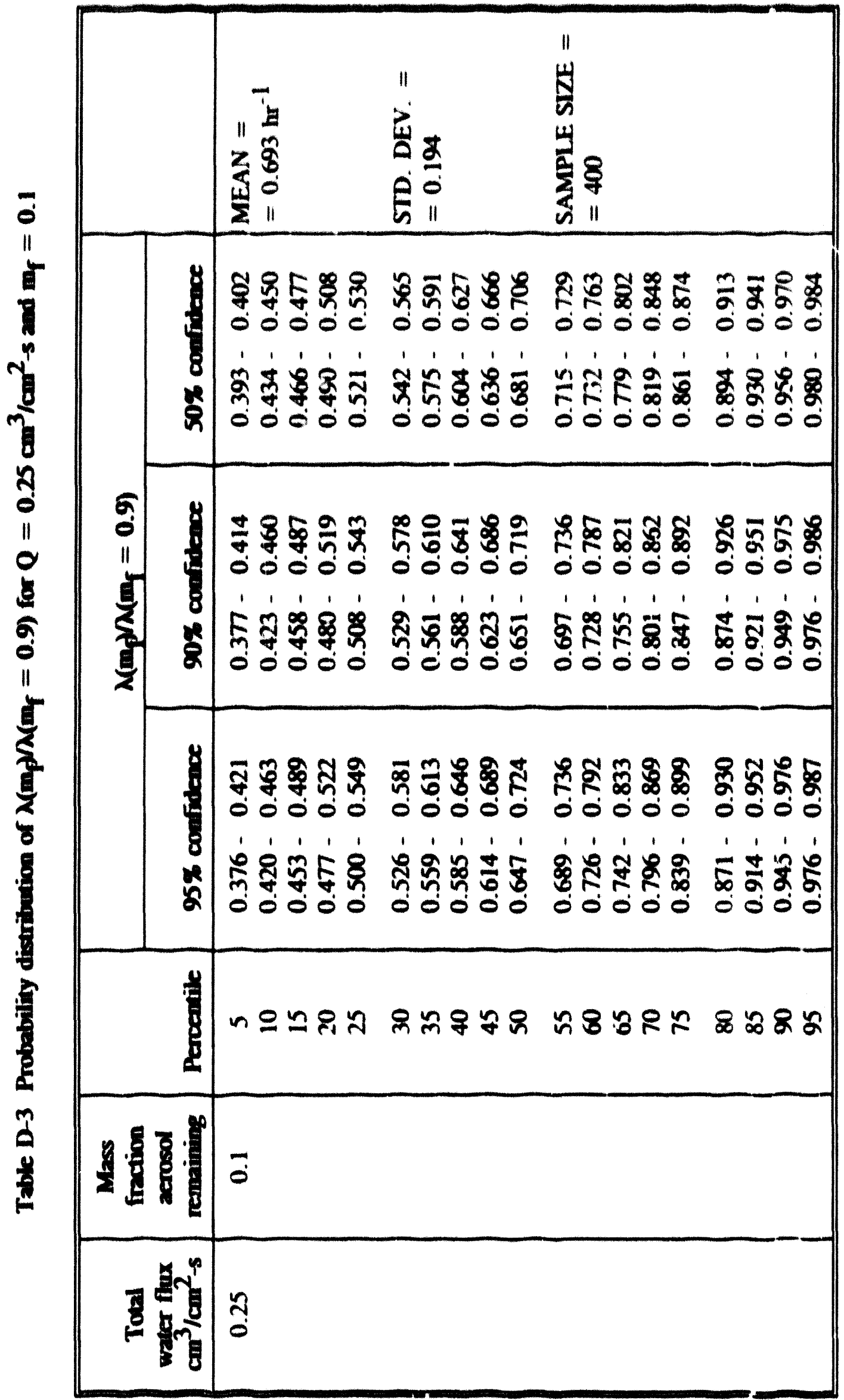




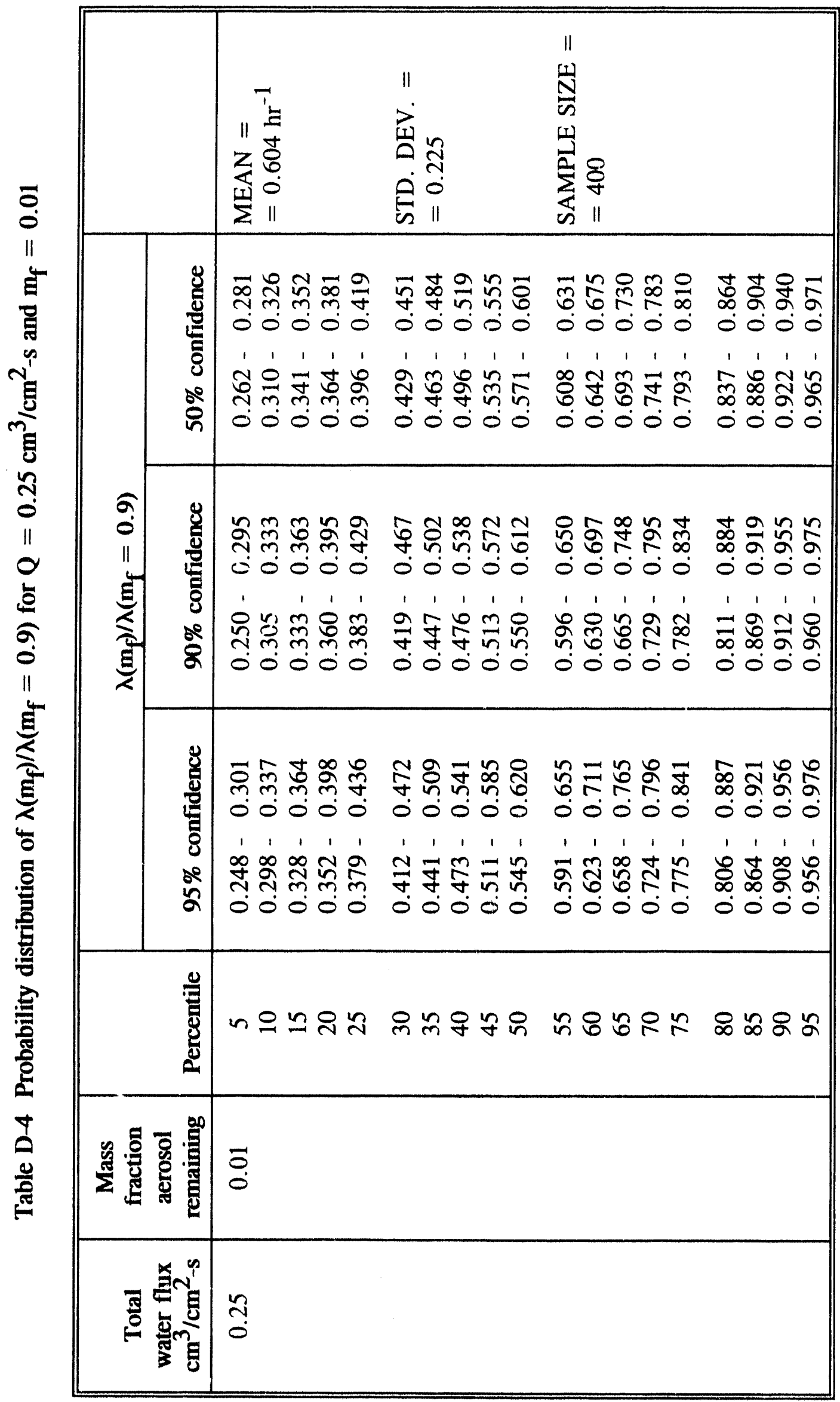

D-5 


\section{Appendix D}

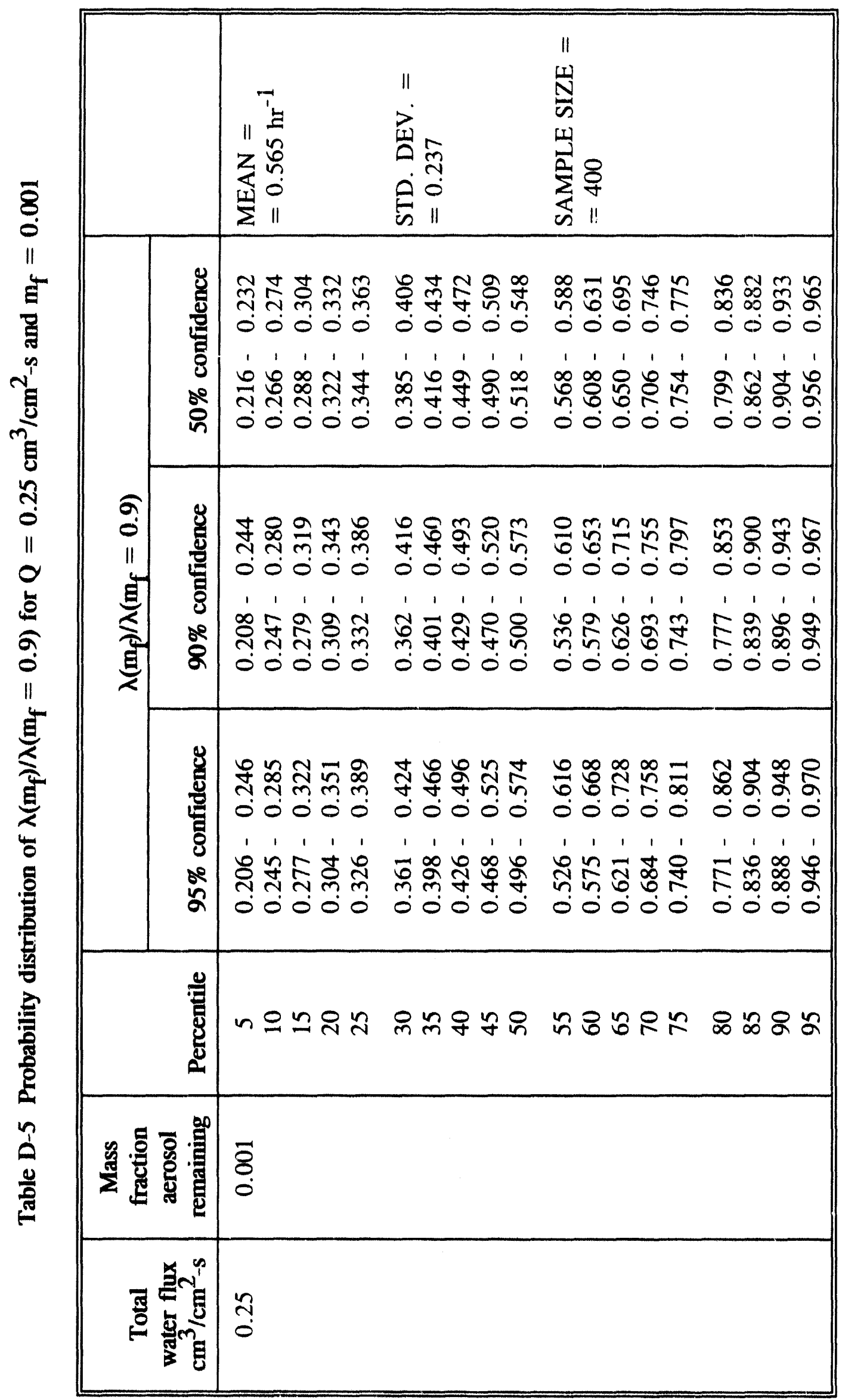


Appendix D

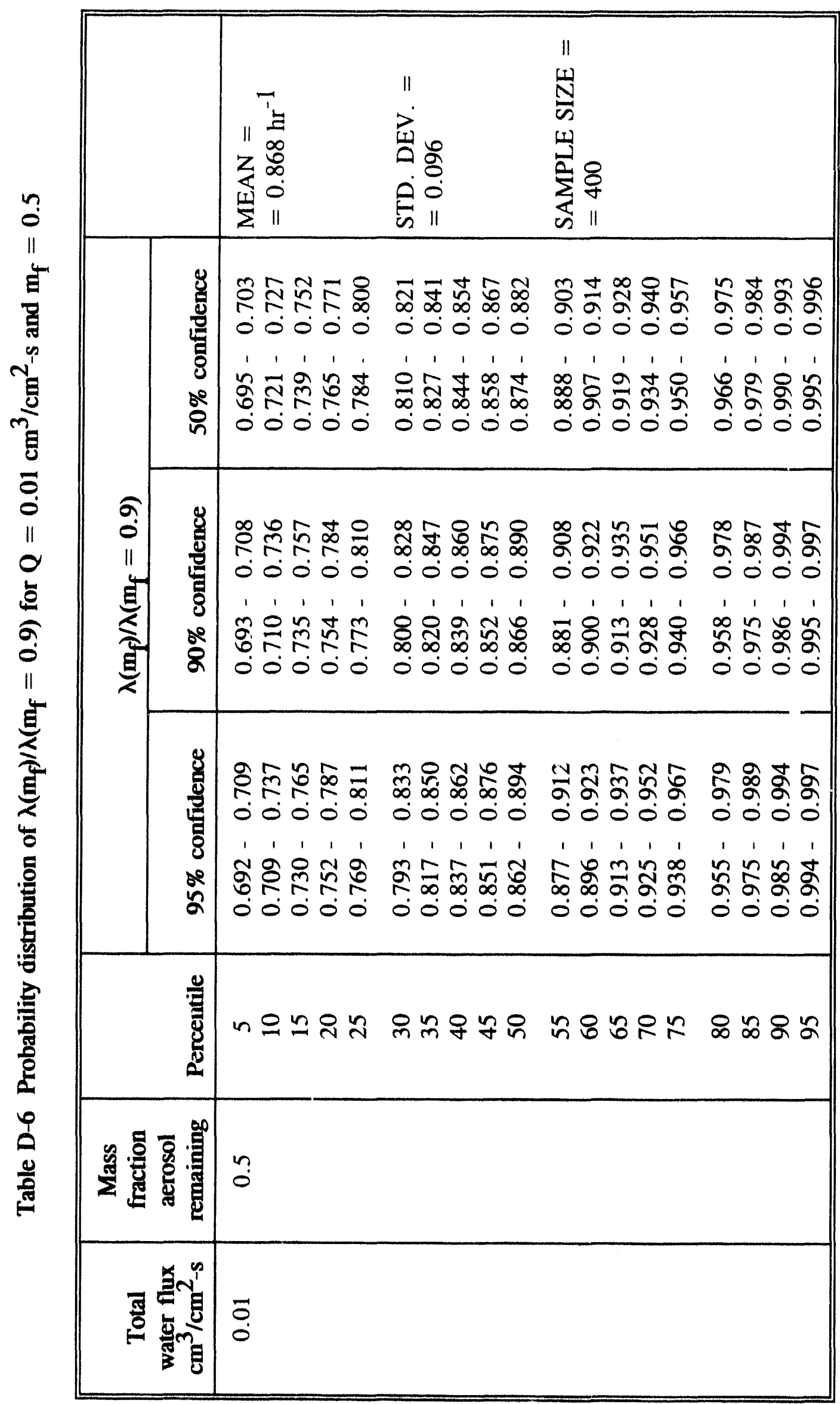

D-7 


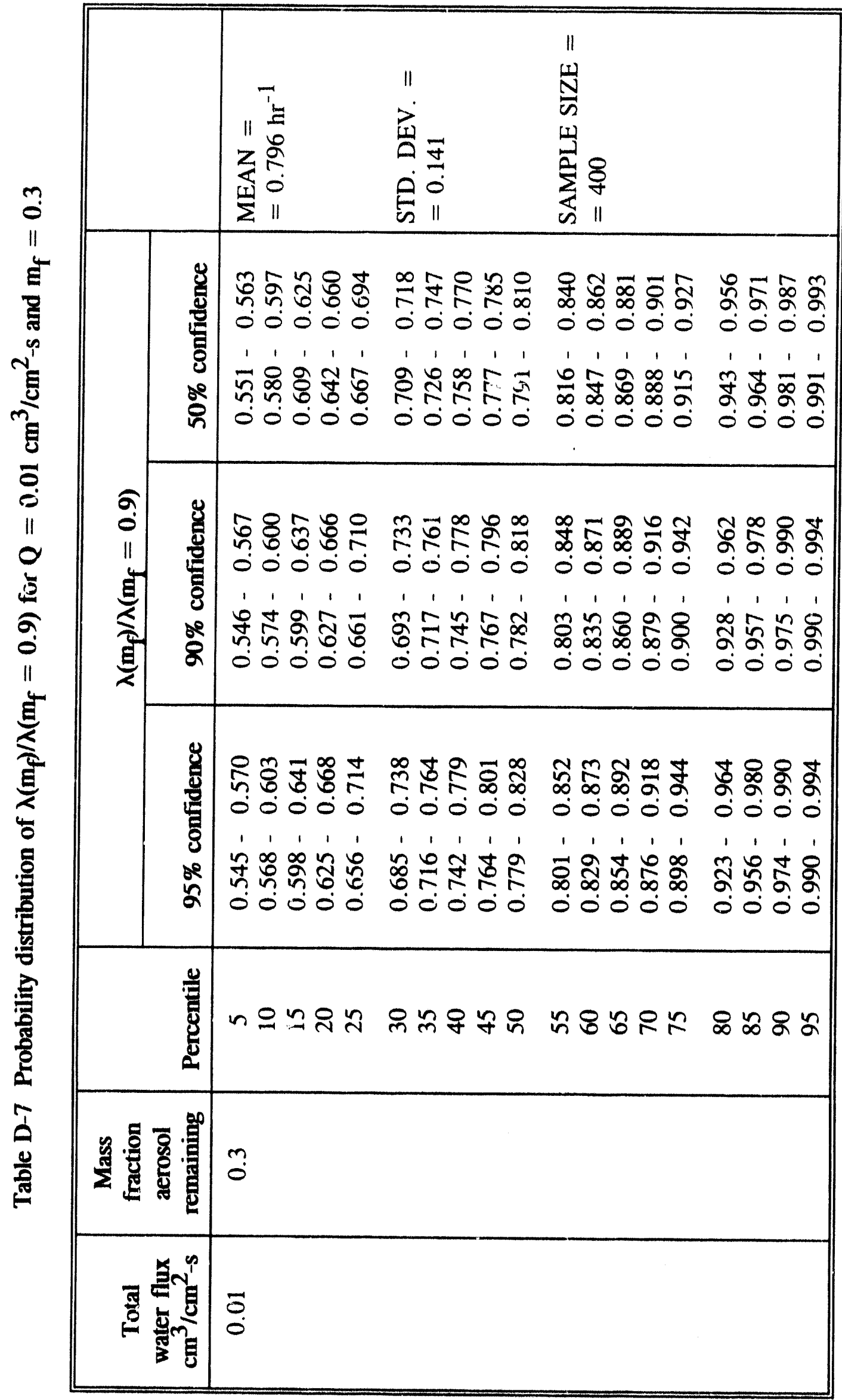


Appendix D

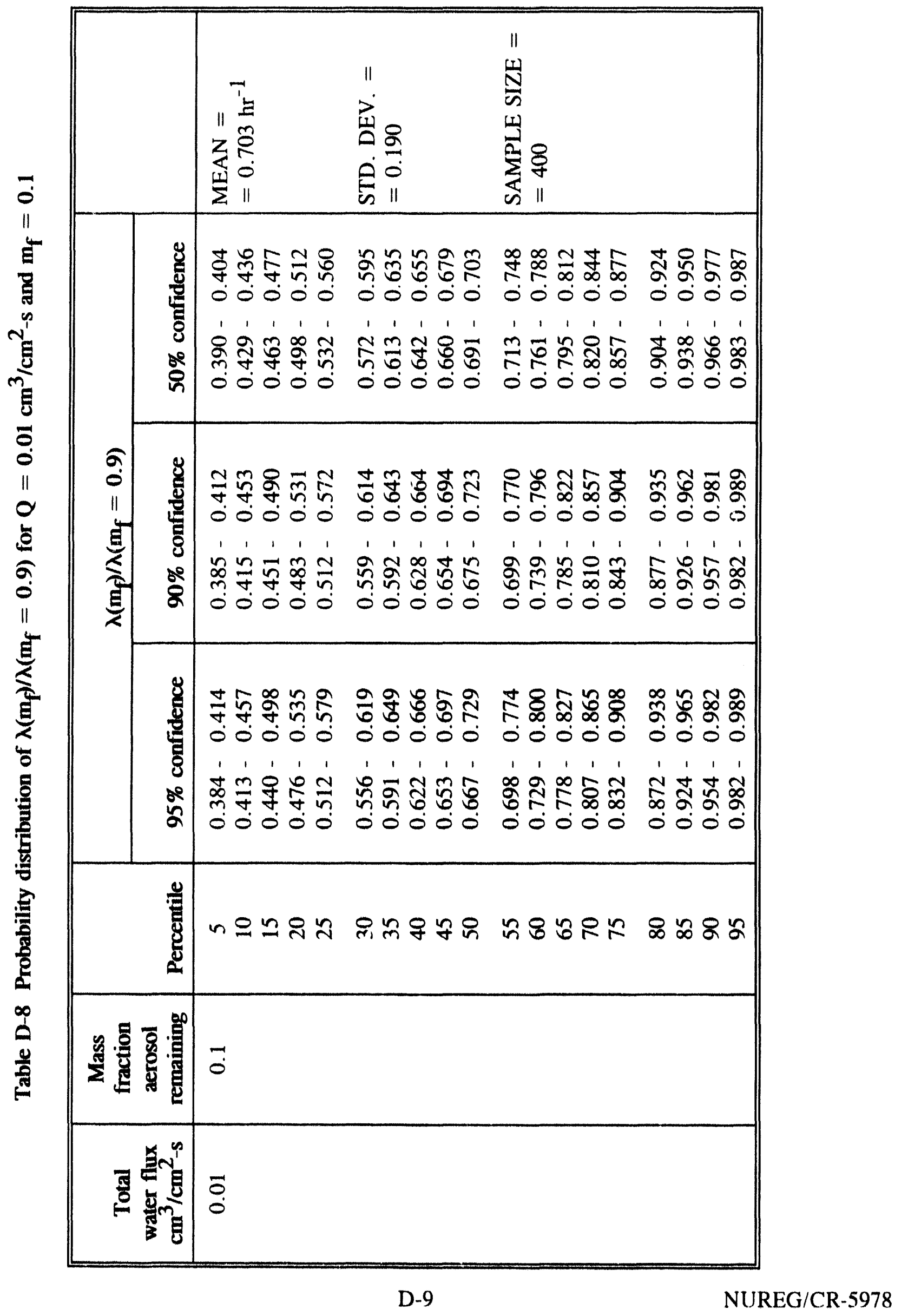


Appendix D

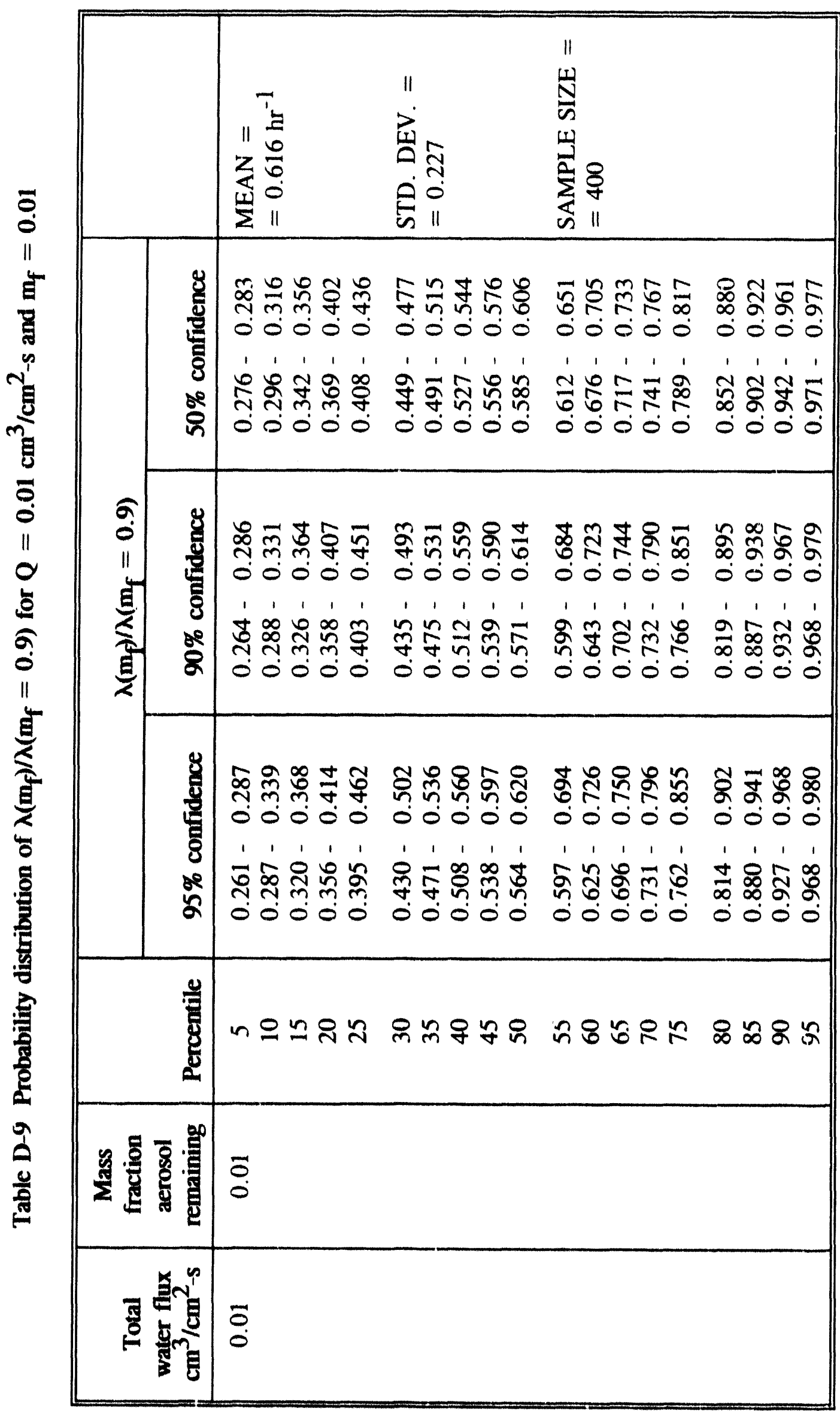


Appendix D

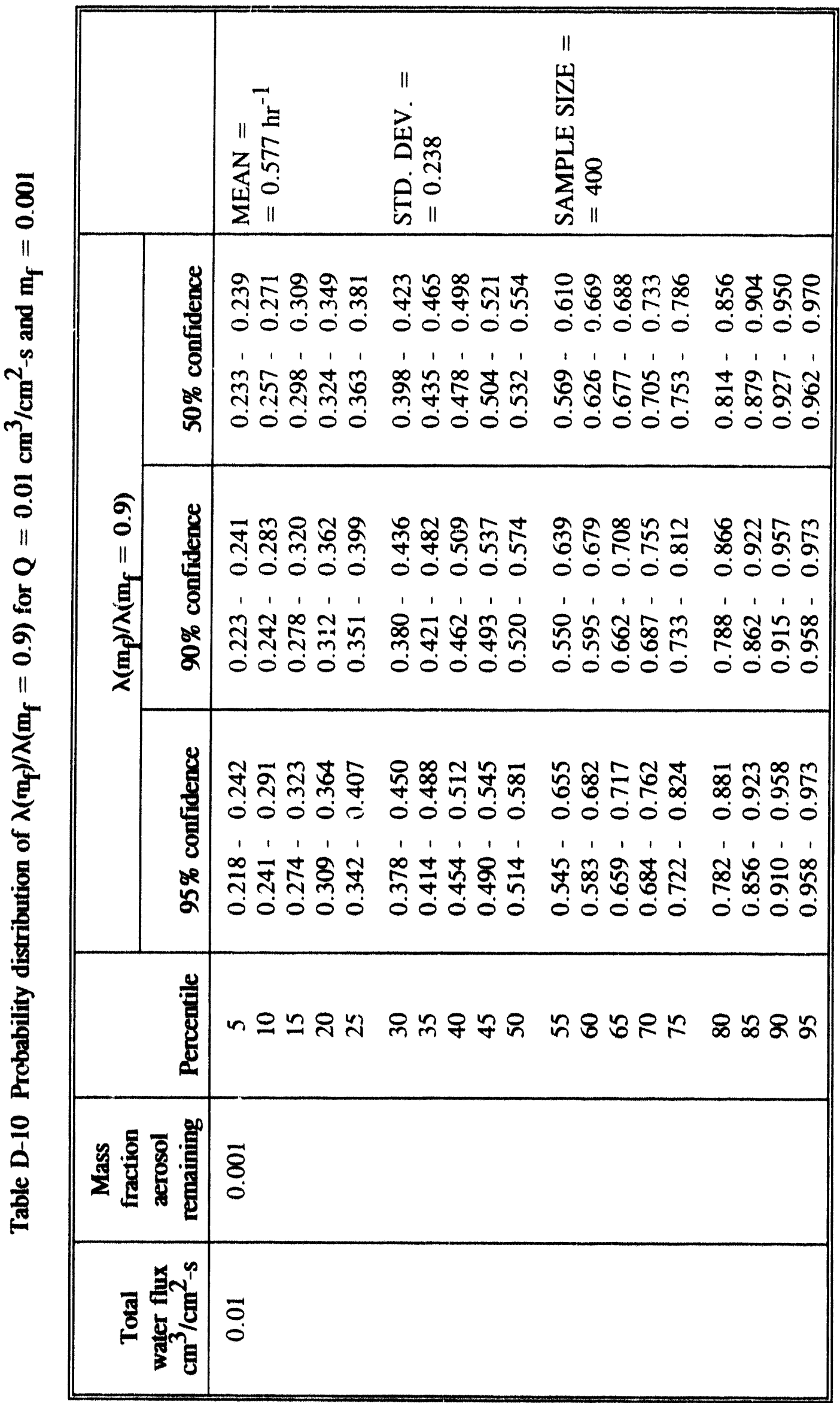

D-11 
Appendix D

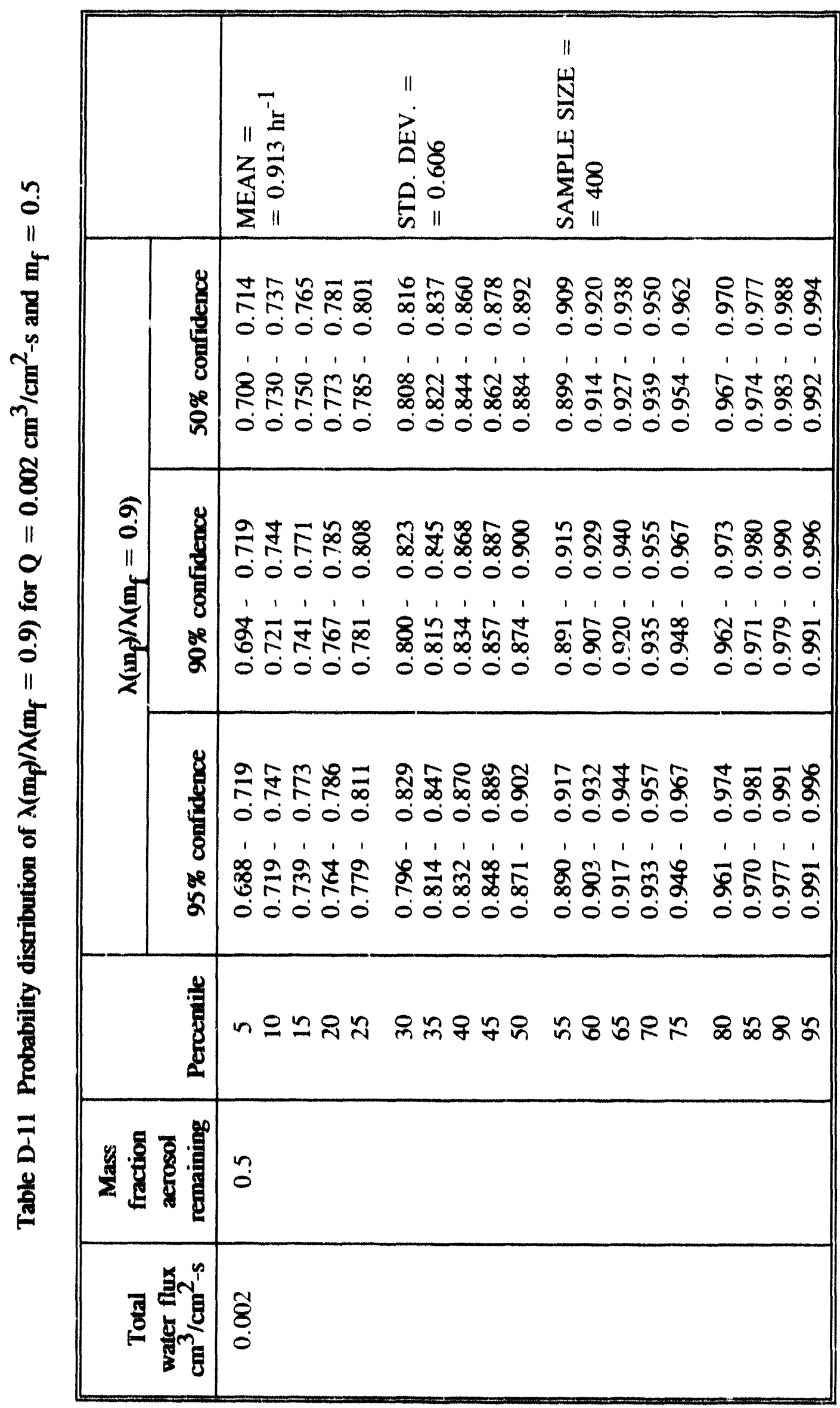


Appendix D

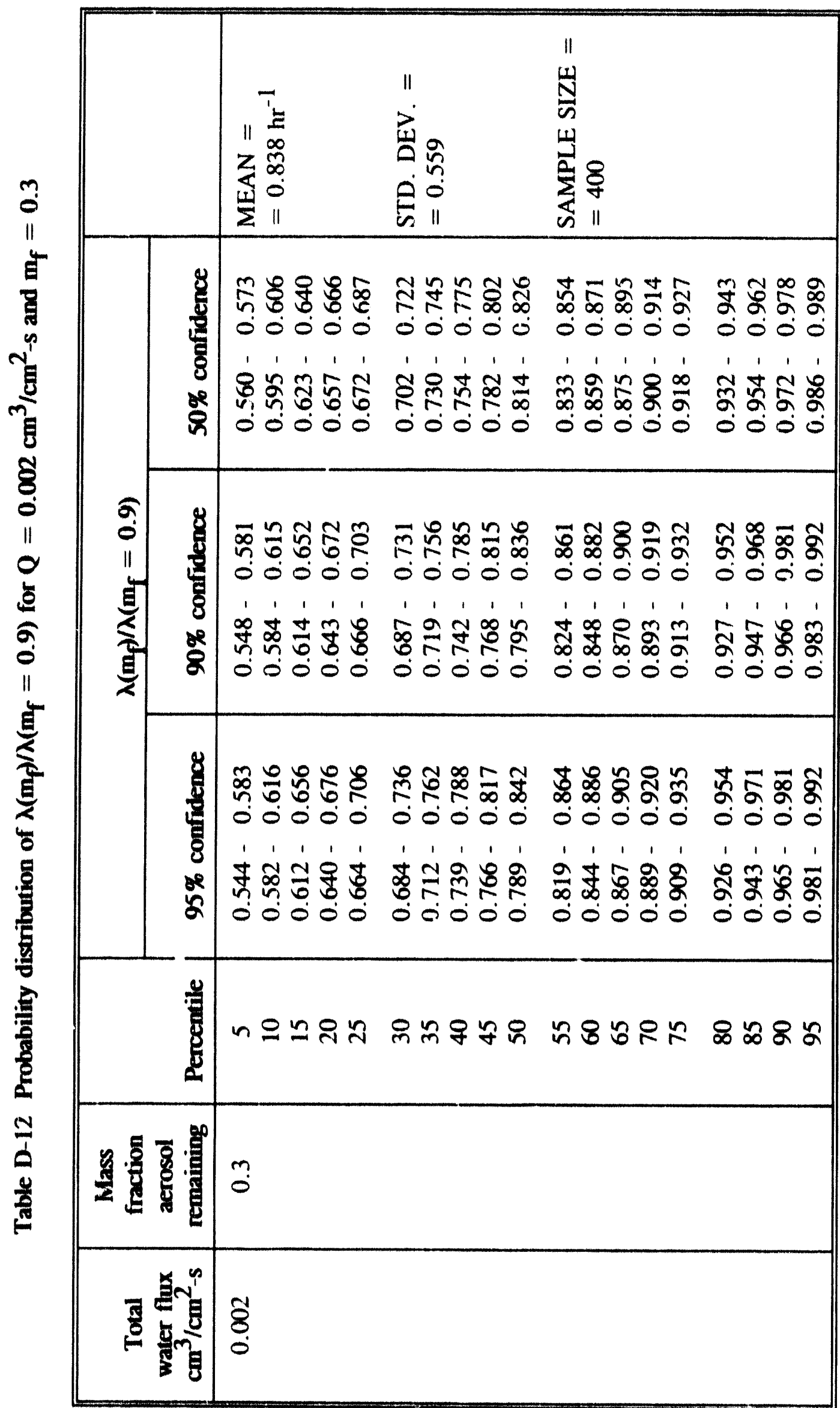


Appendix D

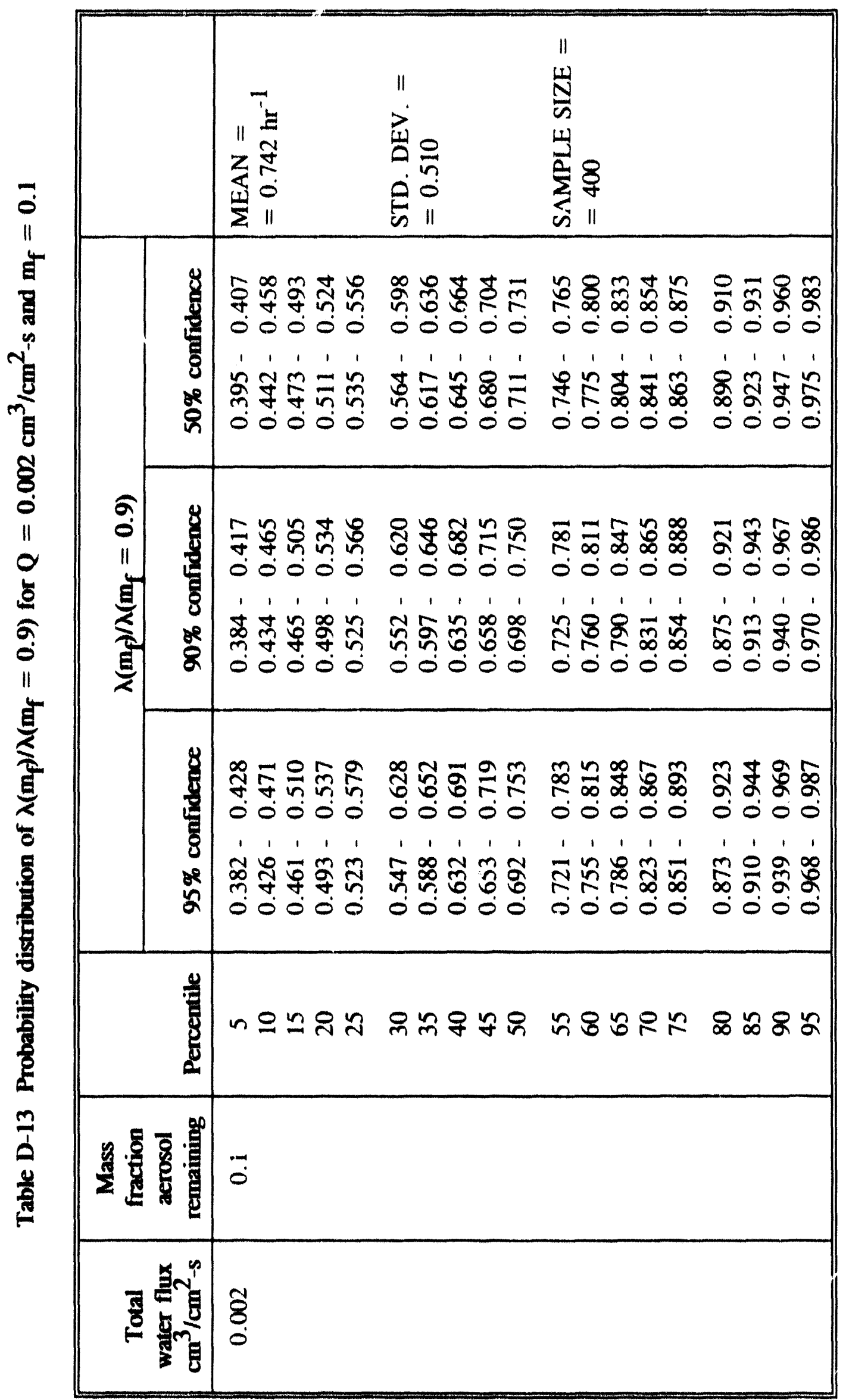


Appendix D

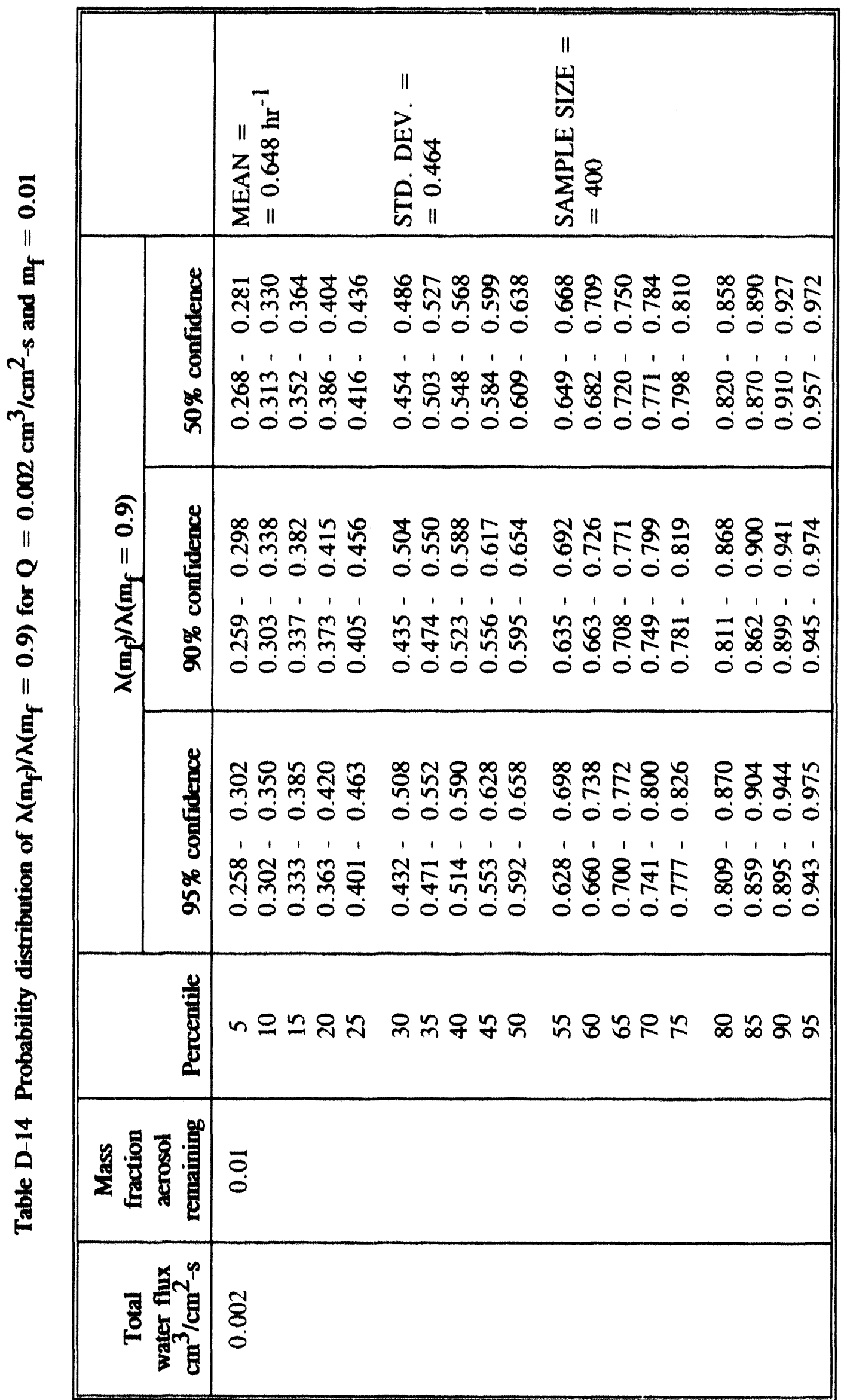

D-15 
Appendix D

\begin{tabular}{|c|c|c|c|c|}
\hline & 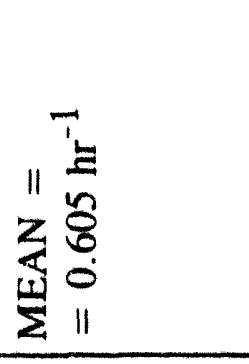 & 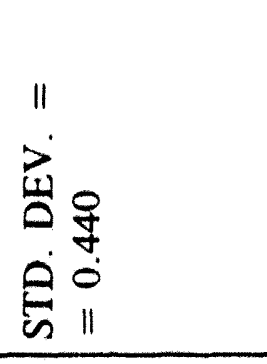 & 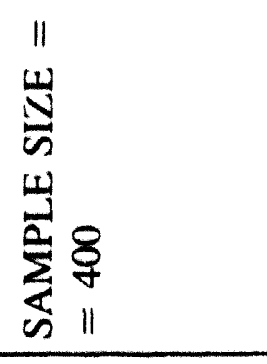 & \\
\hline 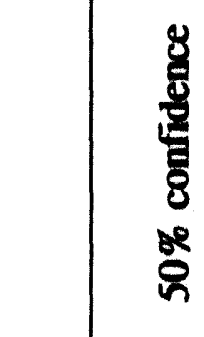 & 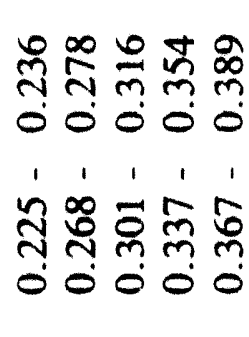 & 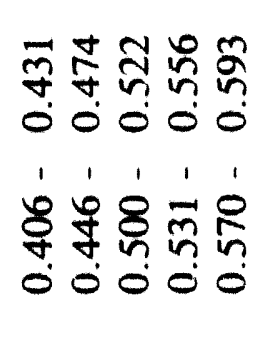 & 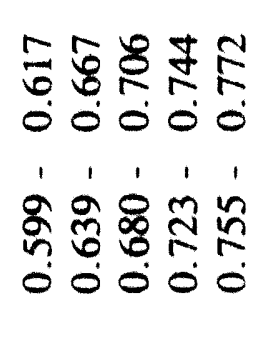 & 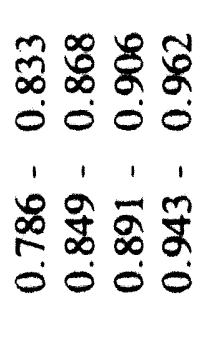 \\
\hline \multirow[t]{2}{*}{ 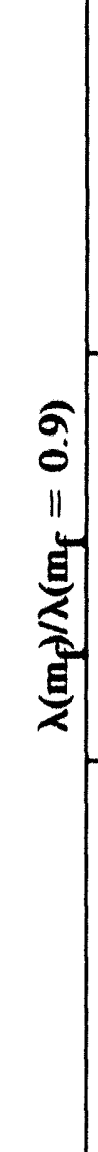 } & 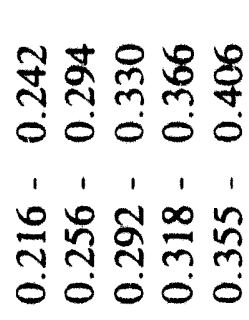 & 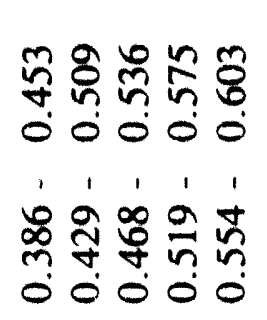 & 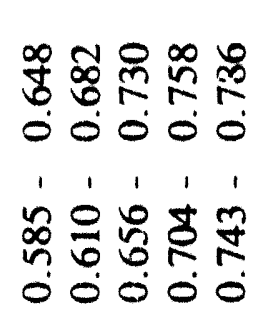 & 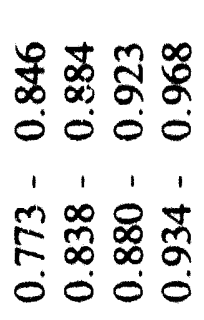 \\
\hline & 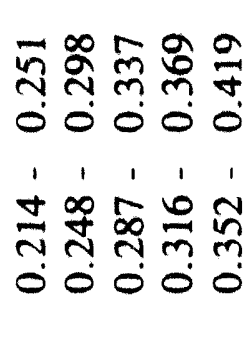 & 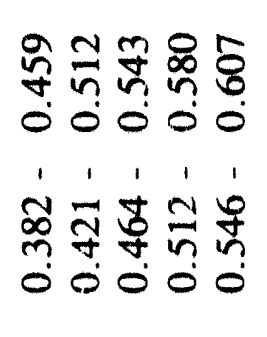 & 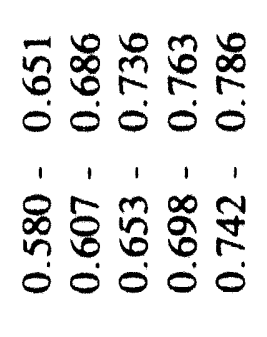 & 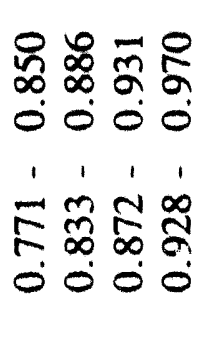 \\
\hline 胥 & n으류 & 이ำ \& & 드음요 & ஃஃタ \\
\hline 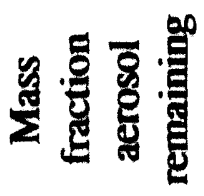 & סִ & & & \\
\hline 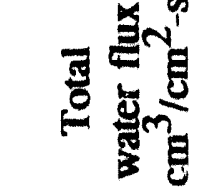 & $\begin{array}{l}\text { \&े } \\
0\end{array}$ & & & \\
\hline
\end{tabular}




\section{DISTRIBUTION:}

U.S. Nuclear Regulatory Commission (16) Office of Nuclear Regulatory Research

Attn: E. Beckjord, NLS-007

T. Speis, NLS-007

W. Minners, NLS-360

T. L. King, NLS-358

L. Soffer, NLS-324

R. Lee, NLN-344

A. Reuben, NLN-344

M. Cunningham, NLS-372

F. Eltawila, NLN-344

J. Mitchell, NLS-314

A. Behbahani, NLN-344

R. Meyer, NLS-007

J. C. Ryder, NLS-007

S. B. Burson, NLS-324

S. Basu, NLS-344

B. Sheron, Nis-007

Washington, D.C. 20555

U.S. Nuclear Regulatory Commission (4) Office of Nuclear Reactor Regulation

Attn: R. Palla, 10E4

R. Barrett, 10E4

W. Lyon, 8E23

J. Lee, 10D4

Washington, DC 20555

U.S. Department of Energy (2)

Office of Nuclear Safety

Attn: S. Blush

P. Worthington

1000 Independence Ave., S.W.

Washington, DC 20585

U.S. Department of Energy

NE-42

Attn: W. F. Pasedag

19901 Germantow/n Rd.

Germantown, MD 20585
U.S. Department of Energy

EM-36

Attn: H. Eckert

12800 Middlebrook Road

Germantown, MD 20874

U.S. Department of Energy (2)

Albuquerque Operations Office

Attn: C. E. Garcia, Director

For: C. B. Quinn

R. L. Holton

P.O. Box 5400

Albuquerque, NM 87185

Los Alamos National Laboratories

Attn: M. Stevenson

P.O. Box 1663

Los Alamos, NM 87545

Electric Power Research Institute (2)

Attn: A. Michiels

R. Sehgal

3412 Hillview Avenue

Palo Alto, CA 94303

University of California Los Angeles (4)

Nuclear Energy Laboratory

Attn: I. Caffon

D. Okrent

W. Kastenberg

G. Apostolakis

405 Hilgaard Avenue

Los Angeles, CA 90024 
Brookhaven National Laboratory (6)

Attn: R. A. Bari

T. Pratt

N. Tutu

G. Greene

V. Mubay

R. Davis

$130 \mathrm{BNL}$

Upton, NY 11973

Fauske and Associates, Inc.

Attn: R. Henry

16W070 West 83rd Street

Burr Ridge, IL 60952

Battelle Columbus Laboratory (4)

Attn: R. Denning

J. Gieseke

K. Lee

C. Alexander

505 King Avenue

Columbus, $\mathrm{OH} 43201$

Department of Energy

Scientific and Tech. Info. Center

P.O. Box 62

Oak Ridge, TN 37831

EG\&G Idaho

Willow Creek Building, W-3

Attn: R. Hobbins

P.O. Box 1625

Idaho Falls, ID 83415

Battelle Pacific Northwest Laboratory

Attn: M. Freshley

P.O. Box 999

Richland, WA 99352

Wang Lu

TVA

400 Commerce, WGC 157-CK

Knoxville, TN 37902
Professor R. Seale

Department of Nuclear Engineering

University of Arizona

Tucson, Arizona 85721

Oak Ridge National Laboratory (3)

Attn: T. S. Kress

S. Hodge

T. Wright

P.O. Box Y

Oak Ridge, TN 37830

S. Rosen

Nuclear Fuel Engineering

ABB Combustion Engineering

Nuclear Power

1000 Prospect Hill Road

P.O. Box 500

Windsor, CT 06095-0500

Alan Nelson

NUMARC

1776 I Street NW

Suite 300

Washington, DC 20006

Professor T. G. Theofanous

University of California Santa Barbara

Chemical and Nuclear Engineering Dept.

UC-Santa Barbara

Santa Barbara, CA 93106

D. Osetek

Los Alamos Technical Associates

Building 1, Suite 400

2400 Louisiana NE

Albuquerque, NM 87110

David Leaver

TENERA

1340 Saratoga-Sunnyvale Rd.

Suite 206

San Jose, CA 95129 


\section{FOREIGN DISTRIBUTION}

Alan Jones

ISPRA

CEC Joint Research Center

21020 Varese

ITALY

Japan Atomic Energy Research Institute

Tokai Research Establishment

Attn: Dr. S. Matsuura, Deputy Director General

Tokai-mura, Naka-gun, Ibaraki-ken

319-11

JAPAN

Japan Atomic Energy Research Institute (4)

Severe Accident Research Laboratory

Attn: K. Soda

J. Sugimoto

N. Yamano

Y. Maruyama

Tokai-mura, Naka-gun, Ibaraki-ken

319-11

JAPAN

Japan Atomic Energy Research Institute Reactor Accident Laboratory

Attn: Dr. T. Fujishiro, Head

Tokai-mura, Naka-gun, Ibaraki-ken

319-11

JAPAN

Technische Universitat Munchen

Attn: Professor H. Karwat

8046 Garching, Forschungagelande

Munich

GERMANY
Kernforschungszentrum Karlsruhe (4)

Attn: H. Alsmeyer

P. Hofmann

B. Kuczera

S. Hagen

Postfach 3640

75 Karlsruhe

GERMANY

Nucleare e delie Protezione Sanitaria

(DISP) (2)

Attn: Mr. Manilia

Mr. G. Petrangeli

Ente Nazionnle Energie Alternative (ENEA)

Viale Regina Margherita, 125

Caselle Postale M. 2358

I-00100 Roma A. D.

ITALY

Dr. K. J. Brinkman

Reactor Centrum Nederland

1755 ZG Petten

THE NETHERLANDS

M. Jankowski

International Atomic Energy Agency

Division of Nuclear Reactor Safety

Wagranerstrasse 5

P.O. Box 100

A/1400 Vienna

AUSTRIA

Stratens Karnfraftinspektion (2)

Attn: L. Hammer

W. Frid

P.O. Box 27106

S-10252 Stockholm

SWEDEN 
Studvik Energiteknik AB

Attn: K. Johansson

5-61182 Nykoping

SWEDEN

Institute of Nuclear Energy Research

Attn: Sen-I Chang

P.O. Box 3

Lungtan

Taiwan 325

REPUBLIC OF CHINA

P. Fehrenbach

Atomic Energy Canada, Ltd.

Chalk River, Ontario

CANADA KOJ IJO

Korea Advanced Energy Research Institute

Attn: H. R. Jun

P.O. Box 7

Daeduk-Danji

Choong-Nam

KOREA

POSTECH

Dept. of Mechanical Eng.

Attn: Moo Hwan Kim

P.O. Box 125

Kyungbuk 790-600

KOREA

Md. C. Lecomte

CEN FAR

60-68 Av. du G. Leclerc-B.P.6

92265 Fontenay aux Roses Cedex

FRANCE

Dr. A. Meyer-Heine

CEN Cadarache

13108 Saint Paul Lez Durance

FRANCE
H. Bairiot, Chief

Department LWR Fuel

Belgonucleair

Rue de Champre Mars. 25

B-1050 Brussels

BELGIUM

J. E. Antill

Berkeley Nuclear Laboratory

Berkeley GL 139 PB

Gloucestershire, England

UNITED KINGDOM

W. G. Cunliffe

Bldg. 396

British Nuclear Fuels, Ltd.

Springfield Works

Salwick, Preston

Lancashire, England

UNITED KINGDOM

AEA Technology (7)

Attn: A. Nichols, 102/A50

T. Butland

B. Brivsher, 105A/A50

J. Mitcinell, 01/A50

P. Smith, 215, A23

D. Sweet, 210/A32

D. Williams, 210/A32

Winfrith, Dorchester

Dorset DT2 8DH, England

UNITED KINGDOM

Itaru Kaneko

Chemical Techology Group

Nuclear Engineering Laboratory

Toshiba Corporation

4-1 Ukishima Cho, Kawasaki Ku

Kawasaki 210

JAPAN 
Japan Atomic Energy Research Institute

Attn: K. Sato

Fukoku Seime Building

2-2-2, Uchisaiwai-cho, Chiyoda-ku, Tokyo JAPAN

Mr. F. Abbey (2)

AFA Technology

Safety and Reliability Directorate

Wigshaw Lane

Culcheth

Cheshire WA3 4NE

UNITED KINGDOM

Simon J. Board

CEGB National Power

Barnett Way

Barnwood, Gloucestershire GL4 7RS

ENGLAND

Nigel E. Buttery

Central Elect. Gen. Board, Booths Hall

Chelford Road, Knutsford

Cheshire WA16 8QG

ENGLAND

Professor Agustin Alonso

E.T.S. Ingenieros Industriales

Jost Gutierrez Abascal 2

28006 Madrid

SPAIN

Jose Angel Martinez

Sub. Emplazamientos y Programas Loop

CONSEJO DE SEGURIDAD NUCLEAR

Justo Doradoll

28040 Madrid

SPAIN

Juan Bagues

CONSEJO DE SEGURIDAD NUCLEAR

SOR Angela de la Cruz No. 3

28056 Madrid

SPAIN
G. Caropreso

Dept. for Environmtl Protection \& Health

ENEA CRE Casaccia

Via Anguillarese, 301

00100 Roma Ad.

ITALY

P. Ficara

Department for Thermal Reactors

ENEA CRE Casaccia

Via Anguillarese, 301

00100 Roma Ad.

ITALY

Klaus Trambauer

Gesellschaft Fuer Reaktorsicherheit

Forschungsgelande

D-8046 Garching

GERMANY

UKAEA (3)

Attn: D. Sweet

S. Kinnersly 203/A32

D. Williams 210/A32

Winfrith, Dorchester

Dorset DT2 8DH

UNITED KINGDOM

UKAEA Culham Laboratory

Attn: B. D. Turland E5.157

Abingdon

Oxfordshire OX14 3DB

UNITED KINGDOM

UKAEA

Reactor Development Division

Attn: T. Butland

Winfrith, Dorchester

Dorset DT2 8DH

UNITED KINGDOM 
M. R. Hayns

AEA Reactor Services

B329

Harwell

Didcot

Oxfordshire OX11 ORA

UNITED KINGDOM

Japan Atomic Energy Research Institute

Severe Accident Research Laboratory

Attn: Dr. K. Soda, Head

Tokai-mura, Naka-gun, Ibaraki-ken

319-11

JAPAN

Japan Atomic Energy Research Institute Reactivity Accident Laboratory

Attn: Toyoshi Fuketa

Tokai-Mura, Ibaraki-Ken

319-11

JAPAN

R. D. MacDonald

Atomic Energy Canada, Ltd.

Chalk River, Ontario

CANADA KOJ IJO

Atomic Energy Canda Ltd.

Attn: Vijay I. Ngth

Sheridan Park Res. Comm.

Mississauga, Ontario

Canada L5K 1B2

Oguz Akalin

Ontario Hydro

700 University Avenue

Toronto, Ontario

CANADA M5G 1X6

K. N. (Kannan) Tennankore

Safety Research Division

Whiteshell Nuclear Res. Establishment

Pinawa, Manitoba

CANADA ROE 1 LO
J. Clive Wood

Safety Research Division

Whiteshell Nuclear Res. Establishment

Pinawa, Manitoba

CANADA ROE $1 L O$

Korea Adv. Energy Research Institute

Attn: Hee-Dong Kim

P.O. Box 7

Daeduk-Danji

Choong-Nam

KOREA

Chang K. Park

Korea Atomic Energy Research Institute

Korea Advanced Energy Research Institute

P.O. Box 7, Daeduk Danji

Taejon 305-353

KOREA

Jong In Lee

Severe Accident Assessment Department

Korea Institute of Nuclear Safety

P.O. Box 16, Daeduk-Danji

Daejeon, 305-353

KOREA

Institute of Nuclear Energy Research

Attn: Yi-Bin Chen

P.O. Box 3

Lungtan

Taiwan 32500

REPUBLIC OF CHINA

Dr. A. Tattegrain

CEN Cadarache

13108 Saint Paul lez Durance

FRANCE

Dr. G. Hache

CEN Cadarache

13108 Saint Paul lez Durance

FRANCE 
Jacques Duco

Centre d'Etudes Nucleaires (IPSN-DAS)

Commissariat a l'Energie Atomique

Boite Postale No. 6

F-92265 Fontenay-aux-Roses Cedex

FRANCE

Maurice Gomolinski

Protection and Nuclear Safety Institute

Commissariat a l'Energie Atomique

Boite Postale No. 6

F-92265 Fontenay-aux-Roses Cedex

FRANCE

Michel Livolant

Inst. de Protection et de Surete Nucl.

Commisariat a l'Energie Atomique

Boite Postale No. 6

F-92265 Fontenay-aux Roses Cedex

FRANCE

Jorma V. Sandberg.

Department of Nuclear Safety

Finnish Center Radiation \& Nucl. Safety

P.O. Box 268

SF-00101 Helsinki

FINLAND
Lasse Mattila

Nuclear Engineering Laboratory

Technical Research Center of Finland

P.O. Box 169

SF-00181 Helsinki

FINLAND

S. Chakraborty

Swiss Federal Nucl. Safety In ipectorate

CH-5303 Wurenlingen

SWITZERLAND

J. Peter Hosemann

Light Water Reactor Safety Program

Paul Scherrer Institute

CH.5232 Villigen PSI

SWITZERLAND

Vladimir Asmolov

1.V. Kurchatov Institute of Atomic Energy

Moscow 123182

Kurchatov Square

CIS 


\section{SANDIA DISTRIBUTION}

6400 N. R. Ortiz

6403 W. A. von Riesemann

6404 D. A. Powers (5)

6412 A. Camp

6413 F. T. Harper

6413 T. D. Brown

6413 J. C. Helton

6413 L. A. Miller

6414 J. Kelly

6415 K. D. Bergeron

6418 S. L. Thompson

6422 M. D. Allen

6422 N. Bixler

6422 J. E. Brockmann

6422 T. K. Blanchat

6422 T. Y. Chu

6422 R. M. Elrick

6422 T. J. Heames

6429 K. E. Washington

6429 D. C. Williams

6429 K. K. Murata

6501 J. V. Walker

6602 J. L. Sprung

7141 Technical Library (5)

7151 Technical Publications

8523 Central Technical Files 


\begin{tabular}{|c|c|}
\hline 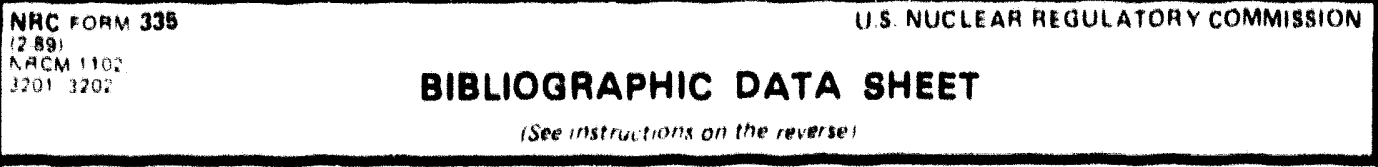 & 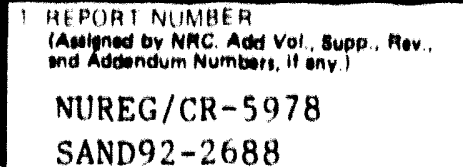 \\
\hline \multirow{3}{*}{$\begin{array}{l}\text { P TITLE AND SUBTITLE } \\
\text { Source Term At: enuation by Water in the } \\
\text { Mark } 1 \text { Boiling Water Reactor Drywe } 11\end{array}$} & \\
\hline & 3 DATE REPORT PUHLISHED \\
\hline & 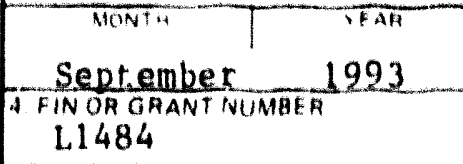 \\
\hline \multirow[t]{2}{*}{5 AUTHOAISI } & $\begin{array}{l}6 \text { TYPE OF AEPORT } \\
\text { Technical }\end{array}$ \\
\hline & 7. PERIOD COVERED Wheidure Date: \\
\hline \multicolumn{2}{|c|}{ 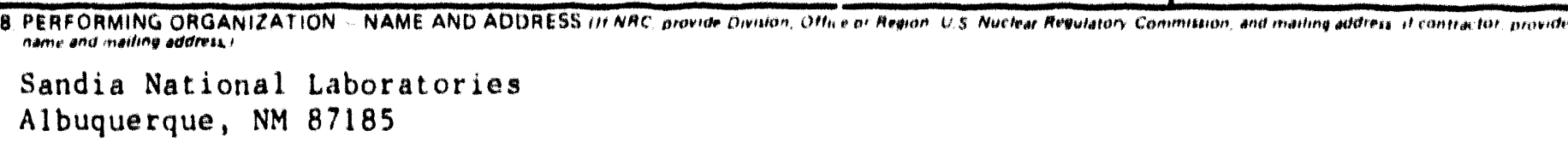 } \\
\hline 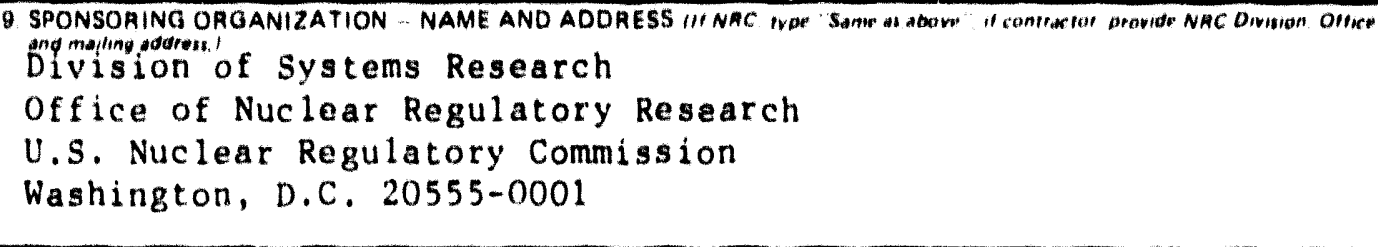 & 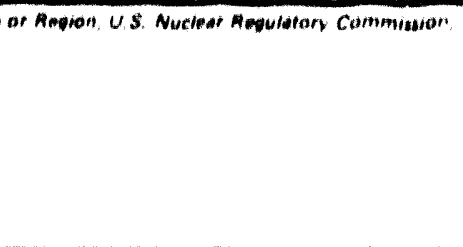 \\
\hline 10 SUPPLEMENTAAY NOTES & \\
\hline
\end{tabular}

11 ABSTRACT 1200 worda or ion

Mechanistic models of aerosol decontamination by an overlying water pool during core debris/concrete interactions and spray removal of aerosols from a Mark I drywell atmosphere are developed. Eighteen uncertain features of the pool decontamination model and 19 uncertain features of the model for the rate coefficlent of spray removal of aerosols are identified. Ranges for values of parameters that characterize these uncertain features of the models are established. Probability density functions for values within these ranges are assigned according to a set of rules. A Monte Carlo uncertainty analysis of the decontamination factor produced by water pools 30 and $50 \mathrm{~cm}$ deep and subcooled $0-70 \%$ is preformed. An uncertainty analysis for the rate constant of spray removal of aerosols is done for water fluxes of $0.25,0.01$, and $0.001 \mathrm{~cm}^{3} \mathrm{H}_{2} \mathrm{O} / \mathrm{cm}^{2}-\mathrm{s}$ and decontamination factors of $1.1,2,3.3,10,100,1$ and 1000 .

Source term, water pools, aerosols, sprays, source term mitigation, drywell, core debris/concrete interactions Monte Carlo sampling, uncertainty analysis

\begin{tabular}{|c|}
\hline $\begin{array}{l}\text { 13. AVALARTLITYSTATEMENT } \\
\text { Unlimited }\end{array}$ \\
\hline 14 SECUAITY CLASSITICATIN \\
\hline $\begin{array}{l}\text { This Payel } \\
\text { Unclassified }\end{array}$ \\
\hline $\begin{array}{l}\text { This Reponti } \\
\text { Unc lassified }\end{array}$ \\
\hline 15 NUMBER OF PAGES \\
\hline 16 PRICE \\
\hline
\end{tabular}



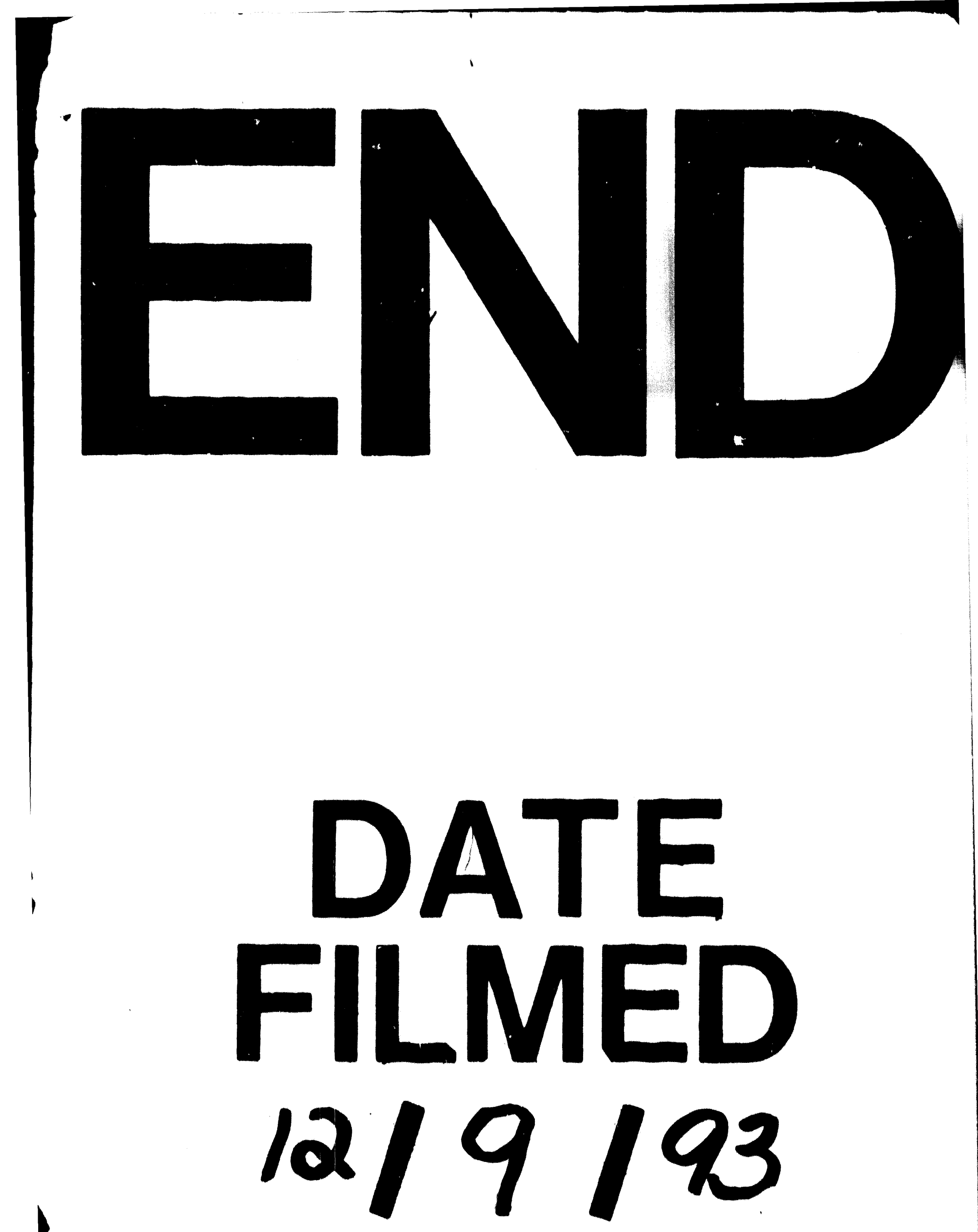

$L$ 


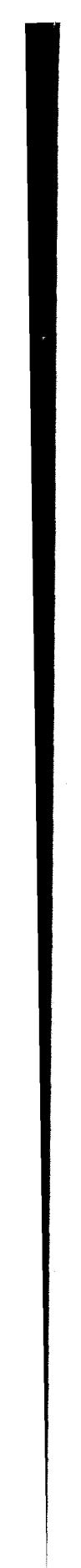

